\title{
BIBLIOGRAFIA
}

Observaciones.-La presente Bibliografia trata de cubrir todo el territorio hispánico en lo que se refiere a Lingüistica (español europeo y americano, judeoespañol, portugués peninsular y extrapeninsular, catalán, vasco); en lo que se refiere a Literatura, cubre sólo el campo peninsular, o sea que excluye la información sobre la América española y el Brasil.

Las reseñas se consignan a continuación del libro (o articulo) reseñado. Cuando éste se ha descrito ya en una entrega anterior de la Bibliografia, se pone entre paréntesis el número de la ficha correspondiente. También se hacen referencias a ediciones anteriores de una obra, a tomós anteriores de una obra en curso de publicación, etc. En todos estos casos, la cifra que precede al número de referencia indica el volumen de la NRFH en que figura la ficha en cuestión. Asi, el "núm. 14-39695" corresponde a la ficha 39695, la cual está en el volumen I4 de la NRFH. Cuando no hay cifra inicial, ha de entenderse que el número remite a una ficha incluida en el presente fasciculo.

\section{SECGIÓN GENERAL}

\section{OBRAS BIBLIOGRÁFICAS Y DE CONSULTA}

18-4191. Bibliografia.-NRFH, $18 \quad(1965$ 66), 209-352,-V. núm. 18-1.

18-4192. Bibliografia. - RFE, $46 \quad(1963)$, 509-561,-V. núm. 18-2.

18-4193. Bibliografia hispanoamericana. RHM, 3o (1964), 57-77, 327-353. - V. núm. $18-3$.

18-4194. Brown, P. A. (comp.) - “An. nual bibliography, 1962".-PMLA, $7^{8}$ (1963), núm. 2B, 79-356.-V. núm. 18-4. 18-4195. Marouzeau, J., et Juliet TF ERnst-L'année philologique. T. 32: Bibliographie de l'année $196 \mathrm{r}$ et com. pléments d'années antérieures. - I.es Belles Lettres, Paris, 1963 . xxii 698 pp. -V. núm, 18-5.

18-4196. Bibliographie [Edad Media]. CCM, 8 (1965), 85-139, 231-294, 465550; 9 (1966), 93-157.-V. núm. 18-6.

18-4197. KuHN, Alvin (ed.) -Bibliographie r956-60.-M. Niemeyer, Tübingen, 1964. $74^{\circ}$ pp. (ZRPh, Supplement zu Бd. $72-76$ ) .-V. núm. 17-349.

18-4198. Registo bibliográfico [Portugal y Brasil].-BIB, 5 (1964), $7-66,5^{65}-627$. -V. núm. 18-7.

18-4199. Palfrey, Thomas R., Joseph G. Fucilla \& William C. Holmrook (comps.) $-A$ bibliographical guide to the Romance languages and literatures. $5^{\text {th }}$ ed.-Chandler's, Evanston, Ill., 1963 . xit-122 pp. || $R F, 77$ (1965), 220-223 (Leiner) .

18-420o. The year's work in modern language studies. T. 25: 1963. Ed. by Graham Orton.-The Modern Humanities Research Association, Cambridge, 1964 $\mathrm{x}+698$ pp.-V. núm. 18-10. || ZRPh, $81 \quad(1965), 589-590$ (Engler); FS, 19 (1965), 332-333 (Ewert).

18-4201. LA DU, R.-“American doctorai degrees granted in the field of modern languages in 1962-1963". - $M L J, 4_{4}^{8}$ (1964), 227-232.-V. núm. 18-11.

18-4202. Sмither, W. J. - "Dissertations in the Hispanic languages and literatures, 1963 ".- $\boldsymbol{H}, 47$ (1964), 326-933.V. núm. 18-12.

18-4203. Index translationum. T. 14: 1961.-Unesco, Paris, 1963. 766 pp.V. núm, $18-13$.

18-4204. "Teses de licenciatura apresentadas à Faculdade de Letras da Universidade de Coimbra: 1963". - ABP, 9 (1963), 133-147.-V. núm. 18-17.

18-4205. Malclès, L.-N.-Manuel de bibliographie (N. 18-30). || BBF, 9 (1964), $83-85$ (Lelièvre); $A U P, 34$ (1964), 467 (X) .

18-4206. Bestermann, Theodore - $A$ world bibliography of bibliographies. 
$4^{\text {th }}$ ed. Ts. 1-2: $A \cdot K$,-Societas Bibliographica, Lausanne, $196_{5} .-V$. núm. 1230665 .

18-4207. Hirsch, R., \& H. J. Heaney"A selective check list of bibliographical scholarship for 1962". - $S B, 17$ (1964), 229-252.-V. núm. 18-29.

18-4208. GoLDSCHMint, E. P.-The printed book of the Renaissance: Three lectures on type, illustration, ornament. $2 \mathrm{~d}$ ed.- Van Heusden, Amsterdam, 1965.

18-4209. GofF, F. R. - "An undescribed Spanish incunabulum". - Gutenberg Jb., 1964, $110-114$.

18-42 10. Serís, Homero-Nuevo ensayo de una biblioteca española de libros raros y curiosos, formado en presencia de los ejemplares de la Biblioteca de The Hispanic Society of America en Nueva York y de la Ticknor Collection en la Biblioteca Pública de Boston. T. 1.Hispanic Society of America, New York, 1964. xxii + 223 pp.-V. núm. 16-45798. II RHM, 3o (1964), 323-324 (Carrasco Urgoiti); $H R, 33$ (1965), 344 (Green); $R R, 57$ (1966), $117-119$ (Sobejano); $B H S$, 43 (1966), $5^{6-57}$ (Wilson); H, $4^{8}$ (1965), 935 (Woodbridge).

18-4211. MATEU Y Llopis, F.-“Gótico y romano en la prototipografía hispana. A propósito de la Biblia valenciana de 1477-1478".-Gutenberg Jb., 1964, 55-6o.

18-4219. Pérez Gómez, A.-"EI Catón en latin $y$ en romance (Zaragoza, Paulo Hurus, 1493-1494)". - Gutenberg Jb., $1964,115-119$.

18-4213. Madurell Y Marimón, J. M."Anuncio de una escuela y un documento pontificio". - Gutenberg Jb., $1964,147-150$.

18-4214. Peixoto, J.-"Alemães que trabalharam no livro em Portugal nos sécs. Xv et xvi".-Gutenberg Jb., 1964, 120-217.

18-4215. Ferreira de Assunção, G. J."Obras de tipografia belga na biblioteca de Mafra. Século xvi".-BIB, 5 (1964), 260-270.

18-4216. Alves, A. L.-"Livros do século XVI existentes na Biblioteca Pública $e$ Arquivo Distrital de Evora. 3: Tipografia francesa". $-B J D E, 1964$, núm. 5, 5-111.-V. núm. 18-36.

18-4217. PÉrez GoyenA, Antonio-Ensayo de bibliografia navarra desde la creación de la imprenta en Pamplona hasta el año rgro. T. 9.-Institución Príncipe de Viana, Pamplona, $196_{4}$. 807 pp.-V. núm. 18-45.
18-4218. Costa RoQue, M. DA - "Livros antigos viseenses. Século xvI".- $B A, 23$ (1964), 275-292.

18-4219. Pinto Loureiro, José-Bibliografia coimbrã.-Câmara Municipal, Coimbra, 1964. 344 pp.

18-4220. "Documentos". $-A B P, 8$ (1962), $87-13$. [Impresos de Coimbra, siglo XVII].

18-4221. Costa Garcez-“Subsídios para uma bibliografia geral de Lisboa".Rev. Municipal, Lisboa, 1964, núms. $100,69-76 ; 101 / 2,101-16 ; 103,55-86$. 18-4222. Machado Gonçalves, A.-Algu * mas espécies de maior valor bibliográfico da Biblioteca Pública de Ponta Delgada.-Ponta Delgada, 1963. 5o pp. [Sep. de Insu, t. 19].

18-4223. Álvarez Solar-Quintes, N. "La imprenta musical en Madrid en el siglo xvin".-AnM, 18 (1963), 161-195. 18-4224. Sol Clot, Román-150 años de prensa en Lérida.-Inst. de Ests. Ilerdenses, Lérida, 1964. 1xvi +532 pp.

18-4225. VAN DER VeKENÉ, EMILE-Bibliographie der Inquisition: ein Versuch.Georg Olms, Hildesheim, 1963. 323 pp. || Era, 17 (1965), 393 (Zimmermann). 18-4226. Sollana, EMILIo DE-Escritores de la provincia capuchina de Valencia (N. 18-53). II Collectanea Franciscana, 34 (1964), 212-213 (Mareto).

18-4227. Devoto, D.-"Sobre algunos libros de Lastanosa". $-\mathrm{BH} i$, C6 (1964), $84-90$.

18-4228. Union list of periodical's in the Romance languages and literatures in British National, University and special libraries.-Univ. of London Library, 1964 . vi +150 pp. $\| F S, 19$ (1965), 439-440 (Rickard).

18-4229. "Panorama, 1837-1868".-BIB, 5 $(1964), 126-185,312-372,491-555,660-$ 700. [Indice de la revista].

18.4230. Estevens, Manuel Santos (cd.) - Repertório das publicações periódi. cas portuguesas: 1961-1962,-Biblioteca Nacional, Lisboa, 1964.

18-4231. BuchBerger, Michael-Lexikon für Theologie und Kirche. 2. Aufl. Bd. 8: Palermo-Roloff. Bd. 9: RomTetzel. - Herder, Freiburg, 1963-1964. 1368, 1384 cols. $-V$. núm. 18-82.

18-4232. Viller, M., F. Cavallera, \& J. DE GUIBERT-Dictionnaire de spiritunlité, ascétique et mystique, doctrine et histoire. Fondé par..., continué sous lá direction de Charles Baumgartner, assisté de M. Olphe-Galliard. T. 5: 
Faber-Fyot.-Beauchesne, Paris, 1962-64. 1632 cols. $-V$. núm. 17-51.

18-4233. Enciclopedia de la cultura española. T. 1: Abad Sansón-Canción popular. T. 2: Cancioneros-España.-Edit. Nacional, Madrid, 1962, 1965. 1000, $1040 \mathrm{pp}$.

18-4234. Enciclopedia Vergara. $9^{\text {a }}$ ed. Vergara, Barcelona, 1964. 1553 pp., ilustr. - V. núm. $16-46784$.

18-4235. Enciclopedia luso-brasileira de cultura. T. 1: A-Amo.-Verbo, Lisboa, 1963 .

18-4236. Actas del II Congreso español de estudios clásicos (Madrid-Barcelona, 196r).-Sociedad Española de Estudios Clásicos, Madrid, $1964.688 \mathrm{pp}$. || $R E L$, 42 (1964), 671-672 (Fontaine); Hum, 16 (1964), 217-219 (Mayor); $A S T, 3^{6}$ (1963), 389-39o (Vives); EtC, 32 (1964), 412 (Walbrecq).

V. también núms. 4332, 435 8-9, 4423, $4455,45^{27}, 4717-8,495^{2}, 5^{08} 5,5^{104-6}$, $5115,5140,5400,5798-9,5803,5935$, $597^{6-7}, 6$ gor, $74^{87}$.

\section{Archivos, manuscritos, textos, crítica textual, paleografia, ciencias auxiliares}

18-4237. Kristeller, Paul OSkar-Latin manuscript books before 1600 (N. 1645826). \|RFIC, 92 (1964), 96-99 (Pratesi); HJ, 84 (1964), 246-247 (Sydow); Augu, 4 (1964), 231 (Trapp).-V. núm. 18-100.

18-4238. Kristeller, Paul Oskar - Iter Italicum: a finding list of uncatalogued or incompletely catalogued humanistic manuscripts of the Renaissance in Italian and other libraries. T. 1: Italy: Agrigento to Novara. The Warburg Institute, London, 1963. xxviii + 533 pp. || Lat, 23 (1964), 372374 (Bakelants); $S p, 39(1964), 712-$ 714 (Bühler); $M S$, 1o (1966), 108-109 (Ermatinger); $R F, 7^{6}(1964), 47^{6} \cdot 479$ (Sottili); RN, 17 (1964) 206-210 (Trinkaus); Ital. Studies, $20(1965), 118-119$ (Weiss).

18-4239. Gunrol, A. D.-“Las bibliotecas eclesiásticas de la diócesis de Jaca a finales del siglo $\mathrm{xv}$ ".-Arg, $1962,55-100$. 18.4240. MiQuel Rosell, F.-Inventario general de manuscritos de la Biblioteca Universitaria de Barcelona, 3 (N. 17-69). $\| A I A, 25(1965), 468$ (Castro); RHS, 59 (1964), 265 (Colombás). 18-4241. FÁbreGA GraU, A. - "Inventario de los manuscritos de la biblioteca arzobispal del Seminario Conciliar de Barcelona".-AST, 37 (1964), 275-317.

18-4242. Rubió I BaLAguer, J.-"Els 1libres de l'abat Savarès a la biblioteca de Ripoll".-AMon, 9 (1962), 227-237. 18-4243. Beaujouan, G. - Manuscrits scientifiques médiévaux de l'Université de Salamanque (N. 18-113). || $R H E$, 59 (1964), 295-296 (Colombás); AIHS, 16 (1963), 79-8o (Wickersheimer).

18-4244. García y García, Antonio-Los manuscritos juridicos medievales de la Hispanic Society of America. - New York, 1964. 63 pp. || $A I A, 24$ (1964), 336 (Barrado).

18-4245. BARchiest, R.-"Fundo de manuscritos. Aquisições recentes da Biblioteca Nacional de Lisboa". - BIB, 5 (1964), 124-125.

18-4246. García Álvarez, M. R.-“Catálogo de documentos reales de la Alta Edad Media referentes a Galicia".Comp, 8 (1963); 301-375, 589-650.

18-4247. López CaLo, J. - "La notación musical del Códice Calixtino de Santigo y la del Ripoll, y el problema de su interdependencia".-Comp, 8 (1963), $557-565$.

18-4248. Gros, M. S.- "Les fragments parisiens de l'Antiphonaire de Silos". $R B, 74 \quad\left(19^{64}\right)$, 308-315.

18-4249. Cuesta, I. F. DE LA-"El Breviarium gothicum de Silos". - HS, 17 (1964), 393-394.

18-4250. GaLÈs, JEAN-Les testaments des "Libri antiquitatum" de la cathédralc de Barcelone (995-1080).-[Tesis, Toulouse, 1962].

18-4251. JANINI, J. - "Los sacramentavios de Tortosa y el cambio de rito". $-A S T$, 35 (1962), $5-56$.

18-4252. Mundó, A., i A. Olivar-“F1agments d'un curiós sacramentari-martirologi".-SpF, 21 (1963), 12-53.

18-4253. JUNYENT, E.--"El necrologi del monestir de Ripoll".-AMon, 9 (1962), $217-225$.

18-4254. Coll I Alentorn, M.-"El cronicó de Sant Cugat".-AMon, 9 (1962), $245^{-269}$.

18-4255. MAtroso, Fr. José-“Os cartórios dos mosteiros beneditinos na diocese do Porto".-AEM, 1 (1964), 139166.

18-4256. Gil Julián, J.-“Pergaminos del Museo Arqueológico Provincial de Badajoz".-REE, 20 (1964), $175^{-184}$.

18-4257. Mourinho, A. M.-'Documentos 
medievais sobre Portugal existentes em alguns arquivos de Espanha". - $B A u$, 16-17 (1964), 379-408.

18-4258. Fernández Pomar, J. M.-"Los Anecdota Graeca matritensia de la Real Biblioteca".-Helm, 15 (1964), 313-350.

18-4259. Tovar, A. - Catalogus codicum Graecorum Universitatis Salamantinae. T. 1: Collectio Universitatis Antiqua.Universidad, Salamanca, 1963. 88 pp. (ACS, 25, núm. 4). \| Em, 32 (1964), 107-111 (Fernández Pomar).

18-4260. GARcía, A. - "Los manuscritos del decreto de Graciano en las biblio. tecas y archivos de España".-Studia Gratiana, 8 (1962), 161-193.

18-4261. Levi Della VidA, G. - "Manoscritti arabi di origine spagnola nella Biblioteca Vaticana". - Collectanea $A$. Albareda (Roma, 1962), 2, 133-189.

18-4262. VIVES I MiRET, J.-"L'escriptori del monestir de Santes Creus".-StMo, 1 (1959), 143-154. || Cîteaux, 14 (1963), 324 (Mikkers).

18-4263. LÓPEz DE TORO, J., et al.-Miniatures espagnoles et flamandes dans les collections d'Espagne. - Bruxelles, 1964. $\mathrm{xv}+99 \mathrm{pp}$.

18-4264. "Archivo General de Indias de Sevilla. Patronato Real (1480-1790); Contaduria General del Consejo de Indias (1500-1778); Casa de Contratación de Sevilla (1492-1795)".-BFP, 9 (1964), $17-89$.

18-4265. Catálogo del Archivo Municipal de la Ciudad de Alcira. Primera parte. -Ayuntamiento, Alcira, 1961. 545 pp. 18-4266. Martínez Diez, G. - "Hacia la edición crítica de la Hispana".-MisCo, $41 \quad(1964), 377-397$.

18-4267. Silva Cunha, R.-"Documentos dos Reservados da Sociedade de Geografia de Lisboa, colecção Vidigueira". -Bol. da Soc. de Geografia, Lisboa, 82 (1964), 289-297.

18-4268. Udina I Martorell, F.-“Els privilegis reials atorgats al monestir de Montserrat en una confirmació de Carles I (1519)".-AMon, 9 (1962), 83-88.

18-4269. Cerro Sánchez-Herrera - Aporción al estudio del fuero del Baylio.Rev. de Derecho Privado, Madrid, 1964 . $180 \mathrm{pp}$.

18-427o. Floriano, A. C.-Colección diplomática del monasterio de Belmonte (N. 16-45847). || Cîteaux, 13 (1962), 94-95 (Cocheril) ; $M A$, 7o (1964), 561 (Gautier-Dalché) .-V. núm. 18-153.

18-4271. Fernández, L. (ed.)-Colección diplonática del real monasterio de Santa Maria de Benavides (Boadilla de Rioseco-Palencia).-Int. Tello Téllez de Meneses, Palencia, 196o. 52 pp.

18-42\%2. Batlle Y Prats, L.-"Alfonso II en los cartularios del Archivo municipal de Gerona".-VII Congreso de Historia de la Corona de Aragón (Barcelona, 1962), 2, 161-169.

18-4273. Ubieto Arteta, Antonio - Cartulario de San Juan de la Peña.-Valencia, $1962-63$. 2 ts. (Textos medievales, 6, 9).

18-4274. Molno, M.-El fuero de Jaca. Ed. crítica. - C.S.I.C., Zaragoza, 1964. lxxii $+66_{4}$ pp. (Fuentes para la historia del Pirineo, 1). I| Sef, 25 (1965), 121-125 (Cantera).

18-4275. Foerster, Hans-Abriss der lateinischen Paläographie. \& Aufl.-Hiersemann, Stuttgart, 1963. 322 pp., ilustr. -V. núm. 9-14593. || Het Boek, 37 (1965), $119-120$ (Dekker); EtC, 32 (1964), 204 (Delande); BBF, 9 (1964), 437 (Riché) ; HJ, 84 (1964), 247-249 (Schieffer).

18-4276. Ullman, B. L.-The origin and development of humanistic script (N. 16-45874) . I| Lat, 23 (1964), 860-863 (Cambier) --V. núm. 18-180.

18-4277. Geschichte der Textüberlieferung der antiken und mittelalterlichen Literatur, 1 (N. 17-55). \|BBF, 9 (1964), 14-15 (d'Alverny); Germanis. tik, 3 (1962), 365-366 (Fischer); RFIC, 40 (1962), 52-55 (Gallavotti); $R B P H$, 42 (1964), 1404-1409 (Hélin); BHR, 26 (1964), 267-271 (Monfrin); Augu, 4 (1964), 224 (Pold); Lat, 22 (1963), 872-873 (Préaux).-V. núm. 18-172.

18-4278. Timpanaro, S. - La genesi del metodo del Lachmann (N. 17-3391). II $R S C, 12$ (1964), 216-217 (d'Agostino); BBudé, 1964, 116-122 (Dain); RevPh, $3^{8}$ (1964), 326 (Ernout); $A C, \quad 33$ (1964), 239-243 (François); $P I, 6$ (1964), 130 (Garzya); CR, 14 (1964), 208-2og (Goodyear); RevPh, $3^{8}$ (1964), 327-329 (Irigoin).-V. núm. 18-175.

18-4279. VAN Groningen, B. A.-"La critique des textes".-Verhandelingen der koninklijke Nederlandse Akademie van Wetenschappen, afdeling Letterkunde, 7o (1963), núm. 2, 77-121.

18-4280. Dearing, V. A.-A manual of textual analysis (N. 16-41915). || REL, 42 (1964), 187-192 (Froger).-V. núm. $17-3384$.

18-4281. D'Ors, A. - “El progreso de la 
epigrafía romana de Hispania (19581962) ".-Akte des IV. intern. Kongresses für gr. und lat. Epigraphik (Wien, 1964), 298-309.-V. núm. 16-41923.

18-4282. Navascués, J. M. DE-"Caracteres externos de las antiguas inscripciones salmantinas. Su trascendencia epigráfica e histórica".-Akte des IV. internat. Kongresses für gr. und lat. Epigraphik (Wien, 1964), 280-297.

18-4283. Ainaud, J.-"Una inscripció inèdita en vers de l'escola de Ripoll".$E R, 8$ (1961), 21-23

V. también núms. 4315, 5459 .

\section{HISTORIA}

18-4284. Bibliographie internationale des sciences historiques. T. 29: 1960.-Colin, Paris, 1969. xxvi + 479 pp. - V. núm. 18-19o.

18-4285. Pirenne, J. H. - Panorama de l'histoire universelle, d'après "Les grands courants de l'histoire universelle" de Jacques Pirenne.-Albin Michel, Paris, 1969. $x+397$ pp., ilustr. 18-4286. MCNEILL, W. H.-The rise of the West. A history of the human community.-Univ. of Chicago Press, Chicago, 1969 . xviii +8 go pp., ilustr. $\| E t C$, 32 (1964), 85 (Carré); $C R, 14$ (1964), 327-329 (Hopper).

18-4287. QUIRIN, H. - Einführung in das Studium der mittelalterlichen $\mathrm{Ge}$ schichte (N. 17-3398). \|MA, 70 (1964), 627-629 (Joris); Germanistik, 4 (1963), $377-37^{8}$ (Schlenke); $A F r H, 5^{6}$ (1963), 211-214 (Spätling); DLZ, 84 (1963), $4^{60-464}$ (Töpfer); MIOG, 7o (1962), 410-411 (Wührer) --V. núm. 18-199.

18-4288. Steinen, W. vON DEN-Der Kosmos des Mittelalter (N. 17-3409). II ReSR, 49 (1961), 279-28o (Dumeige); $H Z, 196$ (1963), 136-141 (Grundmann). -V. núm. 18-207.

18.4289. Pirenne, Henri-Histoire économique et sociale du moyen âge. Éd. rev. et mise à jour, avec une annexe bibliographique et critique par $\mathrm{H}$. Van Werveke.-P.U.F., Paris, 1963. xi +244 pp. \|CCM, 7 (1964), 513 (Boussard).

18-4290. Ferguson, Wallace K.-Europe in transition, 1300-1520. - Houghton Mifflin Co., Boston, 1962. xiii +625 pp. II Canadian Historical Rev., 45 (1964), 51-52 (Bayley); $A H R, 69$ (1964), 731-732 (Douglas); CHR, 50 (1964), 250-251 (Herlihy); $R N, 17$ (1964), 2426 (Pirenne).
18-4291. Bronowski, Jacob, y Bruce MazLISH - La tradición intelectual de Occidente. De Leonardo a Hegel. Trad. de J. M. Gimeno.-Norte y Sur, Madrid, 1969. || ROcc, 8 (1965), 229-233 (Truyol).

18-4292. Deshayes, J.--"Le premier Congrès International sur le Siècle des $\mathrm{Lu}$ mières".-AESC, 19 (1964), 942-946.

\section{Espa $\tilde{n} a$}

18-4293. Blázquez Martínez, J. M.-Religiones primitivas de Hispania, t. 1 ( $\mathrm{N}$. 18-246). || Caesaraugusta, 19-20 (1962), 158-159 (Beltrán); RevPh, 38 (1964), 158 (Ernout); RHR, 166 (1964), 83-85 (Fontaine); Zeph, 12 (1961), 197-202 (Michelena); Bol. del Seminario de Estudios de Arte y Arqueol., Valladolid, 28 (1962), 312-313 (Palol); Germania, 42 (1964), 323-326 (Schmoll) . 18-4294. Michel, R. J., \& L. López SanCHO-A $B$ C de civilización hispánica. -Bordas, Paris, 1962.442 pp., ilustr. || BHS, 43 (1966), 74-75 (Brown); LR, $18 \quad(1964), 383-384$ (Groult); $H, 4^{6}$ (1963), 437 (Rothberg) .

18-4295. AmbruzzI, Lucio-Cursillo histórico de la civilización española y sumario de historia de la literatura española. $2^{\text {a }}$ ed.-S.E.I., Torino, 1962. 315 pp., ilustr.-V. núm. 16-44036.

18-4296. Clocchiatti, E.-"Datos sobre el contrato editorial de la Historia de los heterodoxos españoles". - BBMP, 39 (1963), 228-234.

18-4297. Mastrelli, C. A.-"Sull'origine e sul nome dei Visigoti". - $A G I t, 49$ $(1964), 127^{-1} 4^{2}$.

18-4298. FILIPPO, L. DI-"Pi y Margall: los estudios sobre la Edad Media".USF, 1964, núm. 59, 257-269.

18-4299. MONRoE, JAMES T.-History of Spanish Arabic studies.-[Tesis, Harvard Univ., 1964].

18-43oo. Manzanares de Cirre, M.-"Don Pascual de Gayangos (1809-1897) y los estudios árabes". - AlAn, 28 (1963). $445-461$.

18-4301. Lapeyre, Henri-Géographie de l'Espagne morisque. - École Pratique des Hautes Etudes, Paris, 1959. 301 pp. (Démographie et sociétés). \|AESC, 18 (1963), 800-802 (Castillo) .

18-4302. VAJDA, J.-"Quelques aspects de la philosophie juive en Espagne au xive siècle". $-E L u, 8$ (1964), 42-53.

18-4303. Cruz Hernández, M.-"La filoso- 
fía árabe occidental del siglo xrv". ELu, 8 (1964), 66-72.

8-4304. Gilbert, R.-Para el antiguo ré. gimen universitario".- $H J V, 2,437-460$. 18-4305. Montiel, Isidoro-Historia de la Universidad de Sigüenza.-Ed. Universitaria, Maracaibo, 1963. \| $M L J, 4^{8}$ (1964), 318-319 (Millares Carlo); RlD, $14(1964), 185^{-1} 87$ (Millares Carlo); Bol. de la Biblioteca General de la Iniè. del Zulia, Maracaibo, 1963 , núm. 5, 73-75 (Millares Carlo); HR, 34 (1966), 64-66 (Morón-Arroyo).

18-4306. ANGlés, H. - "Spanien in der Musikgeschichte des 15 . Jahrhunderts". $-H J V, 1,321-35^{6 .}$

18-4307. TPARRAguirre, D.-“Quelques aspects de l'enseignement dans les universités espagnoles à l'époque de la Renaissance".-[En] Pédadogues et juristes (Paris, 1963), 73-85.

18-4308. Tellechea, J. I.- "La création de l'Université d'Alcala et sa signification dars la Renaissance espagnole".-[En] Pédagogues et juristes..., 197-147.

18-4309. Maravall, José Antonio - Las comunidades de Castilla, una primera revolución moderna.-Revista de Occidente, Madrid, 1963. 260 pp. \|I Sef, 24 (ig64), 379-380 (Cantera); ROcc, 6 (1964), 110-115 (Carande); $B H i, 67$ (1965), 152-156 (Pérez); CuH, 58 (1964), $653-656$ (Trías Vejarano) ; BISD, 1964 , núm. 31, 282-284 (Yrurbe); Ins, 1965, núms. 228/9 (Zulueta).

18-4310. Caro Baroja, J.-"Honor y vergüenza. (Examen histórico de varios conflictos populares)". - RDTP, 20 (1964), 410-460.

18-4311. Hauben, Paul Jacob - Spanish protestant refugees in western Europe dwing the second part of the sixteenth century.-[Tesis, Princeton Univ.; resumen en $D A, 24(1963-64), 2443]$.

18-4312. Tellechea Idígoras, J. I.-"Juan Sánchez. Apunte para la historia de un heterodoxo español (1559)". - BAH, 151 (1962), 245-255.

18-4313. Defourneaux, Marcelin - L'Inquisition espagnole et les livres français au $x$ riiie siecle.-P.U.F., Paris, 1963.-V. núm. 13-36095. I| Ins, 1963, núm. 198 (Cano); CCL, 1964, núm. 87, 81-82 (Cruz); HAHR, 44 (1964), 234-235 (Desmarais) ; $B S V, 21 \quad(1965), 213^{-217}$ (Elorza); $R y F, 168$ (1963), 503 (Iturrioz); ROcc, 7 (1964), 255-262 (Maravall); NRTh, 86 (1964), 314 (Mols); $B D G A, 1963$, núm. 74, 73 (Moreno);
RHLF, 64 (1964), 313 (Pomeau); BHi, $66(1964), 190-192$ (Sarrailh).

18-4314. Díaz-Plaja, Fernando-El siglo xx. La guerra (1936-1939).-Gráf. Faro, Madrid, 1963. 726 pp., ilustr. (La historia de España en sus documentos).-V. núm. 17-3451. $\| H, 47$ (1964), 428 (Betoret-Paris).

P o $\quad r t u g$ a l

18-4315. Daupiás d'Alcochete, N.-“O arquivo histórico do Hospital de S. José". $-B I B, 5$ (1964), 271-311.

18-4316. Veríssimo Serrão, J. - História breve da historiografia portuguesa (N. 17-159). I| AESC, 18 (1963), 805 (Mauro); $B H i, 66(1964), 242$ (Ricard).

18-4317. Oliveira Martins - História de Portugal. $14^{\text {a }}$ ed.-Guimarães, Lisboa, 1964. 610 pp. (Obras completas).

18-4318. Saraiva, A. J.-Para a história da cultura em Portugal (N. 17-3465). II Annali di Ca' Foscari, 1964, 165.171 (Meregalli).

18-4319. MoRalejo Laso, A.-"Versos del Códice Calixtino de Santiago relativos a sucesos de la historia medieval portuguesa". $-B A u, 16-17 \quad(1964), 185^{-193}$.

18-4320. Borba, H.-“Os reis de Portugal $\mathrm{e}$ as suas relações com as artes, as letras $\mathrm{e}$ as ciências".-Atlântida, 7 (1969), $57^{-}$ 72, 114-126; 8 (1964), 53-65, 114-132, $225^{-240}, 341-35^{8} ; 9 \quad\left(19^{6} 5\right), 55-61 .-V$. núm. $18-349$.

18-4321. Moreira DE SÁ, A.--"Dúvidas e problemas sobre a universidade medieval portuguesa".-RFL, 1964, núm. 8 , 240-273.

18-4322. Cruz, António-Santa Cruz de Coimbra na cultura portuguesa da Idade Média. - Bibliotheca Portucalensis, Porto, 1963-64. xxiv + 419 pp. (Colectânea de estudos da Biblioteca Pública Municipal do Porto).

18-4323. MEREA, P.-"Sobre as antigas instituições coimbrãs". $-A C o, 19-20$ (1964), $35-78$.

18-4324. Estatutos da Universidade de Coimbra, 1559 . Introd. e notas de Serafim Leite. - Universidade, Coimbra, 1963. 394 pp. (Acta Universitatis Co. nimbrigensis) .

18-4325. Veríssimo Serrão, J.-"Portugueses no estudo de Salamanca, 1250-1550". $-R F L, 5$ (1961), $5^{1-515}$.

18-4326. NoERE dE GuSMão, A.-“Cantores e músicos em Évora nos anos de 1542-53".-AAPH, 14 (1964), 95-121. 
18-4327. Pinto de Castro, A. - "Correspondentes portugueses de Cosme III de Médicis"- $-R H L P, 2$ (1964), 231-287.

18-4328. Vidaco, J.- "Os portugueses e a sua situação de estrangeiros no império dos Filipes (1580-1640)". - Bro, $7^{8}$ (1964), $149^{-157}$.

18-4329. RÉvah, I. S. - “Le plaidoyer en faveur des 'nouveaux-chrétiens' portugais du licencié Martín González de Cellorigo (Madrid, 1619)".- REJ, 122 (1969), 279-398. I| Sef, $24(1964), 44^{6}$ (Cantera).

18-4330. Brito E Aguião, M. P. B. R."Inquirições sobre a pureza do sangue, 1761".-Boletim de Trabalhos Históricos, $23(1963), 27-38$.

18-4331. Braz Teixerra, A.-“Apostila a uma sintese provisória da cultura portuguesa do séc. $\mathrm{xx}$ ".-Esp, $19^{6} 4$, núm. 2.

\section{HISPANISMO Y VIAJES DE EXTRANJEROS}

18-4392. Follché-Delbosc, R., \& L. BARRRAU-DIHIGo-Manuel de l'hispanisant (N. 16-41788). \| Krat, 6 (1961), 205* 206 (Redard).

18-4333. Aubrun, CH. V. - "Hispaniste, hispanisant, hispanisme, etc." $-L N L_{\text {, }}$ 1964, núms. 3/4, 3-11.

18-4934. PÉRez Gómez, A.-"Hispanismo en Francia en el siglo xvi".- $-I b, 1961$, núm. 5, 129-140. || $L R, 19$ (1965), 72-73 (Groult) .

18-4335. Sarrailh, J.-“A propos de A.-R. Lesage américaniste".-Cahiers de l'Inst. des Hautes Études de l'Amérique Latine, 1964, núm. $5 ; 72$ pp. $\| B H i, 66$ (1964), 426-429 (Mas).

18-4336. Aubrun, CH. V. - "L'Institut d'Études Hispaniques (rapport 19611962)".-AUP, 33 (1963), 190-196.

18-4337. RicaRD, R. - "Gabriel Laplane (1901-1964)". - BHi, 66 (1964), 253.

18-4398. ReYes, R.-"Pietro Monti, hispanista italiano del siglo $\mathrm{XIX}^{\prime \prime} .-F M$, 1964, núms. 15/16, 309-320.

18-4339. BOCK, HANS-JOACHIM-El Instituto Ibero-Americano. Su origen y desarrollo. - Colloquium Verl., Berlin, 1964. $16 \mathrm{pp}$.

18-4340. Rodríguez Richart, J.- "Información de Alemania”. - $B F E, 1964$, núm. 13, 20-26.

18-4341. Vantuch, A. - "Professeur Werner Krauss (1900-1965)". - PhP, 8 (1964), 415-416.

18-4342. Peralta, J.-"Los estudios his- pánicos en Suecia".-CuH, 59 (1964), 403-410.

18-4343. Moser, G. M. - "Contemporary Portuguese scholarship in North America".-LBR, 1 (1964), 19-42.

18-4344. Roberts, W. H.-“Brazilian and Portuguese studies in progress".- $L B R$, l (1964), 97-102.

18-4345. Proske, Beatrice Gilman - $A r$ cher Milton Huntington.-The Hispanic Society of America, New York, 1963. 28 pp., ilustr. || $H, 47(1964), 195$ (Leavitt); $H R, 32$ (1964), 9o (Serís); S, 18 (1964), 92-93 (Serís).

18-4346. Martínez Ortiz, J.-"Tenuel y sus amantes en la obra del gran hispanista Archer Milton Huntington".-. Teruel, 1964, núm. 31, 139-151.

18-4347. García Mazas, José-El poeta y la escultora. (Biografia de los Huntington).-Revista de Occidente, Madrid, 1962. $54^{\circ}$ pp. I| Era, $17(1965)$, 87-92 (Rüegg).

18-4348. Ramón Y Fernández Oxea, J-"La exposición \&El peregrino en el camino de Santiago»". - Comp, 8 (1963) , 221-228.

18-4349. Guerra Campos, J.-"Peregrinos a Santiago de los siglos XI al XIX".Comp, $9(1964), 309-328$.

18-4350. Mouzat, J.-“L'Espagne -Catalogne et Castille-, pays estraing de Gaulcem Faidit".-ER, 9 (1961), 183$18 \mathrm{~g}$.

18-4351. Cocheril, M. DE-"La Peregrinatio hispanica de frère Claude de Bronseval".-StMo, 3 (1961), 179-219.

18-4352. Cioranescu, Alejandro - Thomas Nichols, mercader de azúcar, hispanista y hereje. Con la ed. y traducción de su Descripción de las Islas Afortunadas. Instituto de Estudios Canarios, La Laguna de Tenerife, $196 \mathbf{3}$. 130 pp. || $B H i, 66$ (1964), 228.229 (Ricard) .

18-4353. Fielding, H.-The journal of $a$ voyage to Lisbon (N. 17-209). I| CEn, 25 (1964), $64^{\circ}$ (Coley); NQ, 209 (1964), 159 (Rawson)

18.4354. McGann, Thomas F. (ed.) Portrait of Spain: British and American accounts of Spain in the nineteenth and twentieth centuries.-Knopf, New York, 1963. xix +390 pp., ilustr. \|HAHR, 44 (1964), 393-394 (Herr).

18-4355. Taine, Hipóltto A.-Viaje a los Pirineos. $2^{\text {a }}$ ed.-Espasa-Calpe, Madrid, 1963. 220 pp. (Austral, 448).

18-4356. FRANK, WALDO-Retratos cultu- 
rales. Trad. por León Felipe, A. Lázaro Ros y J. Héctor de Zaballa; pról. de Antonio Espina. - Aguilar, Madrid, 1963. 1476 pp., ilustr. [España virgen y otras obras]. II Ins, 1964, núm. 210 (Cano).

18-435\%. Brenan, GrRAld-La faz actual de España. 2a ed. - Losada, Buenos Aires, 1964 .

V. también núms. 5210-1, 5222 .

\section{LINGÜISTICA}

\section{OBRAS GENERALES}

18-4358. Bibliographie linguistique de l'année rg6I et complèment des années précédentes. - Spectrum, Utrecht-Anvers, 1963 . $x l i+37^{8}$ pp. - V. núm. 18 . 423.

18-4359. Waterhouse, VIOLA-Bibliography of the Summer Institute of Linguistics.-Santa Ana (California), 1964 . $\mathrm{xi}+6_{3} \mathrm{pp}$.

18-4360. Mixus, F.-"En marge du Sixic̀me Congrès International des Linguistes" (N. 13-36243). \| Phon, 6 (1961), 105 -109 (Rothe).

18-4361. Linguistic reading lists for teaApplied Linguistics of the Moderm chers of modern languages.-Center for Language Association of America, Washington, D. C., 1963 . ix+114 pp. \| $I t, 41$ (1964), 120-123 (Fucilla); $\boldsymbol{H}, 47$ (1964), 446-447 (Murguía).

18-4362. Dictionnaire de linguistique de l'École de Prague. Publ. du Comité In. temational de Linguistes. - Spectrum, Utrecht, 1960. 103 pp. \| $L F, 86$ (1963), 364-365 (Trost).

18-4363. Dubois, J., et P. Marcie-"Terminologie linguistique". - $\operatorname{Fr} M, 32$ (1964), 206-213.

i 8-4364. HofmanN, J. B., \& H. RubenBAUER-Wörterbuch der grammatischen und metrischen Terminologie, 2. Aufl. (N. 18-540). \|l Krat, 9 (1964), 79 (Knobloch); Gymn, $71 \quad(1964), 4^{85}$ (Schmidt); Lat, $23\left(19^{6} 4\right), 163$ (X).

${ }_{1} 8-43^{6} 5$. Miscelanea homenaje a André Martinet (N. 13-36226). \| Phon, 6 (1961), 97-125 (Rothe).-V. núm. 17. $35^{14}$.

\section{Teoría del lenguaje}

18-4366. WARtBURG, W. voN-Einführung in Problematik und Methodik der Sprachwissenschaft. 2 Aufl. -Max Nie- meyer, Tübingen, 1962. $248 \mathrm{pp} .-\mathrm{V}$. núm. 10-22104. || Germanistik, 4 (1963), 197-198 (Baumgärtner); $R J, 15$ (1964), 199-201 (Beyerle); LF, 12 (1964), 414 (Kurzová); Krat, 8 (1963), 202-203 (Ris); IF, 68 (1963), 192 (Schmidt); ZRPh, 81 (1965), $157-159$ (Weinrich). 18-4367. Wartburg, W. von - Problemes et méthodes de la linguistique. Trad. par P. Maillard. $2^{\mathrm{e}}$ éd., augm, avec la collab. de $S$. Ullmann.- P. U. F., Paris, Ig63. 262 pp. - V. núm. 6-8432. I| ZRPh, 8o (1964), 636 (Baldinger); $F i$ lol. Nauki, 7 (1964) 188-192 (Budagov). 18-4368. Locker, E.-"Principii e metodi della linguistica universale".--Rendiconti, 98 (1964), 33-62.

18-4369. Terracini, Benvenuto - Lingua libera $e$ libertà linguistica: introduzione alla linguistica storica.-Einaudi, Torino, 1963. 223 pp. (Saggi, 333).-V' núm. 9-1367o. || RLiR, 3o (1966), 224 (Bourguignon); Lan, 40 (1964), $288-$ 291 (Hall); NRFH, 18 (1965-66) , 177179 (de Stefano).

18-4370. LEPSCKY, G.-“Aspetti teorici di alcune correnti della glottologia contemporanea".-ASNP, 30 (1961), 187 268 .

18-437ı. Taalonderzoek in onze tijd. Servire, Den Haag, 1962. 128 pp. $A$ GIt, $5^{\circ}$ (1965), $74^{-76}$ (Francescato). 18-4372. Benveniste, E.-"Coup d'ocil sur le développement de la linguistique". Comptes Rendus de l'Acad. des Inscriptions et Belles-Lettres, 1962, 369380 .

18-4373. Granger, G. - "La linguistique moderne".-Crit, 20 (1964), 551-561.

18-4374. Waterman, JoHn T.- Perspectives in linguistics. An account of the background of modern linguistics.-The University of Chicago Press, Chicago, 1963. ix $+10_{5}^{5} \mathrm{pp}$. \| IJAL, 31 (1965), 270-274 (Hymes); RPh, 17 (1963-64), 823-824 (Malkiel); $M L J, 4^{8}\left(19^{6}\right)$, $111-112$ (Pei); $M L R, 59$ (1964), 437 (Strang); Lan, 41 (1965), 512-518 (Teeter).

18-4375. KuKenheim, L.-Esquisse historique de la linguistique française et de ses rapports avec la linguistique générale (N. 17-3545). || FrM, 31 (1963), 293-234 (Gougenheim); Le Français dans le Monde, 1962, núm. 11, 27 (Gougenheim); Etudes Philos., 1964, 309 (Jacob) ; ZRPh, 81 (1965), 507-513 (Mondéjar) ; $R R, 53$ (1962), 280-283 (Peckham).-V. núm. 18-452. 
18-4376. Salus, P. H.-“American introductions to linguistics: 1933-1963". Orbis, 13 (1964), 309-313.

18-4377. Cisneros, L. J.-“La lingüística”. $-M P, 40 \quad(1959), 140-153$.

18-4378. Hugues, J. P.-The science of language (N. 17-3532). || SL, 17 (196364), 89-91 (Austin); $A A, 65$ (1963), $479-481$ (Hamp).

18-4379. Herculano de Carvalio, José G.-Lições de linguistica (dadas no curso de Introdução aos estudos linguisticos). $3^{\text {a }}$ ed.-Coimbra, 1962-63. $4^{87}$ pp. 18.4380. Hocketr, C. F. $-A$ course in modern linguistics (N. 14-38108). I| Nyelvtudományi Közlemények, Budapest, $6_{5}$ (1963), 243-244 (Fodor); Krat, 6 (1961), 26-3o (Hartmann); ASNP, 29 (1960), 141-148 (Lepscky):-V. núm. 17-3521.

18-4381. Dinneen, Francis P.-An introduction to general linguistics.-Inst. of Langs. and Linguistics, Georgetown Univ., Washington, D. C., 1964 .

18-4382. BALLY, CHARLES-Linguistica generale e linguistica francese. Introd. e appendice di Cesare Segre, trad. di Giovanni Caravaggi.-Il Saggiatore, Milano, 1963. $55^{6} \mathrm{pp}$. (La cultura, 7o). I $Z R P h, 79$ (1963), $69^{8}$ (Baldinger); VR, 23 (1964), $15^{0-1} 5^{1}$ (Heinimann).

18-4383. Martinet, A.-Éléments de linguistique générale (N. 17-3560). II Lan, 41 (1965), 493-504 (Hall); Lan, 40 (1964), 392-393 (Hoijer); Paideia, 19 (1964), 29-33 (Pisani); IF, 66 (1961), 273.274 (Schmidt); BBudé, 1963, 249. $25^{\circ}$ (Wartelle); LMo, 55 (1961), núm. 6, 67-68 (Zephir); $A r O, 30$ (1962), 507-511 (Zgusta) .

18-4384. RuwEr, N.-"La linguistique générale aujourd'hui". - Archives Européennes de Sociologie, 5 (1964), 277310.

18-4385. Szemerényi, O. J. L. - Trends and tasks in comparative philology (N. 18-464). || REA, 66 (1964), 145 (Bruguière); $I F, 68$ (1963), 251-252 (Schmidt); Krat, 8 (1963), 203-204 (Watkins); Lingua, 12 (1963), 446-448 (X).

18-4386. Lepscky, G. C.--"Ancora su l’arbitraire du signe".-ASNP, $3^{1}$ (1962), $65^{-102 .}$

18-4387. Dessaintes, M.-Eléments de linguistique descriptive.-La Procure, Namur, 1960. \|E EtC, 29 (1961), 131-132 (Fonsny).

18-4388. JakoBson, R., et al.-Preliminaries to speech analysis (N. 8-12373).
ArO, 28 (1960), 526-527 (Petracek).-V. núm. 16-46042.

18-4389. Schick, C.-Il linguaggio (N. 17250). $\|$ ASoc, 1962, 527 (Gohen), Riv Fil, 52 (1961), 118-120 (Polacco); IF, 66 (1961), $173^{-1} 7^{6}$ (Schmidt).

18-4390. Martinet, ANDRÉ-A functional view of language. - Clarendon Press, Oxford, 1962. $176 \mathrm{pp}$. ||$R R L, 9$ (1964), $657-661$ (Graur) ; Lan, 40 (1964), 393397 (Hoijer); Word, 19 (1963), 242245 (Moulton) ; $A L, 16$ (1965), 70-74 (Robins); $M L R, 5^{8}$ (1963), $23^{\circ}$ (Ullmann); IJAL, 29 (1963), 274-283 (Voegelin \& Valdman).

18-4391. GreenberG, Joseph H. (ed.) Universals of language.-M. I. T. Press, Cambridge, Mass., 1963. $\mathrm{x}+269$ pp. II $A L, \quad 15$ (1963), 217-220 (Collinson); Lan, $4^{\circ}$ (1964), 260-269 (Haugen); $M L R, 59$ (1964), 435-436 (Potter).

\section{Estudios lingüísticos generales}

18-4392. Proceedings of the Fourth International Congress of Phonetic Sciences (N. 18-502). $\| V J, 12$ (1969), núm. 6, $144^{-1} 4^{8}$ (Lekomtseva et al.).

18-4393. POP, S.-Instituts de phonétique et archives phonographiques (N. 1232529). I| Krat, 6 (1960), 87-88 (Redard).

18-4394. Sebeok, T. A.-“'Selected readings in general phonemics $\left(19^{2} 5^{-1} 9^{64}\right) "$.$S L, 17(1963-64), 3-9$.

18-4395. FAure, G.- "Tendances et perspectives de la phonétique moderne".AFLA, 1964, núm. 38, 167-188.

18-4396. Kantner, Claude E., \& Robert WEst - Phonetics.-Harper, New York 1960. 416 pp. || JSHD, 26 (1961), 408 409 (Bowler).

18-4397. Kaiser, L. (ed.) -Manual of phonetics (N. 13-34378). || Krat, 5 (1960), $14^{-17}$ (Lampach) ; FPh, 12 (1960), 76$7^{8}$ (Mangold); Synthese, Bussum, 11 (1959), núm. 1, 93-94 (Van Soest).V. núm. 16-46073.

18-4398. Rosetri, A.-Introduçâo à fonética (N. 17-3571). || RPF, 13 (1964-65), 349-361 (Head).

18-4399. Lafon, J. C.-Message et phonétique (N. 17-3573). || FPh, 16 (1964), 304-310 (Malmberg).

18-4400. JAKoBson, R.-Selected writings, 1 (N. 18-519). $\mid A L B, 14$ (1964), 371380 (Fónagy) ; RPF, 13 (1964-65), 4054og (Herculano de Carvalho); $R P h, 18$ (1964-65), 321-325 (Hoijer); Jazykoved- 
$n \dot{y}$ Casopis, Bratislava, 14 (1963), 171 174 (Horecký); JAS, 35 (1963), 13021303 (House); Lan, 41 (1965), 77-78 (Sebeok).

18-4401. Brosnahan, L. F.-The sounds of language (N. 17-3577). \|IF, 68 (1963), 179-183 (Schmidt).

18-4402. Rosetri, A.-Sur la théorie de la syllabe (N. 16-46094). II AGIt, 47 (1962), 72-73 (Francescato).

18-4403. Suomalainen, R. - “Qu'est-ce qu'une syllabe? Résumé et commentaire d'une discussion".-BJR, 1963, núm. 7 , 39-45.

18-4404. Pottier, B.-"Introduction à l'étude des structures grammaticales fondamentales".-La Traduction Automatique, 3 (1962), núm. 3, 63-93. - V. núm. $17-3590$.

18-4405. Tesnit̀re, L.-Éléments de syntaxe structurale (N. 16-42141). $\mid V J$, 196o, núm. 5, $125^{-140}$ (Mikus); ASNS, 201 (1964), 274-275 (Schwarze); Rev. des Etudes Slaves, 37 (1960), 159 (Vail. lant); IF, 66 (1961), 176-185 (Wissemann).-V. núm. 16-46114.

18-4.406. CAstilho, A. T. DE-"Estructuralismo, história e aspecto verbal".-Alfa, 1963 , núm. 4, 145-166.

18-4407. TOllenaere, F. DE-Nieuwe wegen in de lexicologie.-N. V. NoordHollandse Uitgevers Maatschappij, Amsterdam, 1963. $150 \mathrm{pp}$. || ZRPh, 80 (1964), 696 (Baldinger); $M L R, 59$ (1964), 661 (Collinson); Orbis, 13 (1964), 315-318 (Van Roey).

18-4408. Baldinger, K.-"Sémasiologie et onomasiologie".-RLiR, 28 (1964), 249272.

18-4409. Pottier, B.-"Vers une sémantique moderne".-TLL, 2 (1964), $107^{\circ}$ $13 \%$.

18-4410. Coseriu, E.-"Pour une sémantique diachronique structurale".-TLL, 2 (1964), 139-186.

18-4411. Duchácek, O.- "Différents types de synonymes"--Orbis, 13 (1964), $35^{-}$ 49.-V. núm. $16-42158$.

18-4412. ZAUNMÜLler, W. - Bibliographisches Handbuch der Sprachwörterbücher (N. 14-39850). || VJ, 10 (1961), 139 (Fomintzev); Krat, 5 (1960), $88-89$ (Redard).

18-4413. Technical translating dictionaries.-The Manchester Public Libraries, Manchester, 1962. 34 pp.

18-4414. BAUMER, I. - "Krankheitsvorstellungen im Spiegel der Sprache".-VR, 23 (1964), 305-320.
18-4415. Bibliographia onomastica, 1960 . -On, 10 (1962-63), 1-212 [España, pp. 56-59; Portugal, pp. 114-115; Amérique latine, pp. 171-172].-V. núm. 18-581.

18-4416. Atti del VII Congresso Internazionale di Science Onomastiche (Firen$z e, 196 x)$. Ts. 1 y 2: Toponomastica, a cura di Carlo Battisti; t. 3: Antroponimia, a cura di Bruno Migliorini; t. 4: Toponomastica e cartografia, a cura di Carlo Battisti.-Firenze, 19621963. 55o, 474, 550, 200 pp. \|RPF, 13 $\left(16^{6} 4^{-6} 6_{5}\right), 43^{6-43^{8}}$ (Cunha Serra); Riv. degli Studi Orient., $3^{8}$ (1969), $7^{6-77}$ (Fronzaroli); $B z N, 15$ (1964), 331-332 (Krahe) ; RF, 77 (1965), 164-168 (Tu. chel).

18-4417. SMith, E. C. - "Bibliography of personal names".-Names, 12 (1964), 220-225.-V. núm. 18-591.

18-4418. Pulgram, E. - "Structural comparison, diasystems, and dialectology". -Ling, 4 (1964), 66-82.

18-4419. MASE, Y.-"Une nouvelle tentative pour tracer les frontières subjectives des dialectes".-Orbis, 13 (1964), $357-579$.

18-4420. Grootaers, W. - "La discussion autour des frontières dialectales subjectives".-Orbis, 13 (1964), 380-398.

18-4421. Malmberc, B.-“Encore une fois le substrat".-StL, 17 (1969), 40-46.

18-4422. Sommerfelt, A.-"Some remarks on the importance of a substratum in linguistic development"--HAM, t. 2, 213-216. || Phon, 6 (1961), 122-123 (Rothe).

\section{LATiN}

18-4423. Revue des Etudes Latines, Tables générales des tomes $I$ (1937) ì XX (196r).-Société d'Études Latines, Bruxelles, 1964. 260 pp.

18-4424. Pisani, V. - Storia della lingua latina, t. 1 (N. 18-597). \| QIG, 7 (1962), 198-139 (Bottiglioni); Lat, 23 (1964), 374-375 (Loicq); Helm, 15 (1964) , 287-288 (Oroz Reta); Conv, 32 (1964), 84-9o (Traina).

18-4425. Tagliaviani, CARlo-Fonetica $e$ morfologia storica del latino. $3^{\mathrm{a}} \mathrm{ed}$. riv. e agg. - Pàtron, Bologna, 1962. $\mathrm{xxx}+335$ pp. II Lat, 23 (1964), 863864 (Maniet); RFIC, 92 (1964), 441 . 447 (Traina).

18-4426. Bonioli, M.-La pronuncia del latino nelle scuole dall'antichità al Ri. nascimento. T. 1.-Giappichelli, Tori- 
no, 1962. xviii $+13^{6}$ pp. (Pubbl. Fac. di Lett. e Filos., 13). II BSLP, 59 (1964), núm. 2, 91 (André); QIG, 7 (1962), 139-140 (Coco); PI, 6l (1964), 146 (Frassinetti); CR, $14(1964), 353$ (Jones) ; $Z R P h, 8$ r (1965), 168-171 (Löfstedt) ; Krat, 9 (1964), 35-37 (Safarewicz)

18-4427. KIECKERS, E.-Historische lateinische Grammatik (N. 17-3618). II Gymn, 70 (1963), 170-172 (Gräffke). 18-4428. LeumanN-HormanN-SzANTYR Lateinische Grammatik. 1. Band: Lautund Formenlehre. 2. Band: Syntax und Stilistik.-Beck, München, 1963. xvi + 391,395 pp. || $Z R P h, 79(1963), 638$ (Baldinger); Em, 32 (1964), 343-349 (Fontán).

18-4429. PAsol, E.-Saggi di grammatica latina (N. 17-3620). || Latinitas, 11 (1963), 77-78 (Ciprotti); Em, 33 (1965), 173-175 (Gil Fernández); $A C$, $3^{2}$ (I963), 312 (Maniet); Paideia, 18 (1963), 54-55 (Soffritti).

18-4430. Woopcock, E. C. $-A$ new Latin syntax (N. 16-46169). II Gymn, 7o (1963), 103-105 (Pfister); Gn, 35 (1963), 521-523 (Ruhstaller); Hermathena, 96 (1962), 97-98 (Wormell).-V. núm. $17-3622$.

18-4431. Traina, A.- "La sintassi latina e la linguistica moderna".-Scuola e Didattica, $9(1963-64), 132-134,245-247$, $361-363$.

18-4432. Habenstein, E. - Lateinische Wortkunde. Auf Grund der Wortbildungslehre. - Klett, Stuttgart, [1963?]. 84 pp. I| Helikon, 3 (1963), $7^{6 \mathrm{t}-7^{67}}$ (Huchthausen).

\section{Latín vulgar y medieval}

18-4433. Mélanges offerts à Mademoiselle Christine Mohrmann. - Spectrum, Utrecht-Anvers, $1963 . \times x x v+281 \mathrm{pp}$.

18-4434. Almeida de Camargo, M. "Quelques réflexions sur l'état actuel des études du latin vulgaire". $-B J R$, 1964, núm. 10, 14-22.

18-4435. HaAdsma, R. A., \& J. NuchelMANs-Précis de latin vulgaire.- J. B. Wolters, Groningen, 1963. 137 pp. RevPh, $3^{8}$ (1964), 353 (André) ; CCM, 8 (1965), 208-209 (Bec); REL, 41 (1963), 393 (Collart); BBG, 9 (1964), 682-683 (Ernst); RLiR, 27 (1963), 488 489 (Gardette); PhP, 7 (1964), 95 (Hampejs); MLR, 59 (1964), 473 (Harris) ; $R R L, 9$ (1964), $559-55_{4}$ (1lies- cu) ; $B H i, 66$ (1964), 250-251 (Molho); BSLP, 49 (1964), núm. 2, 95-97 (Perrot); Lat, 23 (1964), 113 (Ruelle); $A A H G, 16$ (1963), 232 (Sofer); VR, 23 (1964), 130-196 (Stefenelli); REA, 66 (1964), 202 (Thomas); EtC, 31 (1963), 449 (Van Ooteghem).

18-4436. Maurer, T. H., JR.-O problema do latim vulgar (N. 17-3627). I| Alfa, 1963, núm. 3, 145-154 (Castilho).

18-4437. Sofer, Johann-Zur Problematik des Vulgärlateins, Ergebnisse und $A n$ regungen.-Gerold, Wien, 1963. $43 \mathrm{pp}$. II BSLP, 59 (1964), núm. 2, 94 (André); RevPh, 37 (1963), 361 (Ernout); Krat, 9 (1964), $9^{1-92}$ (Hiltbrunner); $Z R P h$, 8o (1964), 362-363 (Löfstedt); RHIE, 59 (1964), 639 (Mallet); REL, 40 (1962), 267 (Marouzeau); Lat, 22 (1963), 581 (Préaux); ASNS, 202 (1965), 471-472 (Reichenkron); IF, 68 (1963), 337-339 (Simone); VR, 23 (1964), $137-13^{8}$ (Stefenelli); RFIC, $9^{2}$ (1964), 461-463 (Tandoi); RF, 75 (1963), 449*450 (Väänänen).

18-4438. StefENelLI, A. - Die Volksspiache im Werk des Petron (N. 18-616). || BSLP, 59 (1964), núm. 2, 92-94 (André) ; $L N, 25$ (1964), 123-124 (Boscherini); ASNP, 32 (1963), 249-254 (Campanile); $L F, 12$ (1964), 413.414 (Kurzová); ZRPh, 80 (1964), 127-131 (Löfstedt); $N, 4^{8}$ (1964), $344-34^{6}$ (Nelson); $R J, 15$ (1964), 201-204 (Rothe). 18-4439. Motgnet, C.-Essai sur le mode subjonctif en latin post-classique (N. 16-42258). || RBPH, 41 (1963), 957-959 (Delbouille).-V. núm. 17-318.

18-4440. Díaz y Dfaz, M. C.-Antologia del latin vulgar, $2^{3}$ ed. (N. 18-615). II RHE, 59 (1964), 265 (Mallet).

18-4441. Mohrmann, C. - Eitudes sur le latin des chrétiens, t. 2 (N. 17-3632). II ReSR, $5^{2}$ (1964), 168 (Daniélou); $\mathrm{Ci}$ teaux, 14 (1963), 181-184 (Manning). $-V$. núm. 18-619.

18-4442. Prinz, O. (ed.) - Peregrinatio Egeriae, $5^{\text {a }}$ ed. (N. 17-323). I| Gymn, 70 (1963), $25^{6}$ (Schmeck).

18-4443. Herrero Llorente, Victor José - Peregrinación de Egeria. Introd., trad. y notas de...-Aguilar, Madrid, 1963. 134 pp. (Bibl. de iniciación al humanismo).

18-4444. Koll, H. G.-"Die mittellateinische Philologie in den Ländern der iberischen Halbinsel".-MJ, 1 (1964), 162-195.

18-4445. LöfSTEDT, E.-Late Latin (N. 16- 
46200). || Gn, 35 (1963), 217-219 (Hofmann).-V. núm. 17-3630.

18-4446. WALThER, HANS-Proverbia sententiaeque latinitatis medii aevi. Lateinische Sprichwörter und Sentenzen des Mittelalters in alphabetischer Anordnung. 1: $A-E$. - VandenhoeckRuprecht, Göttingen, 1963. xlviii + 1095 pp. (Carmina medii aevi posterioris latina, 2/1). $\| A B, 82$ (1964), 476 (Gaiffier); $M I O G, 7^{2}(1964), 45^{2}$ (Wolfram).

18-4447. Morris, S. (ed.)-Fons perennis. An anthology of medieval Latin for schools.-Harrap, London, 1962. $130 \mathrm{pp}$. I) Lat, 23 (1964), 181 (X).

18-4448. Van de Woestijne, P.-"Dictionnaire du latin médiéval". - $B A B, 49$ (1963), 448-457,-V. núm. 17-340.

18-4449. Blatt, Frans, et al. - Nounm glossarium mediae latinitatis, $a b$ anno DCCC usque ad annum MCC. Fasc. miles-mozytia. - Munskgaard, Köbenhavn, 1963 ; cols. $485-882 .-V$. núm. 173639. \| DtA, 17 (1961), 572-575 (Häfeie).

I 8-4450. Lloyd, W., \& B. A. Daly-“Some techniques in mediaeval Latin lexicography".-Sp, 39 (1964), 229-239.

18-4451. Niermeyer, J. F.-Mediae latinitatis lexicon minus. Fasc. 10: prosedere-sequipeda.-Brill, Leiden, 1963; pp. 865-960.-V. núm. 17-3636. \|BEC, 121 (1963), 259-260 (Boussard); Helm, 15 (1964), 293 (Campos); Lat, 22 (1969), 377 (Huygens).

18-4452. Plezia, M.-Lexicon mediae et infimae latinitatis Polonorum. T. 2, fasc. 6-7: concentus-consuetudo. - Polska Akad. Nauk, Warszawa, 1963-64; cols. 801-1120.-V. núm. 18-631. || Rev$P h, 38$ (1964), 337 (Ernout).

18-4453. DiAz y DÍAZ, M. C.-Index scriptorum latinorum medii aevi Hispanorum (N. 16-42296). II Scott. Histor. Rev., 42 (1969), 40-46 (Imrie); Scott. Studies, 7 (1969), 117-120 (Rae).-V. núm. $18-629$.

18.4454. Glossarium mediae latinitatis Cataloniae, t. 1 (N. 17-3643). || Lingua, 12 (1963), 444 (Fuchs); Augu, 4 (1964), $4^{81}$ (Gavigan); LF, 11 (1963), $34^{8}$ (Spevácek).

V. también núms. 4472-3.

\section{LINGÜISTICA ROMÃNICA}

18-4455. Duchicek, O. - Bibliografické uvedeni do románské jazykovedy. I.-
SPN, Praha, 1963. 202 pp. \| PhP, 7 (1964), 208-210 (Skultéty).

18-4456. Actes du Colloque International de Civilisations, Littératures et Lan. gues Romanes (N. 17-376). \| BICC, 19 (1964), 578-589 (Montes).

18-4457. Recueil d'études romanes (N. 1440014). II Rev. des Etudes Slaves, 37 (1960), 161-162 (Vaillant).-V. núm. 18-637.

18-4458. IORDAN, I.-“Etat actuel de la linguistique romane et ses perspectives de développement".-CLR (IO), $71^{-}$ 84. If $C u N, 25(1965), 15^{1}$ (Menichetti).

18-4459. IORDAN, I.-“Lucrări recente de lingvistică romanică generala”.-RFRG, 7 (1963), $121-126$.

18-446o. Nascentes, A.-"A filologia românica no Brasil".- $L P a, 1961$, núna. 12.-V. núm. 17-353.

18-1461. MaLkiel, Y.-"Distinctive traits of Romance linguistics".-[En:] Language in culture and society, by Dell Dimes (New York, 1964), pp. 671-688. 18-4462. IoRDAN, I.-Einführung in die Geschichte und Methoden der romanischen Sprachwissenschaft (N. 18653). $\| A L B, 14(1964), 408-411$ (Gáldi); $D L Z, 84$ (1963), 795-797 (Militz). 18-4463. Skultety, J., \& Z. HAMPEJSÚvod do románskej jazykovedy (N. 16. 42322). I| RLR, 75 (1963), 289-29o (Guiter).-V. núm. 17-3664.

18-4464. RIBEIRo, Jỗo-Rudimentos de filologia românica. Notas suplementares de Joaquim Ribeiro.-J. Ozon, Rio de Janeiro, 1963. $119 \mathrm{pp}$. \| $P h P, 7$ (1964), 326-327 (Hampejs).

18.4465. Tagliavini, C.-Le origini delle lingue neolatine, $3^{*}$ ed. (N. 16-46254). II Analele Universităti din Timisoara, 1 (1963), 343-347 (Ivănescu).-V. núm. $18-656$.

18-4466. Viwos, B. E.-Manual de lingüistica románica. Trad. del italiano por Francisco de B. Moll.-Aguilar, Madrid, 1963 . xxiii + $14^{6}$ pp. (Biblioteca de cultura e historia).-V. núm. 1229436. || $A O, 13$ (1963), 382-383 (Alar$\cos$ Llorach); BICC, 19 (1964), 583$5^{84}$ (Simbaqueba Reina).

18-4467. Lausberg, Heinrich - Romanische Sprachwissenschaft. 1: Einleitung und Vokalismus. 2. Aufl.-de Gruyter, Berlin, 1963. 211 pp. (Sammlung Gö. schen, Bd. 128/128a). - V. núm. 1229439. || ZRPh, 79 (1963), 638 (Baldinger); $L N, 25$ (1964), 30 (Gh. Gh.). 
18-4468. ELCOCK, W. D.-The Romance languages (N. 17-3665). \| Krat, 8 (1969), 214-215 (Rychner).-.V. núm. 18-657.

18-4469. Gamillscheg, Ernst - Ausge. wählte Aufsätze. Bd. 2. - Niemeyer, Tübingen, $1962.445 \mathrm{pp}$. \|RJ, 16 $(1965), 181-182$ (Christmann); $V R, 23$ (1964), $15^{1-152}$ (Holmer); RF, 76 (1964), 209-218 (Piel).

18-4470. Pei, Mario A.-Studies in Romance philology and literature.-University of North Carolina, Chapel Hill, 1963. $136 \mathrm{pp}$. (Studies in the Romance Languages and Literature, 44).

18-4471. IORDAN, IORGU-Dos estudios de lingüistica románica.-Univ. de la República, Montevideo, 1964. $31 \mathrm{pp}$.

18-4472. Porteau, Paul - Deux études d'histoire de la langue. 1: Latin parlé, latin vulgaire et roman commun. 2: Langue d'oc et langue d'oill.- P.U.F., Paris, 1963. 52 pp. (Publ. Fac. des Lettres de Clermont-Ferrand, $2^{\mathrm{e}}$ sér., 14). II RevPh, $3^{8}$ (1964), 355 (Ernout).

18-4473. Sabatini, F.- "Tra latino taido e origini romanze".-Studi Linguistici Italiani, 4 (1963-64), 140-159.

18-4474. Pulgram, E. - "Proto-languages as proto-diasystems: proto-Romance".Word, 20 (1964), 373-383.

18-4475. Husschmm, J. - Mediterrane Substrate (N. 17-3682). || Era, 16 (1964), 79-8I (Yarrill).

18-4476. SZEMERÉnYI, O.-“On reconstructing the Mediterranean substrata".$R P h, 17$ (1963-64), 404-418. [Sobre J. Hubschmid, Mediterrane Substrate, y Substratprobleme].

18-4477. Hubschmid, Johannes-Thesaurus praeromanus. Grundlagen für ein weitverbreitetes mediterranes Substrat, dargestellt an romanischen, baskischen und vorindogermanischen p-Suffixcn.Francke Verlag, Bern, 1963, Fasz. 1: 96 pp. || BSLP, 59 (1964), núm. 2, 183${ }_{185}$ (André) ; RevPh, 38 (1964), 330332 (Ernout); $B S Y, 20$ (1964), 484$4^{87}$ (Michelena) ; $A$ GIt, 5o (1965), 687o (Parlangèli); Lat, 23 (1964), 378 (Rocher); RF, $77 \quad(1965), 126-130$ (Rohlfs); IF, $69 \quad(1964), \quad 273-277$ (Schmoll).

18-4478. Reichenkron, G.- "Grundsätzliches zum Problem des Vorrömischen ( $\mathrm{Zu}$ Johannes Hubschmids Thesaurus praeromanicus)".--RJ, 15 (1964), 182199.

18-4479. Krofber, A.-“Three quantitati- ve classifications of Romance" (N. 1642334). || $Z R P h, 80(1964), 610-612$ (Stimm).

18-4480. Iordan, I.-"Romîna si spaniola, arii laterale ale latinitătii”.-SCL, 15 $(1964), 7^{-14}$. [Y trad. francesa en $R R L$, $\left.9(1964), 5^{-14}\right]$.

18-4481. L.̈̈DTKE, H.-"Die Entstehung romanischer Schriftsprachen". - VR, 23 (1964), 3-21.

18-4482. IORDAN, I., et al. (eds.)-Crestomatie romanică. T. 1.-Editura Academici Republicii Populare Romine, Bucuresti, 1962. 884 pp. || BSLP, 59 (1964), núm. 2, 111 (André); SCL, 15 (1964), 105-109 (Copceag); RLiR, 27 (1963), 230-231 (Gardette); Orbis, 14 (1965), 275-280 (Plomteaux); RLi, 9 (1964), 335-340 (Stan).

18-4483. Weinrich, H. - Phonologische Studien zur romanischen Sprachgeschichte (N. 14-38264). II Conv, 30 (1962), 73-76 (Dardano). -V. núm. 17-385.

18-4484. Michelena, L.-"Románico y circunrománico sobre la suerte de latín ${ }^{2}$ ". $-A O, 14$ (1964), 40-60.

18-4485. Sala, M.-“Romania occidentală si Romania orientală. In legătura cu tratamentul sonantelor".-SCL, 15 (1964), 169-179. [Y trad. francesa en $S t L, 17$ (1963), 26-39].

18-4486. SAlA M.-"Romania orientalc et Romania occidentale, 2: Sur la corrélation de quantité consonantique". $R R L, 9 \quad\left(19^{64}\right), 4454^{69}$.

18-4487. POSNER, R. R.-Consonantal dissimilation in the Romance languages (N. 18-66o). I| FS, 18 (1964), 85-87 (Barnett); ZRPh, 81 (1965), 394-401 (Mon. déjar).

18-4488. Matthews, W.-“Qu'est-ce que la dissimilation?"- $R P h, 17(1963-64), 642-$ 667. [Sobre R. R. Posner, Consonantal dissimilation in the Romance languages].

18-4489. Pfister, M.-Die Entwicklung des inlautenden Konsonanten-Gruppe -tssin den romanischen Sprachen (N. 173674). II RPh, $17(1963-64), 464-467$ (Blaylock).

18-4490. Reichenberger, K.-“Zur Sonotisierung palataler Anlautkonsonanz. im Westromanischen".- $V R, 23\left(196_{4}\right), 5^{6-}$ 68.

18-4491. Hall, R. A., JR.-"Initial consonants and syntactic doubling ii West Romance".-Lan, 4o (1964), $55^{1-556}$.

18-4492. SchürR, F.-“Grundsätzliches zu den Fragen der Romanischen, insbe- 
sondere italienischen Dipthongierung". -ASNS, 201 (1964), 321-339.

18-4493. LLOYD, P. M. - "An analytical survey of studies in Romance word formation".- $R P h, 17 \quad(1963-64), 73^{6}$ 770 .

18-4494. Hasselrot, B.-Etude sur la formation diminutive dans les langues romanes (N. 13-36351). || Krat, 7 (1962), $182-187$ (Cho); Leuv. Bijdr., 5o (1961), 16-22 (Roelandts).-V. núm. 16-46278.

18-4495. Pottrer, B. - "Contraintes dans le choix morphosyntaxique". $-R R L, 9$ $\left(19^{64}\right), 15^{-17}$. [La preposición de en francés y en español].

18-4196. Masis, B.-["Localización cronológica del sufijo romance -ata"]. Filol. Nauki, 5 (1962), 201-205. [En ruso].

18-4497. Posner, R.-“Romance imperfect and conditional endings: $A$ further contribution".-StN, 37 (1965), 3-10.

18-4498. Togrby, K.- "Les désinences de l'imparfait dans les langues romancs". $-S t N, 3^{6} \quad(1964), 3^{-8}$.

18-4499. Müller, B. - "Das lateinische Futurum und die romanischen Ausdrucksweisen für das futurische Geschehen".- $R F, 7^{6} \quad(1964), 44-97$.

18-4500. Gottschalk, Klaus - Dieter Untersuchungen zur Frage der Passiv. ersatzformen im Romanischen. Eine Studie am Werk von P. Calderón de la Barca unter Beachtung der französischen, italienischen und spanischen Grammatik.-[Tesis, Univ. de Marburgo, 1962]. 40o pp. $\| Z R P h, 80$ (1964), $5^{6} 3$ (Baldinger).

18-4501. Heger, K. - "Kriterien zur Bewertung der lexikalischen SonderstelIung einer Sprachlandschaft". - ZRPh, $80(1964), 15-34$.

18-4502. Lexicologie et lexicographie francaise et romane (N. 17-3688). II IAN, 22 (1964), 245-249 (Budagov); Rev. des Études Italicnnes, 9 (1964), 306. 307 (C. M.).

18-4503. Rohlfs, G. - Diferenciación léxica de las lenguas románicas (N. 17-399). \|I $H R, \quad 32 \quad(1964), \quad 256-259$ (Brault); RPF, $12 \quad(1962-63), 637-63^{8}$ (Magno).

18-4504. Vonesch, R.-"A propos de la différenciation lexicale des langues romanes".-BJR, 1963, núm. 7, 14-26.

18-4505. KrÜGER, FrITZ-El mobiliario popular en los paises románicos. [Tomo A].--Instituto de Estudos Románicos da Universidade, Coimbra, 1969. 933 pp. (RPF, suplem, 3).-V. núms. 16$46313 / 4$. BICC, 19 (1964), 179-180 (Ares Montes); Caesaraugusta, 21-22 (1964), 204-205 (Beltrán); $Z V, 1$ (1965), 160-163 (Bierhenke); REt, 2 (1964), 471-477 (Chaves); RLiR, 27 (1969) , 492 (Gardette) ; ZE, 89 (1964), 287-288 (Giese) ; $R F, 76 \quad(1964), 229$ 231 (Kröll) ; H, $47 \quad(1964), 189$ (Moser); RDTP, 20 (1964), 243-245 (Pérez Vidal); $R P F, 13(1964-65), 396-400$ (Pérez Vidal); Fil, $10(1964), 230-233$ (Vidal de Battini); Schweiz. Archiv für Volkskunde, 6o (1964), 247-248 (Wildhaber).

18-4506. Buser, Peter - Geschichte der V'erben für 'bitten, beten, verlangen' und der zugehörigen Nomina actionis in den romanischen Sprachen.-[Tesis, Univ. de Berna, 1964].

18-4507. Kahane, H. \& R. - "RomanoAegyptiaca" (N. 16-46304). II ZRPh, 80 (1964), 610 (Stimm).

18-4508. Kahane, H. \& R., \& A. PietranGELI-"Egyptian papyri as a tool in Romance etymology".- $R P h, 17$ (196364). 310-319.

18-4509. KAHANE, H. \& R.-“Christian and un-christian etymologies". - The Harvard Theological Review, 57 (1964), 23-38. [Sobre abismo, longino, marrano, pagano y galimatias].

18-4510. JäNicke, OTto-Die Bezeichnungen des Roggens in der romanischen Sprachen.-[Tesis de la Univ. de Basilea, 1964$]$.

18-4511. SCHMID, H.-“"Zur Entwicklungsgeschichte der romanischen Zahlwörter".-VR, 23 (1964), 186-238.

18-4512. Stan, I.-"Problèmes d'onomasiologie romane. Autour de la terminologie du bâtiment".- $R L i, 9(1964), 625$ 631 .

18-4513. Tilander, G.-“Etimologías románicas".-AFA, 14/15 (1963-64), 341343 .

18-4514. Tilander, G.-"Francés antiguo, provenzal, catalán ades, italiano adesso, antiguo español adieso". - $A F A$, $14 / 15 \quad(1963-64), 315-317$.

18-4515. Aliner, Mario L. - Origin and history of the Italian word "ambasciata" 'embassy'.-The Hague, 1963. 39 pp. $\| R P h, 18(1964-65), 469-475$ (Stefanini) .

18-4516. Aebrscher, P.-"Basilica, eclesia, ecclesia. Étude de stratigraphie linguistique".-RLiR, 27 (1963), 119-164. || SCL, 15 (1964), 261-262 (Mihăescu). 
18-4517. Aerischer, P. - "L'antécédance d'ecclesia sur basilica au sens de 'bâtiment servant au culte chrétien' prouvé par les Evangiles?"-Studi in onore di Alfredo Schiaffini, 1965 , pp. 6-12.

18-4518. Rohlfs, G. - "Zur Etymologie von bizarre".-ZRPh, 8o (1964), 120 . 126.

18-4519. Alessio, G. - "Sull'etimologia di brezza e di brisa". - BALM, 1963-64, núms. $5 / 6,25-38$.

18-4520. Kahane, H. \& R.-"Carestia".Essays... A. H. Schultz (Columbus, Ohio, 1964), 118-122.

18-4521. Tilander, G.-"Origine et évolution sémantique de chercher" (N. 17. 518). $\| Z R P h$, So (1964), 624 (Höiler).

18-4522. Trlander, G.-"Origen y cvolución semántica de frôler dilucidados por el verbo español rozar". - $A F A$, $14 / 15 \quad(1963-64), 311-314 .-V$. núm. $6-8509$.

18-4523. Aebischer, P.-"La diffusion de plebs 'paroisse' dans l'espace et dans le temps". - RLiR, 28 (1964), 143-165.

18-4524. Heisic, K. - "Franz. tort, ital. torto, span. tuerto, port. torto, engl. wrong 'unrecht"'.-NS, 13 (1964), 333$33 \%$.

18-4525. WARtBuRG, W. von - "Tropare und turbare".-ER, 8 (1961), 95-104.

V. también núms. $4^{199}, 4^{6} 66$.

\section{LINGÜISTICA HISPĀNICA}

18-4526. VIDAL, LORENZO-En torno al problema de las lenguas nacionales espa. ñolas.-Hermandad de Inspectores de Enseñanza Primaria, Madrid, 1964. 16 pp. (Bibl. auxiliar de educación, 165).

18-4527. Vázquez de Parga, M. L.-"Bibliografía de don Ramón Menéndez Pidal".-RFE, 47 (1964), 7-127.

18-4528. Umbral, F.- "Los saberes y los días de don Ramón Menéndez Pidal". $-M u H, 1964$, núm. 191.

18-4529. Yanguas, J.-"El secreto de don Ramión".-FH, 2 (1964), 577-578.

18-4530. Antelo Iglesias, A. - "Filología e historiografía en la obra de Ramón Menéndez Pidal". - BICC, 19 (1964), 397-415.

18-4531. LAPFsA, R.-."Ofrenda de tres noticias". $-F H, 2$ (1964), 589-594.

18-4532. Oliver, A.- "Menćndez Pidal y Rubén Dario".-FH, 2 (1964), 595-600.

18-4533. Estudios dedicados a Menéndez Pidal. T. 7, vol. 2: Indices,-C. S. I. C.,
Madrid, 1962. xii + 255 pp.-V. núm. 17-428. || LR, $18 \quad(1964), \quad 3^{84-385}$ (Groult).

\section{LENGUAS PENINSULARES}

\section{Catalán y valenciano}

18-4534. ManczaK, W.-“Le provençal et le catalan",-Actes du IIe Congrès In. ternat. des Langues et Litt. du Midi de la France (Aix, 1961), 53-60.

18-5435. BADía Margarit, ANTONI M.Llengua $i$ cultura als països catalans.-Edicions 62, Barcelona, 1964. 197 pp. (A l'abast).

18-4536. Pericay, P., y J. Maluquer de Motes--"Problemas de la lengua indigena en Cataluña".-II Symposium de Prehistoria Peninsular (Barcelona, 1963), 101-143. || REA, 66 (1964), 146 (Lafon).

18-4537. Rubio García, L.- Estudios histórico-lingüisticos del antiguo Condado de Ribagorza (N. 17-4250). $\| A F A$, 14/15 (1969-64), 375-378 (Mondéjar); Arg, 11 (1960), núm. 41, 94 (Vidal).

18-4598. Carrascal Sánchez J.-“La penetración de la lengua catalana en el dominio gascón".-AFA, I4/15 (1963. 64), 103-233.

18-4539. Martínez Ruiz, J.-“otro aviso de rebato en lengua catalana $(1560)$ ". $-A F A, 14 / 15 \quad(1963-64), 267-270 .-\mathrm{V}$. núm, $17-3724$.

18-4540. Martínez Ruiz, J.-“Actas valencianas de embargos de navíos (1553)". $-A F A, 14 / 15 \quad(1963-64), 25^{1-261}$.

18-4541. MIRACLE, JOSEP - Un moment clau de la história de l'ortografia catalana.-R. Dalmau, Barcelona, 1964. 62 pp. (Episodis de la història, 52).

18-4542. Carbonell, J.-"Notes sobre els Principis de la lectura menorquina de 1804 ".-ER, 8 (1961), 195-214.

18-4543. Montsiá, Bernardo-El valenciá en vint lliçons. Regles de gramàtica, exercicis $i$ clau. - Fermar, Valencia, 1964. 104 pp. (Entre tots ho forem tot).-V. núm. 11-27408.

18-4544. SOFF, IRENE-Die Formen der $k a$ talanischen Verbalendungen von den Anfängen der schriftlichen Uberlieferung bis 1400.-Erlangen, 1962. xix + 235 pp. [Tesis]. $-V$. núm. 16-42471. ASNS, 201 (1964), 76-78 (Roth).

18-4545. RocA I Pons, J.-"Estar + gerundi en catalá antic".-ER, 8 (1961), $189-193$. 
18-4546. HiLty, G, - "Oratio reflexa en catalá".-ER, 8 (1961), $185^{-187}$.

18-4547. MeIER, H.-"Kat. atansar".-ER, $8(1961), 175,-178$.

18-4548. Gulsoy, J.-“Corominas' research for his Onomasticon Cataloniae".-HR, $32(1964), 247-255$.

18-4549. Griera, A.- "E1 culto de los santos". $-B D E, 37$ (1961), 5-23.

18-4550. Badia I Margarit, A. M. - "Els noms de lloc catalans Maçana (i afins) a la llum de la documentació llatina medieval".-ER, 8 (1961), $157-174$.

18-4551. Corominas, J.-"El problema de Quatretonda i Quatremitjana, i la toponímia mossàrab del Maestrat". BSCC, 39 (1963), 340-352. || $Z R P h, 8$ o (1964), 642 (Baldinger).

18-4552. Sanchis Guarner, M.-“Factores históricos de los dialectos catalanes".EMP, 6, 151-186.-V. núm. 12-32609.

18-4553. MOLL, F. DE B.--"Espigoladures dialectals".-ER, 8 (1961), 179-184.

18-4554. Haensch, G.-Las hablas de la Alta Ribagorza (N. 18-1299). $\|$ RLR, 75 (1963), 267-269 (Guiter).

V. también núms. $4514,4^{800}, 4^{897}, 4905$, $5^{2} 51$.

\section{Gallego y portugués}

18-4555. III Colóquio internacional de es. tudos luso-brasileiros (N. 17-3750). II NRFH, $18 \quad(1965-66), 205-208$ (Lope Blanch) .

18-4556. Anais do Congresso Brasileiro de Lingua Vernácula.-Casa de Rui Barbosa, Rio de Janeiro, 1956-1959. 3 ts.: 38o, 333, 489 pp.-V. núm. 14-38387. II $R P h, 17$ (1963-64), 817 (Woodbridge).

18-4557. MalpiQue, C.-“O Doutor José Leite de Vasconcelos".- $L a b, 26$ (1962). núms, 208, 209, $211,212$.

18-4558. HAMPEJs, Z. - "Filólogos brasileiros" (N. 17-3763). $\mid R J, 14$ (1963), $38_{5} \quad$ (Kröll); RPh, $18 \quad(1964-65), 132$ (Woodbridge).

18-4559. Mattoso CâmarA, J.-“As idéias gramaticais de João Ribeiro".-LPa, 1961 , núm. 12.

18-4560. Roвв, J. W.-"Alfonso Reyes, el Brasil y la lengua portuguesa".-KFLQ, 11 (1964), 33-39.

18-4561. Flusser, V.-.Da língua portuguesa".-Rev. Brasileira de Filosofia, 10 (1960), 560-566.

18-4562. VAZ LEÃo, A. - "Discurso de posse na cátedra de língua portuguêsa". -Krit, 1964, 298-305.
18-4563. Telmo, A.-“Da língua portuguesa".,-Esp, 1964-65, núms. $4 / 5$.

18-4564. Nunes de Figueiredo, J., e A. GoMES FERREIRA-Do latim ao português. A lingua como expressão literária. Porto Edit., Porto; Empresa Lit. Fluminense, Lisboa, $1964 \cdot 71 \mathrm{pp}$. \| $R P F$, 13 (1964-65), 424-425 (Louro Fonseca).

18.4565. Ferreira, T. L.-"A linguagem dos documentos".-RP, $29(1964), 399^{-}$ 410 .

18-4566. Machado, J. P.-“A doação de Açafa (1198)".-RP, 29 (1964), 348. 357. [Con un vocabulario].

18-4567. Azevedo Filho, Leodegário A. $\mathrm{DE}-A s$ unidades melódicas da frase. -Ed. do Professor, Rio de Janeiro, 1964. 45 pp.

18-4568. Muller, Daniel Henry-A study of the effects on pronunciation and intonation of accompanying audio-lin. gual drill with exposure to the writien u'ord.-[Tesis, Univ. of California, Berkeley; resumen en $D A, 24 \quad\left(1963-6_{4}\right)$, $5414-5415$ ]. 82 pp. [Materiales portugueses].

18-4569. Moura Santos, M. J. DE-"Remarques sur deux systèmes vocaliques anciens du portugais du nord". $-B J R$, 1964 , núm. 9, 5-12.

18-457\%. LAcerda, A. DE, \& B. F. HEAd "Análise de sons nasais e sons nasali. zados do português".-RLFE, 6 (1962), $5-71$.

18-4571. Leote Cavaco, R. J.-“Subsídio para a pronúncia correcta do vocábulo estafilococos e outras bactérias". $-R P$, 29 (1964), $221-229$.

18-4572. Elia, Sílvio Edmundo-Dicionário gramatical português. $3^{\text {a }}$ ed.-Glóbo, Porto Alegre, 1962. $205 \mathrm{pp}$.

18-4573. Peixoto DA Fonseca, F. V.-"O ensino das línguas pelos métodos audiovisuais e o problema do português fundamental".-BMP, 15 (1964), 85-98.

18-4574. EY - KRÜGER - Portugiesische Sprachlehre. 13. Aufl--Julius Groos, Heidelberg, 1962 . viii $+278,44$ pp.V. núm, $6-8523$.

18-4575. Rocha lima, Carlos H, da, e Srrafim da Silva Neto - Gramática normativa da lingua portuguêsa. $9^{\text {a }} \mathrm{ed}$. -Briguiet, Rio de Janeiro, 1963. xii + 597 pp. $-V$. núm. 18-777.

18-4576. Bechara, Evanildo - Modema gramática partuguêsa.-Editôra Nacional, São Paulo, 1963. ${ }_{461} \mathrm{pp}$. $\| H, 47$ (1964), 68o (Gomes de Matos). 
18-4577. Marchant, Mercedes-Português para estrangeiros. $4^{\text {a }}$ ed.-Livraria Sulina, Porto Alegre, 1964. 284 pp. $-V$. núm. 17-466. || $R P F, 13(1964-65), 426-$ 428 (Louro Fonseca) .

18-4578. Vázquez Cuesta, P., y M. A. MENDES DA LuZ-Gramática portuguesa (N. 17-3795). $\|$ RDTP, 20 (1964), 389393 (R. L.); $A I O N-R, 7 \quad(1965), 115$ 122 (Reali).

18-4579. Brandão, Cláudio-Sintaxe clás. sica portuguêsa.-Autor, Belo Horizonte, $1963.852 \mathrm{pp}$.

18-4580. Gama Kuri, Adriano Da-Lições de análise sintática. Teórica $e$ prática. $2^{\text {a }}$ ed., melh. e aum.-Fundo de Cultura, Rio de Janeiro, 1963. $174 \mathrm{pp}$. (Domine seu idioma).-V. núm. 18 799 .

18-4581. Abreu Rocha, António de Nova análise sintáctica. (Orientação da doutrina moderna, segundo a nova nomenclatura brasileira). - Vigília, Belo Horizonte, 1962. 159 pp.-V. núm. 1334555 .

18.4582. ABREU, M. I.-“'O estudo comparativo de padrões estructurais em português e em espanhol". - LBR, 1 (1964), núm. 2, 89-95.

18-4583. Santos Jota, Z. dos-"Plural dos compostos".-RP, $29(1964), 567-576$.

18-4584. SÁ Nogueira, RDDRIgo dE - $D i$ cionário de verbos portugueses conjugados. $3^{\text {a }}$ ed.-Livr. Clássica, Lisboa, 1963. $3^{6.8} \mathrm{pp}$.

18-4585. Almeida Tôrres, Artur dE Rêgencia verbal. $4^{\mathrm{a}}$ ed., corr. e aum.Fundo de Cultura, Rio de Janeiro, 1963. 319 pp.

18-4586. Feldman, D. M.-“Analytic vs syntetic: a problem in the Portuguese verbal system". - Ling, 1964, núm. 10.

18-4587. RIBEIRo, JoÃo-Curiosidades verbais. Estudos aplicáveis à lingua nacional. Pref. de M. Cavalcanti Proença. $2^{\text {à }}$ ed.-Livr. São José, Rio de Janeiro, 1963 .

18-4588. SeIfert, E.-“Zur Bedeutungsentwicklung von portugiesisch ter". $M M D, 1,595^{-606 .}$

8-4589. Gomes, L. - "Topologia prono minal. O gerúndio".-RP, 29 (1964), $592-595$.

18-4590. VAZ LEÃo, A.-O periodo hipo. tético iniciado por "se" (N. 17-481). I! BdFS, 16 (1964), 291-294 (Contreras); PhP, 7 (1964), 109-105 (Hampejs). 18-4591. KRöLL, H. - "Zum exclamativen se im Portugiesischem".-ER, 8 (1961), $147^{-1} 5^{6 .}$

i 8-4592. Perea Martins, José - Funçöes da palavra "que": comentários de locuçôes, funçöes morfológicas, valôres sintâticos, exercicios, análises. - Ed. e Publ. Brasil, São Paulo, 1963 .

18-4593. Moreno de Oliverra, Maria MANUELA-Processos de intensificação no português contemporaneo. (A entoa. cão. Processos morfológicos e sintácticos).-Lisboa, 1962. $\mathrm{x}+25^{6}$ pp. (Publicações do Centro de Estudos Filo. lógicos, 15). \|l RF, 77 (1965), 172-174 (Hess); RJ, 15 (1964), 355-361 (Kröll); CuN, 23 (1963), 279 (Lanciani); RPF, $13 \quad(1964-65), \quad 365-380$ (Maçãs) ; BHi, 66 (1964), $247 \cdot 248$ (Molho); AION-R, 6 (1964), 119-121 (Reali) .

18-4594. Prado Coelho, J. DO.--La mise en relief stylistique de quelques pos sibilités syntaxiques du portugais". Langue et Littérature: Actes du VIII Congrès de la Fédération Internationale des Langues et Littératures $\mathrm{Mo}$ dernes (1961), 261-263.

18-4595. Andrade Canila, Fernando ("Dr. Canhão")-Breviário de Ferdenha. $4^{\text {a }}$ parte: Individuos e sujeitos. $5^{\text {a }}$ parte: [?]. 6 parte: Grande. $7^{\text {a }}$ parte: Peque. no. $8^{\text {a }}$ parte: Pequenos. $9^{\text {a }}$ parte: Coisas $10^{\mathrm{a}}$ parte: Lugares. $11^{\mathrm{q}}$ parte: $F a$ zer. $12^{\mathrm{a}}$ parte: Sem e Muito $13^{\mathrm{a}}$ parte: Ser. $14^{\text {a }}$ parte: $T$ er. $15^{\text {a }}$ parte: Com e Um.-João Francisco Lopes, Lisboa, 1960-1963. 136, 436, 142, 120, 118, 84, $140,222,124,116,138,126$ pp.

18-4596. Delcado, M. J.-“A semântica e a língua".- $R P, 29(1964), 522 \cdot 53^{8}$.

18-4597. RÉvah, I. S.-"Les origines de Jerónimo Cardoso, auteur du premier dictionnaire portugais imprime". $B A L, 36$ (1964), 277-279.

18-4598. Paiva Boléo, M. DE-“Metodologia do estudo etimológico de pala. vras antigas e modernas". - Lições de linguistica portuguesa, $2^{\text {a }}$ parte $\left(196_{t}\right)$, $27 \mathrm{pp}$.

18-4599. Carbonell Pico, M. A. T. "Anotações ao Dicionário etimológico da lingua portuguera de José Pedro Machado".-RP, $29\left(19^{64}\right), 39-42,81-$ $82,172-174,290-23^{2}, 4^{11-416 .-V}$. núm. 18-808.

18-460o. Fontinha, Rodrigo - Dicionátrio etimológico da lingua portuguesa. Domingos Barreira, Porto, 1963. 2000 pp. 
18-4601. Machado, José Pedro-Dicionário da lingua portuguesa. Ts. 2-3: Eoa$K w$--Sociedade da Lingua Portuguesa, Lisboa, $1962-64.1076$ pp.-V. núm. 17491 .

18-4602. Carvalho, J., e Vicente PeixoTo-Dicionário da lingua portuguêsa. $16^{\natural}$ ed., rev.-LEP, São Paulo, 1964 . $1966 \mathrm{pp}$.

i 8-46o3. Florenzano, Éverton - Dicionário de bôlso da lingua portuguêsa.-Ed. de Ouro, Rio de Janeiro, 1963. 606 pp.

18-4604. Henriques, Jary-Vocabulário de bôlso, especializado.-Cia. Bras. de Artes Gráf., Rio de Janeiro, 1969. 196 pp.

18-4605. Dicionário da língua portuguesa. De acôrdo com o pequeno vocabulário ortográfico da lingua portuguêsa. $32^{\text {a }}$ ed.-F. Alves, Rio de Janeiro, 1963. 815 pp. (Dicionários do povo, 1).

18-4606. Saraiva, A. J.-Dicionário critico de algumas ideias a palavras corren. tes (N. 16-46492). $\| P h P, 7\left(19^{6}\right)$, 442-443 (Lidmilová).

18-4607. O'Reilly de Sousa, M.-"Achegas ao Dicionário de fonografia".-RP, 29 (1964), 245-268, 317-332, 381-396, $437-455$.

18-4608. Costa, Altino - Dicionário de coletivos e correlatos. Ed. melh. e aum. por Leonam de Azeredo Penna.-Spiker, Rio de Janeiro, 1963. 342 pp.-V núm. 16-46491.

18-4609. Mendes de Morais, Orlando, e LeONAM DE Azeredo PENA-Dicionáric de sinônimos $e$ antônimos. $7^{\text {a }}$ ed., melh. e aum.-Ed. Científica, Rio de Janeiro, 1964. 2 ts. $-V$. núm. 18-822.

18-4610. Tavares, C. N.-Código interna. cional de nomenclatura botânica. $2^{\text {a }} \mathrm{ed}$. -Lisboa, $1963.78 \mathrm{pp}$.

18-4611. Remusat RenNó, LAIr - Pequeno dicionário etimológico das familias botánicas.-Universidade de Minas Gerais, Belo Horizonte, 1963. 186 pp.V. núm. 14-39946.

18-4612. D'Oliveira Feijāo, Raul-Elucidário fitológico. T. 3: P-Z.-Instituto Botânico, Lisboa, 1963. 394 pp. (Artigos de divulgação, 10).-V. núm. 17. 495 .

18-4613. Castilho, A.-“A linguagem na culinária".- $B C B D, 13$ (1964), 13-16, $5^{2-}$ $55,87-89,134^{-1} 3^{6}, 244^{-246}$.

18-4614. Carbonell Pico, Maria Alexan. DRA $-A$ terminologia naval portuguesa anterior a $1460 .-$ Sociedade de Língua Portuguesa, Lisboa, 1963. 721 pp.-V. núm. 16-42586.
18-4615. Leitão, Humberto, e J. Vicente Lopes - Dicionário da linguagem de marinha antiga $e$ actual.-Ed. do Centro de Estudos Históricos Ultramarinos, Lisboa, 1963. $\mathrm{xx}+434 \mathrm{pp}$.

18-4616. Fernandes Pereira, FranciscoDiccionário numismográfico luzitano [Lisboa, 1835]. Ed. fac-similada.-Sociedade Portuguesa de Numismática, Porto, 1963. $4^{0} \mathrm{pp}$. (Publicações, 116).

18-4617. Vocabulário de termos técnicos em quatro línguas [português, inglês, italiano, alemão]. $3^{\mathrm{a}}$ ed., rev. e aum.Ed. Industrial Teco, São Paulo, 1961. 2 ts.

18-4618. Martínez Almoyna, Julro-Dicionário de espanhol-português. $3^{\text {à }} \mathrm{ed}$. Porto Editora, Porto, 1963. $1066 \mathrm{pp}$. -V. núm. 14-40322.

18-4619. Masucci, Oberdan - Dicioncírio português-italiano, italiano-portuguès. Pref. de G. F. Porta.-Leia, São Paulo, 1963-64. $\times x+4^{80}, \quad \times x x i+832$ pp. $-V$. núm. 17-3860.

18-4620. Sousa VieIra, José DE-Diciona rio de português-francês. - Domingos Barreira, Porto, 1963. 820 pp.-V. núm. 18-836.

18.4621. Dias Miguel, ANtónio-Vocabulário esencial do francês. $3^{\text {a }}$ ed. remodelada.-Sá da Costa, Lisboa, 1963. 229 pp.

18-4622. Pinheiro, Eduardo - Dicionário francês-português. $7^{\mathrm{a}}$ ed.-Figueirinhas, Porto, 1964. 718 pp.-V. núm. $17-3^{8} 51$. 18-4623. TAylor, J. L. $-A$ PortugueseEnglish dictionary (N. 14-40148). I| Lingua, 9 (1960), 109 (de Jong).-V. núm. 17-511.

18.4624. Ferreira, Júlio Albino-Dicionário inglês-português. Nova ed.-Domingos Barreira, Porto, 1964. 888 pp.V. núm. 10-20151.

18-4625. Morais, ARMando DE-Dicionário de inglês-português. - Porto Editora, Porto, 1964. $195^{8} \mathrm{pp}$.

18-4626. TAYlor, James L.-English-Portuguese metallurgical dictionary.-Insti tute of Hispanic American and LusoBrazilian Studies, Stanford Univ., 1963 . $229 \mathrm{pp}$.

18-4627. Holbfk, Jaroslav, \& Zdenek HAMPEJs - Portugalsko-cesky a ceskoportugalsky kapesni slovnik. - SPN, Praha, 1964. $666 \mathrm{pp}$. \| PhP, 7 (1964), 442 (Dubský).

18-4628. Dinotos, SÁBAdo-Dicionário hebraico-português. - H. Koersen, São Paulo, 1962. $470 \mathrm{pp}$. 
18-4629. Nayagam, X. S. T.--“Antão de Proença's Tamil-Portuguese dictionary, 1679".-Tamil Culture, 11 (1964), 117 127.

18-46go. Knowrton, E. C., JR.-“Antão de Proença's Vocabulario tamulico lusitano. Indo-Portuguese elements". Tamil Culture, 11 (1964), 135-164.

18-4631. VIANA, M. J. - "Dicionário de português-chi-yao e chi-yao-português". -Memórias do Instituto de Investigaçño Cientifica de Moçambique, 3 (1961), 1-172.

18-4632. Mаснаdo, J. P.-“Os mais antigos arabismos da língua portuguesa (séculos rX-XII)".-BAu, 16-17 (1964), 240-248.

18.4633. Gama, E.-“Colhendo em estranha seara"- $R P, 29(1964), 89-100$. [Materiales onomásticos y lexicográficos].

18-4634. Arraes DE Alencar, J.-"Divagações filológicas".- $R P, 29$ (1964) , 585591.

18-4635. A. S.-"Vocabulário ultramarino".-Infantaria, $31 \quad$ (1964), 468-4 83 .

18- ${ }^{6} 63^{6}$. Correia, M.-."A propósito da nomenclatura anatómica”. - $B A L, 36$ (1964), 126-136.

18-4637. Périssé Duarte, N.-"As refeições em Portugal. Apreciações filológico-folclóricas através de textos".- RP, 29 (1964), 5-10. [Sobre almoçar, comer, jantar, etc.].

18-4638. Pacheco de Amorim, D.-"Algarismo".-Inst, 125 (1964), 21-44.

18-4639. Gifse, W.-"Port. cara 'Banknote" ". $-R J, 15$ (1964), 312-314.

18.4640. Cortês Pinto, A.-"Nota filológica sobre a palavra resmo".- $R P, 29$ $(1964), 25-28$.

18-4641. Lapa Carneiro, E.- $O$ papagaio. -Barcelos, 1964. 19 pp. [Designaciones y folklore de la cometa]. I| $R D T P$, 20 (1964), 548 (Pérez Vidal).

18-4642. Tilander, G. - "Portugués antiguo miona, miana".-AFA, 14/15 (196364), 345-347.

18-4643. MAchado, J. P. - "Esta palavra mecenas..."-RP, 29 (1964), 233-235.

18-4644. Tilander, G.-"La etimología de port. fecho, fechar, dilucidada por la construcción de las cerraduras primitivas".-AFA, 14/15 (1963-64), 357-366.

18-4645. Mota Ribeiro, M. DA-“Os nomes geográficos".-APC, 25 (1960), 169177 .

18-4646. Ribeiro da Cunha, A.-“Toponímia tumular". $-D B, 2 \quad(1963), 171$ 189.-V. núm, 9-17197.
18-4647. PmL, J. M.-“Über die Name der sog. Divisio Theodemiri" (N. 14. $\left.4^{\circ} 380\right)$. || RFE, $4^{6}(1963), 208$ (Llorente). $-V$. núm. 17-545.

18-4648. Pires Gonçalves, J.-“Monsaraz e su termo", 2a pte. $-B J D E, 1963 .-\mathrm{V}$. núm. 18-871. || Sef, 24 (1964), 383-384 (Cantera) .

18-4649. SousA, A. DE-"Onomástica p1eromana. O nome Aveiro" (N. 17-551). || BSLP, 59 (1964), núm. 2, 287 (Lejeune) .

18-465o. Almeida Calado, Adelino de"Abegão". Estudo linguistico. - Elvas, $19^{63}$. 40 pp. ( $A$ sombra do aqueduto, estudos elvenses).

$18-465$. Costa Ramalho, A. Da-"Eborae et novi Eboraci".- $H u C, 15 / 16$ (196364) $434-435$.

18-4652. Machás, J.- "Nos tempos que já lá vão... Etimologia de Machiaes. Etimologia de Lardosa". $-E C B$, 1963, núm $9,40-47$.

18-4653. Morerra, D. - "Enquadramento onomástico de Meinedo (Lousada)".$B C P, 26 \quad\left(196_{3}\right), 93-116$.

18-4654. Dinis Cabral, A. A.-A serra da Merefa. Tema filológico.-Porto, 1963. 12 pp.

18-4655. Amaral, J.-“Alcunhas".- $B C B D$, $13(1964), 33^{8-34^{\circ}}$.

18.4656. Tavares DE Sousa, J. P. DE L."Algumas considerações acerca do ada. giário".-APCE, 1, 363-368.

18-4657. Pires de Lima, Fernando de C.Adagiário português. - Livr. Clássica, Lisboa, 1963. 180 pp. || RDTP, 19 (1963), 437-438 (Castillo de Lucas).

18-4658. Ribeiro dA Cunha A.-“Estudos de linguagem popular". $-D B, 3$ (1964), $185-196$.

18-4659. LüDTKE, H.-"Beiträge zur Lautlehre portugiesischer Mundarten" (N. 13-36429). I| Phon, 6 (1961), 104-106 (Rothe).

18-4660. Carvalho Costa, Alexandre Curiosidades do falar popular do Alto Alentejo. - Junta Distrital, Portalegre, 1963. $100 \mathrm{pp}$.

18-4661. RIBeiro, M.-“Estudos sobre a aldeia da Glória, Salvaterra de Magos".-RP, 28 (1963), 231-251, 297-314. 18-4662. Pinharanda Gomes-"A gíria de Quadrazais".-RP, 29 (1964), 194-203. 18-4663. Oliveira Almada, Maria Dulce DE-Cabo Verde. Contribuição para o estudo do dialecto falado no seu arqui. pélago.-Junta de Investigações do Ultramar, Lisboa, 1961. 166 pp. (Estudos 
de ciências politicas $e$ sociais, 55 ). $-\mathrm{V}$. núm. 16-46543.

18-4664. Rrsco, V.-“o idioma galego na nosa vida e na nosa cultura".-Grial, $1963,59-66$.

18-4665. LoRenzo VÁzQuez, R.-“Estudios etnográfico-lingüisticos sobre la Mahía y aledaños"-CuEG, 18 (1963), 129147; $19(1964), 10-64 .-\mathrm{V}$. núm. 18907.

18-4666. Pensado, J. L.-“Ordinales desconocidos del galaicoportugués". $-Z R P h$, $80 \quad(1964), 35^{1-355}$.

18-4667. Pres, J. M.-"Beiträge zu einem galicischen etymologischen Wörterbuch".-FFS, 83-100. II ZRPh, 80 $\left(19^{6}\right), 568$ (Hatzfeld) .

18-4668. Rodrigues, A. DALl' I.-“'Os estudos de linguística indigena no Brasil".-Rev. de Antropologia, 11 (1963), núms. $1 / 2,9-21$.

81-4669. Seraine, F.-"Normativismo cultural e ideal linguístico". - $R P, 29$ (1964), 417-432.

18-4670. Elıa, S.-“A contribuição linguística do modernismo [brasileiro]".-Cursos de férias (1961-62), Pôrto Alegre, $1963,8 \mathrm{I}-108$.

18-4671. Silva Neto, Serafim da-Introdução ao estudo da lingua portuguesa no Brasil. Pref. de Augusto Magne. $2^{\text {a }}$ ed. aum. e rev.-Instituto Nacional do Livro, Rio de Janeiro, 1963. 275 pp. (Col. de filologia, 5).-V. núm. 8-9333.

18-4672. MatToso CÂmara, J.-"Europäische Sprachen in Übersee: Das brasilianische Portugiesisch". - ASNS, 200 (1963), 321-337.

18-4673. Pompeia Gonzaga, M. A., e V. C. CoAtri - "Tendências linguísticas em São Paulo e a lingua-padrão brasileira".-RP, 28 (1963), 201-211.

18-4674. Lourenço Filho - "Linguagem num romance paulista". - Alfa, 1963, núm. $4,75^{-82}$.

18-4675. DAHL, I.-"The pronunciation of Brazilian Portuguese". - HDJ, 313-319. 18-4676. Luft, Celso Pedro-Gramática resumida de acordo com a nomenclatura gramatical brasileira. $2^{\text {a }}$ ed. rev. e melh.-Globo, Porto Alegre, 1963. xviii $+196 \mathrm{pp}$.

18-4677. Mattoso CÂmara, J. - "Ele comme accusatif dans le portugais du Brésil" (N. 13-36434) . || Phon, 6 (1961), 99-100 (Rothe).-V. núm. 1646565 .

18-4678. Seraine, F. - "Suplemento ao Dicionário de termos populares (re- gistrados no Ceará) ".- $-R P, 29$ (1964), 43-53.-V. núm. 16-46574.

18-4679. Cardoso, A. L.-Toponimia brasilica.-Rio de Janeiro, 1961. $476 \mathrm{pp}$.

18-4680. Seraine, F.-"Relação entre os fatos históricos e a onomástica no Bra. sil".-Rev. do Instituto do Ceará, † 8 (1964), 89-97.

18-4681. Silva Furtado, S, DA-"Presença de N. Sạ da Conceição na toponímia brasileira".-RP, 29 (1964), 29-38.

18-4682. Vidago, J.-"Curaçao, nome por tuguês!?"-RP, $29(1964), 577-584 .-\mathrm{V}$. nưm. $16-46515$.

18-4683. Grünewald, H.-“Brasilianisches Namensrecht". - Das Standesamt, 14 (1961), 86-87.

18-4684. Chaves de Melo, G.-"Dialectos brasileiros". - Brasilia, 1964, núm. 23, 41-43.

18-4685. Révah, I. S.-- “La question des substrats et superstrats dans le domaine linguistique brésilien: les parlers populaires brésiliens doivent-ils être considerés comme des parlers 'créoles' ou 'semi-créoles'?"-Ro, 84 (1963), 433$45^{\circ}$.

18-4686. Câmara Cascudo, Luís da-Jan gada. Uma pesquisa etnográfica. $2^{\text {? }}$ ed. -Letras e Artes, Rio de Janeiro, 1964. ${ }_{16}$ pp.-V. núm. 17-3954.

18-4687. Oberacker, C. H., Jr.-"Transformações da língua alenã no Brasil".-Humboldt, 1963, núm. 8, 18-34; $R P, 28 \quad(1963), 405-419$.

18-4688. Leoni, G. D.-“Appunti per uno studio delle influenze del portoghese sui dialetti italiani a São Paulo del Brasile".-Orbis, 12 (1969), 212-220.

18-468g. ValkhofF, M. - "Contributions to the study of Creole. 2. An historic language: Creole Portuguese".-African Studies, Johannesburg, 19 (1960), núm. 3, $113-125$.

18-46go. Chataigner, A.-“Le créole portugais du Sénćgal. Observations et textes".-Journal of African Languages, 2 (ig63) , 44-71.

18-4691. WILson, W. A. A.-The crioulo of Guine. - Witwatersrand Univ. Press, Johannesburg, 1962.

18-4692. Redinha, J.-“Origem e generalização do nome Angola".-Ultramar, 5 (1964), núm. 15, 5-16.

18-4693. Knowlton, E. C. - "Malaysian Portuguese".-Linguist, 26 (1964), 211 $213,239-241$.

18-4694. Soares, F. A. - "Nomes vernácu. los chineses de algumas plantas de 
Macau". - Estudos Agronómicos, 1969, núm. 3, 81-97.

V. también núms. $4800,4897,49^{28}, 494^{8}$, $543^{1}$.

$V$ a s c o

18-4695. Berriocho:A, V. - "Notas de bibliografía vasca".-BSV, 19 (1969), 372$373 ; 20 \quad(1964), 285-289$.

18-4696. Gamillscheg, E.-“Zum Problem 'Romanen und Basken'". - RF, $7^{6}$ $(1964), 422-425$.

18-4697. Michelena, Luis-Sobre el pasado de la lengua vasca. - Auñamendi, San Sebastián, 1964. 200 pp.

18-4698. Geografia histórica de la lengua vasca (N. 16-46598). || Arg, 12 (1961), 159-160 (Benito-Vidal).

18-4699. Michelena, Lurs-Textos arcaicos vascos. - Minotauro, Madrid, 1964 . 207 pp. (Biblioteca vasca). $\| B S V, 20$ (1964), 335-343 (Omaechevarría).

18-4700. GIFFORD, D. - "An early white Paternoster in Basque?" - BHS, $4^{1}$ (1964), 209-222.

18-4701. Michelena, L.-"Unas cartas del siglo xvir",-BSV, 20 (1964), 75-86.

18-4702. Bertolaso Stella, J.--"Um Nôvo Testamento basco". - Alfa, 1963, núm. 3, 59-70.

18-4703. Michelena, L.-Fonética histórica vasca (N, 18-961). || Lingua, 12 $\left(19^{63}\right), 320-334$ (De Rijk).

18-4704. Elderkin, G. W. $-A$ comparative study of Basque and Greek vocabularies (N. 14-40193). $\| A C, 28$ (1959), 454-455 (Leroy).-V. núm. 16-46617.

18-4705. ZUMALDE, I.- "Algunas palabras vascas del siglo xvI".-BSV, 20 (1964), 21-26. [Y notas de L. Michelena].

18-4706. Gárate, J.-“Las palabras vala y balda o ¿Quién como yo?"-BSV, 20 (1964), 87-90.

18-4707. Irigaray, A. - "Modismos del idioma vasco".-PV, $25(1964)$, núms. $94 / 95$.

18-4708. Gavel, H.-"Notes de toponymie basque".-Actas del III Congreso Internac. de Est. Pirenaicos (Gerona, 1963), t. 6, sección 6, 45-49. $\| A F A, 14^{-15}$ $(1963-64), 3^{81}$ (Mondéjar).

18-4709. Eleizalde, L. DE-“Lista alfabética de voces toponomásticas vascas".$B S V, 20$ (1964), 103-159.-V. núm. 18975 .

18-4710. Merino Urrutia, J. J. B.-“Los topónimos vasco-riojanos". - $B S V, 20$ (1964), 17-19.
18-4711. Garvens, F.-"Elementos vascos en la toponimia cántabro-asturiana".$A S C, 2,21-24$.

18-4712. Michelena, L., y A. YrigaraY"Nombres vascos de persona" (N. 1643052) - || ArO, 29 (1961), 672 (Zgusta).

18-4713. BoudA, K.-“Bemerkungen zum Souletinischen".-BSV, $20 \quad\left(196_{4}\right), 3-8$. 18-4714. Michelena, L. - Historia de la literatura vasca (N. 17-3977). \| PhP, 7 (1964), 444-445 (Tauer).

18-4715. VillasanTe, L.-Historia de la literatura vasca (N. 17-3978). \|P P , 7 (1964), 444-445 (Tauer).

18-4716. Aquesolo, L. DE-“Una obra vasca ignorada: Erle gobernatzalleen guidariya".-BSV, $20 \quad(1964), 367-374$.

V. también núms. 4740, 4749, 4920, 7111.

\section{ESPAFัOL}

18-4717. Potrier, B. - "Bibliographies de linguistique romane. Domanine espagnol".-RLiR, 28 (1964), 211-227. - V. núm. 17-3983.

18-4718. "Artículos sobre lingüística española publicados en los años 1960-1962". $-B F E$, 1964, núm. 12, 43-47.

18-4719. Morf́nigo, M. A.-Programa de filologia hispánica (N. 14-40096). II $H u T, 8$ (1960), 224-246 (Buccianti).V. núm. 16-4245o.

18-4720. Mourelle Lema, Miguel - La lingüistica española en el siglo xix (I800-1880).-[Tesis, Univ. de Madrid; resumen en $R U M, 13(1964), 599]$.

18-4721. Fernández Galiano, M.-"Lengua griega y lengua española".-EClás, 8 (1964), 184-204.

18-4722. IZQuierdo HeRnÁNDEZ, J. L.-“E] español en la geolingüística". - $R d E$, 1957, núm. 2, $165^{-167}$.

18-4723. Bateman, A. D.-“Difusión del español en el mundo" (N. 17-4000). II PhP, 7 (1964), 197 (Hampejs).

18-4724. PÉrez Rioja, J. A.-"El españo] coloquial, ese desconocido".- $R d E, 57$ (1964), núm. 167 .

18-4725. Alonso, D.- "Unidad y defensa del idioma".-BRAE, 44 (1964), 387395.-V. núm. 11-26093.

18-4726. Antuña, J. G.-"La unidad del idioma y la necesaria colaboración de América".-TCA, 441-449.-V. núm. 1646978 .

18-4727. Ferreccio Podestá, M. - "La Real Academia Española. Teoría e historia".-Map, 1964, núm. 1, 234-244. 
18-4728. Kelly, Vincent P. - The opinions of High School teachers Spanish in Indiana concerning professional preparation.-[Tesis de la Universidad de Indiana, 1964].

18-4729. RosEnblat, ANGel - Corrección de pruebas. Nuevas normas ortograficas y prosódicas de la Academia Española.-Editorial Arte, Caracas, 1964. II $\mathrm{CuH}, 6$ o (1964), 391 (T.).

18-4730. Lagomarsindo, Raúl E.-Cómo y porqué de voces y grafismos; análisis de las nuevas normas académicas de prosodia y ortografia. - Sudamericana, Buenos Aires, 1963. $157 \mathrm{pp}$.

18-4731. Motta Salas, J. - Las Nuevas normas de prosodia y ortografia profericlas por la Real Academia Española. Estado actual de ellas".-StB, 3 (1959), $165-192$.

18-4732. Tortoló, A.-"Proyecto de reforma de la ortografía".-TCA, $265^{-275^{\circ}-}$ V. núm. 12-32717.

18-4733. Restrepo, F.-“Temas ortográficos. Reglas sobre el uso de las mayúsculas".-BACol, 14 (1964), 249-251.

\section{Textos lingüisticos}

18-4734. COOPER, L. - El "Liber regum" (N. 16-42772). || HR, 32 (1964), 262. 263 (Lloyd).

18-4735. Illic, Gertrud-Los fuetos leoneses de Zamora, Salamanca, Ledesma y Alba de Tormes. - [Tesis, Univ. de Madrid; resumen en $R U M, 13$ (1964), $592]$.

18-4736. VINCKE, J.-“Europäische Reisen um 1400 im Spiegel aragonesischer Empfehlungs. und Geleitbriefe". FHR, 345-377.

18-4737. VINCKE, J. - "Zum Sprachgeist der Zeit in den Geleitbriefen der katalanisch-aragonesischen Krone des 14. Jahrhunderts".-ER, 9 (1961), 61-66. 18-4738. Harvey, L. P.-"A morisco prayer-book in the British Museum". AlAn, 29 (1964), 373-376.

18-4739. Ebersole, A. V. - "Interesante pragmática de Felipe II $\left({ }_{15}^{86}\right)$ ",- $\boldsymbol{H I}$ 47 (1964), $803-805$.

V. también núms. $4273-44182,4965$.

\section{Historia de la lengua}

18-4740. Michelena, Luis - Lenguas $y$ protolenguas. - Univ. de Salamanca, 1963. 84 pp. $(A c S, 17$, núm. 2). $\| B S V$, $20(1964), 198-203$ (Agud Querol).
18-4741. Tovar, A. - "Indo-European layers in the Hispanic Peninsula".-Proceedings of the 8th International Congress of Linguists, 1958, 705 ss. \| ArO, 29 (1961), 330 (Zgusta).

18-4742. SchmoLL, U.-Die Sprachen der vorkeltischen Indogermanen Hispaniens (N. 16-42745). || Zeph, 11 (1960), 245$24^{8}$ (Michelena).-V. núm. 18-1028.

18-4743. Albertos, M. L.-"Algunas consideraciones lingüísticas-geográficas en torno a la España prerromana",-Zeph, 12 (1961), 221-229.

18-4744. Blázquez, J. M.-"Causas de la romanización de Hispania".-HM, 24 (1964), 5-26, 166-184, 325-357, 485-508.

18-4745. Menéndez Pidal, Ramón-Origenes del español. $5^{\text {a }}$ ed.-Espasa-Calpc, Madrid, 1964. 592 pp. (Obras completas, 8).-V. núm. 11-27496.

18-4746. Menéndez Pidal, Ramón - El idioma español en sus primeros tiem. pos. $6^{\text {a }}$ ed.-Espasa-Calpe, Madrid, 1964. 160 pp. (Austral, 250).-V. núm. 1336466 .

18-4747. Sabatino, M. - The Arabic element in Spanish".-Arab World, New York, 9 (1963), núms. $1 / 2$.

18.4748. Krauss, W. - "El desarrollo del castellano en España y del español en América".- $U H, 1964$, núm. 170, 23-29. 18-4749. Arocena, J. - "Algo acerca del castellano de Elcano".-BSV, 20 (1964), 472-474.

18-4750. García, C. - Contribución a la historia de los conceptos gramaticales. La aportación del Brocense (N. 174013). || NRFH, 18 (1965-66), 180-182 (Lope Blanch).

18-4751. Beccaria, G. L.-"Alcuni ispanismi". $-L N, 25$ (1964), 102-105.

18-4752. Calvo-Sotelo, J. - "Futuro del idioma".- $B R A E, 44$ (1964), $455-460$.

18-4753. Meregalli, F.-"L'avvenire della lingua spagnola”.-Giornale Economico, Venezia, marzo 1959, 3-18.

V. también núm, 4297 .

\section{Fonética}

18-4754. "Últimos estudios sobre fonética y fonología españolas. Enumeración de los trabajos publicados entre 196164 ",-BFE, 1964, núm, 12, 37־42.

18-4755. Flechas, Jenaro - Contribución al análisis comparado de la fonologia inglesa y española y sus implicaciones en la enseñanza del inglés oral a estu. diantes de habla española. - [Tesis, 
Univ. de Madrid; resumen en RUM, $13(1964), 610-611]$.

${ }_{18} 8756$. Flórez, Luis-Lecciones de pronunciación, $2^{\text {a }}$ ed., rev. y aum.-Inst. Caro y Cuervo, Bogotá, 1963. $207 \mathrm{pp}$. I| $B C B, 7 \quad(1964), 441-444$ (Camacho Guizado) ; RPh, ${ }_{18}\left(19^{6} 4^{-65}\right), 53^{13-5^{14}}$ (Hall).

18-4757. Sala, M.-"Probleme de fonologie diacronica spaniola". - SCL, 15 (1964), 83-95. [Y trad. francesa en $R R L, 9$ (1964), 79-92].

18-4758. Frey, Herschel Jerome - $A$ comparative phonology of medieval and modern Spanish: "El libro de buen amor".-[Tesis, Univ. of North Carolina; resumen en $D A, 24(1963-64)$, 3331]. 131 pp.

18-4759. Navarro, T.- "La pronunciación en el $A L P I^{\prime \prime} .-H, 47(1964), 716-7^{21}$. 18-4760. Bustos Tovar, E. DE - Estudios sobre asimilación y disimilación en el ibero románico (N. 16-46689). $\| H R$, $31 \quad(1963,82-87$ (Lloyd); ZRPh, 81 (1965), 389-394 (Mondéjar); PhP, 6 (1963), 221 (Pavlíková).

18-4761. Alarcos Llorach, E.-"Historia y estructura en los sistemas vocálicos his. panos".-ER, 8 (1961), $105-116$.

18-4762. García dE Gudal, Antonio Análisis y sintesis de las vocales caste. llanas. Aplicación a la telefonia secreta. - TTesis, Univ. de Madrid; resumen en RUM, 13 (1964), 662-663].

18-4763. Hara, Makoto-Dos principales problemas de fonologia española: semivocales y neutralización.-[Tesis, Univ. de Madrid; resumen en $R U M, 13$ (1964), 591-592].

18-4764. Navarro, T.- "Nuevos datos sobre el ycísmo en España”.-BICC, 19 $\left(19^{64}\right), 1-17$.

$18-4765$. Giese, W. - "Zu span. - $l d$ - anstelle von arab. $d \bar{a} d^{\prime \prime} .-Z R P h, 80(1964)$, $35^{6-361 .}$

18-4766. Contreras, H.-“'Tiene el espanol un acento de intensidad?"-Rdis, $16(1964), 237-239$.

18-4767. Navarro, T.-“La medida de ill. tensidad".-BdFS, 16 (1964), 231-235.

18-4768. Alvarez Buylla, J. B.-"El valor de la entonación y la práctica do cente".-FM, 4 (1963-64), núms. 11/12, 99-107.

18-4769. Rosenblat, Angel - Fetichismo de la letra.-Instituto de Filología "Andrés Bello", Caracas, 1963. 9o pp. (Cuadernos del Instituto de Filologia "Andrés Bello"). \| RHM, 3o (1964),
325-326 (Agostini de del Río); ins, 1963, núm. 199 (Campos); HR, 33 (1965), 193-194 (Canfield); CBA, 1965, núm. $42,86-87$ (Milano); $R N C, 1963$, núms. $158 / 159, \quad{ }^{6} 65-166$ (Navarro); $R P h,{ }_{17}$ (1963-64), 815-816 (Otero); RDTP, 19 (1969), $33^{\circ}$ (Pérez Vidal); RFE, 46 (1963), $4_{43} 84^{85}$ (Quilis); $B H i$, 65 (1963), 437 (Ricard).

V. también núms. 4392-4403, 4483-92, $4960,4970,49^{8} 5,5984$.

\section{Gramática}

Morfología y sintaxis

18-4770. Agüero Chaves, A.-"Unificación de la terninología gramatical".-TCA, 438-441.-V. núm. 16-46699.

18-477l. Torres Quintero, R. - "Unificación de la terminología gramatical”. TCA, $37^{8-} 398$.

18-4772. Gili Gaya, S.-"Sobre nomenclatura y enseñanza de la gramática".$B R A E, 44$ (1964), 449-453.

18-4773. Fernández Ramírez, S.-“La re visión de la Gramática de la Real Academia Española".-TCA, 399-420.

18-4774. Fernández, S. - "Para la futura gramática".-BRAE, 44 (1964), 431-448.

18-4775. Alonso, Amado, y Pedro HenriQUez Ureña-Gramática castellana. Primer curso. $22^{\text {a }}$ ed.-Losada, Buenos Aires, 1964. 233 pp.-V. núm. 18-1071.

18-4776. Alonso, Amado, y Pedro HenriQUEZ UREÑA-Gramática castellana. S $\epsilon$ gundo curso. $20^{\mathrm{a}}$ ed.-Losada, Bucnos Aires, $1964 .-V$. núm. 18-1072.

18-4777. Carballo Picazo, Alfredo-Es pañol conversacional. Ejercicio de gra. mática. $2^{a}$ ed.-C.S.I.C., Madrid, $19{ }^{\dagger} 4$. $x+174$ pp. $-V$. núm. 17-4039.

18-4778. Turk, Laurel Herbert, \& Editif Marion Allen-El español al dia. $3^{\text {rd }}$ ed.-D. C. Heath, Boston, s. a. xviii + 592 , xii + 492 pp. - V. núm. 11-26118. | $M L J, 49$ (1965), 268-269 (Guerra); $H$, $47 \quad$ (1964), 888-889 (Maris); H, 47 (1964), 673-674 (Resnick).

18-4779. Wolfe, David L., Roger L. HadLiCH, \& JOHN G. INMAN - A struciural course in Spanish. Student workbook; Teachers' manual.-Macmillan, New York, 1963. viii $+240+x v i i$; xiv + 182 pp. \| $M L J, 49$ (1965), $125^{-127}$ (Hoeksema \& Testa).

18.4780. Wentholt, G. H. M.-Español práctico. - Wolters, Groningen, 1960. 222 pp. $-V$. núm. 14-38429. || $R L V$, 29 (1963), 284 (Horrent). 
18-4781. Bertini, G. M. - "Della prima grammatica italo-spagnola".-EMP, 4, 27-35.

18-4782. Prokopová, Limuse - Cvicebnice spanelstiny. Texty, mluvnice, cuiceni. -Státní Pedagogické Nakladatelství, Praha, 1962. 361 pp.-V. núm. 16-46718. 18-4783. Skultéty, Jozef - Spanielska gramatika.-Slovenské Pedagogické Nakladatel'stvo, Bratislava, $1963.173 \mathrm{pp}$. ॥ PhP, 7 (1964), 107-108 (Pavlíková).

18-4784. BarrenecheA, A. M.-“Las clases de palabras en español, como clases funcionales".- $R P h, 17$ (1963-64), 301-309.

18-4785. Aroutioumova, N. D. - "Sur l'unification syntactique des mots dans la langue espagnole".-Ucenije Zapiski Leningradskogo Gosudarstvennogo Universiteta. Serija filologiceskih Nauk, 5 (1962), núm. 2, 31-40.

18-4786. Saporta, S.-." On the expression of gender in Spanish" (N. 16-46727). II BHi, 66 (1964), 244-245 (Molho).

18-4787. BALmori, C. H.-“El género granıatical y las hablas diferenciadas".BFS, 42 (1964), 533-543.

18-4788. SovzA, R. DE-"Las desinencias verbales correspondientes a la persona vos/vosotros en el Cancionero general (Valencia, 1511)".-Fil, 10 (1964), 1-95.

18-4789. MALKIEL, Y.-“Los interfijos hispánicos" (N. 13-34652). \| Phon, 6 (1961), 120-121 (Rothe).

18-479o. Cradmock, J. R. \& E. S. Georges - "The Hispanic sound-suffix -ido".$R P h, 17 \quad(1963-64), 87-107$.

18-4791. Morreale, M. - "E1 sufijo -ero en el Libro de buen amor". - AFA, $14 / 15 \quad(1963-64), 235-244$.

18-4792. González Ollé, Fernando-Los sufijos diminutivos en castellano medieval.-C.S.I.C., Madrid, 1962. $1 \mathrm{x}+340$ pp. (Anejos de la $R F E$ ).-V. núm. 174048. \| BILE, $1964 / 65$, núm. 7, 98-108 (Chiareno); RHM, 3o (1964), 324-325 (Fernández de la Vega); $B I C C, \quad 19$ (1964), 157-164 (Figueroa Lorza); BdFS, 16 (1964), 308-310 (García); $R L R, 7^{6}$ (1964), 93-95 (Guiter); SCL, 15 (1964), $254^{-25} 6$ (Tudorica).

18-4793. CopceaG, D.- "Un caz de omitere a artocolului în limba romîna si limbile ibero romanice". - SCL, 15 (1964), 221-228. [Y trad. española en $R R L, 9$ (1964), 195-201].

18-4794. García Bacca, J. D.-"La importancia de los artículos el, la, lo. O sobre tolerancia y respeto". $-R N C$, 1964, núm. 165, 23-3o.
18-4795. Lapesa, R.-“Los casos latinos: restos sintácticos y sustitutos en español".-BRAE, 44 (1964), 57-105.

18-4796. Lorenzo, E.-"Dos notas sobre la morfología del español actual".$E M P, 6,65-76$.

18-4797. Bustamante Y Rivero, J. L."Doble terminación para oficios y profesiones".- TCA, $42 \mathrm{I}-424$.

18-4798. Dussky, J.-“L'opposition verbonominale en espagnol". $-\boldsymbol{P h P}, 7$ (1964), $15^{8-167}$.

18-4799. Atkinson, D. M.-“A re-examination of the Hispanic radical-changing verbs".-EMP, $5,39-65$.

18-4800. Sten, H.-“Cohésion et décomposition dans les formes périphrastiques verbales des langues ibéro-romanes".-ER, 8 (1961), 139-146.

18-4801. Mendeloff, H. - "The passive voice in Old Spanish",-RJ, 15 (1964), $269-287$.

18-4802. Gordon, Calvin Gustav - The subjunctive mood in representative Spanish works form the I2th to the 18th century.-[Tesis, Univ. of Nebraska; resumen en $\left.D A, 25\left(1964^{-65}\right), 4134\right]$ 18-4803. Douvier, E. - "Le verbe auxiliaire espagnol". $-B J R, 1964$, núm. 10. 18-4804. BlansitT, EdWArd LeE, JR.-The verb phrase in Spanish: classes and relations.-[Tesis, The Univ. of Texas; resumen en $D A, 24(1963-64), 2897]$. 18-4805. Cárdenas, D. N.-"Ser and estar vs. to be".FM, 4 (1963), 61-78.

18-4806. Bouzet, J.-“Orígenes del em. pleo de estar".-EMP, 4, 37-58.

18-4807. Fish, G. T.-“Two notes on estar".-H, 47 (1964), 132-135.

18-4808. FELdman, D. M.-"Some structural characteristics of the Spanish modal verb phrase".-BdFS, 16 (1964), 241255.

18-4809. Lezcano, L. A.-“Unificación en el uso del gerundio".-TCA, 352-353.

18-4810. González Montesinos, M. "Equivalencia temporal del gerundio". -TCA, 456-460.

18-4811. Fierro, A.- “Acerca de la clasificación de las preguntas". - FM, 4 (1963-64), núm. 13, 59-68.

V. también núms. $44^{\circ} 4^{-6}, 4493-45^{\circ 0}, 45^{82}$, $475^{\circ}, 6684,75^{16}$.

\section{Lexicografía y semántica}

18-4812. SAlas, A.--"Los diccionarios académicos y el estado actual de la lexicografía".-BdFS, 16 (1964), 265-283. 
18-4813. LAPESA, R.- "Los diccionarios de la Academia".-BRAE, 44 (1964), 425430 .

18-4814. Fernández de LA Mata, B. J."El dichoso Diccionario".--Norte, Amsterdam, mayo-jun. 1964 .

18-4815. Diccionario histórico de la len. gua española, 1 (N. 17-4079) - ||RFRG, 7 (1963), 166-169 (Sadeanu).

18-4816. Diccionario histórico de la lengua española. Fasc. 3-5: abundar-achupalla.-Real Academia Española, Ma. drid, $1963^{-6} 6_{4}$ xxxi, xix, xxiii pp.+pp. 241-656. - V. núm. 18-1125. \|BILE, $1964 / 65$, núm. $7,147-149$ (Chiareno).

18-4817. Corominas, J.-Diccionario critico etimológico de la lengua castellana (N. 13-36514). || RBPH, $4^{2}$ (1964), 722724 (Horrent); Paideia, 1962, 308-309 (Pisani).-V. núm. 17-4080.

18-4818. Mastrangelo Latini, G. - "Sul Diccionario critico etimologico di Joan Corominas". - Annali di Ca' Foscari, 1964; 5 pp.

18-4819. Corominas, J.-Breve diccionario etimológico de la lengua castellana (N. 17-4084). I| Ro, 83 (1962), 552 (Lecoy); RRL, 10 (1965), 633-639 (Sandru).

18-4820. Casares, Julio - Diccionatio ideológico de la lengua española. $2^{\mathrm{a}}$ ed., $2^{\text {a }}$ tirada. - G. Gili, Barcelond, 1963. 1446 pp. - V. núm. 16-42878. || PhP, 8 (1965), 447-448 (Janda).

18-4821. Arbona. Diccionario enciclopédico hispanoamericano.-Maucci, Barcelona, 1964. $95^{1} \mathrm{pp}$.

18-4822. Bedout. Diccionario de la lengua castellana-Bedout, Medellín (Colombia), 1964. $65^{\circ}$ pp., ilustr.

18-4823. Iter. Diccionario de la lengua española.-Sopena, Barcelona, 1964. $5^{83}$ pp.-V. núm. ${ }^{6} 64^{6} 6_{7} 87$.

18-4824. Diccionario enciclopédico Salvat. $11^{\mathrm{a}}$ ed.-Salvat, Barcelona, $1964.12 \mathrm{ts}$, grabs.-V. núm. 17·4093.

18-4825. Sopena. Diccionario enciclopédi. co de la lengua española.-Sopena, Barcelona, 1964.4 ts.: 4 ogo pp.-V. núm $17-4098$.

18-4826. Reyes, Rafael - Diccionaric francés español y español-francés. $31^{7}$ ed. aum. - Hernando, Madrid, 1964 . 1600 pp.-V. núm. 16-42907.

18-4827. STEINER, ROger JACOB-Two cen turies of Spanish and English bilingual lexicography.-[Tesis, Univ. de Pennsylvania; resumen en $D A, 25(1964-65)$, $4^{66]}$.
18-4828. Gillhoff, Gerd A. - Crowell's Spanish-English and English-Spanish dictionary.-Crowell, New York, 1963 xii + 1261 pp., ilustr. $\| H, 4^{8}$ (1965), 640-641 (Carter).

18-4829. MacGragh, Esteban-Nuevo dic. cionario inglés-español, español-inglés. $2^{7}$ ed.-Juventud, Barcelona 1964. 376 pp.-V. núm. 16-42915.

18-483o. Mayer, William S. - El nuevo diccionario 2oth century, inglés-español, español-inglés.-Fernández, México, 1962. 566 pp. - V. núm. 16-46821.

18-4831. RoBertson, RichaRd-Diccionatio inglés-español y español-inglés. Rev. por Luis Jordá.-Sopena, Barcelona, 1964 . $1241 \mathrm{pp}$.

18-4832. Smith, C. Colin - An English Spanish word list. - Harrap, London, 1964. 109 pp.

18-4833. Haensch, G., \& J. M. Domf́nguez - Bertelsmann Wörterbuch Spanisch. Deutsch, Deutsch-Spanisch (N. 174140). II $R L V, 29$ (1963), 238 (Horrent).

18-4834. DUBSKy, JOSEF - Spanelska-cesky slownik. 2. vyd.-Statní Pedagogicke Nakladatelství, Praha, 1963. 778 pp.-V. núm. 16-42924. \| PhP, 8 (1965), 109111 (Doubek); PhP, 7 (1964), $211-212$ (Pavlíková).

18-4835. Prokopová, Libuse - Spanelsko cesky a cesko-spanelsky kapesni slounik - Pedagogické Nakladatelství, Praha 1964. 646 pp.

18-4836. Collard, H., et al--Vocabulario mayo (N. 18-1199). || IJAL, 29 (1963). 265 (Bright).

18-4837. Gilberti, Maturino - Diccionario de la lengua tarasca o de Michoacán. Ed. bajo la dirección de Ernesto Ramos Mesa.-México, 1962. vi $+518 \mathrm{pp}$. || IJAL, 29 (1963), 267 (Bright).

18-4838. Schermair, A.-Vocabulario siriono-castellano (N. 13-36544) . I| $P H, 9$ (1965), 131-135 (Hasler). - V. núm. 16-46847.

18-4839. Pinto, Constancio - Diccionano catio-español y español-catio.-Manizales, 1960. 88 pp. || IJAL, 29 (1963), 257 (Loewen).

18-4840. LiRA, J. A.- "Diccionario khechuwa-español, apéndices 6,7 " (N. 17-742). || IJAL, 29 (1969), 374 (Bright). 18-4841. Narváez Cadenillas, R.-"Glosario quechua-español de términos de la cultura indígena peruana".-Lenguaje y Ciencias, Trujillo (Perú), 11 (1964), 1-10. 
18-4842. Farfán, J. M. B. - "Diccionario conciso castellano-haqearu-quechua" (N. 17-743). || IJAL, 29 (1963), 373 (Bright).

18-4843. Lindskoog, J. N., \& A. CarrieVocabulario capaya.-Instituto Lingüístico de Verano, Quito, 1964. 129 pp.

18-4844. TuggY, JuAN - Vocabulario candoshi de Loreto.-Instituto Lingüístico de Verano, Yarinacocha, 1966. ${ }_{558} \mathrm{pp}$. $\mathbf{1} \delta .4845$. ERize, E.-Diccionario comentado mapuche-español (N. 16-46848). II $I J A L, 29$ (1963), 373 (Bright); RUBA, 7 (1962), 382-384 (Bucca); Cuadernos del Inst. Nac. de Investigac. Folklóricas, Buenos Aires, 2 (1961), 269-272 (Nardi); NRFH, 18 (1965-66), $187-188$ (Olivera Giménez).

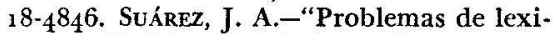
cografía hispanoindia".-RPh, $17(1963$

64), 155-159. [Diccionario comentado mapuche-español, de Esteban Erize].

18.4847. GuAsch, A.-Diccionario castella. no-guarani y guarani-castellano (N. 17 745). UNRFH, $18 \quad(1965-66), 182 \cdot 187$ (Rona).

1S-4848. Garcta Salinero, Fernando Contribución al estudio del vocabula rio español de arquitectura $e$ ingenie. ria de los siglos xvi y xvii. Léxico de trazadores, muradores y alarifes. $-[\mathrm{Te}-$ sis, Univ. de Madrid; resumen en RUM, 13 (1964), 583-584].

18-4849. HATJE, GERD-Diccionatio ilustrado de la arquitectura contemporánea. Trad. de José Maria Mantero.G. Gili, Barcelona, 1964. 305 pp., ilustr. 18-485o. Mateu Sancho, P.-Diccionario de astronomia y astronáutica (N. 174103). I] $R y F, 170 \quad(1964), 141$ (J. C.). 18-4851. Massa DE GiL, Beatriz-Diccionario técnico de biblioteconomia.-Ed. Trillas, México, 1964. $432 \mathrm{pp}$.

18-4852. Rochac, Alfonso - Diccionario del café. - Oficina Panamericana del Café, New York, 1964. 490 pp., ilustr. 18-4853. KARAG, ACISCLO-Diccionario de los deportes.-Jover, Barcelona, 1961-65 6 ts., ilustr.-V. núm. 17-4108.

18.4854. "El léxico deportivo". - TCA, $542-545$.

18-4855. Carreño, A. M.-“Terminología del beisbol".-TCA, 284-287.

18-4856. "Cómo llegar a tener un léxico deportivo castizo y propio del mundo hispánico".-TCA, 339-342.

18-4857. Frrnández de León, GonzatoDiccionario juridico. $2^{\text {a }}$ ed. $-\mathrm{Ed}$. ABC, Buenos Aires, 1961. 4 ts.: 2500 pp.
18-4858. Gianantonio, Héctor A.-Diccionario impositivo, con suplemento mensual de actualización.-Autor, Buenos Aires, 1964. 501 pp.

18-4859. Zaniah - Diccionario esóterico. Compendio enciclopédico de términos relacionados con las ciencias ocultas, teosofia, etc., etc.-Kier, Buenos Aires, 1962. $292 \mathrm{pp}$.

18-4860. Barceló, J. L.-Vocabulario de estadistica.-Ed. Hispano-Europea, Barcelona, 1964. $290 \mathrm{pp}$.

18-4861. LÁzaro, Fernando - Nomenclatura ictiológica, nombres cientificos y vulgares de los peces españoles.-Inst. Español de Oceanografía, Madrid, 1963. 64. $\mathrm{xi}+271$ pp. (Trabajos del I.E.O., $31)$.

18-4869. Cañizo Gómez, José del, Y MANUEL ARroyo VARELA-Nombres vulgares españoles de los insectos perjudiciales a las plantas cultivadas.-Ministerio de Agricultura, Madrid, 1964. 82 pp.

18-4863. Abbagnano, Nicola-Diccionario de filosofia. Trad. de A. N. Galletti.Fondo de Cultura Económica, México, 1969. 1208 pp. || $P H, 8$ (1964), 333-337 (Salmerón); CuA, 1964, núm. 1, 253255 (de la Selva).

18-4864. Boyer, Paul Henri-Diccionario breve de filosofia.-Club de Lectores, Buenos Aires, 1962. 187 pp.

18-4865. Brugger, Walter - Diccionatio de filosofia. $4^{\text {a }}$ ed.-Herder, Barcelona, 1964.628 pp. (Biblioteca Herder). $-\mathrm{V}$ núm. $17-4^{117}$.

18-4866. Pallares, Eduardo-Diccionatio de filosofia. - Porrúa, México, 1964. $\mathrm{xii}+65^{2} \mathrm{pp}$.

18-4867. Ruiz Moreno, Martín-Vocabu. lario filosófico, $3^{\text {a }}$ ed.-G. Kraft, Buenos Aires, 1969. ||$U d A, 41$ (1964), 198199 (Mantilla Pineda).

18-4868. Glosario de terminología maritima interamericana: español, inglés, portugués, francés. - Unión Panamericana, Washington, 1964. 212 pp.

18-4869. Braier, León-Diccionario enclclopédico de medicina. $2^{\mathrm{a}}$ ed.-López, Buenos Aires, 1964. 1600 pp., ilustr.V. núm. 11-27553.

18-487o. Durante Avellanal, Ciro-Diccionario odontológico. $2^{3}$ ed. - Mundi, Buenos Aires, 1964. 800 pp., ilustr.

18-4871. Louros, N. C., B. TriantafiLLopoulo, et A. Comninos-Obstétrique et gynécologie. Glossaire des termes obstétricaux et gynécologiques en fran- 
çais, latin, anglais, russe, allemand, espagnol, italien, grec.-Elsevier, Amsterdam, New York, 1964. 444 pp.

18-4872. COOPER, Ellen Hutchins-Vocabulario inglés para servicio clinico. Spanish wocabulary for clinical service. -Pax-México, México, 1961. 47 pp.

18-4873. Martínez de Campo y Serrano, C.-"Vocabulario militar. Comentarios y propuestas".-BRAE, 44 (1964), 397420 .

18-4874. Bauer, Charlotte - Diccionario de bolsillo geológico-minero. - Don Bosco, Cochabamba, 1964. 283 pp.

18-4875. Scholes, Percy A.-Diccionario Oxford de la música. - Sudamericana, Buenos Aires, 1964. 1302 pp., ilustr.

18-4876. Baumgaertel, Knut, et al.-Diccionario de pedagogia. Trad. de J. Sánchez Díaz.-Eds. Paulinas, Bogotá, 1963. 347 pp.

18-4877. Fernández, RAfall-Diccionatio pedagógico.-Ministerio de Educación, Caracas, 1964. 190 pp. (Vigilia, 5).

18-4878. Wu, C.-“Glosario alemán-castellano de términos pedagógicos".-Lenguaje y Ciencias, 11 (1964), 17-19.

18-4879. Cabra Fernández, Aurelio, y Fernando Varela Colmeiro-Vocabulario del petróleo y de productos petroquimicos inglés-español.-Edics. Interciencia, Madrid, 1963. $28_{5} \mathrm{pp}$.

18-4880. Bateman, A. D. - "Términos de la industria del petróleo".-BACol, 14 (1964), $140^{-146 .}$

18-4881. Warren, Howard Crosby-Diccionario de psicologia. Trad. por $\mathbf{E}$. fmaz, A. Alatorre y L. Alaminos. $4^{\text {a }}$ y $5^{\mathrm{a}}$ eds.-Fondo de Cultura Económica, México, 1963 , 1964 . xvi $+3^{8} 3$ pp. (Biblioteca de psicología y psicoanáli. sis).-V. núm. 16-42890.

18-4882. Piéron, Henri-Psicología; lexicón Kapelusz. Trad. por Ángela Romera Vera y Marta E. Samatan.-Kapelusz, Buenos Aires, 1964. xvii +603 pp. (Col. universitaria, diccionarios).

18-4883. Busto Mendrano, Pío del - Pequeño diccionario tecnológico con seis mil voces correspondientes a términos usuales en farmacia, quimica, fisica, medicina y ciencias naturales.-Dossat, Madrid, 1964. $214 \mathrm{pp}$.

18-4884. Fernández Avello, M. - "Vocabulario de lagar de sidra”.-BIEA, 18 $(1964), 377-381$.

18-4885. CAsares, J.-“La Academia Espa. ñola trabaja".-BRAE, $44(1964), 171$. 174. -V. núm. 17-4.152.
18-4886. Casares, Julio - Novedades en el diccionario académico. (La Academia Española trabaja).-Aguilar, Madrid, 1963. 188 pp. (Col. literaria). II USF, 1964, núm. 59, 285-289 (Buonocore); $A$, 1965 , núm. $408,25^{2-254}$ (Silva Castro).

18-4887. "Enmiendas y adiciones a los diccionarios de la Academia aprobadas por la corporación (marzo-diciembre de 1964)".-BRAE, 44 (1964), 461-473.

18-4888. Nougué, A. - "Contribution aux recherches sur le vocabulaire hispanique". - BHi, 66 (1964), 125-161; 67 (1965), $135^{-1} 5^{1}$.

18-4889. Mateos Muñoz, Agustfn - Etimologias griegas del español. $8^{\text {a }}$ ed.Esfinge, México, 1964. $390 \mathrm{pp}$. - V. núm. $16-46854$.

i 8-489o. Crema, E. - "En la feria de los errores".- $C U, 1964-65$, núm. 87, 97-102. [Etimologias de algunos helenismos].

18-4891. Pensado, J. L.-"Datos para la historia de bombyx en la península ibérica'.- $A O, 14$ (1964), $25^{0-25} 8$.

18-4892. Coseriu, E.-“¿Arabismos o romanismos?" (N. 16-46859). \| RLR, 75 (1963), 263-264 (Guiter); $P h P, \quad 7$ (1964), 107 (Skultéty).

18-4893. Whitted, Joseph Willard - $A n$ etymological lexicon to the "Historia troyana".-[Tesis, Univ. of North Carolina; resumen en $D A, 24 \quad(1963-64)$, 3346]. 146 pp.

18-4894. García de Diego, V.-“Etimologías naturales".-BRAE, 43 (1963), 431$462 ; 44 \quad(1964), 17-56$.

18-4895. Tilander, G. - "Notes étymologiques ibéro-romanes" (N. 17-754). II $R P F, \quad 13 \quad(1964-65), 435-436 \quad$ (Cunha Serra).

18-4896. Martínez Ruiz, J.-"Notas sobre el refinado del azúcar de caña entre los moriscos granadinos. Estudio léxico".-RDTP, 20 (1964), $271-288$.

18-4897. Rohlfs, G.-"Apuntes para una flora popular de España”. - ER, 8 (1961), 121-133. [Abedul-zarzaparrilla: nombres dialectales en español, catalán y gallego-portugués].

18-4898. Rallides, C.-“A semantic pro blem".-H, 47 (1964), 589-591. [Discu. sión, formal].

18-4899. Garcia dE Diego, V. - "Ruidos orales en los hombres". - RDTP, 20 (1964), 403-409. [Sobre dragar, trago, chingar, pimplar, etc.].

18-4900. Orerti, F.-"Disquisiciones sobre el origen de la bombilla".-Cuader- 
nos del Instituto Nacional de Investigaciones Folklóricas, Buenos Aires, I (1960), 151-158. [Y su etimología].

18-4901. León, L. A. - "Etimología del coсuyo". $-L E, \quad 1964$, núm. 130, 25.26 .

18.4902. Tilander, G. - "Origen y evolu. ción del verbo esquilar". $-A F A, 14 / 15$ (1963-64), 327-340.-V. núm. 13-36565.

18-4903. Tilander, G. - Español antiguo estema, estemar",-AFA, 14/15 (1963. 64), 319-320.

18-4904. Lfzcano, L. A.-"E1 vocablo he, su naturaleza y acentuación”. - TCA, $500-504$.

18-4905. LüрtKe, H. - "Sobre el origen de cat. genet, cast. jinete 'caballo armado de lanza y adarga' ".-ER, 8 (1961), $117^{-119}$.

18-4906. Looser, G. - "Sobre el nombre cicntifico del peumo: ¿crytocarya alba - mammosa?" - Rev. Universitaria, Chile, $4^{8} \quad(1963), 23-29$.

18-4907. Migliorini, B. - "Primor e pre. mura".-RPh, 17 (1963-64), 320-322.

18-49o8. Tilander, G. - "Respendo, respennar".-AFA, 14/15 (1963-64), 321325 .

18-49og. Rey, A. - "La sarabande. Essai de sémantique historique".- $R L i R, 28$ (1964), 190-201.

18.4910. Devoto, D.-"Encore sur la sarabande (fin xvie siècle)".-Rey. de Musicologie, 5o (1964), $175^{-207}$.

18-4911. KrotkofF, G.-"A possible Arabic ingredient in the history of Spanish usted".-RPh, 17 (1969-64), 328332.

18-4912. Buesa Oliver, T. - "Acerca de los antónimos viejo-niño”.-AFA, 14/15 (1963-64), 263-265.

V. también núms. $4297,4407-14,4501-25$, $4618,4964,4986-8,5016,6034,6910$, $6989-90,7063,7215,7218$.

\section{Toponimia y antroponimia}

18-4913. Lafon, R. - "Noms anciens de personnes et de lieux du sud de l'Espagne d'après les inscriptions". $-A S C$, $3,401-406$.

18-4914. SchmeJA, H. - "Der Flussname *Vindelis (Hispania Tarraconensis)".$B z N, 12$ (1961), 286-293.

18-4915. GonzÁlez, J. M.-“Algunos ríos asturianos de nombre prerromano (Deba, Bedón, Güeña, Dobra, Sella, Aller, Uerna)".-AO, 13 (1963), 277-291.

18-4916. González, J. M. - "Otros ríos asturianos de nombre prerromano (Eo,
Navia, Ibias, Varayo, Esva)".-AO, 14 (1964), $134^{-1} 4^{8}$.

18-4917. González, J. M.-“Asta, nombre del riachuelo de Valdediós",-Valdediós, Oviedo, 1964, 20-26.

18-4918. Carnoy, A.-“Basque et protoindo-européen dans la toponymie espagnole" (N. 16-42688). \|ArO, 29 (1961), 672 (Zgusta).

18-4919. Pifl, J. M.-"Aureus in der hispanischen Toponomastik". - ER, 8 (1961), $135^{-1} 37$.

18-4920. Guiter, H.-“Manifestations du substrat basque dans la toponymie des Pyrénées orientales".-Bulletin philologique et historique du Comité des travaux historiques et scientifiques, $\mathrm{Pa}$ ris, $1963,337-344$.

18-4921. Pensado, J. L.-"Huellas de nemus en el asturiano". - BIEA, 18 (1964), 3-10.

18-4922. Amieva, C. - "Notas folklóricasgeográficas sobre el pueblo de Barros (Llanes)".-BIEA, 18 (1964), 233o.

18-4923. Lecuona, M. DE - "Etimología de la voz Navarra".-Munibe, San Sebastián, 1962 .

18-4924. Le Flamanc, A.-"Nota filoló. gica. Tarraco, Tarragona, nombre celta".-BAr, 57 (1957), 83-87.

18-4925. Oliver Asín, J. - Historia del nombre "Madrid" (N. 14-40387). CuHE, 1964, 377-378 (González); $R P h$, 17 (1963-64), ${ }_{175^{-1}} 7^{6}$ (Hubschmid); AUCh, 1961, núm. 124, 238-239 (Oroz). $-V$. núm. 16-46923.

18-4926. Tovar, A.- "Papeletas de geografía turdetana”. - Homenaje Cayetano de Mergelina (Murcia, 1961-62; 7 pp. 18-4927. SEco DE Lucena, L.-"Toponimia árabe de la vega y los montes de Granada".-AlAn, 29 (1964), 311327 .

18-4928. Pérez Vidal, J. - "Influencia portuguesa en la toponimia canaria". $-R D T P, 20$ (1964), 255-27o.

18-4929. Vidago, J.-“América. Origem e evolução deste nome". - Ocid, 6 $6_{7}$ (1964), 93-110.

18-4930. ReA, J. - "On the naming of America".- $A S, 39$ (1964), 42-50.

18-4931. Iventosch, H. - "Orinda, California: or, the literary traces in $\mathbf{C a}$ lifornia toponymy".-Names, 12 (1964), $103^{-10} 7$.

18-4932. Brown, A. K. - "San Mateo County place- naming". - Names, 12 (1964), $154-184$. 
18-4933. Holmer, Nils-The Indian place names in Mexico and Central America.-[En] American languages and literatures, 16 (Lund, 1964); $4^{8} \mathrm{pp}$.

18-4934. Cowan, M. M.-"Huixteco (maya-tzotzil) place names". - [En:] Los mayas del Sur y sus relaciones con los nahuas (México, 1961), 195-200.

18-4935. Aulie, E.-"Nombres de lugares en chol (maya)".-[En:] Los mayas del Sur y sus relaciones con los nahuas meridionales (México, 1961), 201-205.

18-4936. Iвar, J.-“Ensayo sobre los indios chonos e interpretación de sus toponimias".-AUCh, 1960, núm. 117 , 61-7o.

18-4937. SÁez Godoy, L.-“Los topónimios de Valparaíso (clasificación)". - Rev. del Pacifico, 1 (1964), 129-141.

18-4938. Acevedo Dfaz, E.- "La toponimia del país y los criterios que la regulan". - Anales Acad. Argent. de Geografia, 1960, núm. 4, 138+141.-V. núm. 16-43032.

18-4939. Martin, Eusebia H.-Notas sobre el cacán y la toponimia del noroeste argentino.-Universidad, Buenos Aires, 1964.45 pp. + 9 mapas. (Cua. dernos de lingüistica indigena, 2).

18-4940. Strube Erdman, L.-"Toponimia indígena de Cuyo (Mendoza, San Juan, San Luis, Pampa Seca)".-Anales de Arqueologia y Etnologia, 17-18 (1963), $119^{-13} 6$.

18.4941. Knowlton, E. C., JR.-“The naming of the Philippines and of the Marquesas Islands". - $A S$, 39 (1964), 302-304.

18-4942. Piel, J. M.-"Sobre a formação dos nomes de mulher medievais hispano-visigodos".-EMP, 6, 111-150.

18-4943. Buechley, R. W.-"A reproducible method of counting persons of Spanish surname". - Journal of the Amer. Statistical Assoc., 55 (1961), 88. 97.

18-4944. Hayne, H.-_Los apellidos en Colombia".-BACol, 11 (1961), 73-74.

$V$. también núms. $4415-7,454^{8-52}, 4708$ 12, $4984,6564,7896$.

\section{Paremiología}

18-4945. Aguilera, M.-"Rica fuente del refranero español".-BACol, I4 (1964), 252-259.

18-4946. Casares, J.-"La frase proverbial y el refrán".-UPB, 27 (1964), 36-49.

18-4947. Parker, A. A. - The humor of
Spanish proverbs. - Hispanic Council, London, 1963. 23 pp. (Diamante 13). II PhP, 7 (1964), 324-25 (Halasová); BHS, 31 (1964), 201-202 (Smith).

18-4948. VIQUEIRA, J. M.-"Sátira castellana e ironía lusa en refranes y modismos".- APCE, 2, 275-306.

18-4949. YNduráin, D.-“Correas y el refranero aragonés".-Zaragoza, 19 (1964), $149 \cdot 155$.

18-495o. Pérez de Gastro, J. L.-“Dialoguismo en el refranero asturiano".RDTP, 19 (1963), 116-138. || BICC, 19 (1964), 595-596 (Suárez Pineda).

18-4951. FEIJóo, S.-Refranes, adivinanzas, dicharachos, trabalenguas... de los campesinos cubanos (N. 17-4231). II BHi, 66 (1964), 168-169 (Devoto).

V. también núms. $4446,6056,6661,6908$, 7066 .

\section{Dialectología}

18-4952. Alvar, Manuel - Dialectología española. Bibliografia.-C. S. I. C., Madrid, 1962. 93 pp. (Cuadernos bibliográficos, 7). $\|$ BHS, 41 (1964), 66 (Crews); Sef, 25 (1965), 213-214 (Fernández); $H R, 33$ (1965), 83-84 (Lloyd).

18-4953. Zamora Vicente, Alonso - Dialectologia española (N. 16-43072). || BHS, 41 (1964), 250-252 (Hodcroft). - V. núm. 17-4240.

18-4954. ROBE, S. L.- "El habla folklóri ca".-FA, $24(1964)$, núms. $1 / 2$.

18-4955. Canfield, D. L.-"The diachronic dimension of 'synchronic' Hispanic dialectology”.-Ling, 1964 , núm. $7,5-9$.

V. también núms. 4418-22.

P $\boldsymbol{e}$ ninsular

18-4956. Atlas lingüistico de la Península ibérica, t. 1 (N. 16-46952). $\| A F A$, $14 / 15$ (1963-64), 370-372 (Alvar); $A l f a$, 1969, núm. 3, $10^{-111}$ (Castilho); ASNS, 201 (1964), 307-311 (Catalán); VR, 24 (1965), 323-335 (Colón \& Lüdtke); $B d F S, 16$ (1964), 285.29o (Oroz); CuH, $5^{6}$ (1963), 457-461 (Palacio); $N, 49$ (1965), 74-75 (Van Praag).-V. núm. $17-3713$.

18-4957. Quilis, A.-“El Atlas lingüístico de la Península ibérica”.-LEsp, 1964. núm. 81 .

18-4958. Stern, C.-“'Sayago and sayagués in Spanish history and literature" (N. $17-841)$. II BICC, 19 (1964), $377-37^{8}$ (Valderrama Andrade). 
18-4959. Myers, O. T. - "Church Latin elements in sayagués".-RNo, 4 (1963), núm. 2, 166-168.

18-4960. Rodríguez-Castellano, L. - "El sonido $\hat{\mathbf{s}}<$ (L-, -LL-) del dialecto asturiano".-EMP, 4, $201-238$.

18-4961. Prieto Bances, R. - "La mío Quintana".-EMP, 4, 167-199.

18-4962. Díaz Castañón, María del CarMEN-El bable de El Cabo Peñas (Gozón y Carreño).-[Tesis, Univ. de Madrid; resumen en $R U M, 13$ (1964), 590]. 18-4963. CAstañón, L.-"Vocabulario gijonés".-BIEA, 18 (1964), 333-376.

18-4964. SöLL, L.-“Astur.-arag. busto". ZRPh, 8 o (1964), 98-101.

18-4965. Rubio García L. - "El dialecto de Jaca a través de sus documentos, siglos X-xu".-Actas del III Congreso Internacional de Estudios Pirenaicos, t. 6 (Gerona, 1963), 75-126. \| $A F A$, $14^{-15}$ (1963-64), 382 (Mondéjar).

18-4966. Tilander, G.-"Palabras desconocidas en el aragonés medieval". $-A F A$, $14 / 15 \quad(1963-64), 349-356$.

i $8-4967$. Buesa Oliver, T. - "Sufijación afectiva en ayerbense".-Actas del III Congreso Internacional de Estudios Pirenaicos, t. 6 (Gerona, 1963), 9-32. II $A F A, 14^{-15}$ (1963-64), 379-380 (Mondé jar).

18-4968. Alvar, M. - Atlas lingüístico y etnográfico de Andalucia, ts. 1 y 2 (N. 17-4272). || BICC, 19 (1964), 343-344 (Montes).

18-4969. Alcalá Venceslada, A.-"Prosodia del Santo Reino".-EMP, 7, 3-15.

18-4970. LAPESA, R.-"Sobre el ceceo y el seseo andaluces" (N. 12-29564). || Phon, 6 (1961), 102 (Rothe).-V. núm. 16. 42792 .

18-4971. Roldán, A.-“El léxico de las viñas en Jerez de la Frontera".-RFE, 47 (1964), 399-420.

18-4972. RoloÁn, A.- "Vocabulario de la toneleria en Jerez de la Frontera". Hom, 1 (1964), 43-55.

V. también núms. 4554, $4921-2$.

Extrapeninsular

18-4973. Galmés de Fuentes, A.-“Algunos dialectalismos canarios en el habla güimarera del siglo xvü". - $A O, 14$ (1964), 61-73.

18-4974. Pavlf́ová, S. - "Los problemas del español de América en las nuevas obras de Ángel Rosenblat". - PhP, 7 (1964), 183-184.
18-4975. RonA, J. P.-Aspectos metodológicos de la dialectologia hispano-americana (N. 14-40427). II IF, 69 (1964), $182-185$ (Stimm); Krat, 6 (1961), 206-207 (Sugranyes).-V. núm. 18-1314.

18-4976. Rona, J. P.--"Relación entre la investigación dialectológica y la enseñanza de la lengua materna".- $R L A$, 1964, núm. 1, 1-12.

18-4977. Stepanov, G. V.-Ispanskii iazyk $v$ stranaj Latinskoi Ameriki.-Izdatelstvo Literatury na Inostrannyj Iazykaj, Moskva, 1963. \| BICC, 20 (1965), $15^{1-}$ 155 (Montes).

18-4978. Morínigo, M. A.-“Futuro de la dialectología hispanoamericana". - Fil, 10 (1964), 143-152.

18-4979. Pottier, B.- “La langue des capitales latino-américaines". - Carav, 1964, núm. 3 .

18-4980. Rosenbi.At, A.-"Base del español de América: nivel social y cultural de los conquistadores y pobladores".-BdFS, 16 (1964), 171-230. \|BICC, 20 (1965), 399-403 (Figueroa Lorza). 18-4981. Konetzke, R.-"Die Bedeutung der Sprachenfrage in der spanischen Kolonisation Amerikas". - Jahrb. für Geschichte von Staat, Wirtschaft und Gesellschaft Lateinamerikas, Köln, I (1964), 72-116.

18-4982. Tovar, A.-Catálogo de las lenguas de América del Sur. Enumeración con indicaciones tipológicas, bibliografia y mapas.-Editorial Sudamericana, Buenos Aires, 1961. 412 pp., ilustr. II TILAS, 2 (1962), 59-66 (Pottier).

18-4983. KIDdLe, L. B.-"American Indian reflexes of two Spanish words for cat". $-I J A L, 3^{\circ}$ (1964), 299-305.

18-4984. Drobinski, A. - ["Elementos indios en las lenguas y la toponimia del Nuevo Mundo".-En: La cultura de los indios, Instituto de Etnografía, Moscú, 1964].

18-4985. Canfield, D. L. - La pronunciación del español en América. Ensayo histórico-descriptivo. Pról. de Tomás Navarro.-Instituto Caro y Cuervo, Bogotá, 1962. 111 pp., ilustr. (Publicaciones del Instituto Caro y Cuervo, 17). || Word, 20 (1964), 266-27o (García); $R P h, \quad 19$ (1965-66), 95-99 (Hadlich); $H, 47$ (1964), 202 (Lacayo); RevIb, $3^{0}$ (1964), 347-349 (Lihani); HR, 32 (1964), 372-375 (Lope Blanch); Lingua, 12 (1963), 338-34o (Van Praag).

18-4986. KANY, C. E. - American Spanish semantics (N. 17-85o). $\| J A F, 74$ 
(1961), 279-281 (Hymes); StL, 17 (1963), 54-59 (Malmberg); $R P h, \quad 17$ (1963-64), $179-184$ (Robe); $R R L, 9$ (1964), 109-113 (Vîntu); SCL, 15 (1964), 110-113 (Vîntu).

18-4987. KANY, C. E. - American-Spanish euphemisms (N. 17-851). \| RPh, 17 (1963-64), $179^{-184}$ (Robe); RRL, 9 (1964), 109-113 (Vîntu); SCL, 15 (1964), 110-113 (Vîntu).

18-4988. Bustamante y Ribero, J. L."Acepción americana del vocablo irrigación".-TCA, 424-427.

18-4989. Coulthard, G. R. - Race and color in Caribbean literature. - Oxford Univ. Press, London, 1962. $15^{2}$ pp. II MLR, 59 (1964), 620-621 (Johnson); FS, 18 (1964), 89-9o (Jones); $R P h, 18$ (1964-65), 524-525 (Malkicl); HAHR, 44 (1964), 640-641 (Morse); $H R, 32$ (1964), 181-184 (Sayers).

18-499o. Bartos, L.-“Notas al problema de la comprensión del habla cubana". $-Z P h, 17$ (1964), 133-136.

18-4991. López Morales, H.-“El supuesto 'africanismo' del español de Cuba".-AO, 14 (1964), 202-211.

18-4992. Tsuzaki, Stanley Mamoru-English influences in the phonology and morphology of the Spanish spoken in the Mexican colony in Detroit, Michi. gan.-[Tesis, Univ. of Michigan; resumen en $D A, 24 \quad(1963-64), 247^{1-2472}$. $124 \mathrm{pp}$.

18-4993. Pazos, M.-Misionologia mexicana. Lingüistica y poliglotas franciscanos (N. 18-1346). \|AFrH, 57 (1964), 269-270 (Morales).

18-4994. Vinlegas, O. U.-“"Aspectos del pasado, presente y futuro sociolingüístico de México".-RMS, 26 (1964), 491 520 .

18-4995. GaOs, V., y G. A. Uribarri-"México se escribe con $x^{\prime \prime} .-I A L, 1964$, núm. 183 .

18-4996. Foster, G. M. - "Speech forms and perception of social distance in a Spanish-speaking Mexican village". $S J A, 20(1964), 107-122$.

18-4997. Malmberg, B. - "Note sur la structure syllabique de l'espagnol mexicain".-ZPh, 17 (1964), $25^{1-255}$.

18-4998. Lope Blanch, J. M.-“Un proceso de traslación semántica en el español de México". - $A F$, 2-3 (1963-64), $337-34^{6}$.

18-4999. Davis, J. E. - "Algunos problemas lexicográficos en el Periquillo Sarniento". - RevIb, 1958-59, 162-171.
18-5000. Jiménez, A. - Picardia mexicana (N. 17-866). \|CCL, 1964 , núm. 85 , $81-82$ (L. G. P.).

18-5001. Magaña Esouivel, Antonio "Lenguaje y modismos".- $L y P, 1964$, núm. 11, 23-24.

18-5002. BRIGHT, W., \& R. A. ThIEL "Hispanisms in a modern Aztec dialect".- $R P h, 18 \quad(1964-65), 444-45^{2}$.

18-5003. MENÉn Desleal, A.-"El habla de Mesoamérica: El voseo en los Cuentos de barro de Salarrué".-Cults, 1964, núm. 31, 19-28.

18-5004. Menén Desleal, A.-"El o y el oyó como peculiaridades lingüísticas salvadoreñas". - Cults, 1964, núm. 33, $5^{0-56 .}$

18-5005. FlóREz, L.-"Principios y método del Atlas lingüistico y etnográfico de Colombia".-BICC, 19 (1964), 201-209. 18-5006. SALA, M.-“El Atlas lingüistico y etnográfico de Colombia”. - BdFS, 16 $(1964), 257-263$.

18-5007. Montes, J. J.-"El Atlas lingüistico de Colombia y el Atlas de Hungria: notas comparativas". $-B I C C, 19$ (1964), 210-220.

18-5008. Lira Urouieta, P.-"Voces usadas en Colombia y en Chile". $-T C A$, $353-369$.

18-50og. "Colombianismos y argentinis. mos".-BACol, 4 (1964), 197-204.

18-5010. Pazos, A.-Glosario de quechuis. mos colombianos (N. 16-47000). II IJAL, 29 (1963), 374 (Bright).

18-5011. Fontanelea, M. B.-"E1 diminutivo en Bogotá" (N. 17-4320). II CuH, 60 (1964), 568 (T.).

i8-5012. Poloniato de Partnoy, A. "Algunos usos de las preposiciones $a$, bajo, con, de, desde, en, hasta, por, sobre, en la prensa de Bogotá". BICC, 19 (1964), 221-247.

18-5o13. Flórez, L.-"Muestra de anglicismos y galicismos en el español de Bogotá, 1964".-BACol, 14 (1964), 260278 .

18-5014. Dulsex, B.-“The rebellious jargon of Barranquilla youth". $-H, 47$ (1964), 591-592.

18-5015. López, C. H.-“Terminología sobre la embriaguez en las regiones caldenses de Calarcá y otras del mismo departamento". - StB, 9 (1959), 193224.

18-5016. BELDA, F.-“Algunos aspectos del léxico de Francisco de Miranda”. NRFH, 18 (1965-66), 65-86.

18-5017. VARESE, S. - "Nomenclatura de 
algunos telares indígenas del Perú".Folklore Americano, Lima, 1963-64, núms. $11 / 12$.

18-5018. Durand, M.-“Castas y clases en el habla de Lima".-Carav, 1964, nún. 3.

18-5oig. Subritski, Y.-["Influjo del quechua en el léxico del español de los países de Ia meseta andina".-En: $L a$ cultura de los indios, Instituto de Etnografía, Moscú, 1964].

18-5020. FARFÁn, J. M. B. - "Quechuismos" (N. 16-47011). || IJAL, 29 (1963), 373 (Bright).

18-5021. Toscano, H. - "Interjecciones quichuas en el español de América".$R J, 15$ (1964), 288-296.

18-5022. Costa Arquedas, J. F.-"Dicrio nario del folklore boliviano. (Frag mentos)". - Folklore Americano, Lima, $1963-64$, núms. $11 / 12$.

18-5023. Pavlíková, S. - ["Algunas observaciones sobre el español en Chile"].PhP, 7 (1964), 4o8-412. [En checo; resumen en español].

18-5024. Gunckel, H.-"Lista de plantas medicinales que vendia el herbolario de Iquique". - Rev. Universitaria, Chile, 48 (1969), 248-249.

18-5025. Rosenblat, A.- "Las generacio. nes argentinas del siglo xix ante el problema de la lengua" (N. 16-47017) II $A G I t, 47$ (1962), $85^{-87}$ (Terracini).V. núm. 18-1386.

18-5026. Pérez Martín, N.-“El problema de la lengua nacional en los primeros románticos argentinos". - USF, 1964, núm. 6o, 221-241.

18-5027. Sánchez Garrido, Amelia - In. dagación de lo argentino. (Lengua, li. teratura, expresión dramática). - Eds. Culturales Argentinas, Buenos Aires, 1962. 20 pp. || LNL, 1965, núm. 1, $107^{-}$ 108 (Marcus).

18-5028. Bilínkina, M. - ["La formación de las particularidades lingüísticas nacionales en la Argentina".-En: Las naciones de Latinoamérica, Instituto de Etnografía, Moscú, 1964].

18-5029. ARCE, J.-“El vocabulario en los actos y decisiones del Congreso de la República". - BAAL, 29 (1964), 6583.

18-5030. NARdi, R. L. J.-“El habla en inspiración”. - Cuadernos del Instituto Nacional de Investigaciones Folklóricas, Buenos Aires, 1960, 217-228. IJAL, 29 (1963), 267-268 (Bright).

18-5031. MEO ZiLio, G.-“Algunos septen- trionalismos italianos en el español rioplatense".- $R J, 15$ (1964), 297-301.

18-5032. Meo Zillo, G.-"Prénoms et sur. noms au Rio de la Plata".-RIO, 16 (1964), 21-32, 105-114.

18-5033. García Jiménez, F.-“Lenguaje y estilo: el vocabulario de un poema gauchesco".- $R d E, 195^{8}$, núm. $6,525-526$. [Santos Vega].

18-5034. Morínigo, M. A.-“Para la etimología de guarango". - BAAL, 29 (1964), 433-437.

18-5035. Assunção, Fernando O.-El gaucho.-Imp. Nacional, Montevideo, 1963. $55^{6}$ pp. If $B I C C$, 19 (1964), 350-353 (Giese).

18-5og6. Rona, J. P. - "Gaucho, cruce fonético de español y portugués"... Rev. de Antropologia, 12 (1964), 8798.

18-5037. Ricci, J.-Un problema de interpretación fonológica en el español del Uruguay (N. 17-4369). || BdFS, 16 (1964), 295-297 (Contreras).

18-5o38. Rosell, Avenir - Trasfogueto. Diálogo lexicológico. - Montevideo, 1962. $24 \mathrm{pp}$.

18-5039. Cadogan, L.- "En torno al bilingüismo en el Paraguay" (N. 174340). || IJAL, 27 (1961), 160 (Bright). 18-5040. Gómez de Abad Santas, IsabelTrayectoria histórica de la lengua española en Filipinas.-[Tesis, Univ. de Madrid; resumen en $R U M, 13$ (1964), $\left.655^{-6} 5^{6}\right]$.

18-5041. Justiniani Rosado, Andreina Contribución al estudio del elemento español en ilongo. - [Tesis, Univ. de Madrid; resumen en $R U M, 13$ (1964), 593].

V. también núms. 4748,4951 .

$J u d e$ o español

18-5042. Hassán, I. M.-“El Simposio de estudios sefardies".-Sef, 24 (1964), 327355 .

18-5043. Cамнy, O.-“Le Symposium sefardi de Madrid".-JS, 28 (1964), 11911205.

18-5044. Barnett, R. D. - "Sephardic meeting in Madrid". - JS, 28 (1964), $1189-1190$.

18-5045. Pérez Castro, F.-Aspectos de la cultura hebraicoespañola.-Univ. Internacional Menéndez Pelayo, Santander, 1964. 9o pp. (Publicaciones de la Univ. Internacional Menéndez Pelayo, 21). II Sef, 24 (1964), 369-370 (Cantera). 
18-5046. Hassán, I. M.-“Estado actual del mundo sefardi". $-B F E$, 1964, núm. 12, $17-21$.

18-5047. ParlangÉli, O. - "Stato attuale delle comunità sefardite in Grecia".Byzantion, 33 (1963), 385-389.

18-504 8. Molho, I. R.- "Comunidades sefardíes de la Diáspora: Burdeos”. OYS, 7 (1964), 87-90.

18-5049. Netanyahu, B.--"The Marranos according to the Hebrew sources of the 15th and early 16 th centuries".-The American Acad, for Jewish Research, 31 (1963), 81-164. I| Sef, 24 (1964), 152-154 (Cantera).

18-505o. Morreale, M.-"El sidur ladinado de 1552 ".- $R P h, 17 \quad(1963-64), 332$. $33^{8 .}$

19-5051. Crews, C. - "A Judeo-Spanish medical ms. (ca, 1400-1450)".-VR, 22 (1963), $192-218$.

18-5052. Cantera Ortiz de Urbina, J."Longevidad y agonía del judeoespañol de Oriente".- $A r b, 5^{8}$ (1964), 148-156.

18-5053. Alvar, M. - "Interpretaciones judeo-españolas del árabe gabba”. $R P h, 17 \quad(1963-64), 322-328$.

18-5054. Benardete, Mair José - Hispanismo de los sefardies levantinos. Trad. por Manuel Aguilar.-Aguilar, Madrid, 1963. 268 pp.-V. núm. 9-13499. || Sef, 24 (1964), 162-163 (Cantera).

18-5055. SAla, M. - "Observatii asupre disparitiei limbilor" [el judcoespañol]. -Probleme de Ling. Generala, 3 (1961), 107-124. [Y trad. francesa en $R L i, 6$ (1961), 185-202].

18-5056. Alvar, M.-“El ideal de belleza femenina en las canciones de boda sefardíes". $-F H, 2(1964), 651-664$.

18-5057. Schallman, Lázaro - Amor y pasión en los judios. - Candelabro, Buenos Aires, 1963. 199 pp. [Hay capítulos sobre la Judía de Toledo y sobre el romancero sefardi]. || Sef, 24 (1964), 159-161 (Millás).

V. también núms. 6507-9.

\section{LITERATURA \\ ESTUDIOS GENERALES}

18-5058. Wilpert, Gero von, et al.-Lexikon der Weltiteratur. Biographischbibliographisches Handwörterbuch nach Autoren und anonymen Werken. Kröner, Stuttgart, 1963. 1417 pp.

18-5059. Die romanischen Literaturen dcs 18. und 20. Jahrhunderts. Bd. 2, Heft
5/9. - Athenaion, Konstanz, [1962?]. [Los facs. $1 / 4$ se publicaron en $193^{6}$ 37]. I| $R F, 75$ (1963), 174-175 (Gautier). 18-5060. Crisafulli, A. S.-"A bibliogaphy of the writings of Helmut A. Hatzfeld".-FHH, 1-21.

18-5o61. Studia philologica... in honorem L. Spitzer (N. 17-959). || NRFH, 18 (1965-66), 203-205 (Alvar).

\section{Teoría y crítica literaria}

18-5062. Reyes, Alfonso - El deslinde. Apuntes para la teoria literaria.--Fondo de Cultura Económica, México, 1963. 525 pp. (Obras completas, 15 ).

18-5063. Wellek, René, e Austin WarREN-Teoria da literatura. Reedição.Publs, Europa-América, Lisboa, 1964 . 392 pp. $-V$. núm. 18-1473.

18-5064. Díaz Plaja, Guillermo-El estudio de la literatura (los métodos históricos).-Sayma, Barcelona, 1963. 147 pp. (Panorama $A-Z$ ). $\| N T, 1964,89_{4}^{-}$ 895 (A. P. N.); $H, 47 \quad(1964), 873$ (Monguió).

18-5065. SoARes AMORA, ANTônIo-Teoria da literatura. $5^{\mathrm{a}}$ ed., rev.-Ed. ClássicoCientifica, São Paulo, 1964. 287 pp.- . núm. $17-925$.

18-5066. Mar'tinez Bonati, F.-La estructura de la obra literaria (N. 17-926). USF, 62 (1964), 393-997 (Boldori); $H u N L, \quad 6 \quad$ (1965), $549-553$ (Rangel Guerra).

18-5067. HALL, Robert A., JR.-Cultural symbolism in literature, - M. Orsini, Roma, 1963. 169 pp. $\mid B A b r, 3^{8}\left(19^{64}\right)$, 186-187 (Den); JAAC, 22 (1969-64), 344-345 (Dickie); $M L R, 59$ (1964), 618 (MacKenzie); Monatshefte, 66 (1964). núm. 6 (Puppe); It, 42 (1965), 307310 (Weingartner).

18-5o68. LAusBerg, H. - Handbuch der literarischen Rhetorik (N. 16-47065). Vetera Christianorum, Bari, 1964, núm. 1, 170-174 (Lomiento); $W W, 13$ (1963), 378-379 (Rupp). - V. núm. 18-1481.

18-5069. Suiffet Bianchi, N.-"De la antigua retórica a la nueva estilística".-$R N a, 9$ (1964), 252-268.

10-5070. Probleme de stilistica. Culegere de articole. - Ed. Stiintifica, Bucurcsti, 1964. 179 pp. [Artículos de V. P. Murat, M. Riffaterre, R. Jakobson, V. V. Vinogradov y S. Saporta].

18-5071. Guiraud, P.- "Les tendances de la stylistique contemporaine".-Style cî littérature ('s-Gravenhage, 1962 ), 9-9.3. 
18-5072. Starobinski, J. - "La stylistique et ses méthodes: Leo Spitzer”.-Crit, 20 (1964), 579-597.

18-5073. Schiaffini, A.-“Leo Spitzer". GSLI, 137 (1960), 653-656.

18-5074. Crisafulli, A. S.-"Helmut Hatzfeld".-FHH, 23-30.

18-5075. HatzFeld, H. A.-"The problem of literary interpretation reconsidered". $-O L, 19$ (1964), 66-76.

18-5o76. Kayser, Wolfgang - Análise e interpretação da obra literária. Introdução à ciência da literatura. Trad. de Paulo Quintela. T. 2. $3^{\text {a }}$ ed.-Arménio Amado, Coimbra, 1963.-V. núm. 14 $3^{8} 5^{66}$.

18-5077. Dundas, J.-"Allegory as a form of wit".-StR, 11 (1964), 223-233.

18-5078. KAYSER, WOLFGANG-The groles que in art and literature. Transl. by Ulrich Weisstein.-Univ. Press, Indiana, 1963. 272 pp., ilust. $-V$. núm. 13. 36788. || $M L J, 49(1965), 122-123$ (Lawso:i).

18-5079. Barasch, Frances K.-The "grotesque". Its history as a literary term. -[Tesis, New York Univ.; resumen en $D A, 25$ (1964-65), 5923-5924].

18-5080. Zwicky, L. B.-"Relations of literature and science: selected bibliography for $1963^{\prime \prime},-S, 18$ (1964), 374381.-V. núm. 17-4395.

18-5081. WeinberG, B. $-A$ history of literary criticism in the Italian Renais. sance (N. 17-4415). || ZRPh, 8o (1964), 214-220 (Buck); MLR, 59 (1964), 148149 (Gordon); $R P h, 17$ (1963-64), 49o496 (Grayson); RLMo, 1966, núm. 5, 161-163 (Nallim) ; $L R, 18$ (1964) 89-92 (Pouilliart); British Journ. of Aesthetics, 4 (1964), $277-278$ (Tatarkiewicz). - V. núm, $18-1517$.

18-5o82. WeImann, R. - "New Criticism" und die Entwicklung bürgerlicher Li. teraturwissenschaft. Geschichte und Kritik neuer Interpretationsmethoden. -Max Niemeyer Verl., Halle, 1962. 364 pp. - V. núm. 16-43284. I| StN, $3^{6}$ (1964), 200-203 (Ahnebrink); $M L N, 79$ (1964), 326-328 (Chadbourne); PhQ 44 $(1965), 411-417$ (Freedman); Leuvensen Bijdragen, $53 \quad$ (1964), $181-18_{3}$ (Janssens); $M L R, 5^{8}$ (1963), 612-614 (Magill); $B A b r, \quad 3^{8} \quad(1964), \quad 44-45$ (Opitz); JAAC, 22 (1963-64), 223-224 (Rieser).

18-5083. Mastrangelo, A. - "Benedetto Croce and the New Critics". - Studi Americani, 9 (1964), $455-465$.

\section{LITERATURA GENERAL Y COMPARADA}

18-5084. Comparative Literature. Cumu. lative index, vols. I-15 (1949-1963). University of Oregon, Eugene, Oregon, 1964. 37 pp.

18-5085. FoleJEwSKI, Z., et al. (comps.)"Annual bibliography: 1963".-YCL, 13 (1964), 97-123.-V. núm. 18-1536.

18-5086. Proceeding of the Third Congress of the International Comparative Literature Association. - Mouton, The Hague, 1962. $3^{67} \mathrm{pp} .-\mathrm{V}$. núm. 1647144. \|CL, 16 (1964), 70-83 (Ball).

18-5087. Bojtár, E.-"Les études comparatives en Union Soviétique depuis 1960".-Helikon, 10 (1964), 62.72.

18-5088. NúNẼz, E. - "Literatura comparada en Hispanoamérica". - CLS, 1 (1964), 41-45.

18-5089. Aubrun, CH. V. - "Incomparable literatura, o la crisis de la literatura comparada".-CCL, 1964 , núm. $85,{ }_{4} 8$ $5^{6 .}$

18-5ogo. Gérard, A. - "Sur la crise de croissance de la littérature comparée". $-R L V$, 3о (1964), 533-543.

18-5ogi. Gicovate, Bernardo-Conceptos fundamentales de literatura comparada: iniciación de la poesía modernista.-Asomante, San Juan, Puerto Rico, 1962. 149 pp. || HR, 32 (1964), 259-261 (Earle); Asom, 1963, núm. 4, 66-67 (Gullón); CL, 17 (1965), 93-94 (Hatzfeld); $R H M$, 3o (1964), 54-55 (JaimesFreyre); $B A b r, 3^{8}$ (1964), 172 (Karsen).

18-50g2. Tunk, EDUARd von - Historia universal de la literatura. Trad. D. Sánchez de Alen.-Rev. de Occidente, Madrid, 1964. 400 pp., ilustr.-V. núm. 10-22854.

18-5093. Foucher, JeAn-Pierre-La litté. rature latine du moyen âge.-P.U.F., Paris, 1963.128 pp. (Que sais-je?, 1043). I| RevPh, 38 (1964), $33^{8}$ (André); $R R, 55$ (1964), 204-206 (Bolle); $L R, 19$ (1965), 278-280 (Bultot); Lat, 22 (1963), 317-320 (Cambier); RLiR, 27 (1963), 227-228 (Gardette); HumRES, 40 (1963-64), 128 (Guillon); $R E L, \quad 4^{2} \quad$ (1964), 646-647 (Lefèvie): $E t C, 3^{1}$ (1969), 432 (Van Ooteghem). 18-5094. Jackson, W. T. H.-The literature of the Middle Ages (N. 17-970). || $R P h, 18$ (1964-65), 486-491 (Bäuml); $M P h$, 6o (1962-63), 131-133 (Chester); $L F, 11$ (1963), 193-194 (Hrabák). 
18-5095. KuHN, H.-Dichtung und Welt im Mittelalter (N. 16-43341). \|WW, 14 (1964), 211-212 (Eggers); German Life \& Letters, 14 (1960-61), 65-66 (Hatto).-V. núm. 16-47158.

18-5og6. Bezzol,A, R. R.-Les origines et la formation de la littérature courtoise en Occident (N. 17-4443). II Bult. de la Société des Bibliophiles de Guyenne, 32 (1963), 107-112 (La Croix Bouton); Annales de Normandie, 12 (1962), 303-304 (Musset).

18-5097. L'attessa dell'età nuova nella spiritualità della fine del medioevo. (Convegni del Centro di Studi sulla Spiritualità Medievale, 3, I6-19 ottobre I960).-Todi, 1962. $45^{8}$ pp. $\| B H R$, 26 (1964), 476-477 (Binz).

18-5og8. BüDEL, OSCAR-Francesco Pe. trarca und der Literaturbarock.Scherpe Verl., Krefeld, 1963. 48 pp. (Schriften und Vorträge des PetrarcaInstituts Köln, 17). \|RPh, 18 (196465 ) , 360-362 (Scaglione)

18-5099. SPITZER, L. - Romanische $\mathrm{Li}$ teraturstudien (N. 17-4449). $\| R P F$, 13 (1964-65), 509-518 (Beau); $M P h, 62$ (1964-65), $179^{-186}$ (Corominas).

18-5100. Newald, R.-Nachleben des antiken Geistes im Abendland (N. 16 . 47163). I| Scholastik, $3^{6}$ (1961), 406407 (Ennen); $W W, \quad 11$ (1961), $5^{6-}$ 57 (Frenzel); Germanistik, 2 (1961), 196-198 (Ristow); Monatshefte, 53 (1961), 90-91 (Wassermann).-V. núm. 18-157x.

18-5101. Berman, R. S.-"Heroic action in the later Renaissance". $-S, \quad 18$ (1964), 113-127. [Calderón, Cervantes, Shakespeare].

18-5102. Torre, Guillermo de-Minorias y masas en la cultura y el arte contemporáneos.-E.D.H.A.S.A., Barcelona-Buenos Aires, $1963.378 \mathrm{pp}$. (Col. El puente). || RLMo, 3 (1964), 120 (Zuleta) ; Ins, 1964, núm. 206 (Adell); Asom, 1965, núm. 2, 77-79 (Babín); ROcc, 5 (1964), 244-253 (Chueca Goitia); $N T$, 1964, núms. 117/8 (F. de A.) ; $A, 155$ (1964), núm. 405, $257^{-}$ 259 (Meissner); Sur, 1963, núm. 284, 103-105 (Roland) ; $L T, 1963$, núm. 44, $181-185$ (Scuderi); ROcc, 7 (1964), 247248 (Scuderi).

\section{Períodos literarios}

18-5103. Toffanin, Giuseppe-Storia dell'Umanesimo. - Zanichelli, Bologna,
1964. 4 ts.: viii $+179, x i+415,202$, 213 pp. || RewPhL, 62 (1964) 5.34 (X). 18-5104. "Bibliographie des articles relatifs à l'histoire de l'humanisme et de la Renaissance, $1963^{\prime \prime},-B H R$, 26 (1964), 643-671.-V. núm. 17-4460.

18-5105. WELls, W. (ed.) - "Literature of the Renaissance in 1963 ". $-S P h, 61$ (1964), 233-483.-V. núm. 18-1597.

18-5106. TAYLOR, R. E. - "Renaissance books".- $R N, 17$ (1964), 72-86, 140-149, 271-297, 357-371.-V. núm. 18-1598.

18-5107. Costa, G.-“La concezione del Rinascimento in Hegel, Burckhardt e De Sanctis".-It, $4^{1} \quad(1964), 403-414$.

18-5108. Orsini, G. N. G.-“'Symonds and De Sanctis: a study in the historiography of the Renaissance".-StR, 11 $(1964), \quad 151-187$.

18-5109. Levin, H.-"The Golden Age and the Renaissance".-[En] C. CAMDEN (ed.), Literary views: critical and historical essays (Chicago, 1964), 1-14. 18-5110. Montano, R.-“'L'estetica del Rinascimento e del Barocco".-[En] Il pensiero della Rinascenza e della Riforma, t. 11 (Milano, 1964), 671936. || CLS, 1 (1964), 250-258 (Carozza). 18-5111. Missac, P.-“Le maniérisme existe-t-il?"-Crit, 2o (1964), 895-904.

18-5112. Charpentrat, P.-"De quelques acceptions du mot baroque".-Crit, 20 (1964), 65o-666.

18-5113. EdWards, Homer F., JR.-The concept of Baroque in German, English and French scholarship. - [Tesis, Emory Univ., 1964].

18-5114. SyPHER, W.-Rococo to cubism in art and literature (N. 16-47216). RIEs, 22 (1964), 146-15o (Gaya Nuño). 18-5115. Erdman, D. V. - "The romantic movement: a selective and critical bibliography”.-PhQ, $43 \quad$ (1964), 433525.-V. núm. 18-1614.

18-5116. Pulvere, L.-"Le problème de la définition du romantisme et de ses rapports avec le préromantisme".Studia Universitatis Babes-Bolvai, Cluj, $9 \quad(1964), 81-94$.

18-5117. JoNEs, W. T. - The romantic syndrome (N. 17-1015). \|JAAC, 22 (1963-64), 472-473 (Dickie).

18-5118. FrYer, W. R.-"Romantic literature and the European age of re volutions".-Renaissance and Modern Studies, Nottingham, 8 (1964), 53-74. 18-5119. Weintraub, W.-“"The problem of improvisation in romantic literature".-CL, 16 (1964), 119-137. 
18-5120. Becker, George J. (ed.)-Documents of modern literary realism.Princeton Univ. Press, Princeton, 1963. 6og pp. [Incluye a Galdós (pp. 147-153), la Pardo Bazán (pp. 261-265) y Clarín (pp. 266-273)]. \| $M L J, 47$ (1963), 341-342 (Fleischmann); RLit, 26 (1964), 225 (Romero).

18-5121. KOFLER, LEO-Zur Theorie der modernen Literatur. Der Avantgardismus in soziologischer Sicht.-Leuchterhand, Neuwied am Rhein, 1962. 285 pp. \|ALitt, 7 (1965), $481-484$ (Hankiss).

\section{Géneros literarios}

18-5122. Larthomas, P. - "La notion de genre littéraire en stylistique".-FrM, 32 (1964), $185-193$.

18-5123. Vernet, J.- "L'origen de les líriques populars àrab $\mathrm{i}$ romànica".-ER, 9 (1961), 1-9.

18-5̆124. Menéndez Pidal, R.-“La primitiva lírica europea (N. 16-47230). I $L R, 19$ (1965), 69-71 (Groult); BICC, 18 (1963), 529-530 (Montes).

18-5125. Newman, Francis Xavier-"Somnium": Medieval theories of dreaming and the form of vision poetry.-[Tesis, Princeton University; resumen en $D A$, $24(1963-64), 4680-81] .434$ pp.

18-5126. Alonso, D.-"Antecedentes griegos y latinos de la poesía correlativa moderna",-EMP, 4, 3-25.

18-5127. Steadman, J. M.-“Verse without rime: sixteenth-century Italian defences of versi sciolti".-It, $4^{1} \quad(1964), 3^{8} 4^{-}$ 402.

18-5128. Richmond, H. M. - "Rural lyricism: a Renaissance mutation of the pastoral".-CL, 16 (1964), 193-210.

18-5129. Prifst, Harold Martin - Renaissance \& baroque lyrics. An anthology of translations from Italian, French and Spanish. - Northwestern Univ. Press, Evanston, 1962. 1xiv + 288 pp. $\|$ MLR, 6o (1965), 111-112 (Graham); Anglia, 81 (1963), 248-250 (Nelson); CEn, 25 (1965), 474 (Nelson); It, 41 (1964), 204-206 (Putney); Seventeenth Century News, Spring-Summer, $19^{6} 3,4-6(\mathrm{X})$.

18-5130. WARNKE, F. J. - "Sacred play: Baroque poetic style". - JAAC, 22 $(1963-64), 455-464$.

18-5131. CoHen, J. M.-The baroque lyric.-Hutchinson, London, 1963. $207 \mathrm{pp.}$ (Modern languages and literature). I|
RHLF, 65 (1965), 294-295 (Ellrodt); $M L R, 5$ (1964), $107-108$ (Grundy).

18-5132. Cohen, J. M.-Poesia de nuestro tiempo. Trad. de Augusto Monterroso. -F. C. E., México, 1969. 368 pp. (Breviarios, 171).-V. núm. 16-47188. $\| A$, 1965, núm. 410, 308-310 (Calderón); Eco, 10 (1964-65), 235-238 (Camacho Guizado) ; $C u A, 1964$, núm. 2, 284-285 (de la Selva).

18-5133. Greene, Thomas - The descent from heaven: a study in epic continuity.-Yale Univ. Press, New Haven-London, 1963. $\mathrm{x}+434$ pp. [Incluye a Camões y a Hojeda]. I| $R N, 17$ (1964), $44-45$ (Allen); $M L J, 4^{8}$ (1964), 531.532 (Jones); $C B, 4^{\circ}(1964), 45$ (McNamee); Italian Quarterly, 8 (1964), 7981 (Patrides); $C L, 17$ (1965), 363-365 (Smith); RR, $5^{6}\left(1^{6} 5\right), 54^{-5} 5^{6}$ (Valency) .

18-5134. REY, A. - "The background of the Romance epic".-[En] Comparative literature (Carbondale, S. Illinois, 1961), 204-222.

18-5135. MANDACH, A. DE - Naissance et développement de la chanson de gesle (N. 18-1641). || $D L Z, 85$ (1964), 209211 (Bahner); Scrip, 17 (1963), 383$3^{8} 4$ (Thorpe).

18-5136. Chanson de Geste und höfischer Roman. Heidelberg Kolloquium, 30. Januar I961.-Carl Winter, Heidelberg, 1963. 83 pp. (Studia Romanica, 4). II $R F, 76$ (1964), 232-236 (Adler); CCM, 6 (1963), 335-337 (Gallais); $Z R P h, 81$ (1965), $184^{-187}$ (Jauernick); FS, 18 (1964), 366-367 (Whitehead).

18-5137. Medieval epics: Beowulf, transl. by William Alfred. The song of Roland, transl. by W. S. Merwin. The Nibelungenlied, transl. by Helen $M$. Mustard. The poem of the Cid, transl. by W. S. Merwin.-Modern Library, New York, 196g. xviii + 574 pp. $\| S p$, 39 (1964), 191-192 (Jones).

18-5198. Monteverdr, A. - "Regolarità e irregolarità sillabica del verso epico".$M M D, 2,531-544$. [Incluye el Cid].

18-5139. Giamatt, A. Bartlett - The earthly paradise in the Renaissance epic.-[Tesis, Yale Univ., 1964].

18-5140. "Bibliographie" [sobre teatro].RHT, 16 (1964), 59-98, 277-318.-V. núm. $17-4520$.

18-5141. Proschwitz, G. von - "Drame: esquisse de l'histoire du mot".-StN, 36 (1964), 9-5o. || ZRPh, 8o (1964), 639640 (Baldinger). 
18-5142. Richthofen, E. von-“Der gegensätzliche Parallelismus westromanischer Dramentechnik".-EMP, 4, 5og534 .

18-5143. Pandolfr, Vito-Storia universale del teatro drammatico.-U. T. E. T., Torino, 1964. 2 ts.: $679,93^{8}$ pp.

18-5144. D'Amico, Sirvio - Historia del teatro dramático. Trad. por Baltasar Samper.-UTEHA, México, 1961. 4 ts. 18-5145. KindermanN, Heinz - Theater. geschichte Europas. Bd. 6: Romantik.O. Müller, Salzburg, 1964. 464 pp., ilustr.-V. núm. 17-1046.

18-5I46. JAcQvot, J. (ed.) - Le théatre tragique (N. 18-1661). $\| A E S C, 19$ (1964), 1037-1042 (Chiche); $C R, 14$ (1964), 22-23 (Garton); RSH, 1964, 392-393 (Robichez).

18-5147. BRÄUtigaM, KurTh (ed.)-Europäische Komödien: Dargestellt an Einzelinterpretationen.-Diesterweg, Frankfurt, 1964 .

18-5148. HERRICK, M. T. - Tragicomedy (N. 17-4527). ||$R H T, 15$ (1963), 177178 (Mélèse).

18-5149. Sron, G.- "Le théâtre baroque ou l'art de la Méditerranée".-Ann. du Centre Univ. Méditerr., 16 (1962-63), 59-71.

18-5150. Weiss, SAmuel A. (ed.) -Drama in the modern world: Plays and es. says. - Heath, Boston, 1964. 576 pp. [Incluye The house of Bernarda Alba].

18-5151. Ginestier, P. - Le théatre con. temporain dans le monde (N. 17-1054). || MLR, 59 (1964), 147 (Bowen).

18-5152. Monner Sans, José María-In. troducción al teatro del siglo $x \times$.Columba, Buenos Aires, 1963. 61 pp. (Esquemas) .-V. núm. 18-1667.

18-5153. Lukńcs, Georg - Die Theorie des Romans.- Luchterhand, Neuwied, 1963. 169 pp. $\| B A b r, 3^{8} \quad(1964), 162$ (Golffing).

18-5154. Muscatine, C.-"Locus of action in medieval narrative". - $R P h, 17$ (1963-64), 115-122.

18-5155. West, PauL-The modern novel -Hutchinson, London, 1963. $45^{\circ} \mathrm{pp}$. II Rlit, 26 (1964), 240-241 (Pérez Gallego).

18-5156. Harris, Wendell V.-“Style and the twentieth-century novel". $-W H R$, $18(1964), 127^{-1} 4^{0}$.

18-5157. EBEL, UDA - Das altromanische Mirakel. Ursprung und Geschichte einer literarischen Gattung. - [Tesis, Univ. de Giessen, 1964].
18-5158. Lehmann, Paul - Die Parodie im Mittelalter. 2 Aufl. - Anton Hiersemann, Stuttgart, 1963. 267 pp. $\|$ Ger. manistik, 5 (1964), 435-436 (Fischer); $E m, 32$ (1964), 366 (Díaz y Díaz); Gn, $3^{6}$ (1964), 312-314 (Wagner).

${ }_{18-5159}$. Highet, G.-The anatomy of satire (N. 17-4542). || RevPh, $3^{8}(1964)$, 176 (André); RBPH, 42 (1964), 1080. 1082 (Bakelants); London Magazine, 3 (1964), 78-81 (Brophy); MPh, 62 (1964-65), 91-93 (Heiserman); $C L, 16$ (1964), 83-86 (Jackson); $A A H G, 17$ (1964), 18-27 (Knoche); MLR, 59 (1964), 93-94 (Peter); $A C, 32$ (1964), 487 (Préaux); ASNS, 202 (1965), 373374 (Sühnel); CJ, 6o (1964), 30-33 (Sullivan).-V. núm. 18-1680.

18-5160. Hocke, Gustay René-Das europäische Tagebuch. Beiträge zur vergleichenden Literaturgeschichte. - Limes Verlag, Wiesbaden, 1963. 1135 pp.

\section{Temas literarios generales}

18-5161. "Bibliographie [arthurienne] pour 1969".-BBSIA, $16(1964), 7-91$.V. núm. 18-1684.

18-5162. LOOMIS, ROger SherMaN - The development of Arthurian Romance.Hutchinson Univ. Libr., London, 1963. 199 pp. (Modern languages and literature $)$. || $M L R, 60$ (1965), $588-589$ (MacDonald); Sp, 39 (1964), 717-719 (Matthews); FS, 18 (1964), 362-363 (Thorpe).

18-5163. SPITZER, LEO - Classical and christian ideas of world harmony.Johns Hopkins Press, Baltimore, 1963. $\mathrm{xi}+232$ pp. $\| M L R, 59(1964), 45^{1}$. $45^{2}$ (Alexander); $R N, 17$ (1964), 112. 113 (Allen); Sp, 39 (1964), 337-339 (Bloomfield); $M L J, 4^{8}$ (1964), 464-465 (Panichas); RivFil, $5^{6}\left(19^{6}\right), 75^{-81}$ (Viano).

18-5̆164. Peroni, L.-“Il motivo di Prometeo nella filosofia del Rinascimento".-RCSF, 19 (1964), 451-457.

18-5165. Stanford, W. B. - The Ulysses theme. 2nd. ed. - Blackwell, Oxford, 1963. $\mathrm{x}+340$ pp.-V. núm. 10-23075. |l $C R, 14 \quad(1964), 336$ (Davison); $M L R, 59$ (1964), 443-444 (Maxwell). 18-5166. Heitner, R. R.-"The Iphigenia in Tauris theme in drama of the eighteenth century".-CL, 16 (1964), 289-309.

18-5167. López Caballero, A.-“El tema Fedra en la literatura". - $R y F, 170$ 
(1964), 425-438. [Incluye a Lope de Vega y a Unamuno].

18-5168. Derche, ROLAND - Quatre mythes poétiques (Oedipe, Narcisse, Psy. ché, Lorelei). - Soc. d'Edition d'Enseignement Supéricur, Paris, 1962. 198 pp. [Estudia, entre otros, a Calderón]. I| Seg, I (1965), 138-140 (Rull).

18-5169. Starnes, D. T.-"The figure Genius in the Renaissance". - StR, 11 (1964), 234-244.

18-5170. VeIT, WALter-Studien zur Geschichte des Topos der Goldenen Zeit von der Antike bis zum I8. Jahrhun. dert.-Universität Köln, 1961, $198 \mathrm{pp}$. [Tesis].

18-5171. Gerhardt, Mia I.-Two wayfarers: some medieval stories on the theme of Good and Evil.-Instituut voor Algemene Literatuurwetenschap aan de Rijksuniversiteit, Utrecht, 1964. 62 pp. (Publikaties voor Algemene Lite ratuurwetenschap, 5).

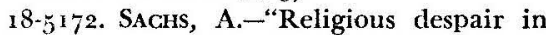
nediaeval literature and art".-MSt, 26 $\left(19^{64}\right), 231-25^{6}$.

18-5173. SNYder, SUSAN BroOKE-The paradox of the despair theme in medie. $\checkmark a l$ and Renaissance literature.-[Tesis, Coiumbia Univ.; resumen en $D A, 25$ $\left.\left(19^{64}-65\right), 1201\right]$.

18-5174. Cook, R. A.- "The influence of the Black Death on medieval litera. ture and language". $-K F L Q, 11$ (1964), $5 \cdot 13$.

18-5175. TavanI, G. - "Il dibattito sul chierico e il cavaliere nella tradizione mediolatina e volgare".- $R J, 15$ (1964), $5^{1-84}$. [Incluye la Razón de amor].

${ }_{18-5} 7^{7} 6$. Herculano de Carvalho, J. "Um tipo literário e humano do barroco: o cortesäo discreto"., $-B B U C, 26$ (19 $\left.f_{3}\right) ; 24 \mathrm{pp}$.

18-5177. SCAGlione, Aldo D.-Nature and lov'e in the late Middle Ages.-Univ. of California Press, Berkeley, 1963. 250 pp. $\| M L Q, 25$ (1964), 493-494 (Cam. bon); GSLI, 141 (1964), 131-132 (Ceserani) ; Critica Storica, 3 (1964), 796 800 (Corrado); RR, $5^{6}\left(19^{6} 5\right), 59^{-60}$ (Ferrante); CL, $17 \quad(1965), \quad 367-372$ (Gianturco); Ital. Studies, 19 (1964), $9^{8-100}$ (Hatwell); Studi sul Boccaccio, 2 (1964), 445-465 (de Panizza); $S p$, $40(1965), 545-547$ (Witke).

18-5178. Scaglione, A. D.-"Again on nature and love in the late Middle Ages". $-M L N, 79$ (1964), 556-559.

18-5179. Ruggerio, Michael J.-The evo- lution of the go-between: Eros and witchcraft. - [Tesis de la Universidad de Harvard, 1964$]$.

18-5180. Henning, Hans - Faust in fünf Jahrhunderten. Ein Überblick zur Geschichte des Faust-Stoffes vom Io. Jahr. hundert bis zur Gegenwart. - VEB Verl., Halle-Saale, 1963. 128 pp. (Wege zur Literatur, 2). \|P PhP, $7 \quad(1964)$, 323-324 (Poláchek).

\section{Relaciones literarias}

Influencias extranjeras

18-5181. Beardsley, T. S., JR.-" The first catalog of Hispano-Classical translations: Tomás Tamayo de Vargas: $\boldsymbol{A}$ los aficionados a la lengua española".$H R, 32$ (1964), 287-304.

18-5182. Salinero, F, G. - "La primera traducción de Vitrubio [sic] en la biblioteca pública de Cáceres".- $R E E, 20$ (1964), 457-465.

18-5183. Fucilla, Joseph G. - "Superbi colli" e altri saggi.-Carucci, Roma, 1963. 332 pp. [Estudios de literatura española, particularmente en su rela. ción con la italiana] || It, 41 (1964), 350-353 (Corrigan); $R L M, 16$ (1963), 277-280 (Martinengo); FLett, 18 (1969), 2 (Raya); HR, 33 (1965), 326-330 (Rivers); $H, 4^{8}$ (1965), 179 (Rothberg); RLit, 27 (1965), 206-207 (Rozas); PI, 7 (1965), $217-218$ (Vallese); $I S, 4^{6}$ (1963), $13^{8}$ (Vallone).

18-5184. Meregalli, F.-“Olaszország és Spanyolország irodalmi kapcsolatai a renaissance-korban". - Osztályának Világirodalmi Folyóira, Budapest, 9 (1969), 325-335.

${ }^{18-5} \mathbf{1}^{185}$. Foster, D. W.-"The misunderstanding of Dante in fifteenth-century Spanish poetry".-CL, 16 (1964), $33^{8}$ 347 .

18-5186. BoHigas, P.-“Un manuscrit dantesc copiat a Catalunya". - ER, 9 (1961), $251-267$.

18-5187. Fucllla, J. G.-Estudios sobre el petrarquismo en España (N. 17-4569). II Conv, 32 (1964), 532-533 (Boni); ZRPh, 80 (1964), 193-196 (Kremers). I 8-5188. BARDI, U. - "Materiale per una bibliografia delle traduzioni spagnole delle opere di Giovanni Boccaccio".Scritti su Giovanni Boccaccio (Firenze, $1964), 135^{-139 .}$

18-5189. Ricciardelit, M.-"Spanish imitators of Sannazaro's Arcadia: A re- 
evaluation". - Proc. of the 15th Pacific Northwest Conference on Foreign Languages (Montana State Univ., 1964), $60-66$.

18-5190. Bertini, G. M.-“"Ludovico Ariosto e il mondo ispanico".- $-E R, 9$ (1961), 269-282.

18-5191. Rossi, G. C.-"Metastasio, Goldoni, Alfieri e $\mathbf{i}$ gesuiti spagnoli in Italia".-AION-R, 6 (1964), $7^{1-116 .}$

18-5192. DE Filippo, L. - "Una parodia spagnola del Oreste alfieriano".-Aiti dell'Accademia delle Scienze dell'lstituto di Bologna, 52 (1963-64); 24 pp.

18-5193. VARr, VíctoR B.-Carducci y España.-Gredos, Madrid, 1963. 234 pp. $(B R H)$.-V. núm. 17-1098.

18-5194. Meregalli, F.-“D'Annunzio en España".-FM, 1964, 265-289.

18-5195. DE FILIPPO, L.-"Pirandello in Spagna".-NA, 99 (1964), 197-206.

18-5196. Clavería, C. - "Notas sobre el significado y fortuna de El caballero determinado".-EMP, 6, 287-311.

18-5197. Prado Collho, J. do-"Presença da França nas letras portuguesas nos séculos xVIII e xIx".- $R d L, 6$ (1964), marzo, 77-93.-V. núm. 17-4577.

18-5198. Donate, J. C. - "Stendhal vu par les Espagnols". - Stendhal Club, Lausanne, 6 (1964), 141-148.

18-5199. Estorninho, C. - "Shakespeare na literatura portuguesa". - Ocid, 67 $\left(19^{6} 4\right), 114^{-129}$.

18-5200. Saraiva Jorge, M. po C. - "As primeiras referências a Shakespeare na literatura portuguesa".-OCid, $66\left(19^{6} 4\right)$, 253-260.

18-5201. Saraiva Jorge, M. do C.-"Shakespeare e a literatura oitocentista posterior a Garrett e Herculano".--Pal, 1965, núm. 23, 16-83.

18-5202. Pérez Gallego, C.-"Dickens en la prensa diaria madrileña del siglo XIX".--RLit, 26 (1964), $109-113$.

18-5203. ILIE, P. - "Nietzsche in Spain: 1890-1910".-PMLA, 79 (1964), 80-96.

18-5204. Rukser, U. - Nietzsche in der Hispania (N. 18-1736). || Era, 16 (1964), $59^{1-597}$ (Beau); RIB, 14 (1964), 445449 (Estiú); RLit, 28 (1965), 297-300 (Fernández Turienzo); Rev. de Filosofia, La Plata, 1964, núm. 14, 112-116 (Klein); $\mathrm{BHi}, 66$ (1964), 199-207 (Pageard); $M L N$, 80 (1965), 284-285 (Reichert); $S, 18$ (1964), $3^{6} 5^{-367}$ (Schanzer).

18-5205. Rukser, U. - "Nietzsche y los poetas de habla hispánica".-Sur, 1964, núm. $286,54-62$.
V. también nums. 4313, 5327, 5352-3, 5402, $5462, \quad 5571, \quad 557^{8}, \quad 55^{81}, 55^{635}, 567^{6-7}$, $5839,6022,6071,6078,6089,6128,6175$, $6375,6541,6545,7075,7088,7534,7557$, $7698,7903-6,7915,8116,815^{6-8}, 8173$.

Influencias hispánicas

18-5206. Rossi, T. M. - "Un argomento portoghese nel teatro italiano del Settecento e del Ottocento". $-E I P, 1964$, núm 23, 175-201. [Inés de Castro].

18-5207. David, M.-"Carducci e Don Quichotte. Une petite polémique oubliée (août 1881)".-Atti e Memorie dell'Accademia Patavina di Scienze, Letlere ed Arti, 75 (1962-63), 203-225.

18-5208. Richthofen, E. von-“La Catalogne et l'Aragon dans quelques épopées et romans arthuriens".-ER, 9 (1961), $209-217$.

18-5209. WeINRICH, H. - "Voltaire, Hiob und das Erdbeben von Lissabon". $A P K, 4$ (1964), 96-104.

18-5210. HoFFMANN, L.-F. -Romantique Espagne (N. 18-1741). || RR, 55 (1964), 61-62 (Bowman); $R F, 77$ (1965), 204. 206 (Krömer); FS, 18 (1964), $160-161$ (Russell); LR, 18 (1964), 94-95 (Vermeylen).

18-5211. Herrero García, A. - "Conceptos curiosos de Andalucia: Paul de Kock".-PSA, 33 (1964), 329-33. [P. de Kock, Un parisien dans l'Andalousie]. 18-5212. Galán Lorés, Carlos-Lo español en Montherlant. - Zaragoza, 1963 . 87 pp. (Cuadernos de filosofia y letras, 49). - V. núm. 18-1748. \| RLit, 24 (1963), 279-280 (Pérez Gallego).

18-5213. HobBs, EDNA EARIE-Spanish influence on the plays of Beaumont and Fletcher.-[Tesis, Florida State Univ.; resumen en $D A, 24 \quad\left(1963-64,283-28_{4}\right]$. $258 \mathrm{pp}$.

18-5214. Dey, Susnigdha-El elemento picaresco en las novelas de Daniel Defoe. - TTesis, Univ. de Madrid; resumen en RUM, 13 (1964), 6og-610].

18-5215. Pollin, B. R. - William God. win's Fragment of a romance".- $C L, 16$ $(1964), 40-54$. [Obra de tema español]. 18-5216. MILLER, TowNSEND-The castles and the crown: Spain 145 r-1555.-Victor Gollancz, London; Coward-McCann, New York, 1963. 379 pp. II HAHR, 44 (1964), 231-232 (Addy); $M L J, \quad 47$ (1969), 335 (Stoudemire); BHS, 41 (1964), 252-254 (Tate).

18-5217. SCHELLERT, D.-"Spaniens Litera- 
tur in deutschen Úbersctzungen". Humboldt, 1969, núm. 19, 50-59.

18-5218. García, C.--"Literatura española traducida en Alemania (1960-1962)".$F M, 4 \quad\left(1963^{-64}\right)$, núms, 11/12, 63-83.

18-5219. Remarque, Erich Marie - La nuit de Lisbonne. Trad. par Dominique Auclères.-Plon, Paris, 1969, 288 pp. || Etudes, 1964, 429 (Holstein).

18-5220. Pinczara, S.-"Recepción de las literaturas ibéricas e iberoamericanas en Polonia",-Alcor, Asunción, 1964, núm. 28.

18-5221. Irving, Washingrca-Cuentos de la Alhambra.-Molino, Barcelona, 1964. 80 pp. (Cuentos de hadas, $3^{\circ}$ ).

18-5222. JoHnson, H. L.-"Longfellow and Portuguese language and literature".$C L, 17$ (1965), 225-233.

18-5223. Martínez López, Enrique-Contribución al estudio de las influencias del barroco literario español en las letras coloniales del Brasil--ITesis, Univ. de Madrid; resumen en $R L M, 13$ (1964), 594-596].

18-5224. Kampman-Porcelijn, M. - "La guerra civil española reflejada en los libros".-Norte, Amsterdam, mayo-jun. 1964 .

18-5225. Bertrand de Muñoz, Maryse La guerre civile espagnole dans le roman européen et américain. - [Tesis, Univ. de Paris, 1962; resumen en $A U P$, 33 ( 1963$), 486-488$ ].

V. también núms. 4334-5, 4346, 5524-6, $5920,6111,6513,65^{81}, 6586,66_{51}, 6716$, $6719-22,6941,7097,7155,7196,8164-5$.

\section{LATINISTAS Y HUMANISTAS}

18-5226. Freire, A.-"Do latim clássico ao latim medieval. Introdução ao huma. nismo medieval português".-BAu, 16$17(1964), 117-125$.

18-5227. Pina Martins, J. V. De - "Pico della Mirandola e o humanismo italiano nas origens do humanismo português".-EIP, 1964, núm. 29, $107-146$.

18-5228. Costa Ramalho, A. Da-"Algumas relações italianas de Cataldo Aquila Sículo".-HuC, $15^{-16}(1963-64), 367$ 379 .

18-5229. Costa Ramalho, A. Da-“Cataldo Sículo em Santarém".-Pan, 1964, núm. 11 .

18-523o. Gomes dos Santos, D. M.-"Buchanan e o ambiente coimbrão no século xvi". $-H u C, 15^{-16}$ (1963-64), 261-327. V. tambièn núms. $4307-8$.
18-5231. Sanchis Guarner, M.-“La ascendencia judía de Juan Luis Vives".$R V F, 6$ (1959-62), 333-337.

18-5232. León Tello, F. J.--"Vives y la estética del Renacimiento",-RevFil, 21 (1962), 503-521.

18-5233. Alcalá, M.-"Luis Vives en la traducción".-Lect, 157 (1964), 19-24.

18-5234. Vosters, S. A.--"Juan Luis Vives en de Nederlanden".-Verslagen en Mededelingen van de Kon. Vlaamse Acad. voor Taal-en Letterkunde, 1964, 65-201.

18-5235. Sepúlveda, JUAN GINÉs DE-Tratados politicos: Exhortación a la guerra contra los turcos. Del reino y deberes del rey. De la compatibilidad entre milicia y religión. Trad., introd. y notas por Ángel Losada.-Inst. de Estudios Políticos, Madrid, 1963. 328 pp. II CuH, $5^{6}$ (1963), 699-7o1 (Garcés).

$18-5^{2} 36$. Longhurst, J. E.-"Alumbrados, erasmistas y luteranos en el proceso de Juan de Vergara".-CuHE, 1962, núms. $35 / 36,337-353 ; 1963$, núms. $37 / 38,35^{6-}$ $371 .-V$. núm. 16-45928.

18-5237. Lopes Dias, J.-“O Renascimento em Amato Lusitano e Garcia d'Orta". $-E C B$, 1964, núm. 11, 5-34.

18-5238. Matos, L. oE-"Erasmo e Amato Lusitano".-BIB, $5 \quad$ (1964), $4^{82-4^{8} 3}$.

18-5239. AlmeidA, A. B. DE-“Notas sobre os Diálogos de Francisco de Holanda". -Pal, 1964, núm. 20, 89-97.

18-5240. Spina Bareili, E.--"Le conversazioni romane di Francisco de Hollan. da". $-V P, 47$ (1964), 329-334.

18-5241. Batallon, M. - "Sur l'humanisme du Docteur Laguna: deux petits livres latins de 1543". - RPh, 17 (1963-64), 207-234.

18-5242. LAGUnA, ANDRés-Discurso sobre Europa. Introd. y traducción por José López de Toro.-Diputación Provincial, Segovia; Joyas Bibliográficas, Madrid, 1962. 295 pp. [Incluye facsínil del texto latino original].

18-5243. Alejandro, J. M. DE-“Dos actitudes ante Europa: Andrés de Laguna y Ortega y Gasset".-Arb, $5^{8}$ (1964), 235-263.

V. también núms. 6948-5o.

1 8-5244. Álvarez Pérez, J. M.-"El organista Francisco Salinas. Nuevos datos a su biografia".- $A n M, 18$ (1963), 21-44.

Luis de León: v. núm. 7884 .

18-5245. Liano Pacheco, Jose María Sanctius. (El Brocense).-[Tesis, Univ. de Salamanca, 1963].

V. también núms. $475^{\circ}, 7903$. 
18-5246. VÁzQULz, José ANDRÉs - Arias Montano, $2^{\text {a }}$ ed. - Sánchez Rodrigo, Plasencia, 1964. 122 pp. (Hijos ilustres de España, 13).

18-5247. Van Durme, M.-“Granvelle et Plantin".-EMP, 7, 225-272. [Y sus relaciones con Arias Montano].

18-5248. MAS, A.- “Un exemple d'antisémitisme espagnol au siècle d'or". $-\mathrm{BH}$, 64 bis (1962), 166-174. [Sobre el Viaje de Benjamín de Tudela traducido por Arias Montano].

Lastanosa: v. núm. 4227.

\section{LITERATURAS PENINSULARES}

\section{Catalana}

18-5249. ManeNT, A.-“L'amenitat en la literatura catalana".-SO, 1965, núm. 11.

18-525o. MOLAs, JOAQUn-Literatura catalana antiga. T. 3: El segle $x v$, primera part.-Barcino, Barcelona, 1963 . 140 pp. (Col. popular Barcino, 203).V. núm. 18-1778. \|CuN, 24 (1964), 122-123 (Tavani).

18-5251. Busquets, J., y F. Millet-."Sobre literatura y lengua catalana”. CuD, 1964, núm. 13 .

18-5252. Triadú, Joan, i Eduard Artells (eds.)-Textos literaris, amb comentaris gramaticals. - Barcino, Barcelona, 1964. || $L N L, 1964$, núm. 2, 99 (Dorandeu).

18-5253. Boнicas, P. - "La matière de Bretagne en Catalogne" (N. 16-47395). || $\mathrm{ZRPh}, 8$ o (1964), 633 (Brummer).

18.5254. SoldevilA, F.-"Un poema joglaresc sobre l'assalt de la ciutat de $\mathrm{Ma}$ llorques".-ER, 9 (1961), 49-59.

18-5255. ANGLÉs, H.-"El canto religioso popular en los manuales litúrgicos de la Tarraconense". - AnM, 18 (1963), $103-108$.

18-5256. Romeu Figueras, J.-"Las poesias catalanas del manuscrito musical de Olot".-AnM, 18 (1963), 45-55.

18-5257. Aramon I Serra, R.--"Els cants en vulgar del Llibre vermell de Montserrat. (Assaig d'edició crìtica)". $A M o n$, io (1964), 9-54.

18-5258. ArAmon I SERrA, R.-“Algunes poesies bilinguies en cançoners catalans".-ER, 9 (1961), $85^{-126}$.

18-5259. Soldevila, F.- "Un poema joglaresc sobre l'engendrament de Jaume I'.-EMP, 7, 71-80.

18-5260. Riquer, Martín DE-Lletres de batalla, cartells de deseixements $i$ capitols de passos d'armes.- Barcino, Barcelona, 1964. 230 pp. (Els nostres clàssics, 90).

18-5261. BReneL, C.-“Sur la version provençale de la relation du voyage de Raimon de Perillós au Purgatoire de saint Patrice".-EMP, 6, 3-21.

18-5262. Aramon I Serra, R.-“Una cançò i tretze cobles esparses inédites".$M M D, 2,21-38$.

18-5263. Romed Figueras, J.-" "Sobre una canción tradicional catalana: Els estudiants de Tolosa".-EMP, 6, 507-545. 18-5264. Rubió Balaguer, JoRd-La cultura catalana del Renaixement a la decadència.- Edicions 62, Barcelona, 1964. 173 pp. (A l'abast).

18-5 26.5 . Molas, J.- "La cultura catalana a l'Europa cinccentista".- $S O, 196_{5}$, núm. 4 .

18-5966. Molas, Joaqum (ed.) - Poesia catalana romántica.-Eds. 62, Barcelona, $196_{5}$. $122 \mathrm{pp}$.

18-5267. Serrahima, M.-“'Sobre el noucentisme".-SO, 6 (1964), núm. 8.

18-5268. Castellet, Josep M., i Johquim Molas (eds.)-Poesia catalana del segle xx. Antologia.-Edicions 62, Barcclona, $19^{6} 9.57^{6}$ pp. II Ins, $19^{6} 4$, núm. 211 (Beser); CuA, 1964, núm. 5, 268273 (Goytisolo); ROCc, 9 (1965), $10_{5}^{-}$ 109 (Tovar); BHS, 42 (1965), 60-62 (Walker) .

18-5269. Manent, A.-“Déu i el seu conjur en la poesia catalana moderna".QVC, 1965 , núm. 29, 7-28.

18-527o. Teixidor, J. - "Cincuenta años de poesía catalana”.-CuD, 1964, núms. $5 / 6$.

18-5 271 . Goytisolo, J. A.-“Poetas catalanes".-JLA, 3 (1964), 1, 6.

18- $\mathrm{o}^{272}$. Rovira I Artigues, Josep M.Els "Goigs". Seguit de llur bibliografia; inici per Camil Geis.-Torrel de Reus, Barcelona, 1964. 94 pp.

18- 5273 . Llompart, Josep Maria-La literatura moderna a les Balears. - Moll, Palma de Mallorca, 1964. 235 pp.

18-5274. Carbonell, J. - "La cultura a Menorca".-SO, 6 (1964), núm. 11.

18-5275. Casasnovas, LuIs - Antologia poética menorquina.-Pauta, Menorca, 1964. || Ins, 1965, núms. 224/5 (Cano). 18-5276. Lewent, K.-"The Catalan troubadour Cerveri and his contemporary, the joglar Guillem de Cervera". $-S p$, $3^{8}$ (1963), $4^{61-472 .}$

18-5277. LeweNt, K.-"On the texts of 
four poems by the Catalan troubadour Cerveri".-NM, 65 (1964), 241-268.

18-5278. Colomer, E. - "Autorretrato de Ramón Llull: conversión y misión".Pens, $20 \quad(1964), 5-26$.

18-5279. Abellà, Delfí-Geni $i$ catalanitat de Ramon Llull.-R. Dalmau, Barcelona, 1964. 62 pp. (Panorama actua! de les idees, 33).

18-ว280. SÁIz BARBERÁ, JUAN-Raimundo Lulio, genio de la filosofia y mistica española. - E.P.E.S.A., Madrid, 1963. 899 pp. || $A r b, 5^{8}$ (1964), 110-112 (Valcárcel Alfayate).

18-丂281. Llinarès, ARMAND - Raymond Lulle, philosophe de l'action.-Faculté des Lettres, Grenoble, 1963. 510 pp. || Ins, 1964, núms. 216/7 (Guy); $R A M$, $4^{\circ}$ (1964), $\log ^{-104}$ (Ricard); $R H P h R$, 44 (1964), 449 (Wendel).

18-5282. Sálz Barberí, J.-“"Consideracio. nes generales sobre Lulio y la doctrina luliana".-RE, 24 (1965), 37-52.

18-5283. Segut, G.-"Relaciones del Cister y de San Bernardo con el Bto. Ramón Llull". - ELu, 8 (1964), 171-189. - V. núm. 14-40695.

18-5284. Sugranyes de Franch, R.- "Les projets de croisade dans la doctrine missionnaire de Raymond Lulle". $-\mathrm{NV}$, 37 (1962), núm, 2, 92-107.-V. núm. $16-47425$.

18-5285. SURANY, G.-B. DE - "Raymond Lulle alchimiste (1232-1315)"--Initiation et Science, Paris, 19 (1964), núm. $60,5^{6-60}$.

18-ว286. SORIA, V.-“La relación en el filósofo Raimundo Lulio". - UPB, 27 (1964), $5^{1-54}$.

18-5287. Antón Cuadrado, E. DE-"Plenitud metafísica de la filosofia luliana". $-E L u, 7$ (1969), 131-151.-V. núm. 181813.

18-5288. XIBERTA, B. M.-“El pressumpte racionalisme de Ramón Llull".-ELu, (1963), $153-165$.

18-万289. Erjo Garay, L.-“Las arazones necesarias del beato Ramón Llull, en el marco de su época".-ELu, 9 (1965), $23-3^{8}$.

18-丂29o. Colomer, E.-Nikolaus von Kues und Raimund Llull (N. 17-4652). I Archiv für Geschichte der Philosophie, 47 (1965), $10_{5}-109$ (Pring-Mill); Rev $P h_{2} L, 61$ (1963), $4^{8} 7-4^{89}$ (Van Steenberghen).

18-5291. Urmeneta, F. DE-“Sobre estética prerrenacentista". - RIEs, 22 (1964), 243-246. [Lulio y Nicolás de Cusa].
18-5292. Platzeck, E. W. - "Descubrimiento y esencia del arte del Bto. Ramón Lluil".-ELu, 8 (1964), 137-154.

18-5993. Rubió Balaguer, J.- "Sobre la prosa rimada en Ramón LIull".-EMP, $5,307-318$.

18-5294. Dolc,, M.-“"El sentiment de la natura en lobra rimada de Ramon Llull".-ER, 9 (1961), $15^{-27}$.

18-5995. Olrver, A. - "El beato Ramón Llull en sus relaciones con la escucla franciscana de los siglos XII-XIV", $-E L u$, 9 (1965), 59-7o.

18-5296. Gama Cafiro, F. DA-"Aportación para el estudio de las fuentes del pensamiento místico del Bto. Ramón Llull".-ELu 8 (1964), 39-41.

18-5297. Sala Molins, L.- "Le refus de l'identification dans la mystique lal lienne".- ELu, 9 (1965), 39-53, 181-192. 18-5298. Barcelona, A. de-"Llull i $\mathrm{e}^{1}$ doctorat de la Inmaculada".- $E L u, 8$ (1964), 5-16.-V. núm. 17-1189.

18-5299. Oliver, A.- "La Donatio Constantini en los escritos y en la mente de Ramón Llull".-ELu, 8 (1964), $155^{\circ}$ 170 .

18-5300. StrgmülLer, F. - "Raimundiana amcricana".-ER, 9 (1961), 29-48.

18-5301. García Pastor, Jesús, J. N. HillGart, y Lorenzo Pérfz Martínez Manuscritos lulianos de la Biblioteca Pública de Palma.-C.S.I.C., BarcelonaPalma de Mallorca, 1965. 176 pp. $-\mathrm{V}$. núm. $18-1806 / 7$.

18-5302. Lulli, R.-Opera latina, ts. 1-2 (N. 17-1195). $\| G r, 41 \quad(1963), 168 \cdot 171$ (Caminero); $\mathrm{BHi}, 66$ (1964), 442 (Llinarès); Études Philos., 16 (1961), núm. 97 (Llinarès).

18-5303. Lull, Raimend-Opera latina. T. 3-4: Liber de praedicatione. Edidit A. Soria Flores.-Maioricensis Schola Lullistica, Palmae Maioricarum, 19611963. $\mathrm{xx}+407$, xvi +649 pp.--V. núm. $17+1195$. If $R y F, 171(1965), 543-544$ (Iturrioz)

18-5304. RiEdLINGER, H.-“Ein wiedergefundenes werk Raimund Lulls aus der Zeit des Viennenser Konzils: De divina habentia",-ELu, 7 (1963), 181-188.

18-5305. Pring-Mill, R. D. F.- "Ramón Llull y la $D e$ divisione naturae".-FLu, 7 (1963), $167-180$.

18-5306. Pring-Mill, R, D. F.-“La estructura del Liber da natura del beato Ramon Llull".-Atti del III Congresso Internaz. di Filos. Medioevale (Trento, $1964), 566-575$. 
18-5307. Garcias Palou, S.-"Circunstancias históricas que inspiraron la composición del Tractatus de modo convertendi infideles del Bto. Ramón Llull". -ELu, 7 (1963), 189-202.

18-5308. Llull, R.-Antología (N. 171189). || BHi, $66(1964), 44^{2-443}$ (Llinarès).

18-53og. Pring-Mill, R. D. F.-Ramón Llull y el número primitivo de las dignidades en el "Arte general".-Dolphin, Oxford, 1963. 68 pp.-V. núm. 16-47421. || BHi, $66 \quad(1964), 443$ (Llinarès).

18-5310. DANDO, M. - "Deux traductions provençales partielles du Libre de doctrina pueril de Raymond Lulle associées à des remaniements de La somme le roi".-Ro, 85 (1964), 17-48.

18-5311. SANSONE, G. E.-"R. Llull narratore" (N. 16-47429). \|LR, 19 (1965), 57 (Groult).

18-5312. Carreras ArtaU, J.-"En torno al primer siglo del lulismo".-ELu, 8 (1964), 83-9o.

18-5313. Hillgarth, J. N.-“Some notes on Lullian hermits in Majorca saec. XIII-XVII".-StMo, 6 (1964), 299-328.

18-5314. Alrareda, A. M. - "Lullisme a Montserrat al segle xve. L'ermità Bernat Boil". $-E L u, 9$ (1965), 5-21.

18-5315. Madurell Marimón, J. M.-"La escuela de Ramón Lull, de Barcelona. Documentos".-ELu, 8 (1964), 93-117.V. núm. $17 \cdot 4659$.

18-5316. Batllori, M.-"Giovanni Pico e il lullismo italiano del Quattrocento". -[En:] L'opera e il pensiero di Giovanni Pico della Mirandola (Firenze, 1965), t. 2, $7-16$.

18-5317. Trías Mercant, S. - "Las tesis filosóficas en la Universidad luliana”. $-E L u, 8$ (1964), 191-214; 9 (1965), $8_{5-}^{-}$ 92, $207 \cdot 227$.

18-5318. Pons, A.-“Mn. Mateu Gelabert, ferm apologista de Ramón Lluli".ELu, 6 (1962), 83-104.

18-5319. Madurell Y Marimón, J. M."Desmanes antilulianos". - ELu, 7 (1963), $209-216$.

18-5320. BAADER, H. - "Ramon Lull und die spanische Aufklärung".-FFS, $355^{-}$ 379. |l $Z R P h, 80$ (1964), 573 (Hatzfeld). 18-5321. Olabarrieta, Miriam Thérèse The influence of Ramon Llull on the style of the early Spanish mystics and Santa Teresa.-Catholic Univ, of America Press, Washington, 1963. $\mathrm{x}+183 \mathrm{pp}$. (Catholic Univ. of America Studies in
Romance languages and literatures, 67 ). -V. núm. 18-1824. || BHi, 66 (1964), 227-228 (Ricard).

V. también núm. 7614 .

18-5322. ["Arnaldo de Vilanova"].-Archivo Ibero-Amer. de Hist. de la Medicina, 11 (1959), 433-437.

18-5323. Carreras I Artau, J.-“L'Expositio super Apocalypsi d'Arnau de Vilanova. Autenticitat, data i lloc de composicio".,-ER, 8 (1961), 49-55.

18-5324. Trentman, J. - "Vincent Ferrer on the logician as artifex intellectualis". -Franciscan Studies, 25 (1965), 322337.

18-5325. ANTA JARES, José - La predicación cristiana en la doctrina de San Vicente Ferrer (I350-I4I9).-Seminario Conciliar, Astorga; Eset, Vitoria, 1963 . $110 \mathrm{pp}$.

18-5326. Rubió, J.-“Guillem Ponç, secretari del rei Martí, contemporani de Bernat Metge".-ER, 9 (1961), 67-84. Ausias March: v. núm. $595^{2}$.

18-5327. Wrtrtin, K. - "Guillem de Copons i la seva traducció del Trésor de Brunetto Latini". - BSCC, 39 (1963), núm. 4 .

18-5328. Torrents Llorens, María Luisa - La obra poética catalana de Pere Torroella.-[Tesis, Univ. de Barcelona, $1963]$.

18-5329. Llompart, Josep M.-Joan Alcover. (La història d'un home). - Obra Cultural Balear, Mallorca, 1964. $30 \mathrm{pp}$. [Conferencia].

18-5330. Bonet Balta, JuAn-El sacerdot poeta Jacinto Verdaguer.-Autor, Barcelona, $1964.170 \mathrm{pp}$.

18-5331. Verdaguer, Jacinto-Obras completas. $4^{\text {a }}$ ed. Pròleg: La poesia de J. V., per Marià Manent; epìleg: El sacerdot poeta, per L. Guarner. $4^{\text {a }}$ ed., posada al dia per $\mathrm{J}$. Miracle $\mathrm{i}$ A. Boada.-Selecta, Barcelona, 1964. Xxiv+1578 pp., 16 láms. (Biblioteca perenne, 1).

N. Oller: v. núm. 7265 .

18-5332. VERGÉS FÁBREGAS, J.-"El clasicismo de Costa i Llobera".-Actas del II Congreso español de estudios clás. (Madrid, 1964), $542-547$.

18-5333. Arimany, Miquel - Maragall 1860-1911-1961. - Arimany, Barcelona, 1963. 266 pp. || Ins, 1964, núm. 207 (Tasis).

18-5334. Benet, Josep - Maragall davant la setmana tràgica.-Edicions 62, Barcelona, 1964. 208 pp., láms.-V. núm. 181841 . 
18-5335. Castellet, J. M.-"Sobre Maragall y la semana trágica".-CuD, 1964 , núms. $7,8,14$.

18-5336. JARDf, E.-"Maragall i Ors. Dos temperaments. Dues generacions".-SO, 6 (1964), núm. 8.

18-5337. Valentí Fiol, E.-“Maragall y los clásicos".-Actas del II Congreso español de estudios clás. (Madrid, 1964), $531-541$.

18-5338. Terry, Artur - La poesía de Joan Maragall. - Barcino, Barcelona, 1963. 226 pp. || BHS, 42 (1965), 129130 (Ribbans).

18-5339. Ferreres, R. - "La noche tenebrosa de Joan Maragall".-Atl, 1964, núm. 9, 310-316.

18-5340. FUSTER, JOAN-Las originalidades. Maragall y Unamuno frente a frente. Trad. de Ana Ramón de Izquierdo.Cruz del Sur, Santiago de Chile; Ariel, Barcelona, 1964. 116 pp. (Renucvos de Cruz y Raya, 14).

18-5341. Fuster, J. - "Frente a frente: Unamuno, Maragall". $-I A L, 1964$, núm. 192,-V. núm, 16-45628.

18.5342. Saltor, O.- "Unamuno y Maragall".-CuD, 1964, núm. 13 .

$V$. también núms. $595^{1}, 7663$.

18-5343. Vidal IsERN, J.-“Miguel de los Santos Oliver",-ROcc, 7 (1964), 240244 .

18-5344. Porqueras Mayo, A.-"La ben plantada, de d'Ors. Una meditación de catalanidad".-Atl, 2 (1964), 549-556.

18-5345. D' ORs, Eucenio-La bien plantada.-Eds. R, La Habana, 1964. (Bibl. básica de lit. española).

V. también núms. 5336, 5347, 6268, $7601-9,7614$.

18-5346. Tiempo, C. - “E1 gran poeta Josep Carner, un eupátrida en Bruselas".-Galaxia, Bruxelles, 1964, 11-13.

18-5347. Garriga i Miró, R.-"Josep Carner en el pensament d'Eugeni d'Ors".SO, 7 (1965), núm. 2.

18-5348. Calders, Perf-Josep Carner. Alcides, Barcelona, 1964 . 80 pp. (Biografies populars, 15).

18-5349. Homenaje a Josep Carner.-SO, 7 (1965), múm. 2. [Colaboran A. Manent, J. Oliver, J. V. Foix, J. Teixidor, J. Molas, J. Sarsanedas, R. Garriga i Miró, J. Triadú et al.].

18-535o. CARner, José - Fenosa. L'hamia. driade del violi.-Autor, Valencia, 1964 . 10 pp. +5 láms.

18-5351. Manent, Albert - Carles Riba. -Elcide, Barcelona, 1963. 80 pp. (Bio. grafies populars, 10). \|Ins, 1964, núm. 2 I 4 (Crusat).

18-5352. Alsina Clota, J.- "Carles Riba ante el mundo helénico".-Actas del II Congreso español de estudios clás. (Madrid, 1964), 467-474.

18-5353. VAlentf I Fiol, E.-“Carles Riba i la seva traducció de l'Odissea",-ER, 9 (1961), 127-137.

18-5354. Sagarra, Josep M. DE - Obres completes. T. 4: Teatre: La ferida lluminosa, La paraula de foc, El pobre d'esperit, Soparem a casa, El senyor Perramon, El fiscal Requesens, Cinc traduccions. Epileg de Jordi Carbonell. -Selecta, Barcelona, 1964, $1408 \mathrm{pp}$. (Biblioteca excelsa, 12).-V. núm. 8-12750. 18-5355. Sagarra, José María de-la herida luminosa. Versión y adaptación de José Ma Pemán.-Alfil, Madrid, 1964. 70 pp. (Col. Teatro).-V. núm. 1 $1-263_{3} 63$.

18-5356. SAGARRA, JOSEP M. DE-Memèries. Pròleg de Miquel Batllori. $2^{\mathrm{a}}$ ed. Aedos, Barcelona, $1964.88_{4}$ pp. (Biblioteca biográfica catalana, 7). - V. núm. 10-23177.

18.5357. Foix, J. V. - Obres poèliques. Amb un pròl. del mateix autor.-Nauta, Barcelona, 1964. (La paraula viva). 18-5358. Forx, J. V.-Antología lirica. Est., sel. y versión de Enrique Badosa.-Ado. nais, Madrid, 1963. 127 pp. (Adonais, 212-213). || Ins, 1965, núm. 218 (Crusat); $R O c c, 9$ (1965), 247-253 (Crusat); Agora, $1963-64$, núms. $85 / 93$ (Mantero); CuH, 59 (1964), $4^{11-413}$ (Quiñones).

18-5359. Esclasans, Agustí -Antologia de ritmes inèdits (1955-1964). Pròl. de l'autor sobre Catalunya $i$ el noucentisme literari (Igo6-1964). - Barcelona, 1964. $104 \mathrm{pp}$. (Obres completes).

18-5360. Esclasans, Agusti-Cants de la flama vital (1958-1963). Amb un pròleg doctrinal de l'autor sobre La tercera versió del Poema de Catalunya (19251926).-Autor, Barcelona, 1964. $10_{4}$ pp. (Obras completas).

18-5361. Ferrer, J. M.-“Sobre lobra de Pere Quart".-SO, 7 (1965), núm. 3.

18-5362. Pere QuART-Obra de...-Fontanella, Barcelona, 1963. 304 pp.

18-5363. Bartra, Acustín-Ecce homo. Joaquín Mortiz, México, 1964. 74 pp.

18-5364. Calafat, José-Poesies, Ed. i pròl. de Miquel Dolç.-Moll, Palma de Mallorca, 1964. 123 pp. (Les illes d'or, 84). 
18-5365. CID, F. - "Salvador Espriu, 1'home i el poeta”.-SO, 6 (1964), núm. 4. 18-5366. Molas, J.-“La poesía de Salvador Espriu".-SO, 6 (1964), núm. 4. 18-5367. Espriu, Salvador - La piel de toro. La pell de brau. Texto catalán y trad. castellana de J. A. Goytisolo.Ruedo Ibérico, París, 1963. $208 \mathrm{pp} . \mathrm{V}$. núm. 18-1 86 \}.

18-5368. Melíndrez Mata, Pilar-"Primera historia de Esther", de Salvador Espriu. - [Tesis, Univ. de Barcelona, 1969].

18-5369. Miracle, JoSEP - 60 minutos. Selecta, Barcelona, 1963. 268 pp. (Biblioteca Selecta, 344).

18-537o. Espinás, JOSEP M.-El último rellano. Trad. por Fernando Gutiérrez.Destino, Barcelona, 1963.181 pp. $-V$. núm. 17-4696. \| $R y F, 170 \quad(1964), 135$ (Castro y Delgado).

18-5371. EspiNÁs, Josep M.-Dotze bumerangs. $2^{\text {a }}$ ed.-Alberti, Barcelona, 1964 . 196 pp. (Col. Perfil, 1).

18-5372. Triadú, JoAN - Lectures escollides. Textos literaris catalans amb comentaris gramaticals. Sel. i presentació dels textos per..., anotació gramatical per Eduard Artells. Primer recull.Barcino, Barcelona, 1963. 136 pp. (Col. popular Barcino, 201).

18-5373. Triadú, JoAN-Llegir com viure. -Fontanella, Barcelona, 1963. 234 pp. (Perspectives).

18-5374. Bonet, BLAI-Judes $i$ la primavera.-Selecta, Barcelona, 1963. $245 \mathrm{pp}$. (Bibl. selecta, 343).

18-5375. Fuster, JOAN-Nosaltres, els valencians. $2^{\text {a }}$ ed.-Edicions 62, Barcelona, 1964. 240 pp. (A l'abast, 1). || ROcc, 4 (1964), 119-123 (Manent).

18-5376. Fuster, JoAN-Qüestió de noms. - Ed. "Diccionari Catala-Valencià-Balear", Barcelona, 1963 .

18-5377. FUSTER, JOAN-Diccionari per a ociosos.-A. C., Barcelona, 1964. 206 pp. (Cara i creu, 1).

18-5378. Villalonga, Llorenç - Aquil.les o l'impossible. Alta $i$ benemèrita senyora. - Moll, Palma de Mallorca, 1964. 143 pp. || BAbr, $39(1965), 371 \quad(\mathrm{de}$ Boer).

18-5379. Villalonga, Llorenç - Bearn. $2^{\text {a }}$ ed.-Club Editor, Barcelona, 1964. 290 pp.

18-5380. Villalonica, LloREnç - Desenllaç a Montlleó. - Club Editor, Barcelona, 1963. $106 \mathrm{pp}$.

18.5381. Serrahima, Llus--Com el mar.-
Ossa Menor, Barcelona, 1963. II Ins, 1964, núm. 211 (Crusat).

18-5382. Tubau, I.-"Un catalán de los cotros», Candel". - IAL, 1964, núm. 186.

V. también núms, 4298, 5186, 6013.

\section{Gallega y portuguesa}

I 8-5383. Fernandes, R. R.-“Achegas para a bibliografia de António José Viale, Epifânio Dias, José Maria Rodrigues e José Joaquim Nunes".-RFL, 8 (ig64), $179-206$.

18-5384. Malpique, C. - "Ricardo Jorge, tripeiro $100 \%$ ".-Trip, 4 (1964), 203210.

18-5385. Lorenzana, S.-"Rodrigues Lapa e a cultura galego-portuguesa".-Grial, $1964,139^{-1} 5^{8}$.

18-5386. Veloso, F. J.-“"Galeria de lusófilos: Ernesto Guerra da Cal, um lusófilo galaico-americano". - $G V, 13$ (1962), núms. $5 / 6$.

18-5387. MOREAU, J.-"Penseurs et provinces de Portugal".-BBudé, 1964, núm. 2, $23^{6-25} 5^{1 .}$

18-5388. Mourāo-Frrreira, D. - "Para uma visão poligonal da literatura [portuguesa]".-Esp, 1964 , núm. 1 .

18-5389. Grossmann, R. - "Portugiesische Literatur". - [En] W. H. FrIEDRICH u. W. KiLly (eds.), Literatur I (Frankfurt, 1964$), 239^{-25}$.

18-539o. Meier, H.- "Die Literaturen in portugiesischer Sprache".-[En] Die $\mathrm{Li}$. teraturen der Welt (Zürich, 1964), 395423.

18-5391. Ferreira, Joaqum - História da literatura portuguesa. $3^{\text {a }}$ ed.-Domingos Barreira, Porto, 1964. 1206 pl.

18-5̌392. Carvalhão Buescu, Maria leoNOR-Apontamentos de literatura portuguesa. - Porto Editora, Porto-Lishoa, 1964. $168 \mathrm{pp}$.

18-5393. Renault Pinto, Dinah S.-Pequena história da literatura portuguê. sa.-Melso, Rio de Janeiro, 1964. 383 pp.

18-5394. Rodrigues LApA, M. - Lições de literatura portuguesa. Epoca medieval. $5^{\text {a }}$ ed., rev.-Coimbra Editora, Coimbra, 1964. $43^{6}$ pp. $-V$. núm. 11-27963.

18-5395. Nemésio, Vitorino (ed.) - As grandes polémicas portuguesas. Com pref.-Verbo, Lisboa, 1964. [Ensayos de Cidade, M. Martins, J. Pina Martins, P. Ramos, Mourão-Ferreira, Manuppella et al., sobre los cancioneros, Sá 
de Miranda, Ferreira, D. Francisco Manuel, Verney, et al.]. || Bro, so (1965), 215-219 (Maia).

18-5396. MATos, L. DE-“A expansão maritima e a metáfora portuguesa".-Esp, 1964 , núm. 1 .

18-5397. Guy, A.-"Progrès et lumière de la pensée portugaise à la Renaissance". -RFL, 8 (1964), 41-64.

18-5398. BRAGa dA Cruz, M. A.-"Palito métrico e macarrónea latino-portuguesa".-ABP, 9 (1963), 1-7.

18-5399. Appolis, E. - "Mystiques portugais du Xvire siècle: Jacobéens et $\mathrm{Si}$ gillistes".-AESC, 19 (1964), $3^{8-54}$.

18-5400. Neves Lrma, A. N. D. R.-"Contribuição para o estudo de $O$ livro romántico em Portugal'., $A B P, 9$ (Ig63), $64-97$.

18-5401. Campos, M. DE-“Coisas de há um século: o Grémio Literário Portuense".--Trip, 4 (1964), 133-134.

18-5402. Poupart, R.- "Le Portugal pré symboliste sous le signe de Baudelaire". -Mémoires et Publications de la Socièté des Sciences, des Arts et des Lettres du Hainaut, Mons, 78 (1964), 21 $3^{6 .}$

18-5403. Forjaz Tricueiro, L.-"Do realismo português ao regionalismo brasileiro".-BAL, $3^{6}$ (1964), 94-110.

18-5404. Quadros, ANTónio - Critica $e$ verdade: introdução à alual literatura portuguesa. - Livraria Clássica, Lisboa, 1964. 282 pp. || Bro, 78 (1964), 709-714 (Maia); $S N, 1964$, núm. 1428, 181-182 (Prado Coelho).

18-5405. Ribeiro Alves Júnior, José Estudos de investigação cientifica, lite. rária $e$ histórica, Ed. definitiva refun. dida e coligida por assuntos.-Câmata Municipal, Castro-Marim, 1964. 82 pp. (Obras completas, 3 )

18-5406. Simões, JoÃo GaSPar-Literatura, literatura, literatura... (De Sá de Miranda ao concretismo brasileiro).-Portugália, Lisboa, 1964 .

18-5407. Régio, Joś⿺-Ensaios de interpretação crítica. Camões, Camilo, Florbcla, Sá-Carneiro.-Portugália, Lisboa, 1964 . $24^{8}$ pp. (Obras completas). UOcid, 67 (1964), 280-281 (J. B. P.).

18-5408. Alves das Neves, JoÃo-Temas luso-brasileiros, - Comissão Estadual de Literatura, São Paulo, 1964. 116 pp.

18-5409. Vita, Luís Washington-Monólogos e diálogos. - Conselho Estadual de Cultura, Sáo Paulo, 1964. [Incluye un ensayo sobre Ortega y Gassct].
18-5410. Rocha Pereira, M. H. Da-“O mito de Medeia na poesia portuguesa". $-H u C, 15^{-16}\left(1963^{-64}\right), 34^{8-366 .}$

18-5411. Osswald, M. - "A concepção de $O$ herói na literatura femenina em Portugal". - Humboldt, 1964, núm. 5. 18-5412. Valle Cintra, M. A.-Bibliografia de textos medievais portugueses (N. 17-1237). || $M A, 70$ (1964), 131-135 (d'Heur); Bro, 72 (1961), 247 (Gameiro). 18-5413. VAsilieva-Shvede, Olga, \& AnaTÓlIO GACH - Antologia da literatura portuguesa e brasileira. - Universidade Estatal, Leningrado, 1964. $291 \mathrm{pp.} \mathrm{II}$ PhP, 8 (1965), 446-447 (Hampl).

18-5414. Quintela, Fernando, e Mário Fiúza - Textos literários portugueses anotados, Para retroversões francesas.Livraria Povoense, Póvoa de Varzim, 1964. $6 \mathrm{~g}$ pp.

18-5415. Osório de Oliveira, José-Beira Litoral.-Bertrand, Lisboa, 1964. 170 pp. (Antologia da terra portuguesa).

18-5416. SIMÕES, JoÃo GASPAR - Itinerário histórico da poesia portuguesa. De $x I 89$ a 1964.-Arcádia, Lisboa, 1964. 400 pp. (Biblioteca Arcádia de bolso, 31-32).

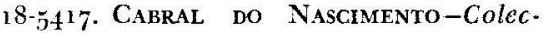
tânea de versos portugueses do século xii ao século $x x$. - Minerva, Lisboa, 1964. 222 pp. (Col. Calavento, 12).

18-5418. Correia, Natália - Antologia da poesia portuguesa erótica e satirica. Dos cancioneiros medievais à actualidade. Ed. de F. Ribeiro de Melo.-Afrodite, Lisboa, [1965?]. $551 \mathrm{pp}$.

18-5419. Tavares Rodrigues, U. - "Os poetas pré-simbolistas portuguêses: seu estado de espírito e suas unidades estéticas".- $J L A, 7$ oct. $1964,2,8$.

18-5420. D'Alge, C.-"Aspectos da moderna poesia portuguêsa".-Clä, Fortaleza, 16 (1964), núm. 2o, $133^{-1} 5^{1}$.

18-5421. LuPI, N.-“A expansão do lirismo português no mundo".-APCE, 2, 265274 .

18-5422. Pimentel, L. M. - "Subsídios para uma bibliografia dos modernos poetas caboverdianos".- $A B P, 9$ (1963), 8-32.

18-5423. Stegagno Picchio, Luclana Storia del tealro portoghese.-Ed. dell'Atenco, Roma, 1964. xi + 410 pp., ilustr. || Ins, 1964, núms. 216/7 (Ares Montes); $B E P, 25$ (1965), 270-273 (Frèches \& Teyssier); $R F, 77$ (1965), 216218 (Hess); $H, 4^{8} \quad(1965), 943$ (Martins); Bro, 81 (1965), 289-290 (Mauricio); $C u N, 24$ (1964), 304 (Menichetti). 
18-5424. Pinto Loureiro, José-O teatro em Coimbra. Elementos para a sua história.-Câmara Municipal, Coimbra, 1964. $4^{13} \mathrm{pp}$.

18-5425. Matos, L. DE-"Teatro de cordel".-BIB, 5 (1964), 640-659. [Folletos del siglo xviri; reproducción facsimilar de un entremés].

18-5426. Campos Coroa, Emílo-O teatro amador em Faro 1845-1964.-Grupo de Teatro do Círculo Cultural do Algarve, Faro, 1964. 62 pp.

18-5427. Rossi, G. C.- "Narrativa portoghese di oggi". $-N A, 1964,415417$.

18-5428. Margarido, A., \& A. Portela FilHo-O novo romance (N. 17-4795). II Bro, 79 (1964), 201-205 (Alves Pires).

18-5429. Cordeiro Melo, A. Claro Ceia, Ruy de Moura Guedes, e Mariano CAlado-Contos portugueses. - Edit. Técnica e Artística, Lisboa, 1964. $23^{6}$ pp. (Col. $A B Z$ ).

18-5430. Cruz, Frederico - Antologia do jornalismo portugués. T. 1: I90o-rgog. -Instituto de Angola, Luanda, 1964. $3^{86} \mathrm{pp}$.

V. también núms. 4320, 5197, 5199-亏201, $5206,5226-30,5945,6504,75^{\circ}$.

$A u t o r e s \quad a n t i g u$ os

18-5431. Sousa, Thomas Frederic- $A$ linguistic analysis of a portion of the $\mathrm{Ga}$ lician translation of the "General estoria" by Alfonso X, el Sabio.-[Tesis, Univ. of Wisconsin; resumen en $D A$, 24 (1963-64), 5418]. $371 \mathrm{pp}$.

18-5432. Martins, M.-"História do Pre. destinado peregrino e seu irmão Precito".-Bro, 78 (1964), 697-7o8.

18-5433. Corbin, S.-La déposition liturgique du Christ au Vendredi Saint (N. 17-4740). $\| S p, 39$ (1964), 130-136 (Pope).

18-5434. Assis Pereira, C. DE-"Trasladação dos corpos de Sāo Bento e sua irmã Santa Escolástica (parte do cód alcobacense 287$)^{\prime \prime} \cdot-R L S P, \quad 5 \quad\left(19^{6} 4\right)$, $5^{2-65}$.

18-5435. Martins, M. - "Fábulas perdidas".-Bro, 79 (1964), 160-167.

18-5496. Martins, M.-"Um livro de horas da Rainha Santa?"-Bro, $7^{8}(1964)$, 439-445.

18-5437. MALer, Bertil-Orto do esposo. T. 3: Correç̧óes dos ts. $I$ e 2, estudo das fontes e do estado da lingua, glos. sário, lista dos livros citados $e$ indice
geral.-Almqvist \& Wiksell, Uppsala, 1964. 161 pp. $-V$. núms. 12-31223.

18-5438. Martins, M. - "Experiência religiosa e analogia sensorial". - Bro, 78 (1964), 552-561. [Sobre el Horto do es. poso].

18-5439. Martins, M.-"Das doze abusões deste mundo".-Bro, $7^{8}$ (1964), 43-45 [E1 Horto do esposo].

18-5440. Martins, M. - "Destemporalizaçāo".-RPFB, 20 (1964), 197·209. [Sobre cl Horto do esposo].

18-5441. Gomes Filho, Antônio (ed.) U'm tratado da cozinha portuguêsa do século $x v$. Introd. de A. G. Cunlia.Inst. Nacional do Livro, Rio de Janeiro, 1963. (Dicionário da lingua portuguésa, textos e vocabulários).

18-5442. Crfspo, F.-“A tradiçāo lírica popular antes e depois dos trovadores".$E C B, 1964$, núm. 13, 42-47. [Cancioneiros].

18-5443. Plereira, A.-“O refrão e os seus problemas".-BCL, 1969, 179-200. [En la lírica medieval].

18-5444. Holliday, F. - "Extraneous elements in the cantiga de amigo".- RFL, $8(1964), 151-160$.

18-5445. DAvis, W. M.-“Análise literária de uma cantiga de Dom Denis".- $L B R$, 1 (1964), núm. 2, 51-61.

18-5446. Anglès, H.- "Les càntiques montserratines del rei Alfons el Savi i la seva importància musical".-AMon, 49 (1962), 19-32.

18-5447. REALI, E.-"Le cantigas di Juyão Bolseyro". - AION-R, 6 (1964), 237 335 .

18-5448. Costa Lopes, A. DA-"A naturalidade portuguesa do jogral Martim de Ginzo",-DB, 2 (1964), $177^{-188}$.

18-5449. Cirillo, Pasqualina - Il canzo. niere di Pero Meogo.-[Tesis de la Lniv. de Nápoles, 1964]. 93 pp.

18-5450. DutTon, B.- "Lelia doura, edoy lelia doura, en Arabic refrain in a thirteenth-century Galician poem?" BHS, 41 (1964), $1-9$.

$18-5451$. Crespo, F. DE D. - "O estranho refrão de uma cantiga trovadoresca". Ocid, 67 (1964), 63-68. [Sobre lelia doura..].

18-5452. Askins, Arthur LeE-A critical edition and study of the "Cancioneiro de Evora", in manuscript CXIV/I-I7 of the Public Library of Evora, Portugal.[Tesis, Univ, of California, Berkeley; resumen en $D A, 24 \quad(1963-64), 5403$ 5404]. $179 \mathrm{pp}$. 
18-5453. Craveiro da Silva, L.-“O agostinismo politico no Speculum regum de Alvaro Pais".-Bro, 79 (1964), $14^{1-}$ 147; $B A u, 18 / 19$ (1965), 312-318.

18-5454. Pais, Álvaro-Espelho dos reis. Estabelecimento do texto e tradução de Miguel Pinto de Menezes. T. 2,-Instituto de Alta Cultura, Lisboa, 1963. 528 pp.-V. núm. 11-27977.

18-5455. Macchr, G.-"Bibliografia di Fernão Lopes".-CuN, 24 (1964), 210287 .

18-5456. Lindley Cintra, L. F.-“Nótula sobre os manuscritos das obras de Fernão Lopes".-Co, 1964 . núm. 29.

18-5457. MACchI, G.-"Di alcuni manoscritti finora sconosciuti delle cronache di Fernão Lopes".-CuN, 24 (1964), $103^{-110 .}$

18-5458. Dias da Silva, Richard-Les connaissances et les opinions de Fornão Lopes sur le monde extérieur au Portugal au xviio siècle. - [Tesis, Paris, $\left.196_{4}\right]$.

18-5459. Santos, R. Dos - "As iluminuras da Crónica de $D$. João $I$ de Fernão Lopes em Madrid".-Co, 1964 , núm. 29. 18-5460. Lopes, Fernão - Crónica de $\boldsymbol{U}$. Pedro.-Civilização, Porto, 1964. $240 \mathrm{pp}$. (Biblioteca histórica de Portugal e Brasil).

18-5461. Belo, R.-"Fernão Lopes, estilista. A propósito da metáfora o evangelho português".-Rumo, 1964 , núm. 84 , $144^{-149}$.

18-5462. MarTins, M.-"Fernão Lopes e as cartas de Ariadna e Dido".-Bro, 79 (1964), 298-302.

18-5469. Rogers, F. M. - The travels of the Infante Dom Pedro de Portugal (N. $17 \cdot 4814)$. || $I B, 9$ (1963), 649-651 (Dias Dinis); $R L C, 3^{8}$ (1964), $14^{6-1} 4^{8}$ (Imbert); $M L R, 60$ (1965), 132-133 (Russell); $I . B R, 1$ (1964), núm. 2, 108-110 (Spina). 18-5464. Eanes de Zurara, G.-Chronique de Guinée (N. 17-1291). II $L N L, 19^{64}$, núm. 2, 110-111 (Marcus).

18-5465. Eanes de Zurara, Gomes-The chronicle of the discovery and conquest of Guinea. Transl. by Charles Raymond Beazley and Edgar Prestage.-Franklin, New York, 1964. 2 ts.

18-5466. Almeida Calado, Adelino de Frei João Ảvares: estudo textual e literário-cultural.-Coimbra, 1964 .

18-5467. Barradas de Carvalho, J.-“A decifração de um enigma: o título $E s$ meraldo de situ orbis". - RHSP, 28
(1964), 339-348. [Pacheco Pereira],--V. núm. 18-1949.

18-5468. Barradas de Carvalho, J.-"As edições e as traduções do Esmeraldo de situ orbis".-RHSP, 29 (1954), 67-8o.

18-5469. Barradas de Carvalio, J.-"O Esmeraldo de situ orbis de Duarte Pacheco Pereira na história da cultura". - RHSP, $29 \quad(1964), 291-307$.

18-5470. Mendes DE Almeida, J.-"Princípio do Esmeraldo de situ orbis feyto e composto por Duarte Pacheco..."Bol. da Sociedade de Geografia, Lisboa, 82 (1964), $187-195$.

18-5471. STEN, H. - "Gil Vicente et la théorie de l'art dramatique".--OL, 3 (1963), supl., 209-219.

18-5472. Pestana, S.-“Estudos gilvicentinos".- $R P, 29$ (1964), 101-109, $468-473$; 30 (1965), 14-18. - V. núm. 18-1951.

18-5473. RECKERT, S.-“Marginalia yicentina. Três apostilas". $-R F L, 8$ (1964), $274-280$.

18-5474. Saraiva de Carvalho, A.-'Dialogo com Gil Vicente. $O$ poeta $\mathrm{e}$ a his. tória". - GV, 15 (1964), 49-54,75-81, $147^{-1} 5^{8}, 169-180$.

18-5475. Teyssier, P.-La langue de Gil Vicente (N. 16-47601). II RPh, 17 (196364), 8og-813 (Herculano de Carvalho). $-V$. núm. $17-4^{8} 19$.

18-5476. Almeida Pavão, J.-Gil Vicente poeta.-Ponta Delgada, 1964. $196 \mathrm{pp}$. I Ocid, 68 (1965), $4^{6}$ (A. C.).

18-5477. Tomliss, J. E.-"Una nota sobre la clasificación de los dramas de Gil Vicente".-DHR, $3 \quad(1964), 115-131 ; 4$ $\left(196_{5}\right), 1-16$.

18-5478. WARdROPPER, B. W.-“Approaching the metaphysical sense of Gil Vicente's chivalric tragicomedies". $-B C$, 16 (1964), núm. 1, 1-9.

18-5479. SAMPAio, J. DE - "Dramaturgia mariana em Gil Vicente".-Pan, 1964, núm. 12, 28-32.

18-5480. Ramos, M. M.-"Gil Vicente e o folclore". - BCL, $1964,337-35^{2}$. - V. núm. 18-1953.

18-5481. Alonso, D.- "E1 hidalgo Camilote y el hidalgo Quijote".-SOE, 2o28.

18-5482. Álvarez BlázQuez, X. M.-"Gil Vicente e Galicia. I. O conto das dúas lousas".-Grial, 1964, $235^{-239}$.

18-5483. VICENTE, GIL - Obras dramáticas castellanas. Ed. T. R. Hart.-EspasaCalpe, Madrid, 1962 . $1 \mathrm{xi}+278 \mathrm{pp}$. (Clàs. cast., 156). \| RPh, 18 (1964-65), 521-522 (Askins); $R P, 28$ (1963), 114 
(Machado); $H, 4^{6}$ (1963), 170-171 (Moser); HR, 32 (1964), 164-169 (Stern); $M L N, 79$ (1964), $5^{61-564}$ (Tomlins). 18-5484. Vicente, GiL - Auto da alma. Leitura, sintese, comentário e. glossário de Manuel dos Santos Alves.-Atlântida, Coimbra, 1964. 96 pp. (Col. Estudo, 2).

18-5485. HART, T. R.- "La estructura dramática del Auto de Inês Pereira". NRFH, 18 (1965-66), 160-165.

18-5486. SPItzer, L.-“La unidad artística del Auto da Sibila Casandra".-[En] Sobre antigua poesia española (Buenos Aires, 1962), 106-128. - V. núm. 1440775 .

18-5487. Vicente, GiL-Comedia del viudo. Ed., pról. y notas de Alonso Zamora Vicente. - Lisboa, 1962. $9^{8}$ pp. (Publicações do Centro de Estudos Filológicos, 13). || RLR, 75 (1963), 290-291 (Guiter); $N, 47$ (1963), $157-158$ (De Jong); $\mathrm{BHi}, 66$ (1964), 225-227 (Molho); RPF, 12 (1962-63): 769-770 (Moura Santos); RHM, 29 (1963), 76 (Sayers) ; $H R$, 31 (1963), 359-962 (Stern); RJ, 16 (1965), 285-387 (Tavani); Bro, 75 (1962), 246-247 (Veloso) .

18-5488. Vicente, GiL-Pranto de Maria Parda. Introd., ed. c commento di L. Stegagno Picchio. - Napoli, 1969. $\left[=A I O N-R, \quad 5,35^{-126}\right] . \quad|| B E P, 25$ (1964), 273-277 (Révah).

18-5489. Oliveira, Jonquin DE-Humanidade e grandeza do "Velho da horta". -Ocidente, Lisboa, $19^{6} 4.9^{6} \mathrm{pp}$.

18-5490. Berardinelli, Cleonice (cd.) Auto de Vicente Anes Joeira. Ed., introd., notas e vocabulário.-Instituto Nacional do Livro, Rio de Janeiro, 1963. 154 pp.

18-5491. Berardineli, C.-“o auto de Vicente Anes Joeira".-1b, núm. 6.

18-5492. Duarte, Infante D. (arcebispo de Braga)-Oração em louzor da filosofia. Pref,, actual. ortográfica e notas de Pinharanda Gomes. - Boletim de Trabalhos Históricos, 23 (1963), 7o100.

18-5493. Pina Martins, J. V. De-“Fr. António de Beja, discípulo de Pico della Mirandola".-RFL, 8 (1964), 91-142.

18-5494. Machado, J. P.-"Versão desconhecida de uma carta de João de Barros". $-R P, 29$ (1964), $175^{-1} 8_{3}$.

18-5495. Rego Martins, Atílio Alfredo -Subsidios para uma edição critica da "Asia" de João de Barros. T. 2.-Braga. 1963. 79 pp.
18-5496. Barros, J. DE-Diálogo em louvor da nossa linguagem (N. 16-43768). I| $A$ GIt, 47 (1962), 81-84 (Terracini).V. núm. 17-4824.

18-5497. Martins, A.-“O catolicismo de Garcia de Orta".-Bro, 77 (1963), 35$4^{6}$.

18-5498. Fraga de Azevedo, J.-"Significado e projecção da obra de Garcia d'Orta".-Jornal da Soc. das Ciências Médicas, 128 (1964), núm. $5,265-230$. 18-5499. Neves Tavares, C. Das-"Garcia de Orta e o Colóquio dos simples".-Ciência, 1964, núm. 3, 134-144.

i 8-5joo. Garcia DA Orta.-Tratado das drogas e medicinas das Indias Orientais. Versão portuguesa. - Junta de Investigações do Ultramar, Lisboa, 1964. xliii $+35^{6}$ pp., ilustr.

18-5501. Boxer, Charles Ralph - Tao pioneers of tropical medicine: Garcia d'Orta and Nicolas Monardes. - The Hispanic \& Luso-Brazilian Councils, London, 1963. $3^{6} \mathrm{pp}$. (Diamante, 14) || $\mathrm{BHi}, 67$ (1965), 200-201 (Cantel); BHS, $4^{1}$ (1964), 265-266 (Lamb); $H A H R, 45$ (1965), 162-163 (Tambs).

V. también núm. 5237 .

18-5502. Verfssimo Serrão, J.-“D. Bartolomeu dos Mártixes e a sucessão de $1580 ",-A P K, 4$ (1964), 261-2\%2.

18-5503. Almeida Rolo, Ravl de-O bispo e sua missão pastoral segundo $D$. Frei Bartolomeu dos Mártires.-Movimento Bartolomeu, Porto, 1964. $3^{88}$ pp. (Bibl. Verdade e Vida).

Montemor: v. núm. 6079 .

18-5504. Ribeiro Chiado, António-Prática dos compadres. Ed. fac-similada. Introd. de Luciana Stegagno Picchio. -O Mundo do Livro, Lisboa, 1964. 44 pp.

18-5505. Frutuoso, Gaspar - Saudades da terra. Livro VI.-Instituto Cultural, Ponta Delgada, 1963 .

18-5506. Frutuoso, Gaspar - Las Islas Canarias. (De Saudades da terra). Pról., trad., glosario e indices por E. Serra, J. Régulo y S. Pestana.-Inst. de Esu dios Canarios, La Laguna de Tenerife, 1964. xvii+199 pp. (Fontes rerum Canarium, 12). \| $B H i, 67(1965), 3^{81-3^{82}}$ (Ricard).

18-5̌̃o7. Dória, A. A.-“Camões visto por Aquilino Ribeiro". - $R C a, 1$ (1964), $13-35$.

18-5508. Saraiva, ANtónio José-Camões. -Jornal do Foro, Lisboa, 1964. $200 \mathrm{pp}$. II Bro, 80 (1965), 375-38 3 (Mendes). 
18-5509. Fressard, Jacques - Camoëns. Seghers, Paris, 1964. 192 pp. (Écrivains d'hier et d'aujourd'hui).

18-5510. Soares de Albergaria-"Camões teria nascido no Porto?”-Trip, 4 (1964), 153-154.

18-5511. Wilurs, R. C.-“Camões e o elasmismo".-Ocid, 67 (1964), 201-208.

18-5512. Brasil, R.-"Leão Hebreu e Camões".-ECB, 1964, núm. 13, 5̌-3o.

18-5513. Camões, Luís DE - Obra completa. Org., introd., comentários e anotações de Antônio Salgado Júnior. Aguilar, Rio de Janeiro, 1963. cix +1029 pp. $\| R L S P, 5 \quad(1964), 287-290$ (Mendonça).

18-5514. CAMöLs, Luís DE-Os Lusiadas. Comentários e estudo crítico de Reis Brasil. T. 3, vol. 1.-Divulgação, Porto, 1963. 380 pp.-V. núm. $17-1334$.

18-5515. CAMŌEs, Luís DE-Os Lusiadas. Introd., análise e dicionário por $\mathrm{H}$. Guedes de Oliveira.-Civilização, Porto, 1963. 428 pp.-V. núm. 17-1336.

18-5516. CAMÖEs, Luís DE-Os Lusiadas. Ed. organizada por Emanuel Paulo Ramos. 6a ed., escolar.-Porto Editora, Porto, 1964 . 580 pp.-V. núm. 10-23243. 18-5517. Camórs, Luís DE - The Lusiads in Sir Richard Fanshawe's translation. Ed. and introd. by Goeffrey Bullough. - Centaur Press, London; Southern Illinois Univ. Press, Carbondale, 1963. $35^{2}$ pp. || $M L N, 8$ o $\left(19^{6} 5\right), \quad 274^{-277}$ (Glaser); NSN, 17 Jan., 1964 (Hill); Seventeenth Century News, 22 (1964), núms. 3/4, 43-44 (Patrick); BHS, 42 (1965), 270-271 (Pierce); BAPE, 15 (1964), 178-185 (X); TLS, Mar. 26, 1964 (X).

18-5518. Camoens, Luis de-Els Lusiades. Trad. poètica per Guillem Colom i Miquel Dolç.-Alpha, Barcelona, 1964. 420 pp. || RVF, $6 \quad\left(1959^{-62}\right), 34^{1-34^{2}}$ (Sanchis Guarner).

18-5519. Freitas, William-Camoens and his epic. A historic, graphic and cultural survey. - Stanford Univ., 1963 . viii +227 pp., ilustr. (Institute of His. panic American and Luso-Brazilian Studies).-V. núm. 12-33128. || RHM, 30 (1964), 321-322 (Ferreira).

18-5520. Saraiva, A. J., e O. Loprs-“A ideologia inerente à composição d'Os Lusiadas".-Vértice, 24 (1964), $5^{18-524}$. 18-5521. WaLker, R. M.-"An interpretation of the role of the supernatural in Os Lusiadas".-RCa, 1 (1964), 83-93. 18-5522. Vidal, N.-."A presença da vida marítima n'Os Lusiadas". - Lab, 27 (1962), núm. 215 .

18-5523. Piva, L.-"OO Concílio dos Deuses: Vênus e Baco n'Os Lusiadas".$R C a, 1$ (1964), 94-157.

18-5524. Houwens Post, H.-“Camões e a epopeia holandesa de Johan Frederik Helmers, de $1812 "$.-Ocid, 67 (1964) 3-6. [Y versión francesa en $R C a, 1$ (1964), 78-82; 2 (1965), 129-133].

18-5525. Letzring, Madonna Marie-The influence of Camoens in English literature.-[Tesis, Univ, of Maryland; resumen en $D A, 25 \quad(1964-65), 1915-1916]$.

18-5526. HeAd, B. F.-“Camões and Melville”. $-R C a, 1$ (1964), 36-77.

18-5527. Neto Gonçalves, A.-Sonetos $e$ canções de Luis de Camões.-Livr. Aviz, Lisboa, $1964.84 \mathrm{pp}$.

18-5528. ReICHENBerger, K.- "Der christliche Humanismus des Camões. Biblische und antike Motive in Sôbolos rios que vão".-APK, 4 (1964), $105^{-1} 37$.

18-5529. PAIVA Boléo, J. DE-“A medicina estomatológica na poesia de Canñes". Aç̧ão Médica, 28 (1964), 220-262.

18-5530. CASA, F. P.-"Petrarch and $\mathrm{Ca}$ mões' El-Rei Seleuco".-RF, 76 (1964), $43^{\circ-4} 3^{6}$.

V. también núms. $5^{133}, 5407$.

18-5531. Glaser, E.-"Frei Heitor Pinto's Imagem da vida cristã".-APK, 3 (196263), 47-9o.

18-5532. Révah, I. S.-“Une opinion de l'écrivain Duarte Nunes de Leão sur la justice inquisitoriale". - $B A I, 3^{6}$ (1964), 280-283.

Amador Arrais: v. núm. 6587 .

18-5533. Belchior Pontes, M. de L. Poesia e mística: frei Agostinho da Cruz".-APK, 4 (1964), 138-158.

18-5534. Martins, M. - "Uma visão do Natal em Fr. Agostinho da Cruz".Bro, 79 (1964), 554-559.

18-5535. Dias Curly, M. O.-"Um texto de Cardim inédito em português:" RHSP, 28 (1964), 455-482.

18-5536. Fimiani, Annamaria - João de Lucena: "História da vida do Padre Francisco Xavier".-[Tesis de la Univ. de Nápoles, 1964]. $7^{\circ}$ pp.

18-5537. Crabeé Rocha, A. - “As carlas de Francisco Rodrigues Lobo". - Co, 1964 , núm. 29 .

18-5538. Rodrigues Lobo, Francisco Églogas. Conforme a edição princeps 1605. Introd. e notas de José Pereira Tavares. - Imprensa Nacional, Lisboa, 1964. $274 \mathrm{pp}$. 
18-5539. Quintela, Droco - Obras poéticas. Reprod. fac-similada da ed. de 1615 , com uma introd. de João de Castro Osório.-Acad. Port. de Ex-Libris, Lisboa, 1964. 242 pp.

18-5540. Henriques Vaz, Fernando-“Vi. riato trágico" de Bras Garcia de Mascarenhas. Estudo critico.-Lisboa, 1964 . 24 pp.

18-5541. Carvalmo, J. A. DE-"Aspectos do desengano e da aceitação da vida em D. Francisco Manuel de Mello".Bro, 78 (1964), 277-291, 423-438.

18-5542. Melo, Francisco Manuel de $O$ fidalgo aprendiz. Texto estabclecido, introd. e notas de António Corrêa de A. Oliveira. $3^{\mathrm{a}}$ ed.-Livr. Clássica, Lisboa, 1964 . 110 pp. (Clíssicos portugueses).

18-5543. Melo, Francisco Manuel de Relógios falantes. Apólogo dialogal primeiro. Texto rectificado, pref. e notas de António Corrêa de A. Oliveira. 2a ed.-Livr. Clássica, Lisboa, 1964. 108 pp. (Clássicos portugueses).

18-5544. Cidade, Hernani - P. António Vieira.-Arcádia, Lisboa 1964. $277 \mathrm{pp}$. (A obra $e$ o homem, 13). II Bro, $7^{8}$ (1964), 454-455 (Maia).

18-5545. Domingues, Mário-O drama $e$ a glória do P. António Vieira. $2^{a}$ ed.Romano Torres, Lisboa, 1964. 374 pp). -V. núm. 9-15199.

18-5546. Agostiveo, P. - "A política de Vieira e a entrega de Pernambuco".Esp, 1964.65 , núms. 4/5, 122-134.

18-5547. Hadbert, Maxime - L'Église et la défense des "sauvages". Le Père Antoine Vieira au Brésil.-Acad. Royale des Sciences d'Outre-mer, Bruxelles, 1964. $280 \mathrm{pp}$. RHE, 60 (1965), 913. 917 (De Bie); $B E P, 25$ (1964), 277-278 (Cantel).

18-50448. Cantel, R.- "L'História do futuro du P. António Vieira". - BEP, 25 (1964), 23-49.

18-5549. Sousa Gomes, A.-Madre Mariana Alcoforado. Sua graça e seli amor. -Lisboa, 1964. 16 pp.

18-5550. Delgado, Humberto - O infeliz amor de Soror Mariana. - Civilizaçăo Brasileira, Rio de Janeiro, 1964 .

18-5551. Alcoforado, Mariana - Cartas de amor. Nova restituição e esboço crítico de Jaime Cortesão.-Artis, Lisboa, 1064. 70 pp., ilustr.

18-5552. Díez Cadavid, J. - "Las cartas amorosas de la Monja”. - CCL, 1964, núm. $86,5^{6 \cdot 58}$.
18-5553. Lleras de Ospina, I.-“Las cinco cartas de amor de la monja de Portugal".-CCL, 1964, núm. 84, 27-41.

18-5554. Marrecas, C.- "Sobre las Cartas portuguesas de Sor Mariana Alcoforado".-PSA, 35 (1964), 313-324.

18-5555. Torre, G. DE-"Defensa de Mariana Alcoforado, la monja portugue sa".-CCL, 1964, núm. 91, 53-61.

18-5556. Deloffre, F.-"L'auteur des Let tres portugaises, juge de la tragédie racinienne".-L'Esprit Créateur, Minneapolis, 4 (1964), 183-192.

18-5557. Constantino, Maria Clara R. T. $-A$ espiritualidade germânica no $\mathrm{Pa}$. dre Manuel Bernardes.-Faculdade de Filosofia, Ciencias e Letras, Marília, Brasil, 1963 .

18-5558. Bernardes, Manuel-Como passam mil anos diante de Deus. Comentários por Jesus Belo Galvão.-Coimbra, 1964. 104 pp. (Supl. de Brasilia, t. 12).

A utores modernos

18-55509. Furter, P. - "La structure de l'univers dramatique d'António José da Silva, O Judeu".-BEP, 25 (1964), $5^{1-}$ 75.

18-5560. Silva, António José DA-El prodigio de Amarante (S. Gonçalo). Introd. éd. critique et notes par Claude-Henri Frèches.-Paris, 1964. 285 hojas mecanogr.

18-5561. Pina Martins, J. V. De-“Novos documentos para o estudo da personalidade de Verney".-APK, 4 (1964), $64-95$.

18-5562. Rossi, G. C.-La "Gazeta Literária" del Padre Francisco Bernardo de Lima $(r ; 6 r-1762)$. - Istituto Univer. sit. Orientale, Napoli, 1963. 113 pp. V. núm. 17-4902. $\|$ BEP, 25 (1964), 278-279 (Cantel); $B H i, 66$ (1964), 234 (Cantel); RLit, 21 (1962), 200 (Marcos); RHLP, 1 (1962), 313-315 (Pinto de Castro); $B A b r, 3^{8}$ (1964), 173 (Ricciardelli $\rangle$.

18-5563. RiCARD, R. - "Sur la diffusion des cuvres du P. Teodoro de Almeida".-BIB, 4 (1963), 626-63o.

18-5564. Ricard, R. - "Les ouvrages du P. Teodoro de Almeida en Espagne (compléments)".-BIB, 丂 $\quad(1964), 632-$ 634 .

18-5565. Coelho, E. - "Na Ribeira-Lima com Lima Bezerra".-Ocid, 66 (1964), 23-32. 
18-5566. Gonzaga, Tomás Antônıo-Marilia de Dirceu. Introd. de Judas Isgorogota. - Melhoramentos, São Paulo, 1964 .

18-5567. Pastor de Macfio, L.-“Em que casa faleceu José Agostinho de Macedo?".-Rev. Municipal, Lisboa, 1964, núm. $103,19-25$.

18-5568. Crabbé Rocha, A.-"José Agostinho de Macedo, epistológrafo".- $\mathrm{Co}$, 1965 , núm. $32,38-39$.

18-5569. Domingues, Mário - Bocage. $A$ sua vida e a sua época. Evocação histórica, - Romano Torres, Lisboa, 1964 . 4 oo pp.-V. núm. 17-49og.

18-5570. Simões, Joño Gaspar - Almeida Garrett. Vida, pensamento, obra.-Presença, Lisboa, 1964. 262 pp. (Biografia de bolso, 9). \| RLit, 25 (1964), 237 (Ares Montes).

18-5573. Costa Ramalho, A. DA - "Garrett tradutor de Catulo".-Co, 1964, núm. $27,38-41$.

18-5572. González Ollé, F. - "Sobie el proceso de la creación dramática y una obra de Almeida Garrett". - EMP, 7, 309-329.

18-5573. Almeida Garrett - $O$ arco de Sant'Ana. Crónica portuense.-Figueirinhas, Porto, 1964. 264 pp.

18-5574. Almeida Garretr-Frei Luis de Sousa. Revisão de texto, notas e ques. tionários por Júlio Martins e Jaime da Mota. 2a ed.-Livr. Didáctica, Lisboa, 1964. $138 \mathrm{pp}$.

18-5575. Almeida Garretr-Frei Luis de Sousa. Rev., notas e pref. de M. Rodrigues Lapa. $7^{\text {a }}$ ed.-Lisboa, 1964. $9^{6}$ pp. - V. núm. 18-2078.

18-5576. Machado, J. P. - "Nótula sobre as obras de António Feliciano de Castilho".-BMP, 14 (1963), 4-6, 138-139.

18-5577. Castulho, António Feliciano de -Poesias. Sel., pref. e notas de J. de Almeida Lucas, $2^{\text {a }}$ ed. - Livr. Clíssica, Lisboa, 1963. 96 pp. (Clássicos portugueses).

18-5578. Madeira Pinto, A. S.-“Molic̀re, Castilho e os advogados".-Rev. da Or. dem dos Advogados, 23 (1963), 315-319.

18-5579. Nizza dA Srlva, M. BeAtriz (ed.) - Alexandre Herculano. O historiador. -Agir, Rio de Janeiro, $1963.128 \mathrm{pp}$. (Os nossos clássicos, 76 ).

18-5580. Cunha E Freitas, E. A.-"Uma carta inédita de Alexandre Herculano dirigida ao marquês de Sousa Holstein",-Trip, 4 (1964), 295-296.

18-5581. Saraiva Jorge, M. do C.-"Sha- kespeare e Alexandre Herculano". Pal, 1964, núm. 20, 11-25.

18-5582. Rebelo da Silva-A casa dos fantasmas. Episódio do tempo dos franceses,-Civilização, Porto, 1965. 328 pp. 18-5583. Rebelo dA Silva, Luiz A. - Lágrimas e tesouros. Fragmentos de uma história verdadeira.-Civilizaçäo, Porto, 1964. 308 pp.

18-5584. Rebelo DA Silva - ódio velho não cansa. - Civilização, Porto, 1964 . $292 \mathrm{pp}$.

${ }_{1}^{8-55} 85$. Bessa Luf́s, A.-“Camilo Castelo Branco. Um pé dentro do mar, outro na areia".-TM, 1964, núm. 15, 93-105. 18-5586. Gumarães, D.- "Camilo e S. Miguel de Seide".- $J L A, 19$ febrero 1964 , 8-9.

18-5587. Reis Pereira, J. M. Dos-"Vila do Conde e Camilo Castelo Branco". $-B C C, 1964$, núms. 3/4.

18-5588. Boaventura, M.-“Uma anécdota na vida de Camilo". $-B C C, 1964$, núms. 3 i 4 .

18-5589. Pinheiro Torres, A. M.-"O Dr. J. d'Almeida, um médico de Canilo". -Bol. da Casa de S. Miguel de Seide, 1964, núm. 1, 19-22.

18-5590. Moura Bessa, J. C.-."A sepultura dè Camilo Castelo Branco".-Trip, 4 (1964), $14^{8-1} 5^{2}$.

18-5591. Sousa, C. DE-"Um busto de Camilo". $-B B C, 1964$, núms. $3 / 4$.

18-5592. Castelo Branco, Camilo - Cenas da hora final. $2^{\mathrm{a}}$ ed.-Domingos Barreira, Porto, 1964 .

18-5593. García Morejón, J. - "Camilo Castelo Branco frente a Eça de Qucirós. Dos actitudes unamunianas". $R U M, 13$ (1964), 241-275.

18-5594. LAwton, R. A.-"Technique et signification dans Amor de perdição". $-B E P, 25 \quad(1964), 77-135$.

18-5̆59. D'Ávila Pérez, Gustavo-As traduções do "Amor de perdição".-Portugália, Lisboa, 1964. $14^{6} \mathrm{pp}$.

18-5596. D'Ánila Pérez, G, - “A ópcra Amor de perdição. Música do tripeiro Dr. João M. Arroyo". - Trip, 1964 , núm. 2, 45-52.

18-5597. Cabral, A. - “Algumas questões camilianas através de $A$ queda dum anjo".-JLA, 6 mayo $19^{64}, 7^{-14}$.

18-5598. Castelo Branco, Camilo - $A s$ polémicas. Pref. e notas de Alexandire Cabral. - Portugália, Lisboa, 1964. 2 ts.-V. núm. 18-2105. || $B E P, 26 \quad\left(196_{5}^{5}\right)$, 242-245 (Cândido).

18-5599. Norton, Luís-Doze cartas iné- 
ditas de Camilo Castelo Branco.-Po1tugália, Lisboa, 1964. $100 \mathrm{pp}$.

18-5600. [Castelo Branco, Camilo] "Lma carta inédita ao visconde de Luzares". - Bol. da Casa de Camilo, 1964 , núms. $3 / 4$.

V. también núms. $54 \% 7,5736$.

18-5601. Gama, Arnaldo - $O$ balio de Leça.-Civilização, Porto, 1964. 264 pp. 18-5602. Gama, ARNaldo-A caldeira de Pero Botelho.-Civilização, Porto, 1964 . $256 \mathrm{pp}$.

18-56o3. Gama, Arnaldo - O sargento. mor de Vilar. Episódios da invasāo dos franceses em I80g. - Civilizaçäo, Porto, $19^{64} \cdot 3^{\circ 6} \mathrm{pp}$.

18-5604. Novaes Coelro, N. - "Ramalho Ortigão: o homem c o escritor". RLSP, 5 (1964), 166-194.

18-5605. Rodrigues Cavalhelro- $A$ evolução espirilual de Ramalho. - Livr. Clássica, Lisboa, 1963. $500 \mathrm{pp} .-\mathrm{V}$. núm. $17 \cdot 1423$.

18-5006. Prres de Lima, F. DE C.-"Ramalho Ortigão e Viana do Castelo".REt, 2 (1964), 166-194, 241-254.

18-5607. Ramalho Ortigão - As farpas.

Ts. 1 e $1_{5}$, ed. integral.-Livr. Clássica, Lisboa, 1969. 28o, 26o pp.-V. núm. $17-1426$.

18-5608. Ramalho Ortigão-Últimas farpas, 1911-191.4-Livr. Clássica Ed., Lisboa, 1964. 248 pp. (Obras completas). 18-56og. Ramalho ORtigĩo-A Holanda.

Nova ed. - Livr. Clássica, Lisboa, 1964 . $49^{\circ}$ pp. (Obras completas).

18-561o. Ramalho Ortigão, José Duarte -Holland $188_{3} \ldots$ Vertaald door W. de Jong.-Het Spectrum, Utrecht-Antwerpen, 1964. $192 \mathrm{pp}$.

18-5611. Cunha E Freitas, E. A. DA "Cartas inéditas de Ramalho".-Trit, $1963,291-294$.

18-5612. Ortiz da Fonseca, Maria AmáLIA - Introdução ao estudo de João Penha.-Portugália, Lisboa, 1964. 174 pp. (Novos ensaistas, 1 ).

18-5613. Dinis, Júuo - Uma familia in glesa. Cenas da vida do Porto. Nova ed., actualizada na grafia.-Civilização, Porto, 1964.368 pp.-V. núm. ${ }_{16-47689}$. 18-5614. Dixis, Júlio-A morgadinha dos Canaviais. Crónica da aldeia. Nova ed., actualizada na grafia.-Civilização, Porto, 1964. 424 pp.-V. núm. 18.2113. 18-5615. Dinis, Júlı-As pupilas do senhor Reitor. Crónica da aldeia. Nova ed., actualizada na grafia.-Civilização, Porto, 1964. 280 pp.-V. núm. 17-4942.
18-5616. Dinis, Júlio-As pupilas do senhor Reitor. Crónica da aldeia. - Figueirinhas, Porto, 1964. 360 pp.

${ }_{18-5617}$. Dinis, Júlio-Serões da provincia-Lello \& Irmão, Porto, ${ }_{19} 6_{4} \cdot 344$ pp.

18-5618. Divis, Júlio-Serões da provin cia. Ts. 1-2. Pról. de Egas Moniz-Civilização, Porto, 1964. 264, $26_{4}$ pp.V. núm. 18-2114.

18-5619. Dinis, Júlio - Teatro inédito. Civilização, Porto, $1964 \cdot 3$ ts.: $264,25^{6}$, 270 pp.-V. núm. 17-4946.

18-5620. Pinheiro Chagas, Manufl $-A$ mantilha de Beatriz. 6 $6^{\text {a }}$ ed.-Progresso, Lisboa, 1964. 174 pp. (Progresso, 2).

18-5621. Sá, Victor DE-Antero de Quental.-Livr. Victor, Braga, 1963. 344 pp. (Cultura $e$ acção, 8). || BEP, 25 (1964), 279-281 (Boisvert).

18-5622. Gonçalufs Fonseca, M. DA C. R. - "Algumas líricas filosóficas de Antero de Quental".-Lab, 1961 , núm. 201.

18-562\%. Lopes de AlmeidA, M.-"Cartas de Antero de Quental". $-A B P$, 9 (1963), 98-116.-V. núm. 16-47695.

18-5624. Lins, Álvaro - História literária de Eça de Queiroz. $4^{3}$ ed.-O Cruzeiro, Rio de Janeiro, 1964 . 314 pp.-V. núm. $16 \cdot 47^{6} 98$.

18-5625. VieirA, D.- "Eça e o Douro".$E C B, 1964$, núm. 12, 5-16.

18-5626. Machado de Rosa, A.-Eça discípulo de Machado? Formação de Eça de Queirós (1875-1880). - Fundo de Cultura, Rio de Janeiro, 1963. 25o pp. I) $H, 47 \quad(1964), 432-433$ (Martins); RLSP, 5 (1964), 281-284 (Mendonca): $H, 47$ (1964), 86o (Moser).

18-5627. Mazzara, R. A.- "Paralelos lusobrasileiros: Eça e Érico". - LBR, 1 (1964), núm. 2, 63-73.

18-5628. Garbuglio, J. C.-“Tradições em decadência".- $R L S P, 5 \quad\left(19^{6} 4\right), 149^{-1} 5^{8 .}$ [¿̨Influencia de Eça de Queirós en Lins do Règo?].

18-5629. MotTA, A.-"Venceslau de Morais e Eça de Queiroz". - BAPE, 8 $(1963), 213-214$.

18-563o. ECA DE QuEIRoz-O crime do $P$. Amaro. Ed. crítica por Helena Cidade Moura, baseada nas versões de 1875 , ${ }_{1876}$ e 1880.-Lello \& Irmão, Porto, 1964. 2 ts.: $x x x i i+496,482$ pp.

18-5691. EĢA DE, QUeIroz, José María-El mandarín. La ilustre casa de Ramirez. -Eds. Selectas, Buenos Aires, 1964.

V. también núm. 5593 .

Oliveira Martins: v. núm. 8179. 
18-5632. Guerra Junqueiro-Vibrações liricas. Pról. de João Grave e Luís de Magalhães. - Lello \& Irmão, Porto, 1965. $148 \mathrm{pp}$.

18-5633. Olivelra Guimarães, L. dF. "Junqueiro diplomata". - BCP, 27 (1964), 433-450.

18-5634. Motra, A.- "Venceslau de Morais e os seus trabalhos literários".DAPE, 9 (1964), $144^{-14} 8$.

V. también núm. $5^{629}$.

18-5635. Ávila de Azevedo, R.-“O nosso Cesário Verde e a influência de Charles Baudelaire na literatura portuguesa da sua época". $-B I A, 1964$, núm. 18 , $4 i-49$.

18-5696. Silverra, P. DA-“A Obra corilpleta de Cesário Verde. Correcções e anotações propostas amigàvelmente a Joel Serrão".-I'értice, 24 (1964), 276292, $45^{6-469}$.

18-5637. Verde, Cesário-Obra complela. Ed., pref. e notas de Joel Serrão.-Portugália, Lisboa, 1964. 256 pp. (Poelas de hoje, 35).

18-5639. Verde, Cesário-O livro de Cesário Verde.-Portugália, Lisboa, 1963. (Poetas de hoje).

18-5639. Lemos, Virgílio DE-Aspectos do adjectivo nos contos de Fialho de Almeida.-Sousa \& Almeida, Porto, 1964. $4^{8} \mathrm{pp}$.

18-5640. Costa e Almeida, A. C. DA "Anotações a uma carta de Joaquim de Araújo para Sampaio Bruno". Trip, 3 (1963), núm. 3, 89-9o.

18-5641. Teixetra de Queirós, Francisco - Cartas intimas de António Feijó.Coimbra, 1961. 243 pp.

18-5642. Fejoó, António - "Uma carta inédita". - Vértice, 25 (1965), 593-595. 18-5643. Osório dE Oliveira, J.- "Manuel da Silva Gaio".-Co, 1964, núm. 29, $62-63$.

18-5644. Silva Galo, A. DA-Mário. Episódios das lutas civis portuguesas de 1820-1834.-Civilização, Porto, 1965. 2 ts.: $244,25^{6}$ pp.-V. núm. $17-4937$.

Trindade Coelho: v. núm. 5646 .

${ }_{18-5} 645$. MalpiQue, C. - "Perfil de Manuel Teixeira Gomes".- Lab, 26 (1962), núm. 213; 27 (1962), núms. 214, 215.

18-5646. Miranda de ANdrade-"No centenário de um poeta: António Fogaça. Os seus contemporâneos, os seus versos e una carta a Trindade Coelho".Pan, 1963, núm. 7.

18-5647. Fogaça, António-Obra poética. As comemorações do centenário. Ed. de
Miranda de Andrade-Ciamara Municipal, Barcelos, Portugal, 1965 .

18-5648. "No centenário do poeta Paulino de Oliveira: homenagem a um escritor".-BAPE, 9 (1964), 79-81.

18.5649. Santos, J. E. Dos-"Evocação dos escritores lisboetas Cardoso Gonçalves e Cruz Malgalhães no centenário dos seus nascimentos".-Olisipo, 27 (1964), 116-134.

18-5650. Poppa Vòlture, E. DI-“"António Nobre. Saggio e traduzioni". - EIP, 1964, núm. 23, 43-106.

${ }_{18-56}{ }_{5}$. Novaes Collho, Nelly-Temipo, solidão $e$ morte.-Conselho Estadual de Cultura, São Paulo, 1964 . [Incluye un ensayo sobre António Nobre].

18-5652. Malpique, C.-"O snobismo e a anglofilia de António Nobre".-Trip, 4 $(1964), 107-114$.

18-5653. Malpique, C.-"A tísica, a dor e a morte em António Nobre".-BCP, 27 (1964), 374-432.

18-5654. Gumarães, H. de C.-"Variantes dum soneto de António Nobre".BAPE, $9 \quad(1964), 193-200$.

A utores contemporaneos

Laranjeira: v. núm. $817^{8}$.

18-5655. Guimarāes, D. - “A casa-museu de Teixeira de Pascoaes: no décimo aniversário da sua morte".- $J L A, 8$ enero $1964,8-9$.

18-5656. Carvalhal, M. DO- "Teixeira de Pascoaes nos últimos anos da sua vida de poeta".-BAPE, 9 (1964), 164-167.

$18-5657$. Ferreira, J.- "A ideia de Deus em Teixeira de Pascoais". - $I B, 9$ (1963), $x-6$.

18-5658. Reis Ribeiro, A. DOS - "Quatro cartas de Teixeira de Pascoaes".-Pan, 1964 , núm. 11, 17-20.

V. también núms. $5^{672}, 815^{\circ}$.

${ }_{18.5} 659$. "Afonso Lopes Vieira e António Sardinha numa evocação de Hipólito Raposo",- $-G V, 1_{5} \quad(1964), 5^{-13}$.

18-566o. Ferro, A.- "O teatro de Alfredo Cortez”.-Esp, 196万, núms. 6/7, $102-10_{5}$. 18-5661. Cruz, D. I.- "O mar em três dramaturgos portuguêses".- $J L A, 14$ oct. 1964,4 , 14. [A. Cortez, M. Torga y B. Santareno].

18-5662. Alves, A. - O sistema filosófico de Leonardo Coimbra (N. 17-5020). I $R P F B, 19$ (1963), 293-295 (Magalhães). 18-5663. Commara, Leonardo-Obras completas. T. 9: Jesus. São Francisco de Assis, Tisão franciscana da tida. O ho- 
mem às mãos com o destino.-Tavares Martins, Porto, 1964. 252 pp.

18-5664. Aguas, Neves - Bibliografia de Jaime Cortesão. Parte 1.-Arcádia, Lisboa, $1969.168 \mathrm{pp}$.

18-5665. Sottomaior CARdia - "Raul Proença e a responsabilidade do intelectual".-SN, 43 (1964), 300-302, 323324,331 .

18-5666. Mendes, M.-“Como Raul Proença saudou o aparecimento de um grande livro", $-S N, 44$ (1965), 67-68, 95.

18-566\%. NAMORA, FERNANDO - Aquilino Ribeiro. - Bertrand, Lisboa, 1963. 86 pp. (Realizações Artis, 1). \| PhP, 8 (1965), 103 (Hampl).

18-5668. Malpique, Cruz - Aquilino. 0 homem $e$ o escritor.-Divulgaçâo, Por. to, 1964. 180 pp.

18-5669. Areias, M. - "Como o escricor Aquilino Ribeiro via o Porto".-BAPE, 1964, núm. 27, 14-18.

18-5670. Montezuma de Carvalho, J. de - "Ainda Aquilino Ribeiro e Cervantes".-Co, $19^{6}$, núm. $3^{\circ}$.

18-5671. Ribeiro, Aquilino - S. Bana. boião, anacoreta e mártir. - Bertrand, Lisboa, 1964. 329 pp. (Obras completas).

V. también núm. $55^{\circ} 7$.

18-5672. Prado Coelho, J. Do-“Fernando Pessoa e Teixeira de Pascoaes". $-A P K$, 4 (1964), 212-231.

18-5673. Prado Coelho, Jacinto do-Di. versidade $e$ unidade em Fernando Pessoa. $2^{\text {a }}$ ed., refundida e acrescentada. -Verbo, Lisboa, 1969. 246 pp. (Presenças, 2). $-\mathrm{V}$. núm. 8-9624. | $B E P, 25$ (1964), $281-284$ (Frèches); $B A b r, 3^{8}$ (1964), 459 (Listopad).

18-5674. Lind, G. R. - "Auf der Suche nach dem verlorenen Ich: Fernando Pessoa",-Humboldt, 1964, núm. 10.

18.5675. Prado Coelho, J. Do-"O nacionalismo utópico de Fernando Pessoa". -Co, 1964, núm. 31, 53-57.

18-5676. Hess, R. - "Fernando Pessoa e Walt Whitman".-APK, 4 (1964), 181211.

18-5677. Antunes, M.- "O platonismo de Fernando Pessoa". - Bro, $7^{8}$ (1964), $137-148$.

1 8-5678. Décio, J.-“O mar na poesia de Fernando Pessoa”.-Alfa, 1964, núms. $5 / 6,57-88$.

18-5679. Еhrhardt, M.-“O mar na Ode maritima de Fernando Pessoa".-APK, 4 (1964), 159-180. "I ZRPh, 83 (1967), $673-674$ (Metzeltin).
18-5680. Pessoa, Fernando - Poemas de Alberto Caeiro, $3^{7}$ ed.-Atica, Lisboa, 1963. 118 pp. (Obras completas, 3).

18-5681. Margarido, A.-“Alberto Caeiro: poeta polémico".-JLA, 4 nov. 1964, 4, $14^{-15}$.

18-5682. Pessoa, Fernando - Poesias de Alvaro de Campos.-Ática, Lisboa, 1964 . 338 pp. (Obras completas, poesia, 2).

$18-5683$. Guerra, M. L. - "O tempo na poesia de Alvaro de Campos". - Pal, 1964, núm. 20, 43-6.

18-5684. Pessoa, Fernando - "Briefe und Notizen", - Akzente, München, 1964, $124^{-1} 3^{8}$.

18-5685. Rodrti, E. - "Fernando Pessoa, forasteiro entre os poetas ingleses".Ocid, 66 (1964), 205-215.-V. núm. 182237.

V. también núm. 5688 .

18-5686. Castex, F.-"Le premier poène de Sá-Carneiro?"-BEP, $25\left(199_{4}\right), 257^{\circ}$ 261.

18-5687. Sá-Carneiro, Mário de - Além. Sonhos.-Porto, 1964. $100 \mathrm{pp.}$

18-5688. Mourão Ferreira, D.-“Ícaro e Dédalo: Mário de Sá-Carneiro e Fernando Pessoa".-Co, 1964, núm. 30, 5457 .

V. también núm. 5407 .

18-5689. Cunha, C.-"Mário Beirão, pocta da ausência”.-Pan, 1965, núm. 14 . 18-569o. Berrão, MÁrIo-Lusitánia. $2^{\text {a }} \mathrm{ed}$. -Tavares Martins, Porto, 1964. $110 \mathrm{pp}$. 18-5691. Alves DE Olivelra, M.-"Nuno de Montemor, exemplo de escritor". $G V, 15$ (1964), $4^{6-4^{8}}$.

18-5692. Nuno de Montemor. - Editorial Organizações, Lisboa, 1964. [Varios ensayos sobre él].

18-5693. Antonelli, M. T.-“Joaquim de Carvalho, filosofo portoghese".-MEJC, 1962, núm. 8, 781-783.

18-5694. Barahona Fernandes, H.-“Joaquim de Carvalho: pessoa e atitude espiritual".- $M E J C, 1963$, núm. 9, 889 915 .

18-5695. Barahona Fernandes, H.-Pro fessor Joaquim de Carvalho.-Academia das Ciências, Lisboa, 1964 .

18-5696. Pina de Morais, G. - "Florbela Espanca".-SN, 43 (1964), 172-173.

18-5697. ["Homenaje a Florbela Espanca"].-Rev. Alentejana, 29 (1964), núm. $33^{2}$.

18-5698. Alexandrina, Maria $-A$ vida ignorada de Florbela Espanca.-[Lisboa?], 1964.224 pp.

18-5699. Alexandrina, Maria - Florbela 
Espanca $e$ a sua personalidade. $-[$ Lisboa? 1964 ?]. $28 \mathrm{pp}$.

18-5700. Falcato, J.-"O regresso de Flor. bela Espanca à sua Terra da verdade" $-P a n, 1964$, núm. 11, 42-44.

V. también núm. 5407 .

18-5701. Ferreira de Castro $-A$ lä $e a$ neve. $9^{\mathrm{a}}$ ed.-Guimarães, Lisboa, 1964 . $4^{14}$ pp.-V. núm. $17^{-1} 5^{26}$.

18-5702. Ferreira de Castro - A selva. $21^{\text {a }}$ ed.-Guimarães, Lisboa, 1964. 324 pp.-V. núm. 18-2267.

18-5703. Ferreira de CASTro.-Terra fria. $9^{\mathrm{a}}$ ed.-Guimarães, Lisboa, 1964. 296 pp.

18-5704. Pinmaranda Gomes - "Francisco Costa. Poesia, verdade e vida".-GV, 15 $\left(19^{6}\right)$, 20-26, 33-43.

18-5705. Monteiro, Domingos - O dia marcado.-Soc. de Expansão Cultural, Lisboa, 1964. 174 pp. I| $S N, 1964$, núm. 1428, 311-314 (Prado Coelho); SN, 1964, núm. 1425, 223 (Sasportes).

18-5706. Homem de Mello, Penro - Há uma rosa na manhã agreste. - Ática, Lisboa, 1964. (Poesia). || Bro, 79 (1964), 198-199 (Maia).

18-5707. SAMPAYO, N, DE - "O realismo integral de Branquinho da Fonseca".Co, 1964, núm. 28, 63.64.

18-5708. Branquinho da Fonseca-O $b a$ rão. $4^{a}$ ed. Posfácio de J. Régio.-Portugália, Lisboa, 1963. 67 pp.-V. núm. $17-5072$.

18-57og. StTau Monteiro, Lufs De - $O$ barâo.-Ática, Lisboa, 1964. 128 pp. [Basada en la novela $O$ barão de Branquinho da Fonseca].

18- 57 10. Branquinho da Fonseca - Poesias.-Portugália, Lisboa, 1969. (Antologia de poesia portuguesa).

18-5711. Branquinho dA Fonseca - Rio turvo. $2^{\text {a }}$ ed.-Portugália, Lisboa, 1963 . 256 pp. (Col. contemporânea, 51 ).

18-5712. Graña, B.--"Personalidá e obra de Miguel Torga"--Grial, 1964, 16-38.

18-5713. Torga, Miguel - Diário IX. Coimbra Editora, Coimbra, 1964. 195 pp. I| Bro, 8o (1965), $85^{-87}$ (Maia).

V. también núm. $566 \mathrm{I}$.

18-5714. Paço d'Arcos, Joaquim-Os melhores contos. Sel. e pref. de $\mathbf{H}$. Cidade.-Arcádia, Lisboa, 1963.178 pp. (Col. Antologia, 14). || Ocid, 67 (1964), 132133 (M. S.).

18-5715. Paço D'Arcos, Joaquim - Ansiedade. $6^{\text {a }}$ ed.-Guimarães, Lisboa, 1964 . 296 pp. $\|$ Ocid, 69 (1965), 125 (A. C.). 18-5716. PaÇo D'ARcos, JoAQUim - O bra- ço da justiça.-Guimarães, Lisboa, 1963 $14^{8}$ pp. (Col. Teatro). \| GV, 15 (1964), 129-137 (Dória); Ocid, 68 (1965), 49 (F. S.).

18-5717. Paço d'Arcos, Joaquim - O navio dos mortos e outros contos. $2^{\mathrm{a}} \mathrm{ed}$. -Guimarães, Lisboa, 1964. 320 pp.--V. núm. 9-15210.

18-5718. Malpique, Cruz - Perfil literário de João de Araújo Correia.-[Lisboa? 1965?]. 222 pp.

18-5719. Araújo Correia, JoÃo DE-Montes pintados.-Portugália, Lisboa, 1964. 162 pp. I| Ocid, 67 (1964), 287-288 (A. C.).

18-5720. Mariano, Gabriel - Uma introdução à poesia de Jorge Barbosa. Seguida de uma seleção de poemas.-Seção Cultural da Associação Acadêmica, Praia, 1964.

18-5̆721. Ferreira, Vergílio-Aparição. $4^{\mathrm{a}}$ ed.-Portugália, Lisboa, 1964. 268 pp. (Col. Contemporânea, 8).-V. núm. 175087 .

18-5722. Ferreira, Vergílio - Espaço do invisivel.-Portugália, Lisboa, 1965. 282 pp.

18-5723. Alves Redol - A barca dos sete lemes. $4^{\text {a }}$ ed.-Europa-América, Lisboa, 1964. 416 pp. (Século XX).-V. núm. $17-1559$.

18-5724. Alvfs REDOL - The man with seven names. Transl. by Linton L. Barret.-Knopf, New York, 1964. $3^{82}$ pp. [Trad. de $\boldsymbol{A}$ barca dos sete lemes]. $\| \boldsymbol{H}$, $4^{8} \quad(1965), 607-608$ (Moser).

18-5725. KORGES, J.-“A masterpiece from Portugal: Alves Redol's The man with seven narnes".-CritF, 1965 , núm. 1, 720.

18-5726. Alves Redol - Fanga. $6^{\mathrm{a}}$ ed. Portugália, Lisboa, 1963. 344 pp. (Col. contemporânea).

18-5727. Alves REDOL-Histórias afluentes.-Portugália, Lisboa, 1963. $328 \mathrm{pp}$. (Col. contemporânea, 53). \| RLit, 25 (1964), 265-266 (Ares Montes).

18-5728. Vasconctilos, J. C. DE-"A poesia de Manuel da Fonseca".-JLA, 3 abril 1963 .

18-5729. Fonseca, Manuel DA - Poemas completos. - Portugália, Lisboa, 1963. ${ }_{17} 8 \mathrm{pp}$. (Col. Poetas de hoje). \| Bro, 78 (1964), 181-187 (Silva).

18-5730. Fonseca, MANuel DA-Aldeia nova. Contos. $3^{a}$ ed.-Portugália, Lisboa, 1964. 234 pp. (Col. contemporânea, 58). 18-5731. Sena, JoRGE DE-Metamorfoses.Morais, Lisboa, 1963. $15^{\circ}$ pp. (Circulo 
de poesia, 28). \| Ocid, 67 (1964), 283 (A. C.); Bro, 78 (1964), 306-314 (Maia). 18-5732. Jesus, E. DE - "Notas para uma interpretação da poesia de Natércia Freire".-Rumo, 8 (1964), $3^{82-3^{8} 4}$.

18.5733. CASTro, A. DE-"Natércia, cantor de nuvens".-Co, 1964, núm. 28, $5^{1-52}$.

18-5734. Freire, Natércia - Liberta em pedra.-Delfos, Lisboa, 1963. 102 pp. Bro, 78 (1964), 306-314 (Maia).

18-5735. MOURÃo-FERREIRA, D.-“Do movente e do fixo na poesia de Natércia Freire. A propósito de Liberta em pedra".-Esp, 1964, núm. 2, 66-7o.

18-5736. César, Amândio-A casa assom. brada de $S$. Miguel de Seide.-Câmara Municipal, Vila Nova de Famalicão, 1964. 104 pp.

18-5737. César, Aviândo - Coraçăo sem expedientes.-Verbo, Lisboa, 1964.264 pp.

18-5738. César, Amândio - Natal. 2a ed. -Pax, Braga, 1964. 44 pp. (Metrópole $e$ ultramar, 7 ).

18-5739. CÉSAR, AMÂNDIO - Roxo-rei!Lisboa, ${ }^{1963 .} 4^{6} \mathrm{pp}$. (Col. aniológica best-sellers, 8 ).

18-5740. Breyner Andresen, SOPHIA DE M. -O cavaleiro da Dinamarca.-Figueirinhas, Porto, 1964. $73 \mathrm{pp}$.

18-574. Breyner Andresen, Sofia de $M$. -A fada Oriana.-Ática, Lisboa, 1964 . $104 \mathrm{pp}$.

18.5742. Breyner Andresen, Sofia dF. M. - Liuro sexto. Posfácio da autora. $2^{\text {a }} \mathrm{ed}$ -Morais, Lisboa, 1964. 80 pp. (Círculo de poesia, 17).-V. núm. 17-1571.

18-5743. Breyner Andresen, Sofia de M. -Poesia sempre. Ts. 1-2. Sel. de Alberto Lacerda.-Sampedro, Lisboa, 1964 . 139, 200 pp. (Nosso mundo).

18-5744. Mourão-Ferreira, DAvm - Infinito pessoal ou a arte de amar. 2a ed.-Guimarães, Lisboa, [1963]. 弓० pp. (Poesia e verdade).-V. núm. 18-2334.

18-5745. Mourão-Ferreira, David-O irmão.-Guimarães, Lisboa, [1965? ]. 102 pp.

18-5746. Couto Viana, António M. - $O$ acto $e$ o destino. $2^{\text {a }}$ ed.-Mocidade Portuguesa, Lisboa, 1964. 34 pp. (Teatro da mocidade portuguesa juvenil).

18-5747. Couto Viana, António M.-Auto do Bom Pastor. $3^{\text {a }}$ ed.-Serviço de Publicações da Mocidade Portuguesa, Lisboa, 1964. $40 \mathrm{pp}$.

18-5748. Couto Viana, António Maniel -Relatório secreto. - Verbo, Lisboa,
1963. 64 pp. (Col. Poesia). I Ocid, 67 (1964), 281-282 (M. S.).

18-5749. Tavares Rodrigues, Urbano-De Florença a Nova Iorque.-Portugália, Lisboa, [1963]. $290 \mathrm{pp}$. (O livro de bol. so, $4^{6-47)}$.

18.5750. Tavares Ronrigues, Urbano Exilio perturbado. - Bertrand, Lisboa, [1963]. $280 \mathrm{pp}$. (Autores portugueses). II $B A b r, 37$ (1963), 115 (Dimmick).

18-5751. Tavares Rodrigues, Urbano- $A$ s máscaras finais. - Bertrand, Lisboa, 1963. $27^{2} \mathrm{pp}$.

18-5739. TAlares Rodrigues, Urbano-A samarra.-Cor, Lisboa, 1964. 3o pp.

18-5753. Tavares Rodrigues, Urbano Terra ocupada. - Bertrand, Lisboa, 1964. 288 pp. (Autores portugueses).

18-5̌754. Lindeey Cintra, L.-"Sebastião da Gama. Um depoimento". - TM, $1965,463-478$.

18-575̃. GaMa, Sebastião da-Serra Mãe. $3^{\mathrm{a}}$ ed. - Ática, Lisboa, 1969. $147 \mathrm{pp}$. (Obras, 1).

18-5756. Palla E Cario, J.- "Significa do real e dimensões morais na obra de José Cardoso Pires".-TM, 1969, núm. $11,6-21$.

18-5757. Cardogo Pirls, José-O anjo ancorado. Est, do autor por Alexandre Pinheiro Torres. $3^{\mathrm{a}}$ ed., rev,-Arcádia, Lisboa, 1964. $218 \mathrm{pp}$.

18-5758. Cardoso Pires, José-O hóspede de Job.-Arcádia, Lisboa, 1964. $25^{6}$ pp. $S N, 1964$, núm. 1424, 180 (Cochofel).

18-5759. Bessa Luís, Agustina-Os quatro rios.-Guimarães, Lisboa, 1964. 260 pp.

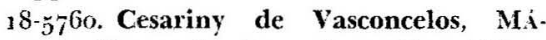
Rı- $U m$ auto para Jerusalém.-Minotauro, Lisboa, 1964. $76 \mathrm{pp}$. (Col. Teatro) .

18-5761. Ramos Rosa, António - Poesia liberdade livre.-Morais, Lisboa, 1962. 254 pp. (O tempo e o modo, 15-16). I) $B A b r, 3^{8}$ (1964), 104 (Listopad).

18-5762. Ramos Rosa, ANTónio-Terrear r96r-1962. Poemas, pinturas de vespereira.-Minotauro, Lisboa, 1964. $24 \mathrm{pp}$. 18-5763, Ramos Rosa, ANTónio-Ocupa são do espaço. - Portugália, Lisboa. 1969. 96 + li pp. (Poetas de hoje, 12). || Bro, 79 (1964), 193-199 (Maia).

${ }_{15}-5764$. Botelho, Fernanda - $O$ enigma das sete alineas.-Lisboa, ${ }^{1963} .5^{6} \mathrm{pp}$. (Col. antológica best-sellers, 4).

18-5765. Botelho, FERNANDA-Xerazade $e$ os outros. Tragédia em forma de ro- 
mance. - Bertrand, Lisboa, 1964. 272 pp. (Autores portugueses). $\| B A B r, 39$ (1965), 246-247 (Listopad).

Santareno: v. núm. $5^{661}$.

18-5,66. Gonçalves, Egrto - Os arquivos do siléncio. Pref. de Óscar Lopes. Portugália, Lisboa, 1969 .

$18-5,67$. MAIA, J.-“A poesia de António Gedeão". - Bro, 80 (1964), 87-91.

18-5768. Gedeão, António-Poesias contpletas. Pref. de Jorge de Sena.-Portugália, Lisboa, 1964. (Poetas de hoje). II Ocid, 67 (1964), 282-293 (A. C.) .

18-5769. Gedeão, António-Poema para Gralileo. No IV centenário do seu nascimento.-S. I., 1964, 8 pp.

18-577o. Bravo-Villasante, C. - "Numo de Sampayo. (Noticia, versión y selec. ción)".-ROCC, 10 (1965), 209-214.

18-5771. Sampayo, Nuno dE - O eterno instante.-Morais, Lisboa, 1964. 64 pp. (Circulo de poesia, 29). \| Ocid, 67 (1964), $289-284$ (A. C.); Bro, 79 (1964), 193-199 (Maia).

18-5772. Helder, Herberto-Os passos em volla. - Portugália, Lisboa, 1963. 160 pp. If $B A b r, 3^{8}$ (1964), 223 (Listopad).

A utores gallegos

18-5773. Carballo Calero, Ricardo-His. toria da literatura galega conlemporanea. T. 1.-Galaxia, Vigo, 1963. $566 \mathrm{pp}$. 18-5774. Alonso Montero, Jesús - Cen años de literatura galega. Catálogo da exposición bibliográfica. - Círculo de las Artes, Lugo, 1964 .

18-5775. Cicco, J. - "Escritores gallegos". -Lyra, 1964, núms. 192/4.

18-5776. Iglesia Alvariño, Aquilino- $A$ lengua dos poetas do norte de Lugo. Discurso. Contestación de R. Otero Pedrayo.-Real Academia Gallega, La Coruña, 1964. $4^{\circ} \mathrm{pp}$.

18-5777. Serrano Castilla, Francisco Aportación al estudio de la critica li. teraria en Galicia en los últimos cien años:-[Tesis, Univ. de Madrid; resumen en $R U M, 13$ (1964), 605-606].

18-57;8. Josta, VInCENzo-Echi di Finislerre. (Antologia di poeti gallegos). Gugnali, Modica, 1964. 105 pp. RHM, 3o (1964), 140 (Bosch).

18-5779. Álvarez, G.-"A nova xeneración intelectual galega".-Grial, 1964, $389-391$.

18-5780. Guerra da Cal, E.-"O renascimento galego contemporáneo".-LBR, 1 $(1964), 5-18$.
18-5781. Varela, J. L.-"Un capítulo del ossianismo español: Eduardo Pondal". -EMP, 6, 557-590.

18-5782. Ruiz Peña, J.-“"Rosalía de Cas. tro".-BIFG, 43 (1963), 14-19.

18-5783. "El centenario del casamiento de Murguía y Rosalía".-BAG, 29 (1959), 140-143.

18-5784. Rodriguez Yord, J.-"Una carta a Rosalia”.-BAG, 29 (1959), 57-58.

$18-5785$. Carballo Calero, R.- "Machado desde Rosalia".-Ins, 1964, núms. 212/3 18-5786. Castro, Rosalía de - Poems. Transl. by $\mathrm{Ch}$. D. Ley. Introd. and sel. by J. Filgueira Valverde.-Ministry of Foreign Affairs, Madrid, 1964. 206 pp. \|| EL, $19^{6}{ }_{5}$, núm. 308 (Iglesias Laguna).

$18-5787$. Castro, Rosalía de-En las ori. llas del Sar. Ed., pról. y notas de J. Alonso Maestro, - Anaya, Salamanca. Madrid, 1964. 119 pp. (Bibl. Anaya).

18-5788. Filcueira Valverde, J--"Sobre la Alborada y la amplitud musical de Rosalía". - Museo de Pontevedra, 16 (1962), $55-56$.

18-5789. López Alonso Montero, J. "Traducciones de la poesía de M. Curros Enríquez"--Bol. de la Comisión Prov. de Monum., Lugo, 7 (1964), núms, $61 / 62$.

18-579o. Lugris, RAirón - Vicente Risco na cultura galega. - Galaxia, Vigo, 1963. 157 pp. || $B A b r, 3^{8}$ (1964), 455$45^{6}$ (de Boer).

18-579\%. García Viñó, M.-“Alvaro Cunqueiro, una excepción en la narrativa española actual".-PE, 1964, núm. 103 .

18-5792. Gungueiro, Álvaro - Tesoutos novos e vellos.-Galaxia, Vigo, 1964 . 119 pp., ilustr. || $B A b r, 39$ (1965), 374 (de Boer).

18.5793. Castelao-Un ollo de vidro: memorias d'un esquelete.-Galaxia, Vigo, 1964. 34 pp., ilustr.

18-5794. María, M.- "A poesia galega de Celso Emilio Ferreiro". - Grial, 1964, 495507 .

18-5795. Lorfnzana, S.- "Galicia na obra de Cuevillas",-Grial, 1964, $103-110$.

18-5796. Guerra da Cal, Ernesto - Rio de sonho e tempo (1959-1962).-Gala. xia, Vigo, $19^{6} 3.118 \mathrm{pp}$. \| $B A b r, 3^{8}$ (1964), 220 (de Boer); RHM, 29 (1963), 306-307 (Sayers).

18-5797. Vázquez, Pura $-A$ saudade $i$ outros poemas. - Sainés, Vigo, 1963 . 64 pp. II RHM, 3o (1964), 199-140 (Bosch); H, $4^{8}\left(19_{5}^{6}\right), 618$ (Bosch). 


\section{LITERATURA ESPAÑOLA}

18-5798. Simón DíAz, José - Bibliografia de la literatura hispánica. T. 3, vol. 1. $2^{\mathrm{a}}$ ed.-C. S. I. C., Madrid, 1963. viii-623 pp. $-V$. núm. 9-14083. ॥ BAbr, $3^{8}$ (1964), 301 (Duncan); Ins, 1963, núm. 202 (Marra-López); RLit, 23 (1963), 272 (Rozas)

18-5799. Simón Díaz, José-Manual de bibliografia de la literatura española.-G. Gili, Barcelona, 1964. 616 pp. II NT, 1964, 617-618 (A. D. T.); Dest, 29 febr. 1964 (Díaz-Plaja); RLit, 24 (1963), 246-247 (Díez Taboada); $P E$, 1964, núms. 99/100, 114-116 (Esquer); BSCC, $4^{\circ}(1964), 234-235$ (Esquer Torres); $R J, \quad 15$ (1964), 364-366 (Franzbach) ; $A r b, 5^{8}$ (1964), 361-362 (Gómez Galán); $E L, 1964$, núm. 289 (Larrea); Ber, 19 (1964), 93 (Lope Toledo); $R I T$, febr. 1965 (Manzano); $L N L$, 1964, núm. 2, 108-109 (Marcus); Ins, 1964, núm. 214 (Marra-López); $B D G A$, 1964, núm. 76, 55 (Pérez-Rioja); Idea, 21 (1964), 361 (Rossi); RFE, 46 (1963), 490-493 (Rozas); $T R, 1964$, núm. 2o4, 157 (Toro).

18-5800. Rozas, J. M., y J. M. Dílz TABOADA-"Estudios de historia y crítica de la literatura española, publicados en España desde mayo de 1962 a mayo de 1963". $-B F E, 4$ (1964), 19-25.

18-5801. "Tesis de interés literario".RLit, 25 (1964), 197-205.-V. núm. 175138 .

18-5802. Ortiz Armengol, P.-."Para una guía literaria de España. Fichas geo gráficas sobre Ceuta, Melilla, Cádiz, Huelva y las Islas Canarias".-EL, 1964, núms. $282 / 3,286$.

18-5803. Malkiel, Y.-"Supplement to $\mathrm{M}$. R. Lida de Malkiel bibliography".$R P h, 17$ (1963-64), 523-524.-V. núm. $17-1638$.

18-5804. Garcla, S.-"Una revista romántica: El Observatorio Pintoresco, de 1837".-BBMP, 4o (1964), 337-359.

18-5805. Chelini, R.-"Una nota di costume: El Panorama".-MSI, 1964, núm. $8,122-132$. [Revista madrileña, ${ }_{1} 8{ }_{3}^{8}$ 1841 ].

18-5806. Fox, E. I. - "Two anarchist newspapers of $1898^{\prime \prime} .-B H S, 41$ (1964), 160-168. [Publicados por Luis Bonafoux; colaboraciones de Lnamuno, Azorín, Vicente Medina].

18-5807. Paniagua, Domingo - Revistas culturales contemporáneas. T. 1: De
"Germinal" a "Prometeo" (I897-1912). -Punta Europa, Madrid, 1964. 194 pp. 18-5808. Benf́tez Claros, R.-"Problemas de investigación en el español literario".-PFE, 1, 481-487.

18-5809. Maravall, J. A.-“La estimación de lo nuevo en la cultura española".CuH, 57 (1964), 187-228, 439-469.

18-5810. Rozas, J. M.-“Joaquín de Entrambasaguas". $-B F E$, 1964 , núm. 11, $3^{-14}$.

\section{Historia y crítica literaria}

18-5811. LAPESA, RAFAEL-Introducción $a$ los estudios literarios. $2^{\text {a }}$ ed.-Anaya, Salamanca-Madrid, 1964. 204 pp. (Manuales Anaya, 3). II RLit, 26 (1964), 206 (Romero).

18-5812. Caramella, S.-.Per un'estetica ispanica".-Riv. di Estetica, Padova, 9 (ig64), 268-274.

18-5813. Baquero Goyanes, M. - "Réalisme et utopie dans la littérature espagnole".-TR, 1964, núm. 193, 66-9o. -V. núm. $17-5162$.

18-5814. Iglesias Laguna, Antonio- ¿Por qué no se traduce la literatura española?-Ed. Nacional, Madrid, 1964. 35 pp. (Ateneo).

18-5815. Fogarasi, M. - "Gondolatok az olasz és a spanyol irodalmi nyelv történetérül". - Filologiai Közlöny, 10 $(1964), 371-379$.

18-5816. De Filippo, Luigi-Due note di letteratura spagnola.-A. Chicca, Roma, 1964. $80 \mathrm{pp}$.

18-5817. Grossmann, R. - "Spanische Litcratur".-[En] W.-H. FrIEDRICH u. W. KILLY (eds.), Literatur, I (Frankfurt, 1964), 284-305.

18-5818. Río, ÁNGEL DEL-Historia de la literatura española. T. 1: Desde los origenes hasta I700; t. 2: Desde I700 hasta nuestros dias. Ed. rev.-Holt, Rinehart \& Winston, New York, 1963-64. xviii + 466 pp.-V. núm. 3-2610. $H, 47$ (1964), $88_{3}-88_{5}$ (Stoudemire).

18-5819. Chandler, R., \& K. Schwartz$A$ new history of Spanish literature (N. 17-5154). || $A U C h, 122$ (1964), 233235 (Benavides Lillo); $R P h, 17$ (1963. 64), 496-498 (Helman).-V. núm. 182397.

18-5820. Sanz, León, y Elena Villamana -Historia de la literatura española. $5^{\text {? }}$ ed.-Libreria General, Zaragoza, 1964 . 18-5821. Serrano Poncela, Segundo-Introducción a la literatura española.- 
Universidad Central de Venezuela, Caracas, 1963. 336 pp. - V. núm. 16-44035. 18-5822. Adams, Nicholson B., \& John E. KelleR-Breve panorama de la literatura española. Trad. por Antonio Llorente Maldonado de Guevara.-Castalia, Madrid, 1964. 259 pp.-V. núm. 16-47862. || RHM, 30 (1964), 322 (Carrasco Urgoiti); $M L J, 49$ (1965), 266 . 267 (Dauster); $H, 4^{8}\left(19_{5}^{6}\right), 401-402$ (Schweitzer).

18-5823. García López, José-Historia de la literatura española. $8^{\text {a }}$ ed.-Vicens Vives, Barcelona, 1964. 708 pp. (Manuales Vicens Vives). - V. núm. 182400.

18-5824. Garcfa López, José-Historia de la literatura española y universal. $5^{\text {a }}$ ed.-Teide, Barcelona, 1963. 236 pp.

18-5825. Perés, Ramón Domingo-Historia de la literatura española $e$ hispanoamericana.-Ramón Sopena, Barcelona, 1964. 734 pp., ilustr. (Bibl. Hispa. nia).-V. núm. 16-47864.

18-5826. Giménez Caballero, ErnestoLengua y literatura de la hispanidad. T. 2: La Edad de Oro. Tercer curso: Epopeya y mistica. - Autor, Madrid, 1964. 514 pp., ilustr.-V. núm. 8-12802.

18-5827. Oteiza, Alberto M.-Panotama de la literatura medieval española.Olimpo, La Plata, 1964. 120 pp.

18-5828. Alonso Alonso, M. - "Traducciones arábigo-latinas en el siglo XIV o a fines del siglo xiI".,-ELu, 8 (1964), $54-65$.

18-5829. Schirmann, J.-"La poésie hébraïque du moyen âge en Espagne".Mélanges de Philosophie et de Littérature juives, Paris, 3/5 (1958-62), 171210.

18.5830. Scudieri Rugcieri, J.--"Per uno studio della tradizione cavalleresca nella vita e nella cultura spagnola medioevale".-SLSp, 11-6o.

18-5831. STEIGer, A. - "Überlieferungsgeschichte der spanischen Literatur des Mittelalters". - Geschichte der Textüberlieferung, 2 (Zürich, 1964), 539-597. 18-5832. Alonso, DÁmaso-De los siglos oscuros al de oro. (Notas y articulos a través de setecientos años de letras españolas). $2^{\text {a }}$ ed.-Gredos, Madrid, $196_{4}$. 294 pp. (Campo abierto, 14).-V. núun. $14-38897$.

18-5833. Villegas Morales, Juan-Ensayos de interpretación de textos españoles (medievales, clásicos y modernos).Editorial Universitaria, S. A., Santiago de Chile, 1963. 191 pp. $\| H, 4^{8}$ (1965), $3^{81-382}$ (Marin).

18-5834. Scudier Ruggieri, Jole-Poesia lirica e prosa narrativa in Ispagna dalle origini alla fine del secolo xvi. Ateneo, Roma, 1963. 276 pp. (Univer. sità degli Studi di Roma, Facoltà di Lettere e Filosofia).

${ }_{18}^{8}{ }_{5}^{8} 35$. SPITzer, Leo-Cinque saggi di ispanistica. Presentazione di Giovanni Maria Bertini.-G. Giappichelli, Torino, 1962. 290 pp. $\| P h P, 8^{\prime}(1965), 443^{-}$ 444 (Hodousek).

18-5836. Lida de Malkiel, M. R. - Two Spanish masterpieces (N. 17-5170). II $M P h, 62$ (Ig64-65), 64-66 (Ayer); HR, 32 (1964), 360-361 (Herriott); Ins, 1963, núm. 195 (Rico); RLit, 28 (1965), 262-264 (Rodríguez Cepeda); $R R, 55$ (1964), 47-48 (Tudisco).

18-5837. Terracini, L. - "Tradizione illustre e lingua letteraria nella Spagna del Rinascimento".-SLSp, 61-98.

18-5838. BARJA, CÉSAR-Libros y autores clásicos. A reprint.-Las Américas, New York, 1964 . xii $+557 \mathrm{pp}$.

18-5839. Shepard, S.- "Las huellas de Escalígero en la Philosophia antigua poélica, de Alonso López Pinciano".$R F E, 45$ (1962), 311-317.

18-5840. SÁNCHEZ, J.-Academias literarias del Siglo de Oro español (N. 17-5185). I| $R J,{ }_{15}$ (1964), 378-381 (Marin); $L R$, 18 (1964), 193-194 (Vermeylen); NG, 10 (1963), 204 (Villapadierna).

18-5841. Gibson, M. C.- "Spanish academies of the Golden Age".-Brigham Young University Studies, 5 (1964), 169 18 .

18-5842. Blanco GonzÁlez, B.-Del cortesano al discreto (N. 18-2427). II JMH, 36 (1964), 44-45 (Herr); HAHR, 44 (1964), 116-117 (Holmes); $R y F, 172$ (1965), 126-127 (Jorge); CD, 177 (1964), 168 (L. G.); RLMo, 3 (1964), 113-115 (Nallim).

18-5843. Casalduero, J.-Estudios de llteratura española (N. 17-5173). I| BHS, $4^{1}$ (1964), $5^{1-5^{2}}$ (Davies).

18-5844. Benftez Claros, Rafael - Vi. sión de la literatura española.-Rialp, Madrid, 1963. 324 pp. (Libros de bolsillo Rialp). I| PEsp, 1964, núm. 142 (Murciano); EL, 1964, núm. 291 (Um. bral).

18-5845. Serrano Poncela, S. - Del Ro mancero a Machado (N. 17-5174). If HuI, 1962, núm. 10, 271-275 (Alonso). 18-5846. Alala, Francisco - Realidad $y$ 
ensueño. - Gredos, Madrid, 1963. 153 pp. (Campo abierto, 9). [Cervantes, Quevedo, Tirso, Calderón, Unamuno, Machado]. || BHS, 42 (1965), 183-184 (Cabañas); $C C L, 1964$, núm. 81, 89-9o (Lancelotti).

18-5847. Alonso, D.-Del Siglo de Oro a este siglo de siglas (N. 18-2432). $\| R y F$, 171 (1965), 437 (Micó Buchón); PEsp, 1964, núm. 134 (Murciano); HR, 32 (1964), 74-76 (Rivers); $H, 47$ (1964), 424-425 (Schwartz); NG, 11 (1964), 192 (Villapadierna).

18-5848. Serrano Poncela, Segundo-Formas de vida hispánica (Garcilaso, Quevedo, Godoy y los ilustrados).-Gredos, Madrid, 1963. 166 pp. (Campo abierto). If Ins, 1963, núm. 204 (Cano); PEsp, 1965, núm. 153 (Murciano); BHS, $4^{1}$ (1964), 264 (Price); H, 47 (1964), 198 (Rothberg).

18-5849. Maldonado de Guevara, F. Tiempo de niño y tiempo de viejo, con otros ensayos.-Facultad de Filosofia y Letras, Universidad, Madrid, 1962. 45 pp. [El Lazarillo y el Quijote]. I $L R, 19$ (1965), 91-92 (Borgers); HR, 32 (1964), 76- 78 (Durán); RF, 77 (1965), 211-213 (Hess); ZRPh, 79 (1963), 462 (Rüegg).

18-585o. Menéndez Pidal, Ramón - De Cervantes y Lope de Vega. 6 a ed.-Espasa-Calpe, Madrid, 1964. 170 pp. (Austral, 120).-V. núm. 12-31333.

18-5851. Maeztu, Ramiro de-Don Qui. jote, Don Juan y la Celestina. $9^{2}$ ed.Espasa-Calpe, Madrid, 1963. 160 pp. (Austral, 31).-V. núm. 12-33826.

18-5852. Dfaz Plaja, Gulllermo - Cuestión de limites. Cuatro ejemplos de estéticas fronterizas (Cervantes, Velazquez, Goya, El Cisne).-Revista de Occidente, Madrid, $1963.23^{6} \mathrm{pp}$. If Ins, 1964, núm. 215 (M.C.); RLit, 24 (1963), 245-246 (Romero); $\boldsymbol{H}, 47$ (1964), 867868 (Ruiz-Fornells).

18-5853. Carsuzán, M. E. - La creación en la prosa de España e Hispanoamérica (N. 10-23353). || PhQ, 43 (1964), 521 (King).

18-5854. Cerny, V.-“Teoria política y literatura del Barroco".-Atl, 2 (1964), $488-512$.

${ }_{18-5855}$. Collard, A. - "España y la Disputa de Antiguos y Modernos".NRFH, 18 (1965-66), $150-156$.

18-5856. Lázaro Carreter, F.- "Sobre la dificultad conceptista".-EMP, 6, 355$3^{86 .}$
${ }_{1} \varepsilon_{-5}{ }^{8} 57$. Sebold, R. P.-“Contra los mitos antineoclásicos españoles". - $P S A, 34$ (1964), 83-114.

18-5858. Caldera, Ermanno-Primi manifesti del romanticismo spagnolo. Università, Pisa, 1962. $126 \mathrm{pp}$. (Istituto di Letteratura Spgnola e Ispano. Americana, 4). \| $H, 47$ (1964), 869870 (Adams); RLit, 23 (1963), 291 (Esquer Torres); $P h Q, 43$ (1964), 521 (King); $A r b, 5^{6}$ (1963), 322 (Larrea); $H R, 33$ (1965), 425-426 (Pattison).

18-5859. Peers, Edgar Allison-A histo$r y$ of the romantic movement in Spain. A reprint.-Stechert-Hafner, New York, 1964. 2 ts.

18-5860. King, E. L. - “¿Qué es el romanticismo español?" - $B I S D$, i 964 , núm. 31, 109-118.-V, núm. 17-5199.

18-5861. Romero Mendoza, Pedro-Siete ensayos sobre el romanticismo español. T. 1: Ambiente romántico; Origen, caracteres y fases del romanticismo; Larra y la prosa costumbrista; La poesia; El teatro.-Servicios culturales de la Diputación Provincial de Cáceres, Cáceres, 1963. 528 pp., ilustr. \| PSA, 32 (1964), 222-224 (Vilar).

18-5862. NordSTröM, Folke-Goya, Saturn and Melancholy.-Almqvist and Wiksell, Stockholm, Uppsala, 1962. 239 pp. $\| H R, 33(1965), 171-175$ (Helman).

18-5863. Randolph, Donald Allen-Eugenio de Ochoa y el romanticismo español.-[Tesis, Univ. of California, Berkeley; resumen en $D A, 24(1963-64)$, 5415-5416]. $3^{62}$ pp.

$18-5864$. Morand, A. - “Antonio Alcalá Galiano nel romanticismo spagnolo".MSI, 1964, núm. 8, 5-37.

18-5865. Barinaga, Augusto-Movimientos literarios españoles en los siglos xix y $x x$. - Alhambra, Madrid, 1964. 312 pp., láms. \| $R y F, 172$ (1965), 273 (Echánove); RLit, 25 (1964), $259^{-260}$ (Esquer Torres).

18-5866. Baquero Goyanes, MarianoPerspectivismo y contraste. - Gredos, Madrid, 1963. 244 pp. (Campo abierto, 7). [Cadalso, Larra, Mesonero, Galdós, Azorín, Miró, Pérez de Ayala, Ortega]. || $B B M P, 39$ (1963), 392 (A. S.); CuH, 6o (1964), 378-385 (Escobar); RLit, 25 (1964), 216 (Esquer Torres); $H, \quad 4^{8}$ (1965), $384-385$ (McMahon); İns, 1964, núm. உog (Moreno Báez); Asom, 1964, núm. 4, 64-65 (Zuleta). 18-5867. BARJA, CÉSAR-Libros y autores 
modernos. A reprint.-Las Américas, New York, 1964 . viii +448 pp.

18-5 568 . GonzÁlez Ollé, F.-“Del naturalismo al modernismo: los origenes del poema en prosa y un desconocido artículo de Clarín".-RLit, 25 (1964), $49^{-67}$.

18-5869. TORrE, G. DE-El fiel de la balanza (N. 17-5203). || HR, 32 (1964), 81-83 (López-Morillas); $P S A, 29$ (1963), 215-216 (Vilar).

${ }_{18-5} 87$ o. Fox, E. I.- "En torno a la actitud romántica de la generación de 1898".-HuNL, 5 (1964), 235-243.

18-5871. Pascual Buxó, J.-“"Imagen del noventa y ocho español". - $A F, 2-3$ (1963-64), 295-311.

18-5872. Carrasquer, F. - “De Spaanse schrijvers van vandaag tegenover de generatie van ' 98 '. - Raam, 1964, núm. $8,59-78$.

18-5873. Gullón, Ricardo - Direcciones del modernismo. - Gredos, Madrid, 1964. 242 pp. (Campo abierto). - V. núm. 16-44086. \|BAbr, $3^{8}$ (1964), 412 (Angeles); Ins, 1964, núm. 208 (Cano); CCL, 1964, núm. 86, 74-75 (Iglesias); BHi, 67 (1965), 169-172 (Laffranque); $A$, 1964, núm. 404, 265-267 (Loveluck); $H, 4^{8}\left(1^{6} 6_{5}\right), 3^{87-388}$ (Palley); RLMo, 1965, núm. 4, 166-167 (Zuleta).

18-5874. RAE, José-El modernismo como tergiversación historiográfica.-Devenir, Buenos Aires, 1964. $3^{8} \mathrm{pp}$.

18-5875. Lozano, Carlos - Rubén Datio in Spain, 1892-1916.-[Tesis, Univ. of California; resumen en $D A, 24$ (196364), $375^{\left.1-375^{2}\right] . ~} 291 \mathrm{pp}$.

18-5876. Álvarez Hernández, DictinoCartas de Rubén Dario. Epistolario inédito del poeta con sus amigos españoles.-Taurus, Madrid, 1963. $23^{8} \mathrm{pp}$. (Persiles, 28).-V. núm. 17-1691. || RLit, 23 (1963), 292-293 (Diez Taboada); $R y F$, 169 (1964), 547-548 (Hanrahan).

18-5877. Martínez Cachero, José Ma. RíA-Andrés González Blanco: una vida para la literatura.-Inst. de Estudios Asturianos, Oviedo, 1963. || BBMP, 39 (1963), 391 (Aguilera); BIEA, 18 (1964), 197-200 (Andreu); Íns, 1964, núm. 210 (Marra López); Rlit, 25 (1964), 244245 (Romero); $A O, 14$ (1964), 292-295 (Santano Cilleros); PSA, 35 (1964), 314343 (Viñuelas).

18-5878. Badosa, Enrique-Razones para el lector.-Plaza \& Janés, Barcelona, 1964. If Ins, 1965, núms. 224/5 (Crusat).
18-5879. Molina, R. - Estudios (N. 17 5205). II LR, 18 (1964), $391-392$ (Groult).

18-580. Diez Canedo, Enrique-Conéer -

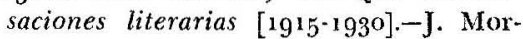
tiz, México, 1964. 3 ts.: $251,264,265$ pp.

18-5881. WERrIe, P.-“Le fantastique espagnol".- $T R, 1965$, núm. 212, 149-156. 18-5882. Durán, M.- "Spanish literature since the War",-[En el vol. colectivo] On contemporary literature (New York, 1964), 193-203.

18-5883. Ayala, F.-"Función social de la literatura". - ROcc, 4 (1964), 97-107 [España, 1923-1963].

18-5884. Flórez, R.- "Después de 25 años de tertulias literarias españolas". $-P E$, 1964 , núm. 103 .

18-5885. Cano Ballesta, J.-“Década de conquistas para las letras españolas. Poesía y novela (1953-1963)". - Ins, 1964, núm. 210.

18-5886. Cano, J. L.-"Nota sobre la crítica literaria en España". - CLS, 1 (1964), 305-310.

18-5887. JIMÉNEZ MARTOS-“Al margen de un mapa literario".-PE, 1964, núm. 94 .

V. también núms. $495^{8}, 5897,6134,6863$, $7933,8064,8191-3$.

\section{Colecciones de textos}

18-5888. Tateo, Francesco (ed.) - Testi letterari spagnoli, dalle origini al Siglo de Oro. - La Goliardica, Milano, 1964. $254 \mathrm{pp}$.

${ }_{1} 8-5889$. Prosistas castellanos del siglo $x v$. T. 2. Ed. y est. prel. de Fernando Rubio.-Atlas, Madrid, 1964. xlix + $3^{\circ} 8$ pp. (BAE, 171).-V. núm. 14-40912. || ArA, $5^{8} \quad$ (1964), 431-432 (Aparicio López); $C D, 17^{8}$ (1965), $364-365$ (Rojo).

18-58go. Menéndez Pidal, Ramón-Antologia de prosistas españoles. $8^{a}$ ed.Espasa-Calpe, Madrid, 1964. 261 pp. (Austral, 110).-V. núm. 11-28141.

18-5891. Barretr, L. L. (ed).-Five centuries of Spanish literature (N. 17-1701). If $H, 47$ (1964), 681-682 (Stamm); $M L J$, $4^{8}$ (1964), $5^{8}$ (Thompson).

18-j892. Resnick, SeYMOUR, \& JEANNe PAsmantIER-Highlights of Spanish iiterature.-F. Ungar, New York, 1963. xxi $+4^{6} 3$ pp.-V. núm. 14-38926. \| $\boldsymbol{H}$, 47 (1964), 682-683 (Chandler); $M L J, 49$ $(1965), 67$ (Seay). 
18-5893. Pattison, W. T. (ed.)-Repre. sentative Spanish authors. T. 2. 2nd. ed.-Oxford Univ. Press, New York, 1963. 328 pp. - V. núm. $4795^{\circ}$. || $H, 47$ (1964), 212-213 (Boudreau); BHS, $4^{2}$ (1965), 67 (Hall); $M L J, 49$ (1965), 127 (Heilman).

18-5894. Paz y Mélia, Antonio-Sales españolas o agudezas del ingenio nacional. Ed. de R. Paz. $2^{\text {a }}$ ed.-Atlas, Madrid, 1964. xii $+3^{67} \mathrm{pp}$. (BAE, $\left.{ }^{1} 7^{6}\right)$. 18-5895. Maeztu, María DE - Antologia, siglo $x x$. $6^{\text {a }}$ ed.-Espasa-Calpe, Madrid, 1964. 248 pp. (Austral, 330). -V. núm. 13-37og4.

18-5896. Rebersat, J., et A. Mercier (eds.) - Siglo veinte. - A. Colin, Paris, 1964. || LNL, 1965, núm. 1, 124.125 (Larose) .

18-5897. Torrente Ballester, Gonzalo - Literatura española contemporánea. T. 1: Estudio critico. T. 2: Lecturas y comentarios. $2^{\text {a }}$ ed.-Guadarrama, Madrid, 1964. 427, 470 pp.-V. núm. 56185 .

18-5898. Bagué, Esteban-Antologia de la literatura española contemporánea.Vicens-Vives, Barcelona, 1964. 263 pp., ilustr. || RLit, 26 (1964), 232-233 (Rozas).

18-5899. Castagnaro, R. Anthony (ed.) -Contemporary Spanish readings,-Las Américas, New York, 1964. 184 pp. II $H, 4^{8}$ (1965), 639 (McMahon).

\section{Temas literarios}

18-5900. Rubio, F. - "Desfavorable concepto moral de la mujer en algunas obras de origen oriental". - $C D, 177$ $(1964), 267-287$. [Citas de la lit. espanola medieval].

18-59o1. Solsona Y QUerol, J.- "El desmayo en la historia y en la literatu. ra".- $A b s$, 28 (1964), 319-330. [Cervantes, Zorrilla].

18-5902. CAstro, Américo - De la edad conflictiva. (El drama de la honra en España y en su literatura). 2 à ed., muy ampliada y corregida.-Taurus, Madrid, 1963. 279 pp. (Col. Persiles).V. núm. 17-5163 || PENN, 15 (1964), 230-232 (Adell); BISD, 1964, núm. 32, 259-261 (de Yturbe).

18-5903. Sánchez Lasso dF La Vega, J-"El mito clásico en la literatura española contemporánea". - Actas del II Congreso español de estudios clís. (Madrid, I964), 405-466.
18-5904. Gallego Morell, A. - El mito de Faetón en la literalura española (N. 17-5221). || EClas, 8 (1964), 153 (Galiano).

18-5905. Cabañas, P.-"Eurídice y Orfeo en la novela pastoril".-EMP, 4, $33^{1}$. $35^{8 .}$

18-5906. Testa, Daniel, P.-The Pyramus and Thisbe theme in 16 th and $x_{7}$ th century Spanish poetry.-[Tesis, Univ. of Michigan; resumen en $D A, 24$ (1963-

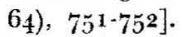

18-5907. ApERribay, B. DE-"Bibliografía mariano-franciscana (siglos XVI y XVII)". $-E M a, 25 \quad\left(19^{6} 4\right), 239^{-25} 6$.

18-ð̆go8. García Miralles, M.-“Fuentes mariológicas dominicanas (1550-1750)". EMa, 25 (1964), 223-238.

18-5909. SAN MARTín DE LA IDA, E.--"María en la Sagrada Escritura, según los escritores agustinos españoles". $-E M a$, 24 (1964), 31-66.

18-5910. Esquerda, J.-"Escritores del clero secular en la mariología clásica es. pañola".-EMa, 25 (1964), 191-208.

18-5911. Caruana Gómez de Barreda, J. - "Los amantes de Teruel" (N. 1644105). I| Teruel, 1964, núm. 31, 204$20_{5}$ (Gregorio); BSCC, 40 (1964), $235^{-}$ $23^{6}$ (J. S. A.).

18-5912. Cuña, Irma-Inmortalidad y ausencia de Pedro de Urdemalas.-Facultad de Filosofía y Letras, México, 1964. ${ }_{17} 6$ pp. [Tesis. Pedro de Urdemalas cn la literatura española $y$ en el folklore hispánico].

18-5913. Marañón, Gregorio-Don Juan. $10^{\mathrm{a}}$ ed.-Espasa-Calpe, Madrid, 1964. 164 pp. (Austral, 129).-V. núm. 16$49^{6}{ }_{3} 8$.

18-5914. Livermore, A.--"The origins of Don Juan".-Music and Letters, $\mathrm{Ox}$ ford, 44 (1963), $257-26_{5}$.

18-591 burlador".-BSCC, 4o (1964), 220-233. 18-5916. Aub, M.--"Hércules y Don Juan". -Ins, 1964, núm. 209; UMx, 20 (1965. 66), núm. 3 .

18-5917. BRUN, J.-"Two gnostic precursors of scientific humanism: Faust and Don Juan".-International Philosophi cal Quarterly, 3 (1963), 227-235.

18-5918. Mazzeo, G.-"Don Juan Tenorio: salvation or damnation?"- $R N \cdot 5$ (1964), $15^{1-1} 55$.

18-5919. MANDEL, OSCAR-The theatre of Don Juan. A collection of plays and views, I $_{3} \mathrm{O}-\mathrm{I}_{96} 6_{3}$--University of Nebrasha Press, Lincoln, 1963. $75^{2}$ pp., ilustr. 
[Autores españoles representados: Tirso, Zorrilla, Grau]. $\| R R, 5^{6}\left(196_{5}^{5}\right)$, 156-158 (Fellows); $B A b r, 3^{8}$ (ig64), 434-435 (Rabassa); College Eng., 25 (1964), 559 (Randall); $H, 47$ (1964), 661-662 (Singer); $R N, 17$ (1964), 122123 (Taylor).

18-5920. Alder, Esther R. - The Don Jian theme in the contemporary French theatre.-[Tesis, Univ. of California (Berkeley), 1964].

18-5921. Avalle-Arce, J. B.-“Un proble. ma resuelto: los cuartos de Osorio".NRFH, 18 (1965-66), 166-169.

18-5922. Bentto Ruano, E.-“Fortuna literaria del Infante D. Enrique de Aragón".-AO, 14 (1964), 161-201. [Sobre todo en la poesía del siglo $\mathrm{xv}$ ].

18-5923. Reynolds, W. A.-"La discutida lealtad de Hernán Cortés y su proyección literaria".-RLit, 25 (1964), 109 . 119.

18-5.924. Chao Espina, E.-"Portugal nas letras espanholas durante o Medievo". $-B A u, 16 / 17$ (1964), 46-68.

18-5925. Viqueira, J. M.-“Coimbra en las letras españolas". - $A C o, 19 / 20$ (1964), $113-17 \%$.

18-5926. López Estrada, Francisco (ed.) - La toma de Antequera. Textos de Ben al-Jatib, Fernán Pérez de Guzmán, Fernando del Pulgar, Álvar García de Santa Maria y Ghillebert de Lanoy. -Antequera, 1964. 143 pp. || RHM, 30 (1964), 320 (Carrasco Urgoiti).

18-5927. Álvarez Tuerienzo, SaturninoEl Escorial en las letras españolas.Publicaciones Españolas, Madrid, 1963. 272 pp., ilustr. || $R y C, 9$ (1964), 298 (Camblor); RLit, 25 (1964), 213-215 (Rozas); NEt, 1964, núm. 29, 273-274 (Suárez Campos).

18-5928. Morales Oliver, Luis-Africa en la literatura española. T. 3: Del Sigló de Oro a la época contemporínea.Instituto de Estudios Africanos, Madrid, 1964. 108 pp.-V. núm. 13-37106.

18-5929. Buchanan, M. A. - "The glove and the lions".-EMP, 6, 247-258.

18-5930. Lida de Malkiel, M. R. - "La abeja: historia de un motivo poético". $-R P h, 17$ (1963-64), $75-86$.

18-5931. Lozoya, Marqués de - "Algunos temas novelescos en el arte hispánico". $-E M P, 4,569-577$.

18-ว932. Sobejano, G.- "Épater le bourgeois en la España literaria de 1900". -FFS, 449-481. || ZRPh, 8o (1964), 574 (Hatzfeld).
18-5933. Salazar, Antonlo - Extravagan. cia y grandeza del disparate (en la literatura española).-San Salvador, 1964. $26+12$ hojas. [Mecanografiado].

18-5934. Vera Camacho, J. P.-“Tres escritores y una temática". - $R E E, 20$ (1964), 533-548. [Forner, Donoso Cortés, Espronceda].

V. también núms. 4346, 5057, 5163-80, $585^{1}, 5942-3,6072,6859$.

\section{POESIA}

18-מ̌ 935. Simón Díaz, José-Impresos del xvi: Poesia.-C.S.I.C., Madrid, 1964. 55 pp. (Cuadernos bibliográficos, 12).

18-5936. LAPESA, R.-“¿Amor cortés o pa. rodia? A propósito de la primitiva lírica de Castilla",-ER, 9 (1961), 11-14 18-5937. SAINz de Robles, F. C.-Historia y antología de la poesia española. $4^{\text {a }}$ ed. - Aguilar, Madrid, 1964. (Obras eternas).-V. núm. 11-25154. || RLit, 2 , (1965), 270-271 (Mantero).

18-5938. Birter, H.-Spanische Versdichtung des Mittelalters (N. 12-33262). II $P h Q, 43 \quad(1964), 55^{20-521}$ (King). $-V$. núm. 16-4413o.

18-5939. SPITZER, L.-Sobre antigua poesia española (N. 17-5248). || NRFH, 18 (1965-66), 188-195 (Alvar); $B L H, 1962$, núm. 4, 118-124 (Bouilly); RLit, 23 (1969), 274-275 (Romero); BHS, 41 (1964), 201 (Smith); $H, 47$ (1964), 424 (Weiss).

18-5940. Terni, C. - "Per una edizione critica del Laudario di Cortona". Chigiana, Firenze, 21 (1964), nuova serie, 1. [La lauda, el zéjel y el villancico, y la "tesis árabe"]. || $C u N, 24$ (1964), $125^{-126}$ (Ziino).

18-5941. VegA, L. A. DE-"La música y la canción árabes influyeron en la lírica española".-Africa, 1964 , núm. 267,12 17.

18-5942. JaReño, E. - "Ojos verdes, ojos negros".-LNL, 1964, núm. 2, 64-74.

18-5943. Wardropper, B. W.-"The reluctant novice: a critical approach to a Spanish traditional song". $-R R, 55$ (1964), $241-247$.

18-5944. Rodríguez Moñino, A.- "Construcción crítica y realidad histórica en la poesía española de los sigios xvi y XVII",-LHC, 30-49.

18-5945. VOSSLER, KARL-Realismo e religião na poesia luso-espanhola do sécu. lo de oiro.-Biblioteca de Altos Estudos, Lisboa, 1964. $3^{\circ} \mathrm{pp}$. 
18-5946. Atwinson, W. C.-"On Aristotle and the concept of lyric poetry in carly Spanish criticism". - EMP, 6, $189-213$.

18-5947. Barnstone, W. (tr.)-"Poetry of the Spanish Renaissance". - Antioch Rev., 24 (1964), 88-93.

18-5948. Alonso, D. - "La poesía lírica vista desde el centro de nuestro Siglo de Oro".-El Escorial, ${ }_{15} 6_{3}-196_{3}$, t. 1 (Madrid, 1964), $583-602$.

18-5949. Pierce, F.-La poesia épica del Siglo de Oro (N. 17-5259). $\| B H i, 66$ (1964), 231 (Chevalier); LR, 17 (1969), 288-291 (Groult); ZRPh, 80 (1964), 562 (Rüegg); $M L R, 60 \quad(1965), \quad 289^{-}$ 290 (Russell).

18-5950. Rodríguez-Luis, J.-“Algunos aspectos de la evolución de lo pastoril de Garcilaso a Góngora".-Hf, 1964, núm. 22, 1-14.

18-5951. Alonso, D.-Cuatro poetas españoles (N. 18-2546). \|NG, $11 \quad(1964)$, 192-193 (Sanzoles).

18-5952. RozAs, J. M.-"Petrarca y Ausias March en los sonetos-prólogo anorosos del Siglo de Oro". - Hom, 1 (1964), $57-75$.

18-5953. Rogers, E.-“El color en la poesía española del Renacimiento y del Barroco".-RFE, 47 (1964), 247-261.

18-5954. Bonneville, H.--"Sur la poésie à Séville au Siècle d'Or". - $B H i, 66$ (1964), $311-348$.

18-5955. Gunlén, J.-Language and poetry (N. 17-5255). I| QJS, 47 (1961), 434 (Lee); $B J A, 2$ (1962), 74 (Waldron). 18-5956. GuiLlén, J--Lenguaje y poesia (N. 18-2547). U Anali di Ca' Foscari, 1963, 17-180 (Meregalli).

18-5957. Chiarini, G.- "La critica letteraria di Jorge Guillén". - Par, 15 (1964), 111-118.

18-5958. Cellaya, Gabriel - Exploración de la poesia.-Seix Barral, Barcelona, 1964. (Biblioteca breve). [Herrera, Bécquer, San Juan de la Cruz]. \|C CuH, 61 (1965), 199-204 (Batlló); Asom, 1964, núm. 3, 84-86 (Cano); Ins, 1964, núms. 212/3 (Cano); PSA, $3^{8} \quad\left(196_{5}^{5}\right), 3^{2} 9^{-}$ 335 (Domingo); Map, 1965 , núm. 1, 197-198 (Fernández Molina); LFr, 17 (1964), 251-252 (García); USF, 1964, núm. 61, 379-380 (Gudiño kieffer); PEsp, 1964, núm. 139 (Mantero); RHM, 32 (1966), 93.94 (Sobejano); BHS, 42 (1965), 259-261 (Terry); BAbr, 39 (1965), 194 (Wade).

18-5959. Kirk, Susanne Brooke-Relacio- nes entre la poesia de Sor Juana linés de la Cruz y la de los poetas del Re. nacimiento y Barroco en España.-[Te. sis, Univ. of Missouri; resumen en $D A$, 24 (1963-64), 3338]. $3^{26} \mathrm{pp}$.

18-5960. Alatorre, A.- "Nota (prescindible) a unos sonetos de Sor Juana". El Rehilete, México, 1964, núm. 11, 4556 . [Antecedenes españoles].

18-5961. Nerlich, Michael - Untersuchungen zur Theorie des klassizistischen Epos in Spanien (1700-1850).-[Tesis, Univ. de Colonia, 1964].

18-5962. Videla, Gloria - El ultraismo. Estudios sobre movimientos poéticos de vanguardia en España.-Gredos, Madrid, 1963. 246 pp. $(B R H) .-V$. núm. 17-1738. | $A, 196_{5}$, núm. 408, 262-264 (Concha); RLit, 24 (1963), 274-275 (Díez Taboada); RHM, 3o (1964), 149$15^{\circ}$ (Fox); $B A b r, \quad(1965), 66$ (Klibbe); $H R, \quad 33$ (1965), 417-420 (Kovacci); $B H i, 67$ (1965), 210-212 (Laffranque); $B H S, 4^{2}$ (1965), $5^{8-60}$ (Morris); $H, 4^{8}$ (1965), $3^{86}$ (Young).

18-5963. Escobar, J.- "Notas sobre el ultraísmo". - CuH, $5^{6}$ (1963), 638-647. [Sobre el libro de G. Videla].

18-5964. IliE, P.-“Futurism in Spain".Criticism, 6 (1964), 201-211.

18-5965. Echeverri Mejía, O.- "Los poetas españoles de la posguerra".- $U d A$, 41 (1964), 783-793; $B C B, 7$ (1964), $1043^{-105} 5^{1 .}$

18-5966. Lorda Alaiz, F. M. - "Spaanse dichters kiezen partij".-De Gids, 127 (1964), núm. 1, $177^{-189 .}$

18-5967. PAz, PILAR-La mujer y la poesia de lo cotidiano. - Edit. Nacional, Madrid, 1964.34 pp. (Ateneo).

18-5968. Jiménez Martos, L.-"Poesía femenina de postguerra". - EL, 1964, núm. 288.

${ }_{1}^{8} 8-5969$. Álvarez, G. - "Poesía española contemporánea”.-APC, 28 (1963), $35^{-}$ 57 .

18-597o. Uribe Ferrer, R. - "La pocsía contemporánea en lengua española”.Lect, $15^{8}$ (1964), 47-62, 78-94--V. núm. $18-2567$.

18-5971. PAsseri Pignoni, V.-“Spirito e forme della lirica spagnola contemporanea".-Sapienza, 17 (1964), 392-408. 18-5972. Bousoño, C.- "La sugerencia en la poesía contemporánea".-ROcc, 7 (1964), 188-208.

18-5973. Bousoño, C.-"Poesía contemporánea y poesía post-contemporánea".PSA, 34 (1964), 121-184. 
18-5974. Castelpoggi, A. J.-“Tres poetas de la España de hoy". - Lyra, 1964, núms. 192/4. [Celaya, Hierro, Carmen Conde].

18-5975. Los premios de poesia "Boscán" (1949-1961).-Plaza y Janés, Barcelona, 1964. 329 pp.

18-5976. Agulló y Cobo, Mercedes-La poesia española en 196r. - C. S. I. C., Madrid, 1963. 62 pp. (Cuadernos bibliográficos, 8). \| $H R, 32$ (1964), 285 (Espantoso-Foley); RHM, 29 (1963), 310-311 (Jinénez); BFE, 4 (1965), 31 (Morales); BHS, $4^{1}$ (1964), 204-205 (Terry).

18-5977. Agulló Y Cobo, Mercedes-La poesia española en 196r.-C. S. I. C., Madrid, 1964. 39 pp. (Cuad. bibliográ. ficos, 8A).

V. también núms. 5̆og1, 5123-6, 5130-2, $5^{185}, 5^{187}, 5906,6110,6271,6450,6907$, 7914 .

\section{Métrica}

18-5978. Navarro, TOMÁs-Arte del verso. $2^{\text {a }}$ ed. - México, 1964. 187 pp. (Ideas, letras y vida). - V. núm. 16$44^{1} 5^{2}$.

18-5979. Henríquez Ureña, Pedro-Estu. dios de versificación española.-Universidad de Buenos Aires, Buenos Aires, 1961. 399 pp. || HR, 31 (1963), 70- $\mathbf{7}^{1}$ (Clarke); $\quad B H i, \quad 66 \quad$ (1964), $24^{6-247}$ (Molho); RPh, 17 (1963-64), 519-520 (Myers); CuN, 23 (1963), 109 (Tavani); $L R, 18$ (1964), 191-192 (Vermeylen).

18-5980. Arnold, H. H.-“Rhithmic [sic] patterns in old Spanish verse".-EMP, $5,15 \mathrm{I}-163$.

18-5981. BALbín, R. DE-Sistema de ritmica castellana (N. 18-2585). ||$L R, 19$ (1965), 29-31 (Groult); RHM, 30 (1964), 138-139 (Porqueras-Mayo); NG, 11 (1964), 191-192 (Quintanilla); $R R$, 55 (1964), 312-313 (Reynolds).

18-5982. Balbín, R. de-“'Sobre la configuración estrófica de la rima castellana".-RFE, 47 (1964), 237-246.

18-5983. Quilis, A. - "El encabalgamien. to desde los orígenes de la poesía española hasta el siglo xvi",-CLR (Io), $791-816$.

18-5984. Quilis, Antonio - Estructura del encabalgamiento en la métrica española. (Contribución a su estudio experimental).-C. S. I. C., Madrid, 1964. xiv + 196 pp., 20 láms. (RFE, anejo 77). $-V$. núm. 17-528o. \|BdF, 21 (1962-63), $374-378$ (Carballo Picazo); RLit, 25 (1964), 217-218 (Diez Taboada); RFE, $4^{6}$ (1963), 498-499 (Esquer Torres); $B F E, 4$ (1965), 29 (Morales \& Rull); CuN, 25 (1965), 297-298 (Tavani).

V. también núms. $5127,5^{198} 8,618_{5}, 6235$, $66_{52}, 808_{4}$.

\section{Cancioneros y antologías}

18-5985. El Cancionero de Juan Alfonso de Baena. Con notas y comentarios.Anaconda, Buenos Aires, 1964. xciii + $74^{8} \mathrm{pp}$.

18-5986. El Cancionero de Gallardo, ed. J. M. Azáceta (N. 18-2588). || HR, 32 (1964), 80-81 (Clarke); Map, 1963 , núm. 1, 308-310 (Ferreccio); RPh, 18 $(1964-65), 237^{-243}$ (Gimeno Casalduero); $L R,{ }_{18} 8$ (1964), $385-386$ (Groult); $R J,{ }_{15}\left(19^{6} 4\right), 371-37^{6}$ (Rico); SCL, 16 $(1965), 437$ (Sala); BICC, 19 (1964), 168-179 (Valderrama Andrade); $N, 48$ (1964), 89 (Van Praag).

18-5987. AzÁceta, J. M. - "El Pequeño cancionero".-EMP, 7, 83-112.

18-5988. Rodríguez-Moñino, A. - Los pliegos poéticos de la colección del Marqués de Morbecq (N. 18-2596). NRFH, $18 \quad(1965-66), 195^{-198}$ (Weber de Kurlat).

18-5989. Rodríguez-Moñino, A. - "Los pliegos poéticos de la colección Campo de Alanje en la Biblioteca Nacional de Madrid (siglo xvi)".-RPh, 17 (196364), $373-380$.

18-599o. Rodríguez-MoÑino, A. - "Doscientos pliegos poéticos..." (N. 1648001). || $L R, 19$ (1965), 64 (Groult). 18-5991. Rodríguez-MoÑino, Antonio Las series valencianas del romancero nuevo y los cancionerillos de Munich (1589-1602). Noticias bibliográficas por...-Inst. Alfonso el Magnánimo, Valencia, 1963.366 pp. $\| E L, 1964$, núm. 292 (Fernández Pousa).

18-5992. Querol, Miguel (ed.)-Villancicos y romances (siglos $x y$ a xvii) a tres y cuatro voces mixtas.-Inst. Español de Musicología, Barcelona. 1964. $36 \mathrm{pp}$. 18-5993. Montesinos, José F. - Romancerillos tardios. - Anaya, SalamancaMadrid, 1964. 134 pp. (Biblioteca Anaya, 23).

18-5994. Simón Díaz, J.-"Las Exequias reales de Gaspar Dávila”. - RLit, $2 \breve{J}$ (1964), $121-123$.

18-5995. Rodríguez-MoNino, A. - "Las 
maravillas del Parnaso" (N. 16-48036). || $L R, 19$ (1965), 63 (Groult).

18-5996. BourG, JEAN-Una justa poética olvidada: las fiestas de Murcia a San Juan de Dios (I63I).-Academia Al. fonso X el Sabio, Murcia, 1964. 115 pp. I| $L N L, 1964$, núms. 3/4, $9^{8}$ (Guenoun); $L N L, 1965$, núm. 4, 100-101 (Larrieu).

18-5997. Blegua, José Manuel-Floresta lírica española. $2^{\text {a }}$ ed., corregida y aum. -Gredos, Madrid, 1963. 2 ts.: 330,329 pp. (Antología hispánica). - V. núm. 14-38963. || $B A b r, 39$ (1965), 71 (Ra. bassa).

18-5998. Las mil mejores poesias de la lengua castellana. $21^{\text {à }}$ ed.-Eds. Ibériricas, Madrid, $1964 .-\mathrm{V}$. núm. $17-5287$.

18-5990. Los 25000 mejores versos de la lengua castellana.-Vergara, Barcelona, 1963. 522 pp. (Circulo de lectores).

18-6000. Muratov, Aleksander (ed., trad.)-Sevrémenna Ispanska poesia.Sofia, 1964. I| İns, 1964 , núms. $216 / 7$ (Zúñiga).

18-60o1. Hoyo, Arturo del (ed.)-Anto. logia del soneto clásico español (siglos xv-xyii). - Aguilar, Madrid, 1964. 145 pp. (Bibl. de iniciación hispánica). I EL, 1964, núm. 303 (J. M.); RLit, 27 (1965), 227-228 (Rozas).

18-6002 SAINz DE Robles, F. C.-Fabulario español. - Espasa-Calpe, Madrid, 1964. $14^{\circ}$ pp. (Austral, 1334).

18-6003. Argumosa, Miguel Angel de Antologia de la poesia montañesa (1500-1963). - Gráf. Iruma, Madrid, 1969. 215 pp. \|| $E L, 1964$, núm. 292 (Jiménez Martos); RLit, 26 (1964), 203-204 (Quintana); PEsp, 1964, núm. 133 (Umbral).

18-6004. Ribes, Francisco - Poesia de España y América. Sel. y pról. de... -Santillana, Madrid, 1964. 88 pp., ilustr. $\| \mathrm{CuH}, 61$ (1965), 215-217 (X). 18-6005. Ausona, Roberto-Antología de poesias religiosas. - Sintes, Barcelona, 1964. 126 pp. (Biblioteca femenina).Y. núm. 16-44182.

18-6oo6. Río, EMilio deL (ed.)-Antologia de la poesia católica del siglo $\times x$.A. Vasallo, Madrid, 1964. II Ins, 1964, núms 212/3 (Cano); Res, 1 (1964), $3^{6} 3_{-3}{ }^{64}$ (Gutiérrez); Bro, 8o (1965), 544 (Maia); PEst), 1964, núm. 144 (Martínez Ruiz); RyF, $171 \quad(1965), 108$ 109 (Saltor).

18-6007. Antón Andrés, José María y Ánciel (eds.)-La troje de la mies.-
Eds. Trivium, Melilla, 1964. [Antología poética]. II Ins, $196_{5}$, núm. 219 (Beceiro).

18-6oo8. Bodin, Vittorio (ed., trad.) $I$ poeti surrealisti spagnoli.-Einaudi, Torino, 1969. cxxiv + 508 pp. $\| C C$, 115 (1964), 165 (de Gennaro); RHM, $30\left(19^{6} 4\right), 5^{0-5} \mathrm{I}$ (Sobejano).

18-6oog. Arana, Vicente, y Agustín Manso (eds.) - [Poesia española contemporánea. Supervisión de M. Senkiévich. Pról. de F. Kelin.-Ed. Progreso, Moscú, 1964].

18-6010. Jiménez Martos, Luis (ed.) Poetas del Sur.-Arcos de la Frontera, 1963. (Col. Alcaraván, 20). Il Agora, 1963-64, núms. 85/93 (Caro Romero); Rlit, 24 (1963), 281-282 (Mantero); $P E, 1964$, núm. 95, $115^{-116}$ (Martínez Ruiz); $E L$, ig64, núm. 288 (Rincón); PEsp, 1964, núm. $13^{8}$ (Umbral).

18-6o11. Cano, José Luis-Antologia de la nueva poesía española. $2^{\text {a }}$ ed. aum.Gredos, Madrid, 1964. 440 pp. (Antologia hispánica).-V. núm. 14-38964. \| Res, 1 (1964), 288-289 (Delgado); Bro, 81 (1965), 713 (Maia); Íns, 1964, núm. 210 (Marra López); PEsp, 1964, núm. 139 (Umbral).

18-6o12. Cano, José Luis (ed.)-Antologia de la lírica española actual.-Anaya, Salamanca-Madrid, 1964. 100 pp. (Biblioteca Anaya, 54).

18-6013. Olmos García, F.-"Una antologia de poetas españoles de hoy".CuA, 1964, núm. 2, 192-233. [Muchos de ellos son catalanes].

18-6oi4. Jiménez Martos (ed.)-Antologia de la poesia española 1962-1963.Aguilar, Madrid, 1964. 344 pp. (Col. literaria).-V. núm. 18-2618. || $P E$, 1964, núm. 137 (Murciano); CuH, 59 (1964), 410-411 (Quiñones); $E L, 1964$, núm. 288 (Rincón).

V. también núms. $4788,5129,5937,6506$.

A utores antiguos

18-6015. Alonso, D.-“Dos notas al texto de las jarchas". $-F F S$, 111-114.

18-6016. Borello, R. A.- "De nuevo sobre las jarchyas". $-C I, 196_{5}$, núm. 2, 129-132.

18-6017. Borello, R. A.-Jaryas andalusies (N. 14-38966). || Etudes Philos., 16 (1961), 69 (Guy).-V. núm. 17-5308.

18-6018. HeGER, K.-Die bisher veröffent. lichten Hargas (N. 17-1747). $\| A S_{N}{ }^{\prime}$, 201 (1964), 291-233 (Hilty). 
18-6oig. Dutron, B.-"Gonzalo de Ber. ceo y la Crónica de Fernán González de Arredondo".-Ber, 19 (1964), 407. 417 .

18-6ogo. Berceo, Gonzalo De-Milagros de Nuestra Señora. Pról. y notas de Antonio G. Solalinde. - Espasa-Calpe, Madrid, 1964. 212 pp. (Clás. cast., 44). -V. núm. 16.48065.

18-6021. Gariano, Carmelo - Análisis estilistico de "Los milagros de Nuestra Señora" de Berceo.-[Tesis, Univ. of Chicago, 1964].

18-6022. Colonge, C. - "Berceo et la source latine des Milagros. Etude du Miracle 6".-LNL, 1964, núm. 2, 1-14. 18-6023. Berceo, Gonzalo DE-La vida de Santa Oria. Introd. e note a cura di Giovanna Maritano. - Istituto Ed. Cisalpino, Milano-Varese, 1964. II Ber, 19 (1964), $47^{8}$ (Lope Toledo); RLit, 27 (1965), 222-224 (Prieto).

18-6024. Berceo, Gonzalo De-Estoria de San Millán. Textkritische Ausgabe von Gerhard Koberstein. - Aschendorff, Münster, 1963. 307 pp. (Forschungen zur romanischen Philologie, 15). \| Ber, 19 (1964), 477-478 (Lope Toledo).

18-6025. Spitzer, L. - "Sobre la cántica Eya velar".-[En] Sobre antigua poesia española (Buenos Aires, 1962), 2738.-V. núm. 14-38971. || NRFH, 18 (1965-66), 190-191 (Alvar).

18-6026. Dutton, B.-"G. de Berceo and the cantares de gesta" (N. 17-1780). il $L R, 19$ (1965), $5^{6}$ (Groult).

V. también núm. $5^{157}$.

18-6027. Garcia LORA, J. - "Pericles y Apolonio".-PH, 8 (1964), 597-611.-V. núm. 11-25161.

18-6028. Andrés Castellanos, María S.La vida de Santa María Egipciaca, traducida por un juglar anónimo hacia 1215. Gramática, fuentes, versificacion, texto y vocabulario.-Real Academia Española, Madrid, 1964. 259 pp. (Anejos del BRAE, 11).-V. núm. 16-44202. 18-6029. Ruiz, Juan-El libro de buen amor. The Gayoso and Toledo manuscripts. A paleographical transcription with a vocabulary, by Eric Woodfin Naylor. - [Tesis, University of Wisconsin; resumen en $D A, 24$ (196364), 285]. 698 pp.

18-6o3o. RUIz, JUAN - Libro de buen amor. Ed. critica a cura di Giorgio Chiarini. - Ricciardi, Milano-Napoli, 1964. Ixxxiv + $426 \mathrm{pp}$. (Documenti di filologia, 8). 18-6og1. Ruiz, JuAN - Libro de buen amor. $10^{\mathrm{a}}$ ed.-Espasa-Calpe, Madrid, 1964. 17o pp. (Austral, 98).-V. núm. $17-5314$.

18-6o32. Ruiz, JuAN - Libro de buen amor. Versión de María Brey. $3^{\text {a }}$ ed. -Castalia, Valencia, 1964. 286 pp. (Odres nuevos).-V. núm. 16-44208.

18-6033. Mendeloff, H.-"Notes on the Brey Mariño version of the Libro de buen amor".-RNo, 6 (1964), 74-81.

18-6034. Morreale, M. - "Apuntes para un comentario literal del Libro de buen amor".-BRAE, 43 (1963), 24937ı. || RPF, $13(1964-65),{ }_{4}^{66-469}$ (Viqueira).

18-6035. Lomba, J.- "La estética de Ibn Hazm y El libro de buen amor".-ELu, 8 ( 1964$), 72-79$.

18-6og6. Guzmán, J. - Una constante didáctico-moral del "Libro de buen amor" (N. 18-2643). || $A U C h, 1964$, núm. 132, 212-216 (Goic).

18-6037. Zahareas, A. N.-“Juan Ruiz's envoi: the moral and artistic pose".$M L N, 79$ (1964), 206-211.

18-6038. Ullman, P. L.-"Stanzas $144^{-1} 5^{\circ}$ of the Libro de buen amor",-P.MLA, 79 (1964), 200-205.

18-6039. Reckert, S. - “Otra vez savras buena guarida*.-RFE, 47 (1964) $445^{-}$ 448.-V. núm. 10-19o88.

18-6040. Criado de Val, M.-'Doña Endrina y doña Garoça. Dos mujeres en la poesía medieval".-EL, 1964, núm. 288.

18-6041. Le Gentil, P.-"A propos des cánticas de serrana de l'Archiprêtre de Hita". - FFS, 133-141. I ZRPh, 80 (1964), 569 (Hatzfeld).

18-6042. ZahAREAs, A. - "Troba cazurra, an example of Juan Ruiz's art". $-R N o$, 5 (1964), 207-211.

18-6043. Willis, R. S.-"Two Trotacon. ventos".-RPh, 17 (1963-64), 353-362.

$V$. también núms. $4758,4791,5836$.

i 8-6044. SPitzer, L.-“Razón de amor"-[En] Sobre antigua poesia española (Buenos Aires, 1962), 38-58.-V. núm. 14-38975. || NRFH, 18 (1965-66), 191192 (Alvar).

V. también núm. $5^{175}$.

18-6045. Groult, P.-"La Disputa del alma y el cuerpo: sources et originalité". $-F H H, 221-229$.

18-6046. Orduna, G.-“"Una nota para el texto del Rimado de palacio: Venecia, Venençia, abenençia".-BHS, $4^{1} \quad(1964)$, 111-113. [López de Ayala]. 
18-6047. Gimeno Casalduero, J.-"Fuentes y significado del Decir al nacimien. to de Juan $I I$, de Francisco Imperial". $-R L C, 39(1964), 115-120$.

18-6048. Clakke, D. C.-“'Church music in the Dezir a las siete virtudes" (N. 16-48092). II BICC, $19(1964), 376$ (Valderrama Andrade).

18-6049. Martínez Martínez, M.-“Consideraciones sobre la estética de Juan de Mena".-Rev. da Fac. de Filosofia da Paraiba, 1 (1956-58), núm. 3.

18-6050. MENA, JUAN DE-La Coronación [Tolouse, 1489?]. Ed. facsimilar. - La fonte que mana y corre, Murcia, 1964. 81 fols. (Incunables poéticos castellanos, 10).

18-6051. Gimeno Casalduero, J.-“"Notas sobre el Laberinto de Fortuna",-MLN, 79 (1964), $125-139$.

18-6052. Tudela, J.- "El Marqués de Santillana por tierras de Soria". - Celt, 1964 , núm. $27,57-77$.

18-6053. WEBber, E. J.-"Further observations on Santillana's dezir cantares" (N. 17-5329). U BICC, $19 \quad(1964), 602$ (Valderrama Andrade).

186054 . Santillana, Marqués DE-Obras. $3^{\mathrm{a}}$ ed.-Espasa-Calpe, Madrid, 1964. 174 pp. (Austral, 552).-V. núm. 12-33302. 18-6055. [SANTillana, Marqués De]-Los prouerbios de Yñigo lopes de Mendoça con su glosa (Sevilla, 1494). Ed. facsimilar.-La fonte que mana y corre, [Valencia], 1964. 88 fols. sin numerar. (Incunables poéticos castellanos, 11).

18-6o56. Santillana, Marqués de [?]-Refranes que dizen las viejas tras el fuego..., por el orden del $A B C$.-Madrid, 1964. $4^{8}$ pp. [Reproducción facsimilar de la ed. de 1542].

18-6057. Cangrotti, Gualmieri - Le "Coplas" di Manrique tra Medioevo e Umanesimo. - Pàtron, Bologna, 1964. 168 pp. (Saggi, 2). \| BHi, 67 (1965), 195 (Le Gentil).

18-605. 8. [MANRIQUE, Jorge]-Glosa famosissima sobre las coplas de don... Com um estudo de Mário da Costa Roque. $-A B A P, 2$ (1969), 17.88 + 40 pp. de facsímil.

18-6059. Manrique, Jorge-Poesie, ed. M. Pinna (N. 18-2665). || RLM, 15 (1962), 226-228 (Aragone); St, 61 (1965), 379. $3^{80}(\mathrm{X})$.

V. también núm. 6243 .

18-6o6o. Glenn, R. F. - "Rodrigo Cota's Diálogo entre el amor y un viejo: debate or drama?"- $H, 4^{8}(1965), 5^{1-5}$. 18-6o61. Cota, Ronrigo-Diálogo entre el Amor y un viejo, ed. E. Aragone (N. 17-5338). I| $R H M, 29$ (1963), 313 (Carrasco Urgoiti); RLit, $26 \quad(1964), 209$ (Palomo).

18-6o62. Vivian, D. S.- "La Passión trobada de Diego de San Pedro y sus relaciones con el drama medieval de la Pasión".-AEM, \& (1964), 451-47o.

18-6o63. Gimeno, J.- "Sobre el Cartujano y sus críticos" (N. 17-1798). || BICC, 19 (1964), 371-372 (Valderrama Andrade).

Enzina: v. núms. 6514-16.

18-6o64. García de Santa María, GonzA. LO-El Catón en latin $y$ en romance (1493-94). - La fonte que mana y corre, [Murcia], 1964. 36 fols. sin num. (In. cunables poéticos castellanos). [Ed. facsimilar. A continuación, "Versiones castellanas del pseudo Catón. Noticias bibliográficas", por Antonıo Pérez Gú. MEZ, 35 pp. sin num., ilustr.].

18-6065. Montesino, Fray Ambrosio Cancionero (Toledo, 1508). [Reprod. facsimilar por Antonio Pérez Gómez]. -La fonte que mana y corre, Cieza, 1964. 73 fols. (El ayre de la almena, 12).

Boscán: v. núms. 6o66-8.

18-6066. Lapadat, B.-"Diferencias técnicas entre Boscán y Garcilaso".-APh, 3 (1964), 203-220.

18-6067. Garcilaso de LA VEGA Y JUAN Boscín-Obrascompletas. $4^{\text {a }}$ ed.-Aguilar, Madrid, 1964.704 pp. (Crisol, 71). 18-6o68. Boscán y Garcilaso - Poesias.Eds. R, La Habana, 1964. (Bibl. básica de lit, española).

18-6069. Martelli, J. C.- "Garcilaso o el sentido de un poetizar".-Lyra, 1964, núms. $192 / 4$.

18-607o. Garcilaso de la Vega-Obras. $8^{\mathrm{a}}$ ed.-Espasa-Calpe, Madrid, 1964. 152 pp. (Austral, 63).-V. núm. 17-1805.

18-6o71. Davies, G. A.-"Notes on some classical sources for Garcilaso and Luis de León".-HR, 32 (1964), 202-216.

18-6o72. Gallego Morell, Antonio - El poeta Garcilaso de la Vega en el teatro español. - Universidad, Granada, 1963. xxiv +304 pp. (Col. filológica). || Ins, 1964 , núm. 206 (Cano); Seg, 1965, núin, 1, 140-141 (Esquer Torres).

V. también núms. $584^{8}, 595^{-1}$.

18-6073. Rodríguez Moñino, A. - "Nuevos sonetos de Cetina. (Noticia bibliográfica)".-EMP, $7,35^{1-35^{6}}-\mathrm{V}$. núm. 13-37148.

Acuña: v. núm. 5196 . 
18-6074. Spivakovsky, E.-"Some notes on the relations between D. Dicgo Hurtado de Mendoza and $D$. Alonso de Granada Venegas". - $A O, 14$ (1964), $212-232$.

18-6075. Spivakovsky, E. - "Which Don Alonso Venegas? Two episodes from the Guerra de Granada and the Historia del rebelión".- $R N, 17$ (1964), 193196. [Hurtado de Mendoza y Mármol Carvajal].

18-6o76. Spivakovsky, E.-"Lo de la Goleta y Túnez, a work of Diego Hurtado de Mendoza?"- $H M, 23$ (1963), 366 379.

18-6077. GonZález OlLÉ, F.-“Interpretación del perqué de don Diego Hurtado de Mendoza".-RFE, 47 (1964), 449. $45^{1}$.

Ramirez Pagán: v. núm. 6079.

18-60\%8. Cinti, B.-"Erasmismo e idee letterarie in Cristóbal de Castillejo".Annali di Ca' Foscari, Venezia, 3 ( 1964$)$, $65-80$.

18-6079. López Eśrtada, F.-"La Epístola de Jorge de Montemayor a Diego Ramírez Pagán. (Una interpretación del desprecio por el cortesano en la Día$n(t)$ "- $-E M P, 6,387-406$.

18-608o. Rodrf́́gez-Mañino, Antonio El poeta Luis Hurtado de Toledo. No. ticias bibliográficas.-Suc. de Vives Mora, Valencia, 1964. $5^{\mathrm{l}} \mathrm{pp}$.

Luis de León: v. núms, 6015, $7877 \cdot 81$.

18-6o81. López de Ubeda, JuAN-Cancionero general de la doctrina cristiana. Introd. bibliográfica por Antonio Rodriguez-Moñino.-Sociedad de Bibliófilos Españoles, Madrid, 1962, 1964. 2 ts.: 314 , $229 \mathrm{pp}$.

Juan de la Cruz: v. núms. 5958, $7^{848.9}$, $785^{8-67}$.

Herrera: v. núm. $595^{8}$.

18-6082. CAmpo Jesús, LuIs deL-Jerónimo de Arbolancha (poeta del stglo $x \approx i)$. Su vida y su obra. Pról. de Leopoldo Cortejoso. - La Acción Social, Pamplona, $19^{6} 4.33^{6} \mathrm{pp}$.

Cervantes: v. núms. $715^{0-2}$.

18-6083. Durán, J.-“El chapetón Ercilla y la honra araucana".-Fil, 10 (1964), $113-134$.

18-6084. Atkinson, W. C.-"Ercilla and the voice of conscience".-FHH, 31-39. 18-6085. Montes, H.- "E1 héroe de $\mathbf{L a}$ Araucana".-CuH, 6o (1964), 258-268.

18-6086. Caillet-Bors, J.- "Hado y fortuna en La Araucana".-Fil, 8 (1962), $403-420$. 18-6o87. Ercilla, Alonso de-La Arauca na. (Selección). $3^{\mathrm{a}}$ ed.-Zig-Zag, Santia. go de Chile, 1964. 216 pp.-V. núm. 18-2691.

18-6088. Cueva, JuAN DE LA-De las rimas, Édition critique des deux volumes par Paul Verdevoye.-[Tesis complementaria, Universidad de Paris, $\left.19^{6} 4\right]$.

18-6o89. López de Toro, J. - "Gregorio Hernández de Velasco, traductor de Tansillo".-EMP, 7, 331-349.

18-6ogo. Spitzer, L.-"No me mueve, mi Dios..." - [En] Sobre antigua poesía española (Buenos Aires, 1962), 129 . 141.-V. núm. 14-38998.

18-6og1. Coste, J.- "La cuarta capellanía perpetua de Francisco de Rioja". $-A H, 40(1964), 147^{-1} 5^{6}$.

18-6092. LAfFon, R. - "Dos décimas del sevillano doctor Juan de Salinas ( $1559^{-}$ 1643)".-Azor, 1964 , núm. 16.

Lope de Vega: v. núms. 6633-43.

18-6o93. Alonso, D., y E. GalvarriatoPara la biografia de Góngora (N. 18 2697). I| HR, 32 (1964), 369-37o (Gates); $A S N S$, 201 (1964), 477-479 (Müller).

18-6094. Darmangeat, Pierre - Góngora. Choix des textes, tableau synoptique, bibliographie par... - Seghers, Paris, 1964. 222 pp. (Écrivains d'hier et d'au jourd'hui, 13). || LNL, 1964, núni. 2, $104^{-10} 7$ (Guinard).

18-6095. Oliver Belmas, Antonio-Don Luis de Góngora y Argote. Su vida, sus mejores páginas, su época. - Nuevas Editoriales Unidas, Madrid, 1963. $25^{8}$ pp. (Genio y figura). $\| F H, 2$ (1964). 1059 (X).

18-6og6. BoDini, VITTORIo-Studi sul ba rocco di Góngora.-Ateneo, Roma, 1964 140 pp. || NA, $100(1965), 24^{6-2} 4^{8}$ (Salsano); PEsp, 1964, núm. 144 (Umbral); BHS, 42 (1965), 262-263 (Waley).

18-6o97. Alonso, D.-La lengua poética de Góngora (N. $16-48156)$. $\| L R, 18$ (1964), 399 (Vermeylen).

18-6098. Müller, Bodo-Góngoras Metaphorik. Versuch einer Typologie. Franz Steiner Verl., Wiesbaden, 1963. 226 pp. I| $R J, 14$ (1963), 363-966 (Navarro de Adriaensens); $R F, 76$ (1964). $479-483$ (Nolting-Hauff); $Z R P h, 80$ (1964), 192-193 (Reichenberger).

18-6099. Loring, S. - La poesia religiosa de Góngora (N. 17-5376). $\| R y F, 169$ (1964), 215 (Rivas Andrés).

18-610o. Pérez, C. A.-"Juegos de pala- 
bras y formas de engaño en la poesía de Don Luis de Góngora".-Hf, $19^{64}$, núm. 20, 5-47; nứm. 21, $4^{1-72 .-V}$. núm. $17-5369$.

18-6101. Góngora, Luis de-Poesias.-Eris. R, La Habana, 1964. (Bibl. básica de lit. española).

18-6102. Testa, D. P.-"Kinds of obscurity in Góngora's Fábula de Pyramo $y$ Tisbe".-MLN, 79 (1964), 153-168.

18-6103. Carballo Picazo, A.-"El sone to Mientras por competir con tu ca. bellos de Góngora".-RFE, 47 (1964), 379-398.

18-6104. Fernández, S.-"El templo de la luz".-UMx, $18(1963-64)$, núm. 7. [E] Polifemo].

18-6105. Carilla, E.-"La estrofa Xl del Polifemo".-RFE, 47 (1964), 369-377.

18-6106. Orozco, E.--"Aspectos descono. cidos de la polémica de las Soledades de Góngora". - APCH, 395-400.-V. núm. $17-53^{8} 5$.

18-6107. Orozco, E.- "Nuevos textos de la polémica de las Soledades de Gón. gora".-FH, 2 (1964), 613-624.

18-6108. Gates, Eunice JoIner (ed.)-Documentos gongorinos (N. 17-5386). II BHS, 4o (1963), 63-64 (Jones); RHM, $3^{\circ}$ (1964), 147-148 (Pollin); $R R, 54$ (1963), 222-223 (Porqueras-Mayo); $L R$, 17 (1969), 175-176 (Vermeylen).

18-6109. Gallego Morell, A.-“Algunas noticias sobre don Martín Vázquez Siruela".-EMP, 4, 405-424.

18-6110. DEhENNin, ELsA - La résurgence de Góngora et la génération poétique de 1927 (N. 18-2726). H RLC, $3^{8}$ (1964), 473-474 (Darmangeat); HR, 33 (1965), 182-185 (Gates); LR, 19 (1965), 273275 (Pouilliart); RBPH, $4^{2}$ (1964), 1025-1029 (Rand); ASNS, 201 (1964), 397-399 (Sobejano); RHM, 3o (1964), 301-303 (Testa).

V. también núms. $595^{\circ-1}, 6539$.

18-6111. Alonso, D.-"Ln soneto de Medrano imitado por Ariosto".-SOE, $55^{-}$ 74 .

18-6112. Alonso, D., y S. Reckfre-Vida $y$ obra de Medrano (N. 17-5346). II $R J, 15$ (1964), 382-385 (Schrader).

18-6113. Alonso, D.- "Para la biografía de Luis Carrillo. La santidad de Luis Carrillo".-SOE, 55-74.

18-6114. López Estrada, F. - "Historia y poesía en el poema heroico de Rodrigo Carvajal y Robles sobre la con. quista de Antequera (1627)".-APCH, $361-370$.
18-6115. López EstradA, F. (ed.)-Poema del asalto y conquista de Antequera. - Real Academia Española, Madrid, 1963. 289 pp. (Anejos del BRAE, 9) LNL, 1963, núm. 3, 109-111 (Marcus); BHS, 41 (1964), $189-191$ (Pierce); $R F E$ $4^{6}$ (1963), 499-500 (Rull); AlAn, 29 (1964), 383-385 (Vallvé).

Quevedo: v. núm. 7887 .

18-6116. Herrero Llorente, V. J--"Jáuregui, intérprete de Lucano". - Helm, 15 (1964), 389-410.

Hojeda: v. núm. $5^{133}$.

18-6117. Rozas, Juan Manuel-El Conde de Villamediana. Bibliografia $y$ contribución al estudio de sus textos.-C. S. I. C., Madrid, 1964. $108 \mathrm{pp}$ (Cuader. nos bibliográficos, 11). \| RLit, 25 (1964), 225-226 (Díez Taboada); $R V^{\prime} F$, 6 (1959-62), 338-339 (Esquer Torres); BHS, 42 (1965), 214-215 (Price); Seg, 1965, núm. 1, 16o (Quilis); $P E, 11$ (1964), 103-105 (Rull).

18-6118. Rozas, J. M.-“Los textos dispersos de Villamediana”. - RFE, 47 $\left(19^{64}\right), 341-367$.

18-6119. Rosales, Luis-Pasión y muerte del Conde de Villamediana.-Real Academia Española, Madrid, 1964. 112 pp. II $\mathrm{CuH}, 6$ o $(1964), 388-989$ (X).

18-6120. RÉvaH, I. S.-“Un pamphlet... d'Antonio Enríquez Gómez" (N. 17 5397 ). ||$L R, 19(1965), 284-285$ (Vermeylen).

18-6121. Scholberg, K. R.--"Dos obras de titulos de comedias de Miguel de Barrios".-Hf, 1964 , núm. 2o, $55^{-67}$.

18-6122. Serrano Castilla, Francisco José de Cobaleda y Aguilar. Ensayo sobre un poeta inédito del Barroco español.-Santiago de Compostela, 1963. $5^{2}$ pp. || BBMP, 39 (1963), 391-392 (Aguilera); RLit, 27 (1965), 236 (Rodriguez Cepeda).

A utores modernos

Jovellanos: v. núms. 7913-5.

18-6123. Samaniego, FÉLIX MARfA-Fábulas. $4^{\text {a }}$ ed.-Espasa-Calpe, Madrid, 1964. ${ }_{1_{3} 6}$ pp. (Austral, 632).-V. núm. 12 33320 .

18-6124. Samaniego, Félix María de Fábulas.-Dalmau Carles, Pla, Gerona, 1964. 76 pp. (Col. Esopo).

18-6125. Demerson, G. - "Investigación sobre una familia extremeña: la de Meléndez Valdés". - REE, 20 (196.4), $447-455$. 
18-6126. Guinard, P.-J. - "Aspects de la société espagnole au début du $\mathrm{xix}^{\mathrm{e}}$ siècle: l'afrancesado Juan Meléndez Valdés",-Rev. d'Hist. Écon. et Sociale, 41 (1963), 391-401.

18-6127. Demerson, G.-Don Juan Meléndez Valdés et son temps (N. 175408). If $\mathrm{CuH}, 67$ (1966), 776-777 (Amorós); $A O, 14$ (1964), 289-292 (Caso González); RLit, 23 (1963), 289-291 (Romero); ROcc, 7 (1964), $371-380$ (Sarrailh); HR, 33 (1965), 175-182 (Sebold); HAHR, 44 (1964), $27^{\circ}$ (Worcester).

18-6128. Demerson, G.--"Sur une oruvre perdue de Meléndez Valdés: la traduction de l'Éneide". - BHi, 64 bis (1962), 424-436.

18-6129. Juliá Martínez, E.-"Doble faceta literaria de fray Vicente Martinez Colomer".-RFE, 47 (1964), 309-329.

18-613o. CANo, J. L.-"Un centenario olvidado: Cienfuegos".-ROcc, 7 (1964), $365-369$.

18-6131. Reinoso, Félux José - "Textos sobre estética" [ed. por E. Pardo Canalis].-RIEs, 22 (1964), 65-83.

18-6132. Derozier, A. - "Polémiques sur un passage de Quintana".-LNL, 1964 , núm. 1, 31-45.

18-6133. Armas Ayala, A. - "Graciliano Alfonso, un prerromántico español".RHC, 35 (1962), 52-81.-V. núm. 171864 .

18-6134. Guenoun, P.-“Lista, Juretschke et la Real Academia Sevillana de Bue. nas Letras".-LNL, 1964, núm. 2, 4247.

18-6135. Llorens, V. - "Los motivos de un converso". - ROcc, 5 (1964), 44-60 [Blanco White].

18-6196. GonzÁlez Rurz, N.-"Bibliografía literaria del Duque de Rivas".LEsp, 8 (1965), núm. 91 .

18-6137. Ribians, G.- "El regreso de Angel Saavedra de su destierro".-RFE, 47 (1964), $421-427$.

18-6138. Marial, J.-"Don Alvaro: otra batalla del romanticismo".-Lyra, 1964, núms. $192 / 4$.

18-6139. Chelini, R. L.-“J. E. Hartzenbusch e il suo Romancero pintoresco". -MSI, 1965. || RLit, 28 (1965), 256 (Rodríguez Cepeda).

18-6140. Hartzenbusch, Juan Eugenio Los amantes de Teruel. Ed., pról. y notas de J. Hesse. - Aguilar, Madrid, 1964. (Bibl. de iniciación hispánica).

18-6141. Hartzenbusch, Juan Eugenio -
Los amantes de Teruel. Ed. a cura di E. Smergani. - Andò, Palermo, 1964 . $17^{\circ} \mathrm{pp}$.

18-6142. Hartzenbusch, Juan Eugenio Los amantes de Teruel. La jura de Santa Gadea. 6a ed. - Espasa-Calpe, Madrid, 1964. 212 pp. (Clás. cast., 113).

18-6143. Martinengo, A.-"Il Viaje histórico di Espronceda da Gibilterra a Lisbona. Autobiografia o trasfigura. zione fantastica?"-SLSp, 275-283.

18-6144. Martinengo, A. - "Espronceda e la pena di morte".-SMV, 12 (1964), $65^{-103 .}$

18-6145. Díez TaboadA, J. M.-“Vivencia y género en Espronceda y Bécquer".Hom, 1 (1964), 9-23.

18-6146. Martinengo, A. - "Para una nueva edición de Espronceda".-BICC, 19 (1964), 147-162, $565-57$ o.

18-6147. Espronceda, José DE-Poesía lirica. Sel., est. y notas por N. Alonso Cortés. $5^{\text {a }}$ ed.-Ebro, Zaragoza, 1964. 126 pp., ilustr. (Biblioteca clásica Ebro, $3^{8)}$.

18-6148. Martinengo, A. - Polimorfismo nel "Diablo mundo" (N. 18-2782). II Ins, 1964, núm. 207 (Ares Montes); $H R, \quad 34$ (1966), 84-85 (Casalduero); $M L J, 48$ (1964), 248 (Fucilla); $B H i, 66$ (1964), 235-236 (Marrast); $H, 47$ (1964), 198-199 (Pattison); BHS, 41 (1964), 55-56 (Rees).

18-6149. Caravaca, F.-"Dramatis personae en el Diablo mundo de Espronce. da".-CuH, 59 (1964), 356-372.

18-6150. Caravaca, F. - "Notas sobre el humorismo de Espronceda en El Diablo mundo".-RHM, 3o (1964), 119 125 .

V. también núm. 5934 .

18-6151. Chao Espina, E.-"Pastor Diaz a través de dos cartas inéditas de Parga Sanjurjo",-BAG, 29 (1961), núms. $339 / 344$.

18-6152. PARdo BAzÁN, Emilia - "Pastor Díaz". -- CuEG, 18 (1963), 333-346. [Art. inédito].

18-6153. Aragonés, J. E.-"García Gutiérrez. De Chiclana a Madrid". -- $E L$, $196_{4}$, núms. $282 / 283$.

18-61.4. Johnson, H. L.-"A España, soneto de García Gutiérrez".-NRFH, 18 (1965-66), 169 -171.

18-6155. García Gutiérrez, Antonio-El trovador. Ed. de José Hesse-Aguilar, Madrid, 1964. 152 pp. (Bibl, de iniciación hispánica). 
18-6156. Espresati, C. G.-"La juventud de Amalia Fenollosa, poetisa romántica". - BSCC, 39 (1963), 289-309; $4^{\circ}$ (1964), 104-118, 312-344; $4^{1}$ (1965), $47^{-}$ $79,180-197,275-269,321-335$.

18-6157. IRIBARREN, J. M.-"Los carneros de Ramos Carrión y los locos de Campoamor".-Azor, 1963 , núm. 12.

18-6158. Zorrilla, JosÉ-Leyendas. $4^{\text {n }}$ ed. -Aguilar, Madrid, 1964. 1698 pp. (Col. Joya).-V. núm. 12-33337.

18-6159. Zorrilla, José-Don Juan Tenorio. Introd., notas y vocab. de María Delia Iturralde.-Huemul, Buenos Aires, 1964. 192 pp. (Clás. Huemul, 23). 18-616o. Abrams, F.-"The death of Zorrilla's Don Juan and the problem of catholic orthodoxy".-RNo, 6 (1964), $42-4^{6}$.

18-6161. Zorrilla, José - Traidor, inconfeso y mártir. Ed. de Ricardo Senabre. Calpe, Madrid, 1964. 150 pp. (Austral, 1346).

18-6162. ZoRrilla, José - Traidor, inconfeso y mártir. Ed. de Ricardo Senabre. -Anaya, Salamanca-Madrid, 1964. 164 pp. (Biblioteca Anaya, 31).

18-6169. ZORRILLA, JOSÉ-El zapatero y el rey.-Espasa-Calpe, Madrid, 1964. 213 pp. (Austral, 1339).

V. también núms. 5901, 5919.

18-6164. Carnicer, RaMón-Vida y obra de Pablo Piferrer-C. S. I. C., Madrid, 1963. vii +398 pp. (Anejos de RLit). I) $A r b, 5^{8}$ (1964), 363-966 (Bajona).

Pondal: v. núm. 5781 .

18-6165. Guerrero, F.- "Vida y obras de Narciso Campillo". - RLit, 25 (1964), 69-106.

18-6166. Querol, V. W.-"Poesías desconocidas". Ed. de L. Guarner.-RLit, 25 (1964), 135-194; 26 (1964), 117-198.

18-6167. Crispo Acosta, O. - "Gustavo Adolfo Bécquer”. $-R N a, 8$ (1969), 120$156,24^{8-301 .}$

18-6168. Benf́tez, Rubén-Ensayo de bibliografia razonada de $G$. $A$. Bécquer (N. 18-280o). || RHM, 3० (1964), $3^{24}$ (Dennis); HR, $32 \quad(1964), \quad 273-27^{6}$ (King); $P h Q, 43$ (1964), 523 (King); $B H i, 66$ (1964), $23^{6}$ (Marrast); BHi, 67 (1965), 160-163 (Pageard).

18-6169. Brown, Rica - Bécquer.-Acdos, Barcelona, 1963. $4^{16}$ pp., ilustr. (Biblioteca biografica Aedos, 23). II Ins, $196_{4}$, núm. 207 (Cano); RHM, 3o (1964), 299-301 (Carrasco Urgoti); BHi, 67 (1965), 163-169 (Pageard); BHS, $4^{2}$ (1965) 198-199 (Ribbans). 18-617o. Díaz, José Pedro-Gustavo Adolfo Bécquer. Vida y poesia. a a ed., corr. y aum.-Gredos, Madrid, 1964. $486 \mathrm{pp}$. (BRH).-V. núm. 14-39015. || BAbr, 39 (1965), 194 (Angeles); ibid., $3^{8}$ (1964), 300-301 (Browne).

18-6171. Gudel, G. - "Día de Aragón: Bécquer en Veruela". - Zaragoza, 19 $\left(19^{6}\right), \quad 193^{-218}$.

18-6172. Casto, A. - "El monasterio de Veruela y Gustavo Adolfo Bécquer. En el centenario de las Cartas de su celda". -Medicamenta, 43 (1964), $104-108$.

18-6173. Manzano, R. - "Bécquer y los andaluces".-Azor, 1964 , núm. 16 .

18-6174. Sofovich, L.-"Historia madrileña".-Lyra, 1964, núms. 192/4. [Sobre Bécquer].

18-6175. Balbís, R. DE-"Un influjo germanista en Bécquer" (N. 18-2811). $M a p, 1964$, núm. 2, 282-283 (Ferrada). $18-6176$. Schulman, I. A. - "Bécquer y Martí: coincidencias en su técnica literaria".-DHR, 3 (1964), $57-87 .-V$. núm. 17-5423.

18-6177. Aguirre, J. M.-"Bécquer y slo evanescente.-BHS, 41 (1964), 28-39.

18-6178. BALbín, R DE- "Sobre un poema becqueriano desconocido". - RLit, 26 (1964), $91-96$.

18-6179. MUÑoz VALle, I.-"La tradición clásica en la lírica de Bécquer".-ACtas del II Congreso español de estudios clas. (Madrid, 1964), 500-510.

18-6180. Bécoler, Gustavo Adolfo Obras completas. Pról. de Joaquin y Serafín Alvarez Quintero. 11 ${ }^{\text {a }}$ cd. Aguilar, Madrid, 1964. 1332 pp. (Joya). -V. núm. $11-26525$.

18-6181. Bécquer, Gustayo Adolfo-Ri. mas. Ed., introd. y notas de José Pedro Díaz-Espasa-Calpe, Madrid, 1963. cxix $+14^{8}$ pp. (Clas, cast., 158). $\| L T$, 1964, núm. 47, 166-17o (Garciasol); BHS, 42 (1965), 199-200 (Ribbans).

18-6182. Bécquer, Gustayo AdOlfo-Rimas y leyendas. Advertencia preliminar de Lconcio Gianello.-Castellvi, Santa Fe, Argentina, 1964. 174 pp.

18-6183. Bécourr, Gustavo Adolfo-Rimas $y$ leyendas, $7^{\mathrm{a}}$ ed.-Aguilar, Madrid, 1964. 574 pp. (Crisol, 27o). $-V$. núm. 18-2806.

18-6184. Zardoya, C.-“Las Rimas de G. A. Bécquer a una nueva luz" (N. 175419). $\| P h Q, 43$ (1964), 524-525 (King). $18-6185$. BALbín, R. DE- "Una estrofa heterométrica en G. A. Bécquer".-EMP, $7,129-134$. 
18-6186. WoOLSEY, W.-“La mujer inalcanzable como tema en ciertas leyendas de Bécquer". $-H, 47$ (1964), 277-281.

V. también núm. 6145 .

18-6187. Cubero Sanz, Manuela-Vida y abra de Augusto Ferrán.-[Tesis, Univ. de Madrid; resumen en RUM, 12 (1963), 756-757].

Rosalía de Castro: v. núms. $5782-8$.

Pérez Galdós: v. núms. 7262-3.

18-6188. Fogelquist, D. F. - "Salvador Rueda y Rubén Dario". - RHM, 30 (Ig64), $189-204$.

18-6189. Ferreres, R.-"Diferencias y coincidencias entre Salvador Rueda y Rubén Dario".-CuH, 57 (1964), 39-44. 18-61go. VÁzquez Otero, D. - Salvador Rucla (N. 16-48289). || RLit, 23 (1969), 305 (Diez Taboada).

Unamuno: v. núms. 8o73-93.

18-6191. Lozano, P.--"Archivo epistolar de Carlos Fernández Shaw".-RLit, 22 (1962), 125 -210.

Valle-Inclán: v. núm. 7325 .

18-6192. Esquer Torres, R. - “Algunos datos de interés acerca de Gabriel $y$ Galán".-RLit, $25 \quad(1964), 125$-132.

18-6199. Esquer Torres, R.-"Sobre Ga. briel y Galán y el ms. de $E l$ l $m a^{\text {s" }}$ (N. 16-48297). || LR, $19(1965), 69$ (Groult).

18-6194. Gabriel y Galán, José MaríaCastellanas. Nuevas castellanas. Extre. meñas. '2 ${ }^{\mathrm{a}}$ ed.-Espasa-Calpe, Madrid, 1964. 210 pp. (Austral, 808).

18-6195. Arauz DE Robles, S.- "Manuel Machado, místico laico". - EL, 1964, núm. 297.

18-6196. Dominicis, M. C. - "Antonio y Manuel Machado y su Don Juan de Mañara".- $H, 4^{6} \quad\left(19^{63}\right), 73^{\circ}-734$.

18-6197. Albornoz, A. DE-"Bibliografia de Antonio Machado",- $L T, 12$ (1964), $505-553$.

18-6198. "Homenajes a Machado". - ins, 1964, núm. 208. [Noticia].

18-6i99. ONís, F. DE-"Introducción: Antonio Machado $(1875-1939) "-L T, 12$ (1964), $11-20$.

18-6200. "Antonio Machado". - Arriba, Madrid, 23 febr. 1964. [Varias colaboraciones].

18-6201. Torre, G. DE-“Antonio Machado a los veinticinco años de su muerte".-CCL, 1964, núm. $86,5^{1-55}$.

18-6202. Lorda Alaiz, F. M.-"El vigésimoquinto aniversario de la muerte de Antonio Machado en Holanda".-Ins, 1964, núm. 210 .
18-6203. Vivanco, L. F.-"Palabras sobre Antonio Machado".-CuD, 1964, núm. 7. 18-6204. Armijo, R.-"Semblanza de A. Machado".-Rev. de Educación, Santo Domingo, 33 (1963), 73-78.-V. núm. 18-2819.

18-6205. Bergamín, J.-"Antonio Machado, el bueno". $-L T, 12$ (1964), 257-264. 18-6206. Kelin, F.-"Encuentros con Antonio Machado".- $L S, 1964$, núm. 7, 168-17o.

18-6207. CAssou, J.-"Mi alegre leyenda olvidada..."-LT, 12 (1964), 285-295.

18-6208. Tuñón de LARA, M.-"Machado vivant". $-E$, 1964 , núms. 419/20, $39^{-5}$. 18-6209. Marra-López, J. R. - "Antonio Machado: una presencia ejemplar".İns, 1964 , núms. $212 / 3$.

18-6210. LAscaris, C.-"El Machado que se era nada".-LT, 12 (1964), $137-207$. 18-6211. Palley, J.- "Los tres tiempos de Antonio Machado".-RHM, $3^{\circ}$ (1964), $257-260$.

18-6212. Ruiz de Conde, J.-"La crisis de Antonio Machado hacia 1926". $-L T$, 12 (1964), 111-126.

18-6q13. Abellán, J. L.-"La novela personal de Antonio Machado".-BISD, 1964, núm. 31, 227-236.

18-6214. Haldas, G.-"Exil et mort d'Antonio Machado, ou un destin brisé". $-E, 19^{6}$, núms. 419/20, 55-58.

18-6215. Casalduero, J.-“Machado, poeta institucionista y masón". $-L T, 12$ (1964), 99-110.

18-6216. Garcfa Sabell, D.-"El gran silenciario de España".-Ins, 1964, núms. $212 / 3$.

18-6217. Enjuto, J. - "Apuntes sobre la metafísica de A. Machado", $-L T, 12$ $(1964), 209-220$.

18-6218. Abellán, J. L.-“Antonio Machado, «filósofo cristiano". - LT, 12 (1964), 221-239.

18-6219. Muñoz G., L.- "La muerte, tema poético de A. Machado".-Map, 1964, núm. 1, 88-96.

18-622o. Durín, M.-“Antonio Machado, el desconfiado prodigioso".-Ins, 1964, núms. $212 / 3$.

18-6221. GonzÁlez, R. A.-"Las ideas políticas en Antonio Machado".-LT, 12 $(1964), 15^{1-170 .}$

18-6222. Campos, J. - "Antonio Machado y Giner de los Ríos: comentario a un texto olvidado". $-L T, 12$ (1964), 59-64. 18-6223. Rosario, C.- "La realidad y Antonio Machado".-LT, 12 (1964), 369$3^{86 .}$ 
18-6224. ZaRDoYA, C. - "Los caminos de Antonio Machado". - LT, 12 (1964), $75-98$.

18-6225. URMenfta, F. DE-"Sobre estética machadiana". - RIEs, 22 (1964), $141-146$.

18-6226. BeCEIro, C. - "Notas para la poética machadiana”.-Ins, 1964, núrns. $212 / 3$.

18-6227. Carilla, E.-"La poesía de Antonio Machado". - RHM, 3o (1964), $245-256$.

18-6228. Parker, J. M.- "The poetry of Antonio Machado". - English Studies in Africa, 7 (1964), 217-226.

18-6229. AyalA, F. - "Un poema y la poesía de Antonio Machado".-LT, 12 (1964), 313-319.

18-62zo. González, J. E.-"Imagen espiritual de Machado desde su poesía".$L T, 12$ (1964), 349-367.

18-6231. Blanco Aguinaga, C.-"Sobre la -autenticidado de la poesía de Machado".-LT, 12 (1964), 387-408.

18-6232. Matos, V.-"Antonio Machado a la luz de las teorías poéticas de Johannes Pfeiffer". - Atenea, San Juan (Puerto Rico), 1 (1964), 37-42.

18-6233. Torre, G. DE--"Teorías literarias de Antonio Machado",-LT, 12 (1964), $297-312$.

18-6234. Guerra Castellanos, E. - "Influencias y coincidencias en la concepción poética de Antonio Machado".-HuNL, 5 (1964), 191-203.

18-6235. Navarro Tomás, T.-"La versificación de Antonio Machado". $-L T$, 12 (1964), 425-442.

18-6236. Gicovate, B. - "La evolución poética de Antonio Machado".-LT, 12 (1964), $321-328$.

18-6237. Ferreres, R.- "Etapas de la poesía de Antonio Machado".-CuH, 59 (1964), 303-319.

18-6238. RoA, R. - "Antonio Machado, poeta del pueblo".-[En su libro] $R e$. torno a la alborada (La Habana, ig64), t. 1, pp. 393-397.

18-6239. DARMAngeat, P.-“Antonio Machado ou le lyrisme de la conscience". $-E, 1964$, núms. 419/20, 32-39.

18-6240. Gullón, R.- "Simbolismo y modernismo en Antonio Machado".- $L T$, 12 (1964), 329-347.

18-6241. Grant, H. F.-“" Ańngulos de enfoque en la poesia de Antonio Machado".-LT, 12 (1964), 455-481.

18-6242. Serrano Poncela, S.-"Borrosos laberintos"., $-L T, 12$ (1964), 265-284.
18-6243. Prccioto, R. S. - "Meditaciones rurales de una mentalidad urbana: el tiempo, Bergson y Manrique en un poema de Antonio Machado".- $L T, 12$ (1964), 141-15o.

18-6244. Rodríguez Forteza, AdelA Contribución al estudio de la naturaleza en la poesía de Antonio Machado. -[Tesis, Univ. de Madrid; resumen en $R U M, 13$ (1964), 601-602].

18-6245. BARnstone, W.-"Sueño y paisàje en la poesía de Antonio Machado". $-L T, 12$ (1964), 127-139.

18-6246. AlBorNoz, A. DE-"La presencia de Segovia en Antonio Machado".Ins, 1964, núms. $212 / 3$.

18-6247. Molina, R. A. - "Antonio Machado y el paisaje soriano". $-L T, 12$ (1964), $65-73$.

18-6248. Diego, G.-“Antonio Machado y el soneto". - LT, 12 (1964), 443454 .

18-6249. Turner, D.-“Machado explicado por Machado".-Ins, 1964, núms. $212 / 3$.

18-6250. Lampreave Taracido, B. - "E1 mundo clásico de Antonio Machado". -Actas del II Congreso español de estudios clás. (Madrid, 1964), 489500.

18-6251. Valverde, J. M.-"Para la lectura de Antonio Machado".-Ins, 1964, núms. $212 / 3$.

18-6252. Machado, A. - Poesie, ed. O. Macrì (N. 17-5461). || BHS, $4^{1}$ (1964), 193-195 (Ribbans).

18-6253. MACRí, O. - "Algunas adiciones y correcciones a mi edición de las poesías de A. Machado". - LT, 12 $(1964), 409-424$.

18-6254. Machado, Antonio - Poesias completas.-Eds. R, La Habana, ig64. (Bibl. básica de lit. española).

18-6255. Machado, Antonio-Campos de Castilla. Ed, de José Luis Cano.-Ana. ya, Salamanca-Madrid, 1964. 128 pp. (Biblioteca Anaya, 38).

18-6256. Machado, Antonio - Castilian ilexes, Versions from..., by Charles Tomlinson and Henry Gifford. - Oxford Univ. Press, London, 1963. xvi + 42 pp. II BHS, 43 (1966), 79 (Terry). 18-6257. Foster, D. W.-"La tierra de Alvargonzález. Una contribución machadeana al romance español". $-R N C$, 166 (1964), 98-110.

18-6258. Beceiro, C.-"Sobre la fecha y circunstancias del poema A José Maria Palacio".-LT, 12 (1964), 39-57.

18-6259. ENJuto, J. - "Comentarios en 
torno al poema Siesta, de Antonio Machado".-Ins, 1964, núms. 212/3.

18-6260. Chapman, J. A.-“Antonio Machado's Espejo sin azogue and a seguiriya gitana".-RNo, 6 (1964), 16-2o.

18-6261. Machado, Antono - Juan de Mairena. Ed. and transl. by Ben Belitt.-Univ. of California Press, Berkeley-Los Angeles, 1963. xxxi + $135 \mathrm{pp}$. || $H, 47$ (1964), 870-871 (Dominicis); BHS, 42 (1965), 204-206 (Grant); NVH, 12 (1964), 31 (M. di M.).

18-6262. Echevarria, J.-"Con Juan de Mairena, años después". - LT, 12 (1964), $171-185$.

18-6263. Tudela, J. - "Unos originales inéditos de Antonio Machado". - Ins, 1964 , núms. $212 / 3$.

18-6264. Carprntero, H.-"Un texto olvidado: discurso de Antonio Machado en el homenaje a Pérez de la Mata". $-L T, 12$ (1964), 21-38.

18-6265. Carpintero, H.-"Un texto olvidado. Prólogo de Antonio Machado al libro Helénicas, de M. H. Ayuso".Celt, 15 (1964), $167-183$.

18-6266. Marrast, R.-"Un texto olvidado de Machado sobre teatro". - Ins, 1964 , núms. $212 / 3$.

18-6267. Albornoz, A. DE- "Cartas y documentos de Antonio Machado".-LT, $12(1964), 24^{1-25} 6$.

18-6268. "Cartas de Machado y d'Ors a Juan Ramón”. - $P E$, 1964, núm. 104 .

18-6269. T[Udela], J.-"Unamuno y Antonio Machado". - Ins, 1964, núms. $216 / 7$.

18-627o. Carrasquer, F., y J. Lechner"La Castilla de Unamuno y de Machado". - Norte, Amsterdam, jul.-ago. 1964 .

18-6271. Cano, J. L.- "Machado y la generación poética del '25". - LT, 12 $(1964), 483-504$.

18-6272. Tuñón dE LARA, A.-“Actualidad de Antonio Machado". - Norte, Amsterdam, jul.-ago. 1964 .

18-6273. Lorda Alaiz, F. M.-"De jonge Spaanse poëzie: In het teken van Don Antonio Machado".-Raam, 1964, núm. 5. $46-62$.

18-6274. Tuñón DE LARA, M.-"Los grandes temas de la cultura española en Ia hora presente".-CuA, 1964, núm. 6, 23-45. [La "vigencia" de A. Machaclo].

V. también núms. $57^{8}, 55^{8} 6,595^{1}$, 6196.
18-6275. Marquina, Enuardo-Teresa de Jesús. Ed. de José Montero Alonso.Anaya, Salamanca-Madrid, 1964. $\quad 152$ pp. (Biblioteca Anaya, 48).

18-6276. Marquina, Eduardo - Dias de infancia y adolescencia. (Memorias del último tercio del siglo xix). Pról. de José María Pemán.-Juventud, Barcelona, 1964. 189 pp., láms. (Grandes biografias). I| Ins, 1964, núms. 216/7 (Cano); Arb, 59 (1964), 404-405 (Santaló) .

18-6277. RoA, R. - "Juan Ramón Jiménez".-[En su libro] Retorno a la albo. rada (La Habana, 1964), t. 1, pp. 457 460.-V. núm. 13-37213.

18-6278. López RUEDA, J.- "Vida y obra del Andaluz universal".-Anales de la Universidad Central, Quito, 93 (1964), 389-411; Cuadernos de Arte y Poesia, Quito, 1964, núm. 13, 133-160.

18-6279. Chrysantis, K.-["Dos poetas españoles: J. R. Jiménez y F. García Lorca"]. - Kypros Lyriké, Nikosia, $196_{3}$, núm. $32 ; 24$ pp. [Con traducciones al griego].

18-6280. Gullón, R.-"Diario de un poe. ta recién casado: Juan Ramón Jiménez en Nueva York y Nueva Inglaterra". $-A W, 16$ (1964), 11-15.

18-6281. Garfias, F.-"Las revistas juan. ramonianas".-PEsp, 1964, núms. 140/1. 18-6282. TORres-Rroseco, A.- "La agonia de Juan Ramón Jiménez".-DHR, 3 (1964), $16_{5}^{-168 .}$

18-6283. Ulibarrí, SABINE R.-El mundo poético de Juan Ramón. Estudios estilisticos de la lengua poética y de los simbolos.-Edhigar, Madrid, 1963. 285 pp. (Estudios de literatura española). $-V$. núm. 14-39058. || $M L J, 4^{8}$ (1964), 59-6o (Ferrer); H, 47 (1964), 199-200 (Palau de Nemes).

18-6284. Suria de Crespo, Carmen DeLIA-El téma de América en la obra de Juan Ramón Jiménez.-[Tesis, Univ. de Madrid; resumen en $R U M, 13$ (1964), 606-608].

18-6285. Jiménez, Juan Ramón-Antolojia para niños $y$ adolescentes. $2^{\text {a }}$ ed.Losada, Buenos Aires, 1964. 207 pp.V. núm. 10-2og13.

18-6286. Jiménez, Juan Ramón-Primeros libros de poesia. $2^{\text {a }}$ ed.-Aguilar, Madrid, 1964. 1594 pp. (Biblioteca pre-

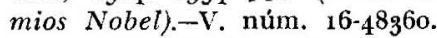

18-6287. JIMÉnEz, JUAN RAMón-Baladas de primavera.-Losada, Buenos Aires, 1964. 130 pp. (Contemporánea, 190). 
18-6288. Jimenez, Juan Ramón - Elejias. Pról. de Francisco Garfias. - Losada, Buenos Aires, 1964. 124 pp. (Contemránea, 192).

18-6289. JimÉnez, JuAn Ramón-Sevilla. Sel. y pról. de Francisco Garfias.-Ixbiliah, Sevilla, 1963. 44 pp. \| CCL, 1964 , núm. 85,81 (D. I. R.); $B A b r, 39$ (1965), 72-73 (Figueira); RLit, 25 (1964), 262 (Mantero); PEsp, 1964, núm. 135 (Murciano).

18-629o. JIMÉNEZ, J. R.-Platero y yo, ed. E. Milazzo (N. 17-5489). \|| RLit, 26 (1964), 244 (Palomo).

18-6291. Jiménez, Juan Ramón-Plalero $y$ yo. Elegia andaluza (1907-1916).Nauta, Barcelona, 1964. 151 pp., ilustr. -V. núm. 18-2873.

18-6292. JIMÉnez, JUAN RAMón-Platero $y$ yo. $7^{\text {a }}$ ed.-Aguilar, Madrid, 1964 . 354 pp. (Col. literaria).-V. núm. 16$483^{6} 4$.

18-6293. Jiménez, Juan Ramón-Platero y yo. Ed. para niños. $22^{\text {a }}$ ed.-Losada, Buenos Aires, 1964.-V. núm. 18-2875. 18-6294. Jiménez, JUAN RaMón-Platero und ich. Andalusische Eligie. Aus d. span. von Doris Deinhard.-Insel Verl., Wiesbaden, 1964. 68 pp. (Insel-Büche. rei, 578).-V. núm. 17-5491.

18-6295. Guillén, F. - "Juan Ramón y Platero". - Critica 63, Rosario, 1963, núm. 6, 9-11.

18-6296. Russell, D. I.- "Platero en su medio siglo".- $\mathrm{CuH}, 60 \quad\left(19^{64}\right), \quad 15^{\circ}$ 154 .

18-6297. GonzÁlez, M. P. - "Marginalia modernista". $-A, 1964$, núm. 403, 7o83. [El modernismo, de J. R. Jiménez]. 18-6298. Gicovate, B. - "El modernisuo y su historia".-HR, 32 (1964), 217226. [Sobre el libro de J. R. Jiménez].

18-6299. Goulakd, Matica-Juan Ramín Jiménez y la critica en Escandinavia.Instituto Iberoamericano, Gotemburgo; fnsula, Madrid, 1969. $188 \mathrm{pp}$. $\|$ St $N$, 37 (1965), 202-203 (Franzbach); $S_{i v r,}$ 1964, núm. 288, 88-89 (Santa Catalina); RLit, 23 (1963), 300-301 (Rozas).

18-63oo. Gullón, R. - Relaciones... entre J. R. Jiménez y los Martinez Sierra (N. 17-5494). \|HAHR, 44 (1964), 266-267 (Terry).

18-6go1. UCEDA, J.-"Juan Ramón Jiménez en relación con los poetas Otero, Hierro e Hidalgo".- $A U H, 25$ (1964), $51-75$.

V. también núms. 6268,6406 . 18-63o2. Poyas, Thérèse-Fernando Villalón ou l'éternel visage de la posisie sur les rives du Guadalquivir.-Jean Grassin, [Paris], 1963. || LNL, 1964, núm. 1, 127-129 (Larrieu).

18-6303. Cirre, José Francisco-La poesia de José Moreno Villa.-Insula, Madrid, 1963. $152 \mathrm{pp}$. || BHS, 41 (1964), 197-199 (Aguirre); Ins, 1963, núm. 202 (Cano); RHM, 32 (1966), 113-114 (Rodríguez Alcalá); CuA, 1964, núm. 2, 289.29o (de la Selva); $\boldsymbol{H}, 4^{8}$ (1965), 182 (Young); Asom, 1965, núm. 1, 89 (Zuleta).

18-6304. DE Filipro, L. - "Roma nella poesia di Ramón de Basterra".-SRo, 12 (1964), 186-193.

A utores contemporáneos

18-6305. TORre, G. DE - "La poesía de León Felipe".-LyP, 4 (1963), 14-16.V. núm. 18-28go.

18-6go6. LEÓN FELIPE - Obras completas. Ed. por Adolfo Ballano Bueno, cuidada por Andrés Ramón Vásquez, pról. de Guillermo de Torre.-Losada, Buenos Aires, 1963. 1076 pp., ilustr. (Col. Cumbre). II CuA, 1964, núm. 4, $181-185$ (de la Selva).

18-6go7. Lizano, Jesús-Federico García Lorca.-Plaza y Janés, Barcelona, 1964. 78 pp. (Enciclopedia popular ilustrada). || PEsp, 1964, núm. 142, 7-8 (Murciano).

18-6308. Lorenz, Günther W. - Federico Garcia Lorca. Vom Autor gekurzte Fassung der Originalausgabe. - Rowohlt, Hamburg, 1963. 179 pp., ilustr. -V. núm. 17-1942. || RLit, 27 (1965), 252-254 (Rodriguez Richart).

18-6309. HubAy, M. - "García Lorca".Válasz, 1948, $227-237$.

18-6310. GuILLÉN, J.-"Federico en personne".-MF, 349 (1963), 714-739; $35^{\circ}$ $(1964), 62-85 .-V$. núm. 16-48382.

18-6311. TolnaI, G. - "Federico García Lorca".-[En su libro] Évek, századok (Budapest, 1958), pp. $4^{1-67 .-V}$. nuim. 16-48379.

18-6312. Ayala Gauna, V. - "Federico García Lorca, poeta y gitano". - La Diligencia, Rosario, 1964 , núm. 16 , 7-25.

18-6313. Marinello, J. - "Sobre Federico García Lorca”-[En su libro] Contem. poráneos (La Habana, 1964), 193-226. [Dos ensayos: "Un poeta clásico" y "Federico en Cuba"]. 
18-6314. Celaya, G. - "Last encounter with Lorca". - MR, 5 (1964), 635639 .

18-6315. Tolnal, G.-“Hej, Federico Ga1cia".-Csillag, 1955, 1654-1662.

18-6916. González Guzmán, P.-"Federico en Almería. Nuevos datos para la biografía de García Lorca". - PSA, 35 (1964), 203-220.

18-6317. El poeta [Garcia Lorca] en La Habana.-Ministerio de Educación Pú-

blica, La Habana, 1961 .

18-6918. RoA, R. - "El crimen fue ch Granada".-[En su libro] Retorno a la alborada (La Habana, 1964), t. 1, pp. $398 \cdot 404$.

18-6319. Couffon, Claude - En Grana. da, tras las huellas de Garcia Lorca. Trad. Lelia Hernández.-Eds. R., La Habana, 1964. 106 pp.-V. núm. 175524. II Casa de las Américas, 1964, núm. 27, 111-114 (Martí).

18-6320. Oliver, W. I. - "The trouble with Lorca".-MD, $7 \quad\left(196_{4}\right), 2-15$.

18-6321. Tolnar, G. - "Federico Garcia Lorca siratója". - Magyar Tudom. Akad. Nyelv és Irodal., Oszt. Közle ményei, 18 (1961), 175-196. - V. núm. $16 \cdot 48391$.

18-6322. Shúmskaia, N. - "De la poesía española: ciclo vocal de Kirill Mol. chánov".,-LS, 1964, núm. 12, 171-174. [Sobre poemas de García Lorca].

18-6323. Tolnai, G. - “Jegyzetek Garcia Lorca lirájáról”. - Nagyuilug, 1957 , 439-448.

18-6324. YaHNi, R.-“Algunos rasgos formales en la lírica de Garcia Lorca: función del paréntesis". - BHi, $66^{\circ}$ (1964), 106-124.

18-6325. HONIG, E. - "Reality and realism in Cervantes and Lorca". $-N M Q$, $34(1964), 31-47$.

18-6326. ARY, R.-"El otro mensaje de Federico García Lorca”.-Lyra, 1964, núms. $192 / 4$.

18-6327. Bosch, R.-“El choque de imágenes como principio creador de García Lorca".-RHM, 3o (1964), $35-44$. 18-6328. Sesé, B. - "Les racines dans l'univers imaginaire de Federico Garcia Lorca".-LNL, 1964 , núms. $3 / 4,44^{-}$ 63.

18-6329. Samatan, M. E.-“El tema de la mujer en García Lorca".-USF, 1964, núm. $60,55^{-69}$.

18-633o. Bogu, A.-"Pauta de lo femeni. no en García Lorca".-La Diligencia, Rosario, 1964, núm. 16, 3-6.
18-6331. Pérez de Calleja, A.-"El sentido de la honra en García Lorca".NEt, 1964, núm. 29, 247-252.

18-6332. Magariños, S.-“García Lorca y la muerte" (N. 17-1951). \|LR, 19 (1965), 199-200 (Molhant).

18-6333. Rio, E. DEL - "Dios en García Lorca”.-RyF, 170 (1964), 490-494.

18-6334. García Lorca, Federico - Los mejores versos de...-Nuestra América, Buenos Aires, 1961, 4o pp. (Cuadernillos de poesía, 11).-V. núm. 16$444^{67}$.

18-6335. Garcfa Lorca, Federico--Obras completas. $6^{\mathbf{a}}$ y $7^{\mathbf{a}}$ eds.-Aguilar, Madrid, 1964. lxxx +2054 pp. (Obras eternas).-V. núm. 18-2910.

18-6336. García LORCA, Federico-Obras completas. T. 6: Asi que pasen cinco años, El maleficio de la mariposa. Farsas breves. 8? ed.-Editorial Losada, Buenos Aires, 1964. 222 pp.-V. núm. 12-31544.

18-6337. Cirre, J. F.-"Algunos aspectos del ejardín cerrado" en las Canciones de Federico García Lorca".-CuA, 1964 . núm. 1, 206-21\%.

18-6338. Garcha Lorca, Federico-libro de poemas. $4^{\text {a }}$ ed.-Losada, Buenos Aires, 1964. (Contemporínea, 149). - V. núm. 12-31538.

18-6939. García Lorca, Federico - Romancero gitano. $8^{\text {a }}$ ed.-México, 1963 . 160 pp.-V. núm. 18-2913.

18-6340. Garcia Lorca, Federico $-\boldsymbol{R} \boldsymbol{\theta}$ mancero gitano. $10^{\text {a }}$ ed.-Losada, Buenos Aires, 1964. 117 pp. (Contemporánea, 116).-V. núm. 17-1962.

18-6341. García Lorca, Federico - The Gypsy ballads. Transl. by Rolfe Humphries. 3d. ed.-Indiana Univ. Press, Bloomington, 1963 . 64 pp.-V. núm. 915314 .

18-6542. Blanquat, J. - "La lune manichéenne dans la mythologie du Romancero gitano".-RLC, $3^{8}(1964), 37^{6}$. 399 .

18-6343. Glasser, D. M.-“Lorca's Burla de don Pedro a caballo".-H, 47 (1964), 295-301.

18-6344. García Lorca, Federico-Poema del cante jondo. $5^{\mathrm{a}}$ ed.-Losada, Buenos Aires, 1964. 127 pp. (Contemporánea, 125)-V. núm. 17-1966.

18-6345. Young, H. T.-"Lorca and the deep song". - Claremont Quart., 11 (1964), núm. 2, 5-14.

18-6346. LIMA, ROBERT-The theater of Garcia Lorca.-Las Americas, New York, 
1963. ix $+33^{8}$ pp. $\| B A b r, 3^{8}(1964)$, 72 (Duncan); $H R, 34$ (1966), 72-73 (Honig); BHS, 42 (1965), 207-209 (Knight); RHM, 3o (1964), 313-314 (Valenzuela) .

18-6347. LAMBRY, JEAN-Histoire interne et externe du théatre universitare $L a$ Barraca.-[Diplôme d'études supérieures, Univ. de París, 1961].

18-6348. Garcfa Luengo, E. - "Revisión del teatro de García Lorca”.-PA, $190_{4}$, núm. $5^{\circ}, 20-26$.

18-6349. Fernández Santos, A.- "La vuelta de Federico García Lorca". - $P A$, 1964 , núm. 50, $17-19$.

18-635o. Cano, J. L. - "Vuelven García Lorca y Casona".-Asom, 20 (1964), núm. 1, 55-57.

18-6351. AbIRACHed, R.-"Retour à Lorca".-Études, 320 (1964), 384-388. [Piezas de Lorca en París].

18-6352. García Lorca, Federico-Teatro. Prol. e trad. di V. Bodini. $3^{\text {? }}$ ed.Einaudi, Torino, 1964. xxiii $+595 \mathrm{pp}$. -V. núm. 17-1970.

18-6353. Garcta Lorca, Federico - Five plays. Comedies and tragicomedies. Transl. by J. Graham-Luján and R. L. O'Connell.-New Directions, New York, 1964. $246 \mathrm{pp}$.

18.6354. García Lorca, Federico-La zapatera prodigiosa. Ed. by J. M. Street and F. Street.-Harrap, London, 1962. 112 pp. II BHS, $4^{1}(1964), 126$ (Morris) .

18-635.5. García Lorca, Federico-La $z a$. patera prodigiosa. $6^{a}$ ed.-Losada, Bue nos Aires, 1964. 114 pp. (Contemporínea, 133).-V. núm. 18-2936.

18-6356. García LORCA, Federico-Mariana Pineda. $4^{\text {a }}$ ed.-Losada, Buenos $\mathrm{Ai}$ res, 1964. 131 pp. (Contemporánea, 115).-V. núm. 13-37283.

18-6957. Torrente Ballester, G.-" $M a$. riana Pineda 1927".-PA, 1964, núm. $5^{\circ}, 27-28$.

18-6958. García Lorca, Federico-Bodas de sangre. $5^{\text {a }}$ ed.-Losada, Buenos $\mathrm{Ai}$ res, 1964. (Contemporánea, 141). - V. núm. $17-1975$.

18-6359. García Lorca, Federico-Bodas de sangre.-Eds. $\mathrm{R}$, La Habana, $196_{4}$. (Col. Repertorio teatral).

18-6360. Tolnái, G.- “Vérnász".-[En su libro] Évek, századok (Budapest, 1958), pp. 233-236. [Bodas de sangre].

18-6361. OlMo, R.- "Prólogo a la versión árabe de Bodas de sangre, por Abd Allah al-Amrani, y resumen del $\mathrm{mis}$ - mo en castellano".-Cuadernos de la Biblioteca Española de Tetuán, 1964 núm. 2, 83-9o.

18-6362. Lisboa, J. Garlos-Lorca e "Bodas de sangre".-Sedegra, Rio de Janeiro, 1961. $237 \mathrm{pp}$.

18-6363. Touster, E. V.-"Thematic patterns in Lorca's Blood wedding". $-M D$, 7 (1964), 16-27.

18-6364. García Lorca, Federico-La casa de Bernarda Alba. Pról. de D. Párez Minik, observaciones y notas de J. A. Bardem. - Aymá, Barcelona, 1964. 122 pp., láms. (Voz imagen, serie teatro, 2). $\| E L, 1964$, núm. 284 (Aragonés); $A u$. las 63, Madrid, 1964, núm. I1 (Ladrón de Guevara); Res, 1 (1964), $125^{-127}$ (Martínez Ruiz); PE, 1964, núm. 95, 111-113 (Ponce).

18-6365. Garcia Lorca, Federico-La $\boldsymbol{c a}$ sa de Bernarda Alba. 6a ed.-Losada, Bucnos Aires, 1964.125 pp. (Contemporánea, 153 ). -V. núm. 16-4843o.

18-6366. García Lorca, Federico-A casa de Bernarda Alba. Trad. Gonçalo Gomes. Nova ed.-P'ubls. Europa-América, Lisboa, $1964.137 \mathrm{pp}$. (Col. Três abelhas).-V. núm. 16-48431.

18-6367. "La casa de Bernarda Alba".$P A, 1964$, núm. 5o, 7-16. [Hablan Bardem, Doménech y otros].

18-6368. Tolnai, G.-“"Bernarda Alba háza".-Csiliag, 1955, 2082-2092. [Reprod. en su libro Vázlatok és tanulmányok (Budapest, 1955), pp. 114-162].

18-6369. Santaló, J. L.-“La casa de Ber. narda Alba, en el Goya”. - Arb, 57 $(1964), 109-111$.

18-637o. VázQuez Zamora, R. - "García Lorca: La casa de Bernarda Alba".Ins, 1964, núm. 207.

18-6371. Aragonís, J. E.-"Sobre La casa de Bernarda Alba". $-H D, 40$ (1964), 343-344.

18-6972. García LorCA, Federico-"Trip to the moon", transl. by Bernice $G$. Duncan.-New Directions in Prose and Poetry 18 (New York, 1964). [Traducción de un script cinematográfico iné. dito].

18-6373. García Lorca, Federico-Conferencias y charlas (N. 17-1986). \| RLit. 25 (1964), 261 (Romero).

18-6374. Otero Secio, A.- "Sobre la' última interview de García Lorca”. $-L T$, 1964 , núm. $48,55-63$.

18-6375. Hess, R.-"Garcia Lorca y Whitman".-Arb, $58 \quad$ (1964), 265-282.

18-6376. András, L. - "Federico Garcia 
Lorca és József Attila".-Jelenkor, Budapest, 1962, núm. 1, 32-36.

18-6377. WiLl, F.-"Palamas, Lorca, and a perspective for comparative literatu. re".-CLS, 1 (1964), 133-142.

$V$. también núms. 5150, 6279, 6806 .

18-6378. Somlyó, G.--Rafael Alberti".[En su libro] $A$ költészet évadai (Budapest, 1963), pp. 194-211.

18-6379. Santos, D.-"Rafael Alberti. Memorial y momento".-EL, 1964, núnt. 305 .

18-63So. Somlyó, G.-"Rafael Alberti, vagy a számüzetés költészete".-Kortárs, $1962,1394^{-1} 4^{00}$.

18-6381. ZardoYa, C.--"Rafael Alberti y sus primeras Poesias completas"., RHM, 3o $(1964), 12-19$.

18-6382. Alberti, Rafael-Antologia poetica. Trad. Vittorio Bodini.-Mondadori, Milano, 1964. (Coll. Lo specchio).

18-6383. Alberti, Rafael - [Poesias. Traducciones de Boris Pasternak y otros.Edit. Literaria, Leningrado, 1964]. II LS, 1964, núm. 8, 180-182 (Vaxmajer). 18-6384. Alberti, Rafael-Teatro. La Lozana andaluza. Noche de guerra en el Museo del Prado. De un momento a otro.-Losada, Buenos Aires, 1964. 199 pp. (Gran teatro del mundo).-V. núm. 16-44530.

18-6 ${ }_{3} 8_{5}$. AlBerti, RAFAEL-Suma taurina. Recopilación, ordenación y notas de Rafael Montesinos.-R. M., Barcelona, 1963. 131 pp., ilustr. por el autor. II IAL, $19^{63}$, núms. $175 / 6$ (C. L. A.); $\mathrm{CuH}, 5^{8}(1964), 235$ (G.); CuH, $5^{8}$ (1964), 608-609 (Quiñones).

18-6386. Alonso, D.-- "La poesía de Pedro Salinas".-SOE, $154^{-16} 6_{5}-\mathrm{V}$. núm. 8-11044.

18-6387. Alonso, D.-“Carta última a Salinas".-SOE, 154-165.-V. núm. 8-11044. 18-6388. Urondo, F.- "Pedro Salinas y la poesía".-Lyra, 1964, núms. 192/4.

18-6989. Milessi, U. - "Segrete ricchezze dell'anima in Pedro Salinas",-Letture, 19 (1964), $483-49^{6}$.

18-6390. ZardoyA, C. - "Jorge Guillén y Paul Valéry".-CLS, 1963, special advance issue, $79-89 ;$ Asom, 20 (1964), núm. 1, 22-32.

18-6391. Ciplijauskaité, B.-"Jorge Guillén y Paul Valéry, al despertar".-Ins, 1963, núm. 205; PSA, 33 (1964), 267. 294.

18-6392. González Muela, JoAQuín-La realidad y Jorge Guillén.-Insula, Ma. drid, 1963. 231 pp. (Col. Insula, 41).
|| İns, 1963, núm. 199 (Cirre); BHS, 41 (1964), 123-124 (Connell); CuH, 57 (1964), 326-328 (López Estrađa); RHM, $3^{\circ}$ (1964), 136-138 (Marín); RLit, 24 (1969), 270-271 (Rozas).-V. núm. 1648466 .

18-6393. Guillés, Jorge-A la altura de las circunstancias (N. 18-2992). $\mid P S A$, $3^{2}$ (1964), 209-211 (de Luis); CCL, 1964 , núm. $83,85.86$ (Gorbea); Ins, 1964, núm. 208 (Gullón); $B A b r, 3^{8}$ (1964), 296 (Irask); $H, 4^{8}$ (1965), 613 (Jiménez).

18-6994. Guilléx, Jorge-El gesto.-Seijas y Goyanarte, Buenos Aires, 1964. 44 pp.

18-6395. Guillén, JoRgE-Tréboles. - La Isla de los Ratones, Santander, 1964. 82 pp. (Poetas de hoy').

V. también núms, $5955-7$.

18-6996. Marinello, J. - "Sobre Miguel Hernández".-[En su libro] Contemporáneos (La Habana, 1964), 23-42. [Dos ensayos: "Miguel Hernández, labrador de más aire", y "Órbita espanola de Miguel Hernández”].

18-6397. [Hernández, Miguel] - Promesse, Bordeaux, 1962, núm. 5. [Núm. de homenaje].

18-6398. Couffon, Claude - Orihuela et Miguel Hernández.-Institut d'F́tudes Hispaniques, Paris, 1963. 157 pp. BHi, 67 (1965), 212-214 (Laffranque); $P S A$, 30 (1969), $377-378$ (de Luis); $I A L$, 1963, núms. $175 / 6$ (P.); BHS, 41 (1964), 195-197 (Terry).

18-6399. Romero, Elvio - [Miguel Hernández. Destino y poesia. Trad. rusa.Edit. de Literatura Extranjera, Moscú, 1964]. || LS, 1964, núm. 5, 186-188 (Yasni).-V. núm. 14-39117.

18-6400. Cano Ballesta, J.-La poesia de - Miguel Hernández (N. 18-2999). || $H$, 47 (1964), 871-872 (Cannon); HR, $3^{2}$ (1964), 370-372 (Cirre); RLit, 27 (1965), 243-245 (Díz Taboada); $S, 19(1965)$, 374-377 (Ferrán); $B H_{i}, 67$ (1965), 177. 182 (Laffranque); $B H S, 41$ (1964), $195^{-197}$ (Terry).

18-6401. Ángeles, J.- “La poesía de Miguel Hernández”.-DHR, 3 (1964), 2333.

18-64o2. Hernández, Miguel - Poesia.Consejo Nacional de Cultura, La Habana, 1964 .

18-6403. Hernández, Miguel - [Anthologie]. Présentation et choix de textes par J.-L. Guereña.-P. Seghers, Paris, 1963. 112 pp. (Poètes d'aujourd'hui). 
18-6404. Hernández, Miguel-El rayo que no cesa. $3^{\text {a }}$ ed.-Espasa-Calpe, Madrid, 1959. 162 pp. (Austral, go8).

18-6405. Hernández, Migule - L'enfant laboureur. Trad. Alice Ahrweiler.-P. Seghers, Paris, s.a. 85 pp. (Autour du monde).

18-6406. Hernández, Migule - "Carta a Juan Ramón Jiménez".-PS $A, \quad 32$ (1964), $163-164$.

18-640\%. Cano, J. L.-"Luis Cernuda".Asom, 20 (1964), núm. 1, 57-59.

18-6408. MÉndez, Concha-"Luis Cernuda".-Ins, 1964, núm. 207.

18-6409. García Martínez, A.-"El poeta Luis Cernuda"., $-H D, 4^{\circ} \quad(1964), 262-$ 263.

18-6410. Arana, M. D.- "Para un homemenaje".-RML, 1964, núms. 1/2, 62. 64.

18-6411. López Estrada, F.-"Estudios y cartas de Cernuda (1926-1929)".-Ins, 1964, núm. 207.

18-6412. Cano, J. L.- "Noticia de una edición casi desconocida de Luis Cernuda".-Ins, 1964, núm. 207. [La invitación a la poesia, Madrid, 1933].

18-6413. Dominco, J.-"Luis Cernuda actor teatral".-PSA, 33 (1964), 225-228. 18-6414. Otrro, C. P.-"Cernuda en California".-Ins, 1964, núm. 207.

18-6415. Cano, J. L.-"En la muerte de Luis Cernuda".-ROcc, 4 (1964), 364 . 368 .

18-6416. Montrzuma de Carvaluo, J."Na morte de Luis Cernuda". - Co, 1964, núm. 28, 65-68. [Y versión española en Alcor, Asunción, 1964, núm. $28]$.

18-6417. Arana, M. D.-"Sobre Luis Cernuda".-PSA, 39 (1965), 311-328.

18-6418. Prieto, G.- "Recuerdos de Luis Cernuda".-Ins, 1964, núm. 207.

18-6419. Fraire, I. - "Presencia de Luis Cernuda".-RML, 1964 , núms. $1 / 2,53^{-}$ 57.

18-6420. AzcongA, E.-"Primera carta inposible a Luis Cernuda".-RML, 1964, núms, $1 / 2,58-61$.

18-6421. Xirav, R. - "Cernuda vivo".$R M L, 1964$, núms. $1 / 2,43-45$.

18-6422. NúNEZ, V.- "Luis Cernuda en su palabra".-Ins, 1964 , múm. 207.

18-6423. Valente, J. A.-"Luis Cernuda en su mito".-Ins, 1964, núm. 207.

18-6424. Charry Lara, F. - "La poesia como destino". $-R M L$, 1964 , núms. $1 / 2$, 30-42.

18-6425. PAZ, O.-"La palabra edifican-
tc".-UMx, 18 (1963-64), núm. 11;PSA, 34 (1964), 41-82. [Sobre Cernuda].

18-6426. Coleman, John A.-The meditative poetry of Luis Cernuda and eclecticism in Spanish literature.-[Te. sis de la Universidad de Columbia $1964]$.

18-6427. Elizondo, S. - "Cernuda y la poesia inglesa".- $R M L, 1964,1 / 2,65-$ 70 .

18-6428. UCEDA, J.-“La patria más profunda. (Apuntes para un comentatio sobre la poesía de Luis Cernuda)".Ins, 1964, núm. 207.

18-6429. Martfinez, D.-"Luis Cernuda, poeta existencial".-RUNC, 5 (1964), $143^{-170}$

18-643o. Martínez, D.-"Pasión y muerte en la poesía de Luis Cernuda".Lyra, 1964, núms. 192/4.

18-6431. Newman, R. K.-"Luis Cernuda. El hombre visto a través de su poesia".-Ins, 1964, núm, 207.

18-6432. Silver, Philip Warnock-"El in Arcadia ego": A study of the poetry of Luis Cernuda. - [Tesis, Princeton Univ.; resumen en $D A, 24$ (1963-64), 2042-2043]. 269 pp.

18-6433. Cernuda, Lurs-Ocnos. $3^{\text {a }}$ ed. aumentada.-Universidad Veracruzana, Xalapa, 1963. 194 pp. (Serie Ficción). || $U M x, 19(1963-64)$, núm. 6 (García Ponce); tns, 1965, núm. 220 (MarraLópez).

18-6434. Müller, E.-"Die Bedeutung der Kunst in Luis Cernudas Desolación de la quimera".-RF, $7^{6} \quad(1964), 202-208$. [Y trad, española en $R M L, 1964$, núms. $\left.1 / 2,46-5^{2}\right]$.

18-6435. LeivA, R.-"La realidad y el deseo".-CCL, 1964 , núm. 82, 84-88.

18-6436. Dlaz Quĩ̃ones, A.--"Elegía anticipada. Glosa a un poema de Luis Cernuda".-Ins, 1964, núm, 207.

V. también núms, 6449,6783 .

18-6437. Arendt, E. - "Vicente Aleixandre".-SFP, 16 (1964), $3^{81-387}$.

18-6438. Mostaza, B.-"Vicente Aleixandre, pocta ex abundantia cordis". LEsp, 1964, núm, 83 .

18-6439. Aleixandre, Vicente - Picasso. Trad. V. Bodini.-All'Insegna del pesce d'oro, Milano, $1964 .-$ V. núm. $17^{-}$ 2044.

18-6440. De Gennaro, G. - "L'itineratio poetico di Dámaso Alonso".-Letture, $18(1963), 83-96$.

18-6441. Alvarado de Ricono, Elsie-la obra poética de Dámaso Alonso,-[Te- 
sis, Univ. de Madrid; resumen en $R U M, 12$ (1963), 750-752].

18-6442. DebickI, A. P.-"Symbols in the poetry of Dámaso Alonso, 1921-1944". $-H, 47$ (1964), 722-732.

18-6443. TORRES Y CASTro, S.- "Un caso de dicroísmo intelectual". - DHR, 3 (1964), 88-93. [Sobre Dámaso Alonso, Hijos de la ira].

18-6444. Alonso, D.-Uomo e Dio (N. 17-5596). || $R L M, 17(1964), 240$ (Ara. gone).

18-6445. Umbral, F. - "Carmen y Lola, en diez preguntas a Gerardo Diego".PEsp, 1964, núms. $140 / 141$.

18-6446. Diego, Gerardo-La suerte o la muerte. Poema del toreo.-Taurus, Madrid, 1963. 234 pp. II Ins, 1964, núm. 211 (Cano); PEsp, 1963, núm. 131 (Manrique de Lara); Agora, 1964, núms. 85/93 (Mantero); RLit, 24 (1963), 268-269 (Mantero).

18-6447. Diego, Gerardo-El cerezo y la palmera. Retablo escénico en forma de triptico.-Alfil, Madrid, 1964. 103 pp. (Col. Teatro).

18-6448. Murciano, C.-"Estrenos teatrales. El cerezo y la palmera, de Gerardo Diego".-PE, 1969 , núm. 81 .

18-6449. Otero, C. P.- "La poesía de Altolaguirre y Cernuda". - RNC, 1964, núms, $162 / 3$.

18-6450. Alonso, D.- "Luis Rosales, la lirica barroca y los desengaños de Imperio".-SOE, 78.89 .

18-6451. Cano, J. L.- "Un poeta en la Academia: Luis Rosales".-Asom, 1964, núrn. 3, 80-82.

18-6452. Martinez Ruiz, F.-"La poesia desolada de Rafael Morales". - $P E$, 1964, núm. $96,37-41$.

18-6453. MoRAles, RAFAEL-"Granadeño", toro bravo. - Edit, Nacional, Madrid, 1964. $14^{\circ}$ pp. || EL, 1964, núm. 303 (Iglesias Laguna).

Carmen Conde: v. núm. 5974 .

18-6454. Celaya, Gabriel - Dos cantatas. -Revista de Occidente, Madrid, 1964. $13^{6} \mathrm{pp}$. \| Ins, 1965 , núm. 221 (Alfaya); $P S A, 33$ (1964), 233-236 (de Luis). 18-6455. Celaya, G.-la buena vida (N. 17-2063). || LNL, 1965, núm. 3, $107^{\circ}$ 108 (Chevallier).

18-6456. Celaya, G.-Los poemas de Juan de Leceta (N. 17-2064). \| Pensam. Navarro, 1965, núm. 10 (Rubio y Carrasco) .

18-6457. Celaya, Gabrifl-Versos de otono.-La Venencia, Jerez de la Fronte- ra, 1963. $4^{8}$ pp. || PEsp, 1964, núm. 134 (Umbral).

V. también núm. 5974 .

Hidalgo: v. núm. 6301.

18-6458. Jiménez, J. O.-“José Hierro en sus Alucinaciones". - CuH, 57 (1964) $280-296$.

18-6459. Hierro, José-Libro de las alucinaciones. - Ed. Nacional, Madrid, 1964. 98 pp. || fns, 1965, núm. 218 (Cano); Res, 2 (1965), 203-208 (Gutiérrez); $E L, 1964$, núm. 298 (Jiménez Martos); PEsp, 1964, núm. 145 (Manrique de Lara); $\mathrm{CuH}, 60$ (1964), $5^{68}$ 573 (Miró).

V. también núms. 5974, 6301 .

18-6460. IlÁrRAz, F.-"Visión patética de la realidad en la poesia de Carlos Bousoño".-Proceedings of the 15 th $\mathrm{Pa}$ cific Northwest Conference on Foreign Languages (Montana State Univ. $1964), 135^{-143}$.

18-6461. Esteban, C.-“Blas de Otero".$M F, 350 \quad(1964), 662-666$.

18-6462. Espinosa Altamirano, H.-"Relectura de Blas de Otcro".-Bol. Bibliogrảf., México, 1964, núm. 294.

18-6463. OTERo, BLAS DE-Esto no es un libro.-Ed. Universitaria, Río Piedras, Puerto Rico, 1963. $180 \mathrm{pp}$. $H, 4_{4}^{8}$ (1965), 613-614 (Jiménez); Educación, San Juan de Puerto Rico, 1964 , núm. 11, 109-110 (Vega Lángara).

8-6464. Otero, Blas DE-Twenty poems. Ed. and transl. by Hardie St. Martin.Odin House, Madison, 1964. 64 pp. II Ins, 1964, núm. 215 (Gullón); Dial, 1965 , núm. 2 (X).

$\mathrm{V}$. tambièn núm. $63_{01}$.

${ }_{18-64} 6_{5}$. IrIARTE, H.- "La función poética de Caballero Bonald". - $\mathrm{CuH}_{\mathrm{H}}, 60$ (1964), $275^{-291 .}$

18-6466. Caballero Bonald, J. M.-Pliegos de cordel.-Jaime Salinas, Barcelona, 1963. $9^{8}$ pp. \| BAbr, $3^{8}$ (1964), 415-416 (Rabassa).

\section{Epica}

18-6467. Abdel Badi, Luft -La épica árabe y su influencia en la castellana. -Instituto Chileno-Arabe de Cultura, Santiago, 1964:-V. núm. 17-2073. \| $A$, 1964, núm. 404, 267-269 (Mengod).

18-6468. Oroz, R. - "Andrés Bello y eI Poema del Cid".-RFE, 47 (1964), 437443 .

18-6469. Fradejas Lebrero, José - Estudios épicos: El Cid.-Inst. Nac. de En. 
señanza Media, Ceuta, 1962. 80 pp. II $R P h, \quad 18 \quad\left(19^{6} 4^{-65}\right), \quad 374^{-3} 36$ (Armistead).

18-6470. Menéndez Pidal, Ramón - El Cid Campeador, $5^{\text {a }}$ ed.-Espasa-Calpe, Madrid, 1964. 246 pp. (Austral, 1000). - V. núm. $17-5624$.

18-6471. Menéndez Pidal, Ramón - En torno al "Poema del Cid".-E. D. H. A. S. A., Barcelona, 1963. 222 pp. (Col. El puente). || Map, 1963, núm. 1, 292293 (Huerta); $A, 1965$, núm. 407, 287292 (Muñoz); ROcc, 7 (1964), 246-247 (Scuderi).

18-6472. Laza Palacios, Manuei - La España del poeta de mio Cid. Comen. tarios a la Crónica de Alfonso VII. Ed. Y nota previa de Ángel Caffarena.-El Guadalhorce, Málaga, 1964. 203 pp.

18-6473. Cantar de myo Cid. Übersetzt und eingeleitet von Hans Jörg Neuschaffer. - Eidos, München, 1964. 271 pp. (Klassische Texte des romanischen Mittelalters in zweisprachigen Ausgaben, 4). II ZRPh, 81 (1965), 602 (Baldinger).

18-6474. Poema de mio Cid. Ed. en castellano antiguo y moderno; versión moderna y notas de Luis Guarner, pról. de Dámaso Alonso. 6 ed. - Aguilar, Madrid, 1969. $73^{8}$ pp. (Crisol, 96).-V. núm. $16-44586$.

18.6475. El cantar del mio Cid.-E.D.A.F. Madrid, $1964.647 \mathrm{pp}$.

18-6476. SpItzzr, L. - "Sobre el caráctes histórico del Cantar de mio Cid".[En] Sobre antigua poesia española (Buenos Aires, 1962), 7-25.-V. núm. 14-39154. || NRFH, 18 (1965-66), 188 . 190 (Alvar).

18-6477. Horrent, J. - "Tradition poétique du Cantar de mio Cid au xile siccle".-CCM, 7 (1964), $45^{1-477}$.

18-6478. Santos AmayA, M.-"Interpretación de un tema del Poema del Cid mediante el análisis de fórmulas épicas".-Educación, 1964, núm. 2, 79-101; 1965 , núm. $3,67-78$.

18-6479. Michael, I.-"A comparison of the use of epithets" [el Cid y el Alexandre] (N. 16-48526). I| LR, 19 (1965), 57 (Groult).

18-6480. Gariano, C.-"Lo religioso y lo fantástico en el Poema de mio Gid".$H, 47$ (1964), $67 \cdot 78$.

18-6481. HaRt, T. R.-"Hierarchical patterns in the Cantar de mio Cid" (N. 17-5641). II AESC, $19(1964), 780$ (Batany); $L R, 19$ (1965), 286-287 (Kies).
18-6482. Nayarro, A.- "El mito del Cid". $-A t l, 2$ (1964), núm. 7, 5-22.

18-6483. Castro, M. DE-“"¿Alanceó toros el Cid Campeador?"-Espiral, Bogotá, 1964, núm. 93, $15^{-17}$.

18-6484. Montgomery, T.-."The Cid and the Count of Barcelona" (N. 17-5643). II $B I C C, 19(1964), 597.598$ (Valderrama Andrade).

18-6485. Udina Martorell, F. - "Quién fue Gerardo de Alemany, herido $y$ apresado por el Cid Campeador". EMP, 4, 629-640.

18-6486. Zahareas, A.-"The Cid's legal action at the Court of Toledo".- $R R$, $55(1964), 161-172$.

18-6487. Almagro, M.-"Calamocha y el Poyo del Campo (Teruel) en relación con el Cid Campeador". - EMP, 6, $613-630$.

18-6488. Fradejas Lebrero, José - Estudios épicos: El cerco de Zamora.-Aula Magna, Ceuta, 1963. 61 pp. || RLit, 23 $(1963), 27^{6}$ (Otaola).

18-6489. Deyermand, A. D.-"La deca. dencia de la epopeya española: las $\mathrm{Mo}$ cedades de Rodrigo".-AEM, 1 (1964), $607-617$.

18-649o. ARmistead, S. G.-“A lost version of the Cantar de gesta de las mocedades de Rodrigo reflected in the second redaction of Rodríguez de Almela's Compendio historial". - UCPMPh, $3^{8}$ (1969), 299-336. I| $R P h, 18$ (1964-65), 518 (Márquez Villanueva).

18-6491. DeYermond, A. D.-."Las mocedades de Rodrigo, poema de Palencia". -Ins, 1964 , núms. $212 / 3$.

18-6492. Scudilri Ruggieri, J. - "Qualche osservazioni su Las mocedades de Rodrigo".-CuN, 24 (1964), 129-141.

18-6493. Armistead, S. G.-"The structure of the Refundición de las Mocedades de Rodrigo".- $R P h, 17 \quad(1963-64), 33^{8}$ 345 .

18-6494. La leyenda de Fernán Gonzilez. $2^{\mathrm{a}}$ ed.-Aguilar, Madrid, $1964.808 \mathrm{pp}$. (Crisol, 185).

18-6495. Poema de Fernán González, ed. E. Polidori (N. 17-2098). || Map, 1964, núm. 2, 280-282 (Ferreccio).

V. también núms. $5^{134-8}$, 6026 .

\section{Romancero}

18-6496. BeAtie, B. A.-"Oral-traditional composition in the Spanish Romancero of the sixteenth century".-Journ. of the Folklore Institute, Indiana Univ., 1 (1964), 92-113. 
18-6497. Pérez Gómez, A. - "Miscelánea cidiana".-EMP, 6, 447-463. [Romances].

18-6498. Catalán, D.-"Un romance histórico de Alfonso XI".-EMP, 6, 259 . 285 .

18-6499. SPItzer, L.-"Los romances espanoles: el Romance de Abenámar".[En] Sobre antigua poesia española (Buenos Aires, 1962), 59-84.-V. núm. 14-39164. || NRFH, $18(1965-66)$, 192194 (Alvar).

18-6500. SPItzer, L.-"Período previo folklórico del Romance del Conde Arnaldos".-[En] Sobre antigua poesia espanola (Buenos Aires, 1962), 85-103.-V. núm. 14-39163. \|NRFH, $18(1965-66)$, 194 (Alvar).

18-6 5 o1. Fradejas Lebrero, J. - "El ro. mancero morisco". - Cuadernos de la Biblioteca Española de Tetuán, 1964, núm. 2, 39-74.

18-6502. Ronrf́guez-Moñino, A. - "La Breve deleitación de romances varios (Valencia, 1668). Noticia bibliográfica". $-I b$, núm. 6.

18-6503. BÉnICHou, P.-"Variantes modernas en el romancero tradicional: sobre la Muerte del Principe Don Juan".-$R P h, 17$ (1963-64), 235-252. || BICC;, 20 (1965), 175 (Montes).

18-6504. Ares Montes, J.--"Primavera del romancero nuevo en Portugal". $-R F E$, 47 (1964), 263-286.

18-6505. KUNDERT, H.-"Romancerillo sanabrés" (N. 17-5661). $\| B I C C, \quad 19$ (1964), 588-589 (Suárez Pineda).

18-65o6. Romancero de la guerra española. Comp. por V. Arana y A. Manso, pról. de O. Sávich.-Edit. Literaria del Estado, Moscú, 1964. [En ruso]. I] $L S, 1964$, núm. 2, 176-177 (Sobol).

18-6507. Gerso-KIwI, E.-"On the musical sources of the Judeohispanic romance".-Musical Quarterly, 5o (1964), $3 \mathrm{I}-43$.

18-6508. Armistead, Samuel G., y JoSEPH H. Silverman - Diez romances hispánicos en un manuscrito sefardi de la Isla de Rodas. Pról. de R. Menéndez Pidal.-Università, Pisa, 1962. 91 pp. (Istituto di Letteratura Spagnola e Ispano-Americana, 3). $\| \mathrm{H}, 4^{8}\left(19^{6}\right)$, $3^{82-383}$ (Abraham); Sef, 24 (1964), 389391 (Cantera); $A r b, 5^{6}$ (1963), 322 (Larrea) ; RLit, 22 (1962), 266 (Quilis); $H R, \quad 34$ (1966), $3^{80-3^{81}}$ (Solá-Solé). 18-6509. Armistead, S. G. \& J. H. SilvlrMAN-"El romancero hispánico entre los sefaradies estadounidenses".-Davar, 1964, núm. 102, 17-31.

18-6510. Timoneda, JUAN-Rosas de romances (Valencia, 1575). - Castalia, Valencia, 1963. xi +83 fols. (Floresta, 8). $\| B H S, 41 \quad(1964), 264-265$ (Smith). 18-6511. Simmons, Merle $-\boldsymbol{A}$ bibliography of the "romance" and related forms in Spanish America. - Indiana University Press, Bloomington, 1963 . 396 pp. (Folklore series, 18). \| ReuIb, $3^{\circ}$ (1964), 329-332 (Corvalán); $H, 47$ (1964), 202-203 (Dauster); BHi, 67 (1965), 183-193 (Devoto); RIB, 14 (1964), 316 (Goodwyn); SFQ, 27 (1969), 336-338 (Reedy).

18-6512. Onís, J. DE--"El celo de los duendes. Una variante americana del romance del Conde Olinos". - CuA, ı64, núm. 3, 219-229.

V. también núms. 5057, 5991-3, 6257.

\section{TEATRO}

V. núms. $5^{140-52}, 6072,755^{0}$.

$A u t o r e s$ antiguos

18-6513. OOstendore, H. T.-“De invloed van de Spaanse tragikomedie La Celestina op enige Nederlandse toneclschrijvers",-NTg, $57 \quad\left(19^{6}\right), 353-3^{64}$.

$V$. también núms. $5^{179}, 5836,5^{8} 51$.

18-6514. Myers, O. T.-"Juan del Encina and the Auto del repelon".-HR, 32 (1964), 189-201.

18-6515. Myers, O. T. - "Encina and Skelton".-H, 47 (ig64), 467-474.

18-6516. Encina, JuAN DEL-Églogas. Ed. de Humberto López Morales. - Las Américas, New York, 1963. $\| R P h, 18$ (1964-65), $5^{19}$ (Myers).

Gil Vicente: v. núms. $5471-89$.

18-6517. Torres Naharro, B. DE-Propalladia, ed. J. E. Gillet, t. 4 (N. 17-2198). || $R R, 55$ (1964), 43.47 (Correa); BHS, $4^{2} \quad(1965)$, $125^{-127}$ (Reckert).

18-6 6 18. Benavides Lillo, R. - "F. de Avendaño y el teatro renacentista español" (N. 16-44664). || LR, 19 (1965), $59^{-60}$ (Groult).

18-6519. Weber de KurLAt, F.- "La imprenta en que se editó la Recopilación en metro de Diego Sánchez de Badajoz".-NRFH, 18 (1965-66), $15^{6-160 .}$

18-6520. Hesler, R.-"A new look at the theatre of Lope de Rueda".-Educational Theatre Journal, 16 (1964), 4754 . 
18-6521. RuEDA, LOPE DE-Pasos comple. tos. $3^{\text {a }}$ ed.-Aguilar, Madrid, $1964 \cdot 43^{2}$ pp. (Crisol, 48 ).

V. también núm. 6924.

Cervantes: v. núms. 6992-3, 5901, 713449.

18-6522. Alvar, M.-"Cinco papeletas bibliográficas sobre Lope de Vega".RFE, $4^{6}\left(19^{6}\right), 45^{1-45^{8}}$.

18-6523. Parker, J. H.-"Progress report". $-B C, 1964$, núm. 1, 19-20; núm. 2, 16. [Bibliografía sobre Lope].

18-6524. Lope de Vega. Estudios reunidos en conmemoración del $I V$ centenario de su nacimiento.-Facultad de $\mathbf{H u}$ manidades y Ciencias de la Educación, La Plata, 1969. 199 pp.

18-6525. Klempa, S. K.-“Lope de Vega születésének negyedik centenáriumára”. -Vigilia, Budapest, 1962, 717-727.

18-6526. Possonny, L.- "Lope de Vega". -Vigilia, Budapest, 1955, 463.469.

18-6527. Van Heugten, W. A. M.-"Lope de Vega, $1562+1695$ ". - Streven, 16 (1962), $258-261$.

18-6528. Pérez Minik, D.-“Se intenta un arreglo de cuentas con Lope de Vega". $-P A, 1964$, núm. 55, 14-21.

18-6529. Díez Crespo, M.-“Actualité de Lope de Vega".-Le Théatre dans le Monde, Bruxelles, 12, núm. 3.

18-6530. Entrambasaguas, J. Dr. - "Voca. tion and vicissitudes of Lope de Vega". -World Theatre, 12 (1963), 164-174.

18-6531. Came, J.- "Estampa de Lope de Vega".-LL, 1962, núms. 68/9, 5-14.

18-6.332. Lefebvre, A.-"Guía de las noches de Lope de Vega".-Map, 1969, núm. 1, 253-261.

18-6533. Astrana Marín, Luis-lope de Vega.-Juventud, Barcelona, 1963. $83^{8}$ pp. (Col. Z, 91/92). $E L, 1964$, núm. 296 (Aragonés).

18-6534. Laplane, Gabriel - Belardo on la vie de Lope de I'ega.-Hachette, Paris, 1963. 288 pp. || LNL, 1965 , núm. 1, 117-118 (Liaussou); Ins, 1964, núm. 207 (Soriano).

18-6535. Zamora Vicente, A.-Lope de Vega (N. 16-48638). If LR, 18 (1964), $194^{-197}$ (Groult).-V. núm. 17-5725.

18.6536. Herczeg, G. - "Lope de Vega értékslésének néhány szempontja”. Filologiai Közlöny, 9 (1963), 170-18o.

18-6537. Zabala, A.- “Alusión de Lope de Vega a unos supuestos amores va lencianos".-EMP, 6, 591-6og.

18-6538. Allende Salazar, B. A.-"Escritores militares $y$ militares escritores.
(En el centenario de Lope de Vega)". -Guión, Madrid, 1963, núm. 249, 23. 31.

18-6539. Castax̃eda, J. A.-“El impacto de Góngora en la vida y obra de Lope de Vega".-RNo, 5 (1964), 174-182.

18-654o. Ghiano, J. C.-"Lope y la autobiografía". $-L V E, 11-27$.

18-6541. ZACCARDI, D. M. DE-"Presencia italiana en Lope".-LVE, $174^{-182 .}$

18-6j42. Entrambasaguas, J. DE - "Lope de Vega y Rubens y, al fondo, Miguel Ángel".-PE, 1964, núms. 99/100, 3043 .

18-6543. Cinri, B.-"Homenaje a Lope en la Venecia del seiscientos".-CuH, 54 (1963), 6og-62o. [Las Essequie poetiche de "Fabio Franchi" (el Conde de la Roca)].

18-6544. HeMPEL, WIDO-"In onor della Fenice iberica". Uber die Essequie poetiche di Lope de Vega, nebst einer kritischen Ausgabe der Orazione del cavallier Marino.-Klostermann, Frankfurt, 1963. 183 pp. (Analecta romani. ca, 13).

18.6545. Alonso, A.- "Lope de Vega y sus fuentes".-[En] $E l$ teatro de Lope de Vega (Buenos Aires, 1963), 193-220. -V. núm. 8-11701.

18-6546. Bellixi, G.--"Lope e la Fénix". $-F L e, 18$ (1964), núm. 4 .

18.6547. Castello, M.-"Lope de Vega e Genova".-Rivista del Comune, Genova, 1969, núm. 1, 24-27.

18-6548. Sabor de Cortazar, C.-“Lope o la multiplicidad de estilos".- $L V E$, 5971.

18-6549. Battistessa, A. J.--"Los modos de trabajo lopesco, o el poeta en su manuscrito".- $-L V E, 28-52$.

18-65 50. Rubens, E. F.-"El sistema dramático de Lope".-LVE, 85-112.

18-6551. Díz-Crespo, M.-"Lope de Vega viewed as a contemporary dramatist".-World Theatre, 12 (1963), 185. 190.

18-65.52. Truebloon, A. S.-“Role-playing and the sense of illusion in Lope de Vega".-HR, 32 (1964), 305-318.

18.6553. Montesivos, J. F.-“La paradoja del Arte nuevo".-ROcc, 5 (1964), 302$33^{\circ}$.

18-6554. Cornejo Polar, A. - "Lope de Vega: de la sumisión a la rebeldía. Notas sobre el Arte nuevo de hacer comedias".-LL, 1962, núms. $68 / 9,22-$ 37 .

18-6555. Nallum, C. O.- “Cosas de Lope". 
$-\mathrm{CuH}, 54$ (1963), $5^{6} 7-574$. [Sobre el Arte nuevo].

18-6556. Entrambasaguas, J. DE - "Le nouvel art d'écrire des comedias en ce temps et l'art éternel de Lope de Vega".-Premières Mondiales, Paris, 1963, núm. 33 .

18-6557. Sinicropi, G.-“El Arte nuevo y la técnica dramática de Lope de Vega”. - Map, 1963. núm. 1, 125-139-V. núm. 16- $44^{6} 77$.

18.6558. Cartaya, G. M. DE-“El sentido arquitectónico en la técnica teatial de Lope de Vega".-Hor, 11 (1965), núm. 17 .

18-6559. Gattr, José Francisco (ed.) -El teatro de Lope de Vega.-Eudeba, Buenos Aires, 1962. 220 pp. [Estudios de Ch. V. Aubrun, J. F. Montesinos, E. M. Wilson, G. Ribbans, L. Spitzer, M. Bataillon y A. Alonso]. II $H u N L, 5$ (1964), 629-634 (Ayala); PhP, 8 (1965), $44^{1-44^{2}}$ (Belic); BHS, 41 (1964), 118119 (Jones); $H, 49$ (1966), 887-888 (Ortigoza); $H R, 33$ (1965), 194 (Reichenberger); Seg, I (1965), 437-443 (Rull). 18-6560. PÉrez, L. C., y F. SÁnche7. EscriBANo-Afirmaciones de Lope de Vega sobre preceptiva dramática (N. 1648640). I| HR, 31 (1963), 364-367 (Parker); RHM, 3o (1964), 146-147 (Pollin).

18-6561. Oliver, Antonio-Vida y obra de Lope de Vega.-Publicaciones Españolas, Madrid, $1963.64 \mathrm{pp}$.

18-6562. Marf́n, Diego-Uso y función de la versificación dramatica en Lope de Vega.-Castalia, Valencia, 1962. 120 pp. (Estudios de $H f, 2)$. $\| B H S, 41 \quad(1964)$, $115^{-116}$ (Dunn); $N, 4^{8} \quad$ (1964), 87 (Geers); Seg, 1 (1965), 152-155 (Juliả Martínez); $H, 47(1964), 427$ (Morley). 18-6563. Galletti, E. B. DE - "Algunos recursos cómicos en las comedias de Lope".-LVE, 113-121.

18-6 564 . Morley, S. Griswold, \& R. W. TYLER-Los nombres de personajes en las comedias de Lope de Vega.-Univ. of California, Berkeley-Los Angeles, 1961. 2 ts.: 722 pp. (UCPMPh, 55). il NSpr, 1962, 246-247 (Baehr); RLR, 75 (1962), $84-85$ (Flecniakoska); $H, 45$ (1962), 584-585 (MacCurdy); USF, 1963 , núm. $57,3^{88-390 ~(M i n i a n ~ d e ~ A l f i e) ; ~}$ Fil, 7 (1961), 203-206 (Moglia); RPh, $17(1963-64), 5^{11-516}$ (Morby); $H R, 3^{\circ}$ (1962), 160-162 (Reichenberger); BFIS, 39 (1962), 122.123 (Varey); $M L N, 76$ (1961), 934-938 (Wardropper).
18-6565. Sánchez Garrido, A. - "Algunas constantes de la figura del donairc".LVE, 122-134.

18-6566. TYLER, R. W.- "Still more 'modern psychology in Lope de Vega"."$B C, 14$ (1963), núm. 2.

18-656\%. Erdman, E. G., JR.-“An additional note on the retrato motif in Lope".-RNo, 5 (1964), 183-186.

18-6568. Gutítrrez Alonso, L.-"El selltimiento religioso en la obra de Lope de Vega",-Anuario da Faculdade de Filosofia, Cièncias e Letras Sedes Sapientiae, São Paulo, $1962-6 g$, núm. 20 , 43-57; RyC, 9 (1964), 83-99, 124-154.

18-6569. Garasa, Delfín Leocadio-San. tos en escena. (Estudio sobre el teatro hagiográfico de Lope de Vega).-Univ. Nacional del Sur, Bahía Blanca, 1960. 134 pp. (Cuadernos del Sur).

18-657o. Entrambasaguas, J. DE - "Santa Teresa de Jesús y Lope de Vega".-RE, $22(1963), 399-407$.

i8-6571. Entrambasacuas, J. de - "Una nueva comedia de Lope de Vega sobre Santa Teresa de Jesús". - RLit, 25 (1964). 5-47. || $E C, 16\left(19^{6} 5\right), 528-529$ (Tomás de la Cruz).

18-6572. Rivas Andés, V.-“Lope de Vega por la Iglesia”.-HD, 1962, 771-778. 18-6573. Flecniakoska, J.-L. - "Les rôles de Satan dans les autos de Lope de Vega". $-B H i, 66$ (1964), 30-44.

18-6574. Parker, J. H.-“El amor conyu. gal: tema dramático lopesco". - Hf, 1963, núm. 18, 15-19.

18-6575. Albarracín Teulón, A.-"Lope de Vega y el hombre enfermo".-CuH, 54 (1963), $4355-535$.

18-6576. LABIB, G.-Der Maure in dem dramatischen Werk Lope de Vegas (N. 16-4865o). I| Seg, 1 (1965), 155-157, y Rlit, 25 (1964), 228 (Díez Taboada). 18-657 7 . NuEz, S. DE LA-“Las Canarias en la obra de Lope de Vega".-AEAtl, 10 (1964), 1 1-159.

18-6578. Durín, M.- "Lope de Vega y el teatro de acción".-Hf, 1969 , núm. 18 , $3^{-1} 4$.

18-6579. DELGADO, W.- "La honra villana en el teatro de Lope de Vega", $-L L$, 1962 , núms. $68 / 9,3^{8-63}$.

18-6580. Fontenla, E. - "Menosprecio de corte y alabanza de aldea en el teatro de Lope".-LVE, 160-165.

18-6581. VocLer, F. W.-"Hippolyte, the woman scorned: Corneille's unconscious debt to Lope de Vega"., $S, 18$ (1964), $171-173$. 
18-6582. Vosters, S. A.-"Lope y Calde. rón, Vázquez y Hugo, Maastricht $\mathrm{y}$ Breda".-RLit, 24 (1963), 127-136.

18-6583. Reese, Lowell G.-Lope de Ve. ga and Shakespeare: a comparative study of tragicomic style.-[Tesis, Univ. of Washington; resumen en $D A, 24$ $(1963-64), 285-286] .186 \mathrm{pp}$.

18-6584. Morgan, P.-"Our Will Shakespeare and Lope de V'ega: an unrecorded contemporary document".-Shakes. peare Survey, 16 (1963), 118-120.

18-6585. Plavskin, S.-["Shakespeare y Lope de Vega".-En: Shakespeare en la literatura universal, Leningrado, 1964$]$.

18-6586. Modern, R.-"Lope de Vega en Alemania",-LVE, $183^{-195}$.

18-6587. Cummino, A. C.- "Lope de Vega e Amador Arrais".-Co, 1964, núm. 27. 18-6588. Morley, S. G. - "Comments on Lopean chronology".-HR, $3^{2}$ (1964), $60-64$.

18-6589. Villarejo, O. M.-“Revisión de las listas de $E L$ peregrino de Lope de Vega".-RFE, 46 (1963), 343-399.

18-6590. ArJons, J. H.-"Ten plays attributed to Lope de Vega" (N. 16$44^{678)}$. I| BICC, 19 (1964), $369-37^{\circ}$ (Valderrama Andrade).

18-6591. VEGA, LCPE dE-Obras. T. 9: Comedias de vidas de santos, 1. Ed. y estudio prel. por Marcelino Menéndez Pelayo. - Atlas, Madrid, 1964. civ + 363 pp. (BAE, t. 177).

18-6592. VEGA, LOPE DE - Teatro scelto: Fuenteovejuna. La ragazza sciocca. San Giacomo il Verde. Il cavaliere di Olmedo. Il castigo senza vendetia. A cura di Cesco Vian.-Club del Libro, Milano, 1964. $486 \mathrm{pp}$.

18-6593. Cersósimo, E.- "Dos versiones de un mismo asunto: $\mathrm{El}$ alcalde de $\mathrm{Za}$ lamea en Lope y en Calderón".-LVE, 149-153.

18-6594. Aragonés, J. E.-“E1 gran Lope de menor cuantía. (El caballero de milagro o El arrogante español)". - EL, 1964, núm. 289 .

18-6595. Fernández-Santos, A.-“Caballero de milagro, de Lope de Vega".$I A L, 1964$, núm. 186, 25.

18-6596. Fernández Santos, A.-“'Crítica teatral de $E l$ caballero de milagro, de Lope".-PA, 1964, núm. 52, 61-62.

18-6597. PÉrez Sierra, R.- "El arrogante español o Caballero de milagro de Lope de Vega".-Ins, 1964, núm. 210.

18-6598. VEGA, LOPE DE-El arrogante español o Caballero de milagro. Adapt. de G. Schroeder,-Edit. Nacional, Madrid, 1964. $129 \mathrm{pp}$.

18-6599. VEGA, LOPE DE - Carlos V en Francia. Ed. from the autograph manuscript with introd. and notes by Arnold G. Reichenberger.-University of Pennsylvania Press, Philadclphia, 1962. 260 pp. || RLM, 1964, 69-74 (Aragone); $H R, 3^{2}$ (1964), 361-66 (Fichter); $R P h, 19$ (1964-65), 142 (Malkiel); $L N L$, 1964, núm. 1, 120-123 (Marcus); $R J$, 14 (1969), 360-361 (McHugh).

18-6600. VEGA, LOPE DE-El conde Fernán Gronzález. Ed. de Raymond Marcus.Centre de Recherches de l'Institut d'Études Hispaniques, Paris, ${ }_{1969}$. $\mathrm{xxx}+92 \mathrm{pp}$. (Chefs-d'cuvres des lettres hispaniques, 4). \|Ins, 1963, núm. 202 (J. C. E.) ; $R P h, 18\left(19^{6} 4^{-6}\right), 13^{8-}$ 139 (Malkiel); LNL, 1964, núm. 1, 125 126 (Mercadier).

18-66o1. SCHEvill, RudolPH-The dramatic art of Lope de Vega, together with "La dama boba", ed. from an autograph in the Biblioteca Nacional de Madrid. - Russell and Russell, New York, 1964. 340 pp. (UCPMPh, 6).

18-6602. VEGA, LOPE DE-La dama boba y La niña de plata. $4^{\text {a }}$ ed.-EspasaCalpe, Madrid, 1964. 216 pp. (Austral, 574).-V. núm. 13-37394.

18-66o3. Wagner, Klaus-Lope de Vega Carpio: "Comedia famosa de Dineros son calidad". Vorarbeiten zu einer kritischen Ausgabe--[Tesis, Univ, de Maguncia, 1964$]$.

18-66o4. Sajón de Cuello, R.-"Lo sobrenatural en Don Pedro en Madrid". - LVE, $166-173$.

18-6605. TYLER, R. W.-"Possible sources of the mole episode in Lope de Vega's Los embustes de Celauro".-RNo, 6 (1964), 6o-61.

18-66o6. VEGA, LoPe DE - La estrella de Sevilla. Peribánez. El caballero de $\mathrm{Ol}$ medo. Fuenteovejuna. Nueva ed.-Aguilar, Madrid, 1964. (Crisol, 32 bis). $-\mathrm{V}$. núm. 14-41239.

18-660\%. VEGA, LoPE DE - Fuenteovejuna. Pról. de E. S.-Plaza y Janés, Barcclona, 1964. 125 pp. (Clásicos Plaza).

18-6608. VEGA, LoPE DE-Fuenteovejuna. Ed., pról, y notas por Tomás García de la Santa. $5^{\text {a }}$ ed. - Ebro, Zaragoza, 1964. 186 pp. (Clásicos Ebro, 84).-V. núm. $17-5779$.

18-66og. VEGA, LOPE DE-Fuente ovejuna y La dama boba.-Introd. y notas por Everet W. Hesse. - Dell, New York, 
1964. 288 pp. (The Laurel language libraiy).

18-6610. VEGA, LOPE DE - Fuenteovejuna. El villano en su rincón. - Juventud, Barcelona, 1963. 253 pp. $(Z, 95)$.

18-6611. Mercadier, G.-“Fuenteovejuna, un mauvais drame?”-LNL, 1964, núm. 1, 9-3o.

18-6612. López Estrada, F. - “El drama de Fuente Ovejuna en las obras de Lope y de Monroy. (Consideración actual). Parte 1: El texto de Monroy".$A U H, 1963,61-153$.

18-6613. Hoock, Helga-Lope de Vegas "Fuenteovejuna" als Kunstwerk.-Philosophische Fakultät der Julius-Maximilians Universität, Würzburg, 1963. 225 pp. \|HR, $33 \quad(1965), 335-337$ (Ciplijauskaité).

18-6614. VegA, LoPE $\mathrm{DE}-E l$ galán de la Membrilla. Ed. critica y notas por Diego Marín y Evelyn Rugg.-Real Academia Española, Madrid, 1962. $226 \mathrm{pp}$. (Anejos del BRAE). II LNL, 1964, núm. 1, 123-125 (Marcus); Fil, 9 (1963), 236-239 (Weber de Kurlat).

18-6615. VEGA, LOPE DE-La hermosa fea. Refundición por Alfonso Paso y Julio Mathías.-Alfil, Madrid, 1964. $76 \mathrm{pp}$. (Col. Teatro).

18-6616. Flechiakoska, J. F.-“La représentation de l'auto La margarita preciosa de Lope de Vega à Ségovie, en 1616".-[En] J. Jacovot (ed.), Le lieu théatral à la Renaissance (Paris, 1964), 227-233.

18-6617. VEGA, LOPE DE-El mejor alcalde, el Rey. Pról. y anotaciones Raquel M. de Alfil.-Kapelusz, Buenos Aires, 1964 . $157 \mathrm{pp}$.

18-6618. VEGA, LOPE DE-La moza de cántaro (N. 17-5784). \| MLJ, $4^{8}$ (1964), $115^{-116}$ (Leavitt); $H, 47$ (1964), 867 (Ortigoza).

18-6619. VEGA, LOPE DE-La nueua victoria de D. Gonzalo de Cordoua. A paleographic edition of the autograph play by $\mathbf{H}$. Ziomek.-Hispanic Institute in the United States, New York, 1962. $211 \mathrm{pp}$. || $A O, 14$ (1964), 262-273 (Alín); $H, 47$ (1964), 197-198 (Marín); HR, 33 (1965), 411-413 (Reichenberger).V. núm. $16-44685$.

18-662o. VEGA, LOPE DE-El Nuevo Mundo. Pról. y adaptación de J. de Entrambasaguas, $2^{\mathbf{a}}$ ed.-Instituto de Cultura Hispánica, Madrid, 1963. xl + 153 pp. || Seg, I (1965), 157-158 (Rozas). 18-6621. HiLty, G.-"Die Jüdin von To- ledo. Grillparzer und Lope de Vega als Gestalter des gleichen Motivs".$R F, 7^{6}\left(19^{64}\right), 124^{-1} 54$. [Las paces de los reyes].

18-6622. VEGA, LOPE DE-Las paces de los reyes y Judia de Toledo. A critical ed. by James A. Castañeda. - Univ. of North Carolina Press, Chapel Hill, 1962. xiv +265 pp.-V. núm. 13-37398. II $R N, 17 \quad(1964), 120-122$ (Bretón \& Ruiz de Conde); BHi, 67 (1965), 203 (Flecniakoska); RPh, 18 (1964-65), 139 (Malkiel); HR, 34 (1966), $15^{8-169}$ (Reichenberger); $H, 4^{6}(1963), 847^{-848}$ (Schweitzer); BHS, 41 (1964), 117-118 (Wilson).

18-6623. Vega, LOPE de - Peribánez y el comendador de Ocaña. La dama boba. -Espasa-Calpe, Madrid, 1963. 284 pp. (Clás. cast., 159).

18-6624. Munhoz Rodrigues, V. - "Sobre Peribáñez de Lope de Vega".- $L P a$, 1964, núm. 13, 48-55.

18-6625. PePE, L. E.-"El tema del honox en Peribánez".-LVE, $154^{-15}$.

18-6626. Jones, R. O.- "El perro del hortelano y la visión de Lope".-Fil, 10 (1964), 135-142.

18-6627. VEGA, LOPE DE-El principe inocente. Ed. y pról. de J. García Morales. -Bibl. Nacional, Madrid, 1964. xxvii + 75 pp. +90 pp. de facsímil. || Seg, 1 (1965), 443-447 (Juliá Martínez).

18-6628. Asturias, Rosario Marfa - $A$ critical edition of the play "El rey don Pedro en Madrid y el infanzón de Illescas".-[Tesis, Univ. of Southern California; resumen en $D A, 24(1963-64)$, $537^{8-5379] . ~} 5^{61}$ pp. [Atribuido a Lope, a Calderón y a Claramonte].

18-6629. Glaser, E.-“Lope de Vega's El robo de Dina". $-R J, 15 \quad(1964), 315^{-}$ 334 .

18-66go. Salomon, N. - "Sur la date de San Isidro labrador de Madrid" (N. 17-2220). $\| L R, 19$ (1965), 60-61 (Groult).

18-6631. VEGA, LOPE DE-El villano en su rincón. Adapt. y pról. de F. C. Sainz de Robles.-Ed. Nacional, Madrid, 1964. 141 pp. (Obras del teatro español).

18-6632. VEGA, LOPE DE-El villano en su rincón y Las bizarrias de Belisa. Ed. de A. Zamora Vicente--Espasa-Calpc, Madrid, 1969. cxxiii+24o pp. (Clás. cast., 157). || BHi, 68 (1966), 406-407 (Bourligueux); Agora, 1963 , núms. $79 /$ 82 (Fraile).

18-6633. Jiménez Borja, J.-“Lope de Ve- 
ga, poeta lírico".- $L L, 1962$, núms. $68 / 9$, $15-21$.

18-6634. VEGA, LoPe de-Poesia lírica. Ed., est. y notas de José Manuel Blecua. $6^{\mathrm{a}}$ ed. - Ebro, Zaragoza, 1964. 124 pp. ilustr. (Clás. Ebro).-V. núm. 16-48701. 18-6635. VEGA, LOPE DE-Antología lirica. Ed., pról. y notas de L. Guarner. Aguilar, Madrid, 1964. (Bibl. de iniciación hispánica). \| RLit, 25 (1964), 231 (Esquer Torres).

18-66g6. VEGA, LOPE DE-Lirica religiosa. Rimas sacras. Ed. facs. y est. de J. de Entrambasaguas.-C.S.I.C., Madrid, 1963. 18 hojas +188 fols. +6 hojas. (Clásicos hispánicos, 1, 4). \|| ArA, 59 (1965), 126 (Aparicio López); RLit, 24 (1963), 255 (Díez Taboada); BSCC, 40 (1964), 236 (Esquer Torres); $A u g$, 10 (196弓), 197 (Legarra); $P E, 1964$, núms. 99/100, 123-124 (Rozas).

18-6637. Aaron, M. Audrey - Conceptos cristológicos en la poesía lírica de Lo. pe de Vega.-Cultura Hispánica, Madrid, 1964.-V. núm. 9-14269.

18-6698. Croce, A. - "La Canción a la muerte de Carlos Félix, di Lope de Vega".-EMP, 4, 391-404.

18-6639. VEGA, LOPE DE-Huerto deshecho (Madrid, 1633). Ed. facsimil. Est. prel. de Eugenio Asensio.-Madrid-Valencia 1963. 44 pp. || Ins, 1963, núm. 204 (Ares Montes).

18-6640. RAMírez, L. H.--"Lo cotidiano trascendente en una epístola de Lope de Vega". $-L L, 1962$, núms. $68 / 9,64-8$ o.

18-6641. VEgA, LOPE DE-La Circe. Poema. Commentaire littéraire, introd. historique et éd. annotée de $\mathrm{Ch}$. V. Aubrun et M. Muñoz Cortés. - Institut d'Études Hispaniques, Paris, 1962. Ixvii +96 pp. (Chefs d'auve des lettres hispaniques, 2). $\|$ BHS, $41 \quad(1964), 256-$ $25^{8}$ (Pierce).

18-6642. Aubrun, C. V.-"La Circe: estudio de estructura".-CuH, 54 (1963), $213-245$.

18-6643. Spitzer, L.-"Al triunfo de Judith de Lope de Vega".-[En] Sobre antigua poesia española (Buenos Aires, 1962), 143-159.-V. núm. 14-39187. 18-6644. VoGLer, F. W. - "La première apparition en France du Peregrino de Lope de Vega $(1614)$ ).-BHi, $66(1964)$, $73-83$.

18-6645. Calonge, S. - "Novela a Marcia Leonarda".-LNL, 1964, núm. 168, 9-3o. 18-6646. VegA, LOPE DE-La Dorotea.Eds. R, La Habana, 1964 .
18-6647. EntrambisaguAs, J. dE - "Las hipérboles y energias de la Dorotea de Lope de Vega".-[En] Études dédièes à la mémoire de Hiram Peri (Jerusalem, 1963), 143-149.

18-6648. Webber, E. J.- "Genre and $L a$ Dorotea”.-BHS, 41 (1964), 73-77.

18-66 49. Iventosch, H.-"The elaboration of an episode from the Quijote in the Dorotea" (N. 16-44694). \| BICC, 19 (1964), 366-367 (Valderrama Andrade). 18-665o. BoXer, C. R., \& J. S. Cummins"The Dominican mission in Japan (1602-1622) and Lope de Vega".-AFrP, 33 (1963), 5-88. [Sobre el Triunfo de la $\mathrm{fe}$.

V. también núms. $5^{167}, 5^{8} 5^{\circ}, 7^{123-4}$, 7167,8208 .

18-6651. Corriere, A. - "Pierre Mebrun's adaptation of La estrella de Sevilla". -Xavier Univ. Studies, 3 (1964), 11-18.

V. también nủm. 6606 .

18-6652. Iglesias Barba, D.-“Crítica teatral de $E l$ hospital de locos de Valdivielso". $-M B, 8$ (1964), 180-183.

Guillén de Castro: v. núm. 7077 .

18-6653. Terés, E.-"Sobre el "vuelo» de Abbās Ibn Firnās".-AlAn, 29 (1964), 365-369. [Una loa de Agustín de Rojas].

18-6654. Vélez de Guevara, Lus-Reinar después de morir.-Edit. Nacional, Ma. drid, 1964. $92 \mathrm{pp}$.

V. también núms. $715^{8-61}$.

18-6655. Paulin, A. M.-"The religious motive in the plays of Juan Ruix de Alarcón". - HR, 29 (1961), 33-44 \| $B I C C, 19$ (1964), 373-374 (Valderrama Andrade).

18-6656. Ruiz de Alarcón, JuAN-Cuatro comedias. Est., texto y comentarios de Antonio Castro Leal. $2^{*}$ ed. - Porrúa, México, 1964. 245 pp. (Sepan cuantos..., 10). [Las paredes oyen, La verdad sospechosa, Los pechos privilegiados, Ganar amigos].-V. núm. 17-2278. 18-6657. Espantoso-Foley, A. M. - "The problem of astrology and its use in Ruiz de Alarcón's $E l$ dueño de ias estrellas".-HR, $3^{2}$ (1964), 1-11.

18-6658. Ruiz de Alarcón, Juan-las paredes oyen. Ed., est. y notas por Isido. ro Montiel. $4^{\mathrm{a}}$ ed. - Ebro, Zaragoza, 1964. 126 pp. (Bibl. clásica Ebro, 86).V. núm, 13-37419.

18-6659. Ruiz de Alarcón, Juan-La ver dad sospechosa. - Culturama, Buenos Aires, 1964. $125 \mathrm{pp}$.

18-666o. Ruiz de Al.arcón, Juan-La ver- 
dad sospechosa y Los pechos privile. giados. Introd. y notas por A. Mazzei. -Troquel, Buenos Aires, 1964. 212 pp. (Clásicos Troquel).

18-6661. Torres Quintero, R. - "Los muertos que vos matáis".-BACol, 14 (1964), 193-196. [La frase no es de Alarcón].

V. tambièn núms. 6664,6680 .

18.6662. W' WDE, G.-"The year of Tirso's birth".-Hf, 1963, núm. 19, 1-9.

18-666̈3. Sanz y Dfaz, José-Tirso de Molina. Estudio y antologia.-Cía. Bibliográfica Española, Madrid, 1964. $23^{8} \mathrm{pp}$. (Col. Un autor en un libro). $\| H, 49$ (1966), 161-162 (Wade); Celt, 1964, núm. 27, 138-139 (Zamora).

18-6664. KenNEDY, R. L.-“Tirso's satire of Ruiz de Alarcón".-BC, 16 (1964) núm. 2, 1-12.

18-666弓. Ayala, F. - "Erotismo y juego teatral en Tirso".-Ins, 1964, núm. 214. 18-6666. Urtiaga, Alfonso-El indiano en la dramática de Tirso de Molina. [Tesis, Louisiana State Univ.; resumen en $D A, 24$ (1963-64), 4201-4202]. 209 pp. 18-6667. Tirso de MolinA - El burlador de Sevilla. Don Gil de las calzas verdes. $6^{\text {a }}$ ed.-Aguilar, Madrid, 1964. $49^{8}$ pp. (Crisol, 5).-V. núm. 16-44708.

18-6668. TiRso DE Molina-L'abuseur de Seville. Êd. critique, introd., trad. ct notes par Pierre Guénoun. - Aubier, Paris, 1962. 307 pp. $\| A r b, 5^{8}$ (1964), 104-106 (Caravaca); TR, 1963, núm. 180, 142 (Christ); LMo, 57 (1963), núm. 1, 6o-61 (Larrieu); BHi, 66 (1964), 179-185 (Nougué); $H, 45$ (1963), 663. 664 (Wade).

18-6669. MorRIS, C. B.-"Metaphor in El burlador de Sevilla".-RR, 55 (1964), $248-255$.

18-6670. WADE, G. E.-“El burlador de Sevilla: some annotations". - H, 47 (1964), $75^{1-761 .}$

18-6671. Rogers, D.-"Fearful symmetry: the ending of El burlador de Sevilla". -BHS, 41 (1964), 141-159.

18-6672. LIDA DE MALKIEL, M. R.- "Sobre la prioridad de ¿Tan largo me lo fiáis?" (N. 17-5813). || BICC, 19 (1964), $607-608$ (Valderrama Andrade).

18-6673. TrRso DE Molina-Don Gil de las calzas verdes. Ed., pról. y notas de I. M. Gil. - Aguilar, Madrid, 1964. (Bibl. de iniciación hispánica). II Seg, 1 (1965), 449 (Rull).

18-6674. MACCuRdY, R. R.-"Tragic harmatia in La próspera $y$ adversa fortu. na de don Alvaro de Luna".-H, 47 (1964), 8z-9o.

18-6675. Samonà, C.-Lettura di "La prudencia en la mujer".-S. 1. n. a. [1964]. $30 \mathrm{pp}$.

18-6676. Tirso de Molina-La prudencia en la mujer. El condenado por desconfiado. $6^{\mathrm{a}}$ ed. - Espasa-Calpe, Madrid, 1964. 178 pp. (Austral, 369).-V. núm. $17-2267$.

18-6677. Hesse, E. W.-"The incest motif in Tirso's La venganza de Tamar".$H, 47$ (1964), 268-276.

18-6678. TIRso DE MOLINA-El vergonzoso en palacio y El burlador de Sevilla. $7^{\text {a }}$ ed. - Espasa-Calpe, Madrid, 1964. 262 pp. (Austral, 73). -V. núm. 16 48743 .

18-6679. Tirso de Molina-La villana de Vallecas, comedia famosa. Éd. et notes de Jean Lemartinet et Gilbert Zonana. -Ediciones Hispano-Americanas, Paris, 1964. 99 pp. || $L N L, 1964$, núm. 2, 107 108 (Larrieu); $B H i, 68$ (1966), 165-166 (Nougué); Seg, 1 (1965), 158-159 (Rull). 18-668o. WADE, G. E.-“Jean Mairet's Galanteries du Duc d'Ossone: two incidents".-RNo, 6 (1964), 57-59. [Fuentes de Mairet: Tirso y Alarcón].

V. también núms. $5^{846}, 5919$.

18-6681. González Román, Gonzalo Calderón de la Barca.-Sánchez Rodrigo, Plasencia, 1964. 121 pp. (Hijos ilustres de España, 32).

18-6682. Lund, Harry - Pedro Caldetón de la Barca: a biography.-Andrés Noriega Press, Edinburg, Texas, 1963. 128 pp. If $H, 4^{8}$ (1965), 937-938 (Hilborn); $B H S, 4^{2} \quad(1965), 131-13^{2}$ (Jones).

18-6683. RicaRD, R.-“Calderón et el mar de Fez" (N. 17-2283). \|LR, 19 (1965), 61-62 (Groult).

18-6684. Flasche, H.-"Studie zur Negation mit no im Sprachgebrauch Calderóns". $-F H H, 129^{-1} 4^{8}$.

18-6685. Aubrun, C. V.-“Realismo y poesía en el teatro. Abstracciones moralcs y referencias a lo real en la tragedia lírica de Calderón". - RUNP, 1964, núm. 18, 297-305.

18-6686. Camón Aznar, J.-"Teorías pictóricas de Calderón y su relación con Velázquez".-Homenaje al profesor Ca. yetano de Mergelina (Murcia, 1961-62), $861-865$.

18-6687. MAs, A. - "La critique interne des textes". - BHi, 66 (1964), 17-29. [Calderón y Quevedo]. 
18-6688. Flasche, H.-“Calderón als Paraphrast mittelalterliche Hymnen". FHR, 87-119.

18-6689. Calderón de la Barca, PedroDramen. Übertr. von Johann Diederich Gries und Joseph von Eichendorff, Nchw. von Edmund Schramm.-Winkler, München, 1963. $86_{5}$ pp. (Spanisches Theater).

18-66go. Calderón de la Barca, P.-A $u$ tos sacramentales, 2 (N. 17-5839). \| $A I A, \quad 25 \quad(1965), 462-463$ (Meseguer); Seg, 1 (1915), 162-163 (Rozas).

18-66gl. Calderón de la Barca, Pedro La hidalga del valle. A Maria el corazón. Dos autos sacramentales. Ed., pról. y notas de E. Frutos.-Aguilar, Madrid, 1963. 214 pp. (Bibl. de iniciación hispánica). || Seg, 1 (1965), 162163 (Rozas).

18-6692. Calderón de la Barca, Pedro$A$ secreto agravio, secreta venganza. $3^{\text {a }}$ ed.-Espasa-Calpe, Madrid, 1964. 168 pp.

18-6693. Calderón de la Barca, PedroEl alcalde de Zalamea. La vida es sue. ño.-Edaf, Madrid, 1964. 280 pp., ilustr. (Biblioteca Edaf, 19).

18-6694. Calderón de la Barca, P.-L'alcalde de Zalamea, ed. R. Marrast (N. 14-4126o). II $A r b, 5^{8} \quad(1964), 106-108$ (Caravaca).-V. núm. 16-48800.

18-6695. Dunv, P. N. - "Patrimonio del alma".-BHS, 41 (1964), $78-85$. [El alcalde de Zalamea].

18-6696. ReYnolds, H. R. - "Mayor of Zalamea. (At the Nottingham Play House)"--NVH, 12 (1964), 19-20.

18-6697. Pagés Larraya, A. - "El Nuevo Mundo en una obra de Calderón".CuH, 57 (1964), 299-319. [La aurora de Copacabana].-V. núm. $17-5845$.

18-6698. Novak, O.-“'Une pièce de Pedro Calderón de la Barca retrouvée en Tchécoslovaquie".-Sbornik praci filosofické Fakulty Brnenské Univ., 13 (1964), $165-167$.

18-6699. Martino, E. - "El gran Duque de Gandia: una comedia "nueva" de Calderón de la Barca". - Hum, 15 (1963), $291-299$.

18-67oo. Casona, A.-“Calderón ha estrenado anoche un drama: El gran $D u$. que de Gandia".-HD, $4^{\circ}\left(19^{64}\right), 25^{8-}$ 261 .

18-6701. Hornedo, R. M. De-"La comedia de El gran Duque de Gandia".$R y F, 169$ (1964), 131-144.

18-6702. MixalcI, D.--Neizvestnaja dra- ma Kal'derona".-VLi, 8 (1964), núm. 3, 252-254. [El gran Duque de Gandia]. 18-6703. Hunter, W. A. - "Toward a more authentic text of Calderón's El gran teatro del mundo" (N. 16-48812). II $L R, 19$ (1965), 61 (Groult).

18-6704. WrLson, E. M.-"La iglesia sitia$d a$, a Calderonian puzzle",-MLR, 59 (1964), 583-594.

18-6705. Soons, C. A.-“El problema de los juicios estéticos en Calderón. $E l$ pintor de su deshonra".- RF, $7^{6}(1964)$, $155-162$.

18-6706. Truman, R. W.-"The theme of justice in Calderón's $E l$ principe constante".-MLR, 59 (1964), 43-52.

18-6707. Stevenson, R.- "The first NewWorld opera". $-A W, 16$ (1964), enero, 33-35. [La púrpura de la rosa, de Calderón].

18-67o8. Calderón de la Barca, PenroLa vida es sueño. El alcalde de Zalamea. - Espasa-Calpe, Madrid, 1964. 204 pp. (Clás. cast., 138).-V. núm. 16. $4884^{\circ}$.

18-67og. Calderón de la Barca, Pedro-. La vida es sueño y El alcalde de $\mathrm{Za}$. lamea. Introd. y notas de Sturgis E. Leavitt.-Dell, New York, 1964. 256 pp. (The Laurel language library).

18-6710. Calderón de la Barca, PedroLa vida es sueño. Introd., notas y vocab. de Eugenio Castelli. - Huemul, Buenos Aires, 1964. 159 pp. (Clísicos Huemul, 21).

18-6711. Calderón de la Barca, PedroLa vida es sueño. Sel., estudio y notas por R. Gastón. $12^{\text {a }}$ ed.-Ebro, Zaragoza, 1964. 142 pp. (Bibl. clás. Ebro).V. núm. $17-5854$.

18-6712. Cepeda Calzada, Pablo-la vida como sueño.-Augustinus, Madrid, 1964. 241 pp. || EM, $20(1964), 512-513$ (Barreiro Suárez); Burg, 1965, 412-413 (N. L. M.); $A u g, 9(1964), 509-515$ (Yagüe).

18-6713. García Bacca, JUAN David-Introducción literaria a la filosofía. $2^{\text {a }}$ ed.-Univ. Central de Venezuela, Ca racas, 1964. 237 pp. [Incluye un análisis de La vida es sueño].

18-6714. Szondi, P.- “La vida es sueño". -Humboldt, 1963, núm. 16, 17-19.

18-6715. Valbuena Briones, A.-“Un preludio $y$ tres interpretaciones de $L a$ vida es sueño".-Atl, 2 (1964), 616-624. 18-6716. EhrgotT, UlRike-Das Schicksal Calderóns in Deutschland unter beson. derer Berücksichtigung der $\ddot{U}$ berset. 
zungen von "La vida es sueño".-[Tcsis, Univ. de Innsbruck, 1964$]$.

18-6717. Whiтву, W. M.-“Rosaura's role in the structure of La vida es sueño" (N. 16-4477o). $\|$ BICC, ig $(1964), 364$ (Valderrama Andrade).

18-6718. Flasche, H. - "Beitrag zu einer kritischen und kommentierten Ausgabe des sauto sacramental La vida es sueño von Calderón".- $H J V, 2,579-605$.

18-6719. Samonà, Carmelo.-Calderón nella critica italiana.-Feltrinelli, Milano, 1960. 119 pp. (Studi di filologia moderna, 5). || RLit, 21 (1962), 197 (José Prades); HR, 32 (1964), 270-273 (Whitby).

18-6720. Schwartz, E. - Hofmannsthal und Calderón (N. 17-2304). || ZAL, 94 (1965), 177-179 (Behler); Seg, 1 (1965), 452-454 (Diez Taboada); $C L, 17$ (1965), 282.284 (Gontrum); GQ 37 (1964), 82.83 (Lehn); BAbr, $3^{8} \quad(1964), \quad 163$ (Perl); HR, 33 (1965), 168-171 (Reichenberger); $R L C, 3^{8}$ (1964), 472-473 (Teichmann).

18-6721. Coghlan, BRIAN-Hofmannsthal's Festival dramas. - Cambridge Univ. Press - Melbourne Univ. Press, 1964. 397 pp. || RLC, 40 (1966), 321-325 (Burger).

18-6722. BADER, O.- "Calderón en Nueva York".-MuH, 1964, núm. 194 .

V. también núms. $5^{101}, 5^{168}, 5^{8} 4^{6}, 65^{82}$, $6593,6628,6794$.

18-6723. Dixon, V.-“Juan Pérez de Montalbán's Segundo tomo de las conedias" (N. 17-2280). $\| L R, 19(1965)$, 61 (Groult); $B I C C, 19$ (1964), 374 (Valderrama Andrade).

18-6724. PArker, J. H.-“La Gitanilla de Montalván: enigma literario del siglo XVIII".-APCH, 409-414.

18-6725. Dixon, V.-“Juan Pérez de Montalbán's Para todos".-HR, 32 (1964), $36-59$.

18-6726. Reichenberger, A. G. - "Recent publications concerning Francisco de Rojas Zorrilla".- $H R, 32 \quad(1964), 35^{1-}$ 359 .

18-6727. Schmidt, Gisela-Studien zu den Komödien des Don Francisco de Rojas Zorrilla (N. 16-48762). || HR, 32 (1964), 357-359 (Reichenberger).

18-6728. Rojas Zorrilla, Francisco deDel rey abajo ninguno. Sel., est. y notas por Pablo Pou Fernández. $5^{\mathrm{a}}$ el.Ebro, Zaragoza, 1964. 114 pp., ilustr. (Bibl. clás. Ebro, 55).-V. núm. 1439198 .
18-6729. Rojas Zorrilla, Francisco deDonde ay agravios no ay zelos. Textausgabe und Kommentar von Brigitte Wittmann.-Droz, Genève; Minard, Paris, 1962. 268 pp. (Kölner Roman. Arbeiten, 26). \| BHS, 41 (1964), 69-70 (Boorman); Seg, 1 (1965), 168-170 (Diez Taboada); LR, 19 (1965), 268. 270 (Groult); $R P h, 18$ (1964-65), 139140 (Malkiel); HR, 32 (1964), 355. 357 (Reichenberger).

18-673o. Rojas ZORrilla, Francisco DrLucrecia y Tarquino. Together with a transcription of Agustín Moreto's Baile de Lucrecia y Tarquino. Ed. by $\mathbf{R}$. R. MacCurdy. - Univ. of New Mexico Press, Albuquerque, $1963 . \mathrm{xii}^{+1}{ }_{15} 6 \mathrm{pp}$. II Ins, 1964, núm. 215 (Gullón); BHS, $4^{2}$ (1965), $57-5^{8}$ (Heathcote); $R N, 17$ (1964), 33-35 (Kossoff); $M L J, 4^{8}$ (1964), $45^{8-459}$ (Leavitt); $R P h, 18$ (1964-65), 141-142 (Malkiel); $L N L, 19^{6}$, núm. 1, 127 (Marcus); HR, 32 (1964), 351-354 (Reichenberger); Seg, 1 (1965), 167-168 (Rozas); H, 47 (1964), 663-664 (Whitby); $S, 18$ (1964), 180-184 (Wilson).

18-6731. Rojas Zorrilla, Francisco DEObligados y ofendidos y gorrón de Sa. lamanca. Ed. de R. R. MacCurdy.Anaya, Salamanca, 1963. 112 pp. (Bibl. Anaya, 26). I| Seg, 1 (1965), 454-455 (Esquer Torres); HR, 32 (1964), 354355 (Reichenberger); RLMo, $196_{5}^{5}$, núm. 4, 167 (Zuleta).

18-6732. Teixeira Carneiro, A.-“Santa Isabel, reina de Portugal, de Francisco de Rojas Zorrilla".-ACo, 19/2o (1964), 335.425 . [Traducción de un estudio de E. Glaser y edición de la comedia].

18-6733. Casa, Frank Paul-The dramatic craftmanship of Moreto. - [Tesis, Univ, de Michigan; resumen en $D A$, $24(1963-64)), 1611-1612]$.

Monroy y Silva: v. núm. 6612 .

Claramonte: v. núm. 6628.

18-6734. Guastavino Gallent, Gulllermo -D. Pascual de Bergadá (I702-1779) y su comedia "El amparo universal y Patrona de Valencia”,-C. S. I. C., Castellón de la Plana, 1963. 122 pp. (Libros raros y curiosos). [Sep. del BSCC]. I| RLit, 26 (1964), 226 (Palomo).

A utores modernos

18-6735. Di Filippo, L.-“La sátira del bel canto en el sainete inédito de D. Ramón de la Cruz $E$ l italiano fingido".$E E B$, 1964, núm. 4, 47-101. 
18-6736. CRUz, RAMóN DE LA - Sainetes. Ed. para niños.-Aguilar, Madrid, 1964 . (El globo de colores).

V. también núm. 6744 .

Jovellanos: v. núms. 7916-7.

18-6737. Ferreres, R. - "Moratín en Valencia (1812-1814)".- $R V F, 6 \quad(1959-62)$, 143-209.

18-6738. Dowr.ing, J. C.-"La noticia de Leandro de Moratin sobre la interpretación de lenguas, 1809 ".-Hf, 1964, núm. 2o, 49-54.

18-6739. Mathias, Julio-Moratin.-Cía. Bibliográfica, Madrid, 1964. $224 \mathrm{pp}$. (Un autor en un libro). \|I EL, 1964, núm. 299 (F. M. R.).

18-6740. Fernàndez de MORAtín, LeAN. DRo-La comedia nueva. Ed., pról. y notas de Rafael Ferreres.-Aguilar, Madrid, 1963. $121 \mathrm{pp}$. (Bibl. de iniciación hispánica). I| Seg, 1 (1965), 170 (Rozas).

18-6741. Melón R. de Gordejuela, S.Moratin por dentro. - Universidad, Oviedo, 1964. 71 pp. (Cuadernos de la Cátedra Feijoo, 16).

18-6742. ROONEY, DOMINIC - Realism in the original comedies of Leandro Fernández de Moratin.-[Tesis, Univ. of Minnesota; resumen en $D A, 24$ (196364), 2040]. $355 \mathrm{pp}$.

18-6743. Fernández de Moratín, Leandro -Teatro completo. $3^{\text {a }}$ ed.-Aguilar, Madrid, 1963. 638 pp. (Crisol).

18-6744. Fernández de Moratín, Leandro -El si de las niñas. Comedia por... y sainete por Ramón de la Cruz. - La Mandrágora, Buenos Aires, 1963. 157 pp. (Bolsi-clásicos, 4).

18-6745. Fernández de Moratín, Leandro -El si de las niñas. Sel., est. y notas por J. M. Alda 'Tesán. $7^{\text {à }}$ ed.-Ebro, Zaragoza, 1964. 124 pp., ilustr. (Bibl. clásico Ebro, 39).

18-6746. Fernández de Moratín, Leandro $-E l$ si de las niñas. Introd., notas y vocab. de Alfredo Tarruella.-Huemul, Buenos Aires, 1964. 105 pp., ilustr. (Clásicos Huemul).

18-6747. Villegas, J.-"Notas sobre Francisca Gertrudis Muñoz y Ortiz y El si de las niñas, de L. F. de Moratín".BdFS, 15 (1963), 343-347.

18-6748. Banda y Vargas, A. DE LA "Juan de Gálvez, pintor de escenas moratinianas".-AUH, 1963, 55-59.

Duque de Rivas: v. núm. 6138 .

Hartzenbusch: v. núms. 6140-2. 18-6749. Mancini, G. - "Motivi vecchi e nuovi nel teatro di Ventura de la Vega".-MSI, 1964, núm. 8, 147-178.

Garcia Gutiérrez: v. núm. 6155 .

18-6750. Burgos, A. M.-"Vida y obra de Tomás Rodriguez Rubí”. - Rlit, 23 (1963), $65-102$.

Zorrilla: v. núms. 5901, 5919, 6159-63.

18-6751. Pueyo Zurdo, Teresa-El teatro de López de Ayala.-[Tesis, Univ. de Barcelona, 1963].

18-6752. EsQUER TORRES, R.-“Tamayo y Baus: sus proyectos literarios inacabados".-BRAE, 43 (1963), 151-164.

18-6753. Esouer Torres, R.-"Tamayo y Baus y Pedro Antonio de Alarcón".$B R A E, 43$ (1963), 464-471.

18-6754. TAmayo y Baus, Manuel-Un drama nuevo. Introd. y notas de A. Sánchez.-Anaya, Salamanca, 1963. 118 pp. (Bibl. Anaya, 32). I| Seg, 1 (1965), 170-171 (Esquer Torres).

18-6755. Esquer Torres, R.-“Un aspecto desconocido de Tamayo y Baus: su obra lírica".-BSCC, 39 (1963), 329$339 ; 40$ (1964), 97-103; 41 (1965), 161 . 175 .

18-6756. Esquer Torres, R.-“Un cuento inédito de Tamayo y Baus". $-B B M P$, 39 (1963), $195-207$.

18-6757. EsQuer Torres, R.-"Una interesante carta de Tamayo y Baus".Hom, 1 (1964), 25-31.

18-6758. Barbadillo, Manuel-Vidas $i i$. terarias del siglo xix: Luis de Eguilaz

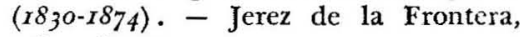
1964. 289 pp.

18-6759. Martinez Olmedilla, AugustoJosé Echegaray.-Dédalo, Madrid, 1964 . $40 \mathrm{pp}$.

18-6760. SÁINz de Robles, F. C.-"Nobel y medio para nuestro teatro". - EL, 1969, núm. 278. [Echegaray y Benavente].

18-6761. Echegaray, José-Teatro escogido. Nueva ed.-Aguilar, Madrid, 1964 . (Bibl. Premios Nobel).-V. núm. 1644792 .

18-6762. Echegaray, José-El gran galeoto.-Las Américas, New York, 1964. 8 o pp.

18-6763. Dicenta, Joaquín-Los bárbaros. Narraciones. Pról. de V. Yasney,-Ed. del Estado de Bellas Letras, Moscú, 1962. 111 pp. [En ruso].

Unamuno: v. núms. 5167, 8094-8101.

Valle-Inclán: v. núms. $73^{1} 5^{-24}$.

18-6764. Bergasa González, F. - "Benavente, hoy y aqui". $-E L, 1964$, núm. 298. 
18-6765. LÁzARo, Ángel-Vida y obra de Benavente.-A. Aguado, Madrid, 1964 . 306 pp., láms.

18-6766. Bravo Aulestia, Juana - Las clases sociales de Benavente.-[Tesis, Univ. de Barcelona, 1963].

18-6767. DAsh, ANNE-Estudio de algunos personajes femeninos en el teatro de Jacinto Benavente.-[Tesis, Middlebury College, 1963].

18-6768. MolHo, Lily S.-The woman in Benavente. - [Tesis, Western Reserve Univ., 1963].

18-6769. Benavente, Jacinto-Obras completas. T. $6.5^{\text {a }}$ ed.-Aguilar, Madrid, 1964. $1112 \mathrm{pp}$.

18-67\%o. BenAVente, JAGINTo - Obras completas. T. 8: 1940-1945. $3^{\mathrm{a}}$ ed.Aguilar, Madrid, 1963. 1116 pp. (Joya).

18-6771. Benavente, Jacinto - Al fin, mujer. La honradez de la cerradura. $3^{\mathrm{a}}$ ed. - Espasa-Calpe, Madrid, 1964 . 170 pp. (Austral, $3^{87}$ ).

18-6772. Benavente, Jacinto - Alfilerazos y Cuando los hijos de Eva no son los hijos de Adán.-Dédalo, Madrid, 1963 . $40 \mathrm{pp}$. (Novelas y cuentos).

81-6773. Benavente, Jacinto-Lo cursi.Dédalo, Madrid, 1964. $36 \mathrm{pp}$. (Novelas y cuentos).

18-6774. Santaló, J. L.-“La gobernado$r a " .-A r b, 57 \quad(1964), 5^{85}-587$.

18-6775. Benavente, Jacinto-Los intere. ses creados. La ciudad alegre y con. fiada. Cartas de mujeres. Nota prel. de F. S. R. $9^{\text {a }}$ ed.-Aguilar, Madrid. 1964. 496 pp. (Crisol, 22).-V. núm. 1023740.

18-6776. Benavente, Jacinto-Los intere ses creados. Señora ama. $15^{\mathrm{a}}$ ed.-Es pasa-Calpe, Madrid, 1963. 178 pp. (Austral, 34).-V. núm. 14-39228.

18-6777. Benavente, Jacinto-La malquerida. La noche del sábado. 10 ạ ed.Espasa-Calpe, Madrid, 1964. 160 pp. (Austral, 84).-V. núm. 16-48913.

18-6778. Benavente, JACINTO - El principe que todo lo aprendió en los libros. $3^{\text {a }}$ ed-Jurculud, Barcelona, 1964. 80 pp., láms. $-V$. núm. 12-31680.

18-6779. Benavente, Jacinto-Recuerdos $y$ olvidos. $2^{\text {a }}$ ed. - Aguilar, Madrid, 1963. $45^{8}$ pp. (Crisol, 400). -V. núm. 16-44798. || $\boldsymbol{H}, 4^{8} \quad\left(19^{6}\right), 179$ (Flynn). 18-6780. Sheehan, R. L.-“Benavente and the United States".- $-H, 47$ (1964), 49750o.

V. también núm. 6760 .
18-6-81. Arniches, Carlos - La pareja cientifica $y$ otros sainetes.-Anaya, Salamanca, 1964. 67 pp. (Bibl. Anaya). 18-6782. Malo Zarco, A.-"El teatro de los Quintero".- $A H$, 1963, núm. 119, $297-300$.

18-6783. "Un texto inédito de Cernuda sobre el teatro de los Quintero".$I A L, 1964$, núm. 184 .

18-6784. Álvarez Quintero, Serafín y JoAQufN-Doña Clarines. Pról. de J. M. Pemán.-Alfil, Madrid, $1963.69 \mathrm{pp}$. (Col. Teatro) .

18-6785. Allvarez Quintero, Serafín y JoAQufN-Entremeses. $2^{\mathrm{a}}$ ed. - Alfil, Madrid, 1963. 134 pp. (Col. Teatro). -V. núm. 13-37446.

18-6786. Álvarez Quintero, SERAFfN y JoAQUín-Los galeotes. Ed. by Margaret Mason.-Univ. of London Press, 1963. 185 pp. \| BHS, 4l (1964), 202 (Edwards) .

18-6787. Alvarez Quintero, SeraffN y JoAQuín - El genio alegre. Las de Cain. Cinco lobitos. - Alfil, Madrid, 1963. $286 \mathrm{pp}$.

18-6788. Alvarez Quintero, S. - Mañana de sol. Libreto de producción, bajo la dirección de L. S, Lavandero.-San Juan, P. R., 1963. $35 \mathrm{pp.}$

18-6;89. Álvarez Quintero, Serafín y JOAQUín-La Puebla de las mujeres. El genio alegre. $9^{\text {a }}$ ed.-Espasa-Calpe, Madrid, 1963. 163 pp. (Austral, 124),-V. núm. 16-48899.

Azorín: v. núm. 8196 .

Machado: v. núm. 6196 .

18-679o. Imbert, J.-“Jacinto Grau, vivo". -Lyra, 1964, núms. 192/4.

18-6791. IMBert, J.-“El maestro lo dijo". -Cuadernos Australes, Buenos Aires, 1959, núm. 3. [J. Grau].

V. también núm. 6919 .

18-6792. O'Connor, Patricia Walker Women in the theatre of Gregorio Martínez Sierra.-[Tesis, Univ, de Florida; resumen en $D A, 23 \quad(1962-63)$, 3899-3900].

196793. Martinez Sierra, Gregorio - El amor catedrático. - Dédalo, Madrid, 1963. 64 pp. (Novelas y cuentos).

V. también núm. 6300 .

Marquina: v. núm. 6275 .

18-6794. Muñoz Seca, Pedro, y Pedro PÉREZ FERnÁNDEZ-Un drama de Calderón.-Dédalo, Madrid, 1964. $3^{6} \mathrm{pp}$. (Novelas y cuentos).

Gómez de la Serna: v. núms. 8223-7. 18-6795. Neville, E. - El baile (N. 17 
2334). $\| B H S, 41$ (1964), 204 (Rib. bans).

García Lorca: v. núms. $5^{1} 5^{0}, 633^{6}, 634^{6-}$ $71,6806$.

18-6796. "Alejandro Casona frente a su teatro". $-P A, 1964$, núm. 49 .

18-6797. Gómez SAnTos, Marino-Españoles en órbita. - A. Aguado, Madrid, 1964. $3^{88}$ pp., láms. [Uno de ellos, Casona].

18-6798. Rodrf́uez Richart, J.-Vida y teatro de Alejandro Casona.-Inst. de Estudios Asturianos, Oviedo, 1963. 204 pp. I| RLit, 24 (1969), 273-274 (Díez Taboada); Seg, 1 (1965), 174-175 (Esquer Torres); Ins, 1964, núm. 214 (Marra-López); $B I E A, 1965$, núm. 54, 212218 (Palacio).

18-6799. DOMENEch, R.-"Para un arreglo de cuentas con el teatro de Alejandro Casona". - Ins, 1964, núm. 209.

18-680o. Moon, Harold KAY - Fantasy and humor in the theater of Alejandro Casona. - [Tesis, Syracuse Univ.; resumen en $D A, 24(1963-64), 5414]$. 18-6801. Leighton, C. H. - "Alejandro Casona y las ideas",-Ins, 1964, núm. 206.

18-6802. Palacio, A.-"Presencia de Asturias en la obra de Alejandro Casona".-BIEA, 17 (1969), 155-201.

18-68og. Olsina, B.-“Austria en el teatro de Casona", $-M K, 10$ (1964), 637639 .

18-6804. González, N.-"El jacarandal de Alejandro Casona".-RyF, 169 (1964), $402-407$.

18-6805. Borrás, A. A.-"Musical underscoring in the dramas of Casona".$H, 47$ (1964), 507.509.

18-6806. Leighton, C. H. - "Casona and Lorca: a brief comparison". - $M D, 7$ (1964), 28-34.

18-6807. Casona, Alejandro-Obras com. pletas. T. 2, $3^{\text {a }}$ ed.-Aguilar, Madrid, 1964. 934 pp. (Autores modernos).-V. núm. $17-5887$.

18-6808. Casona, Alejandro-Teatro. $T$. 1: La sirena varada; La barca sin pes. cador; Los árboles mueren de pie. $4^{\text {a }}$ ed.-Losada, Buenos Aires, 1963. 190 pp. (Gran teatro del mundo).-V. núm. 10-21174.

18-68og. CAsona, Aleyandro-Teatro. T. 3: La dama del alba. La tercera pala. bra. Retablo jovial. $2^{a}$ ed. - Losada, Buenos Aires, 1964. 241 pp. (Gran teatro del mundo).-V. núm. 16-44817. 18-68io. Casona, Alejandro-Tres come. dias poéticas: La sirena varada; Las tres perfectas casadas; Entremés del mancebo que se casó con mujer brava. $4^{\text {a }}$ ed.-Losada, Buenos Aires, 1964 . $151 \mathrm{pp}$.

18-6811. Casona, Alejandro-Los árboles mueren de pie.-Alfil, Madrid, 1964 . 104 pp. (Col. Teatro). \|EL, 1964, núm. 284 (Aragonés); $P A, 1964$, núm. 49 (Domenech); Agora, 1963-64, núms. $85 / 93$ (Fraile); Res, 1 (1965), 123-125 (Rivas Andrés).

18-6812. Casona, Alejandro-Los árboles mueren de pie.-Losada, Buenos Aires, 1964. 106 pp. (Contemporánea, 191). 18-6813. Santaló, J. L. - "Los árboles mueren de pie, en el Bellas Artes".Arb, 57 (1964), 104-106.

18-6814. Iglesias Barba, D.-"Los árboles mueren de pie, de Casona".-Miscellanea Barcinonensia, 8 (1964), 175-177. 18-6815. Aragonés, J. E.-"Sobre Los irboles mueren de pie".-HD, 40 (1964), 344-345.

18-6816. Casona, Ale Jandro - La barca sin pescador,-Alfil, Madrid, 1964. 68 pp. (Col. Teatro).

18-6817. Roig, R.-"Sobre El caballero de las espuelas de oro".-HD, 40 (1964), $80_{5}-806$.

18-6818. Aragón, J. E.-"El Quevedo de Casona".-EL, 1964 , núm. 284 .

18-6819. Santaló, J. L.-"La casa de los siete balcones".-Arb, 57 (1964), 582$5^{84}$.

18-6820. Aragonés, J. E.-"Casona: ¿Un teatro con fantasmas? (La casa de los siete balcones)". - EL, 1964, núm. 289 .

18-6821. VÁzQuez ZAMorA, R.-“La casa de los siete balcones de Alejandro Casona".-Ins, 1964, núm. 210.

18-6822. Casona, Alejandro - La dama del alba. La barca sin pescador.-Losada, Buenos Aires, 1964. (Bibl. con. temporánea, 199).

18-6823. RANi, M. C. - "Azorín, Casona and the Lady of Death".-RNo, 5 (1903), núm. 1, 12-17.

18-6824. Casona, Alejandro-La moline ra de Arcos. Sinfonia inacabada. $3^{a}$ cd.-Losada, Buenos Aires, 1964. 184 pp.-V. núm. 12-33578.

18-6825. Casona, Alejandro-Otra vez el diablo.-Alfil, Madrid, 1964. $63 \mathrm{pp}$.

18-6826. Casona, Alejandro - La sirena varada. $4^{\text {a }}$ ed.-Losada, Buenos Aires, 1964 . 
18-6827. Santaló, J. L.- "La tercera $p a$ labra [de Casona]".-Arb, 59 (1964),

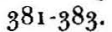

V. también núm. $635^{\circ}$.

18-6828. LAcosta, F. C.- "El humorismo de Enrique Jardiel Poncela".- $H, 47$ $(1964), 5^{01-506 .}$

Alberti: v. núm. 6384 .

18-6829. Calvo Sotelo, JoAQuín-El proceso del arzobispo Carranza.-Soc. Gral. de Autores de España, Madrid, 1964. 108 pp., láms.

18-6830. Hornedo, R. M. DE--"El proceso del arzobispo Carranza". $-R y F, 169$ $(1964), 5^{6}-584$.

18-6831. Santaló, J. L.-“El proceso del arzobispo Carranza".-Arb, 57 (1964), $5^{87-589}$.

G. Diego: v. núms, $6447^{-8}$.

Max Aub: v. núm. 7406 .

18-6892. Garciasol, R. de-“"Antonio Buero Vallejo".-Agora, 1963, núms. 79/82. 18-6833. García Pavón, F. - "Semblanza de Antonio Buero Vallejo". - Agora, 1963, núms. $79 / 82$.

18-6834. Fraile, M.-“Charla con Antonio Buero Vallejo". - Agora, 1963, núms. $79 / 82$.

18-6835. "Antonio Buero Vallejo answers seven questions". - The Theatre Annual, 1962 (Cleveland, 1963), 1-6.

18-6836. Sitja Príncipe, F.-"Acerca de Buero Vallejo". - Agora, 1963, núms. $79 / 82$.

18-6837. Olmo, L.-"Antonio Buero Vallejo. El compañero". - Agora, 1963, núms. $79 / 82$.

18-6838. ARrABAL, F.-"In particular Buero Vallejo".-Agora, 1963, núms. $79{ }^{\dagger}$ 82.

18-6839. CAmpos, J.-“Buero en tres momentos".-Agora, 1963, núms. $79 / 82$.

18-6840. BOreL, J. P.-"Buero Vallejo, más allá de los Pirineos". - Agora, 1969, núms. $79 / 82$.

18-6841. BLAJoT, J.-“Del mundo mental de Buero Vallejo".-Res, 1 (1964), $85-95$.

18-6842. Sortano, E.-"Buero Vallejo, autor moral".-Agora, 1963 , núms. $79 /$ 82 .

18-6843. Guereña, J. L. - "Teatro con Buero Vallejo".-PSA, 31 (1963), 3ox. 310 .

18-6844. Borel, I. P - "Buero Vallejo: tratro y política".-ROcc, 6 (1964), 226 234 .

18-6845. Buero VAllejo, Antonio-Aventura en lo gris.-AIfil, Madrid, 1964.
111 pp. (Col. Teatro). \|BAbr, 39 (1965), 67-68 (Ruple).

18-6846. Buero Vallejo, Antonio - El concierto de San Ovidio. Pról. de J. P. Borel.-Aymá, Barcelona, 1969. 133 pp. (Col. Voz imagen) .

18-6847. Bufro Vallejo, Antonio-His toria de una escalera. Ed. by $\mathbf{H}$. Lester \& J. A. Zabalbeascoa.-University, London, 1969. || MLR, 60 (1965), 292 (Jones).

18-6848. Fostre, D. W.-"Historia de una escalera: a tragedy of aboulia".-Renascence, 17 (1964), 3-10.

18-6849. Buero Vallejo, Antonio-Las Meninas. Ed. by J. Rodríguez-Castellano.-Scribner's, New York, 1963. 260 pp. $\|$ BHS, 42 (1965), 132-133 (Edwards); RHM, 30 (1964), 54 (Florit); $H, 47$ (1964), 895 (Gillespie).

18-6850. Sastre, AlfoNso-Guillermo Tell tiene los ojos tristes.-Alfil, Madrid, 1963. 87 pp. (Teatro).

18-6851. SASTRE, Alfonso-Cuatro dramas de la Revolución.-Edit. Bullón, Madrid, 1963. 304 pp. (Generaciones jun. tas). I| BAbr, $3^{8} \quad(1964), 295$ (Ánge. les) .

18-6852. Sastre, Alfonso-Ana Kleiber. Morte no bairro. Trad. de Egito Goncalves.-Presença, Lisboa, 1969. 26o pp.

18-6853. SAStre, Alfonso-Cargamento de sueños. Prólogo patético. Asallo nocturno.-Taurus, Madrid, 1964. 254 pp. (Primer acto).

18-6854. Sastre, Alfonso-Historia de una muñeca abandonada.-Anaya, Madrid-Salamanca, 1964. 32 pp., ilustr. (Col. Girasol, teatro).

18-6855. SASTRE, AlfoNso-Las noches lúgubres.-Horizonte, Madrid, 1964. 287 pp. (Bibl. Literatura actual).

18-6856. Marra-López, J. R. - "Alfonso Sastre, narrador". - ins, 1964, núms. $212 / 3$.

18-6857. Ponce Muñoz, F.-"Vida de Miguel Mihura”. $-P E$, 1964, núm. 93 .

18-6858. Minura, Miguel-Carlota. Ed. Edith B. Sublette-Odyssey Press, New York, $1963 . \mathrm{xxi}+146 \mathrm{pp}$. $\| M L J, 49$ (1965), $5^{8-59}$ (DeCoster); H, 47 (1964), $67 ;-6 ; 8$ (Lott).

\section{PROSA NARRATIVA}

18-6859. Deyermond, A. D.-“El hombre salvaje en la novela sentimental',-Fil, 10 (1964), 97-111.

18-686o. Petriconi, H.-_Abenteuer nnd 
kein Ende". $-R], 14$ (1963), 27-44. [Ref. a Cervantes y a la novela picaresca, en particular al Lazarillo].

18-6861. HartmanN, Egon (ed.)-Klassische spanische Erzähler. Dt. von Josef von Eichendorff, Georg Spranger, et al.-Neues Leben, Berlin, 1964. $501 \mathrm{pp}$. (Klassiker-Bibliothek).

18-6862. Cuentos viejos de la vieja España. $5^{\text {a }}$ ed.-Aguilar, Madrid, 1964 . 1122 pp. (Col. Joya).

18-6863. Rossell, Ferdinando-Una polemica letteraria in Spagna: il romanzo naturalista.-Università, Pisa, 1963. 110 pp. (Istituto di Letteratura Spagnola e Ispano-Americana, 5). \|RLit, 27 (1965), 241-242 (Esquer Torres); $A r b, 5^{6}$ (1963), 322-323 (Larrea); HR, 34 (1966), ${ }^{184^{-185}}$ (Pattison); BHi, 65 1963), 419 (Ricard).

18-6864. VARELA, J. L.- "Introducción al costumbrismo romántico". - Atl, 1 $(1963), 4^{28-} 435$.

18-6865. Buendia, Felicidad (ed.)-Antologia de la novela histórica española (1830-1844).-Aguilar, Madrid, 1963. 1603 pp. (Obras eternas). || LNL, 1964, núms. 3/4, 103-104 (Picoche).

28-6866. PÉRfz Minik, D.-Novelistas españoles de los siglos xix y $x x$ (N. 1233697). I| MCan, 25 (1963), 156-158 (Armas Ayala).

18-6867. Domin, Hinde (ed.) - Spanien erzählt. Sechsundzwanzig Erzählungen. -Fischer Bücherei, Frankfurt/M., 1963. 200 pp. II ASNS, 200 (1963), 480 (Garcia); RLit, 27 (1965), 261-262 (Rodríguez Richart).

18-6868. Sobejano, Gonzalo (ed.) $-\mathrm{Mo}$ derne spanische Erzähler.- J. P. Bachem, Köln, 1963.248 pp. [Introducción, pp. 5-59]. \| $H R, 33(1965), 426$. 427 (Arroyo); ASNS, 200 (1963), 480 (García); $N, 45$ (1965), 75-76 (Lechner); RLit, 27 (1965), 256-258 (Rodriguez Richart).

18-6869. Gullón, R.- "La novela española moderna".- $-L T, 1963$, núm. $42,45^{-}$ 68.

18-687o. Domin, H.-“Literatur ohne mittlere Generation. Zur modernen spanischen Prosa". - Merkur, 7 (1963), $3^{88-398 .}$

18-6871. WEst, P.-- Eloquentia standing still: the novel in modern Spain". $-K R$, 25 (1963), 203-216.

18-6872. Alban Camoin, Anne MarieLas guerras carlistas en la novelistica de la generación del 98.-[Tesis de la
Universidad Nacional Autónoma, México, 1964$]$.

18-6873. Pérez de la Dehesa, R.-“El judío sefardí en la novela española no. derna: Blasco Ibáñez, Concha Espina, Azorín".-OYS, 6 (1963), xlvii-li.

18-6874. Balseiro, José Agustín-Nouelistas españoles modernos. Primera serie. $7^{\text {a }}$ ed.-Las Américas, New York, 1963. $\mathrm{xx}+470 \mathrm{pp} .-\mathrm{V}$. núm. 17-5916. 18-6875. Bernstein, Jerome S.-Theories of the modern novel in Spain.-[Tesis, Harvard Univ., 1964].

18-6876. Siraux, Y. - "Le roman espagnol".-Rev. Nouvelle, Bruxelles, $196_{3}$, $181-191$, 290-300; 1964, 208-219.

18-6877. Bergasa González, F. - "Visión objetiva de la novela subjetiva". $-E L$, 1964, núm. 286.

18-6878. WinecoFf, J.-“The contemporary Spanish novel".-SAB, 29 (1964), núm. 4, 1-4.

18-6879. Entramasaguas, Joaquín dE (ed.)-Las mejores novelas contempo. ráneas. T. 9.-Planeta, Barcelona, 1963. xix + 1347 pp.-V. núm. 17-5920.

18-6880. Sobejano, G.-"Sobre la novela picaresca contemporánea".-BISD, 1964 , núm. 31, 213-225.

18-6881. WERrIE, P._"Espagne: romanreportage et roman picaresque" $-T R$, 1964, núm. 202, 116-122.

18-6882. Van Praag Chantraine, J.--“El pícaro en la novela española moderna".-RHM, 29 (1963), 23-31. ||$L R, 19$ $(1965)$, 299-300 (Groult).

18-6883. Ferguson, Albert Gordon-Spain through her novel (1940-1960). A stu$d y$ of changes in mores and attitudes as reflected in the nowel.-[Tesis, Nebraska Univ.; resumen en $D A, 24$ $(1969-64), 1615]$.

18-6884. Fernández Santos, Jesús (ed.)Siete narradores de hoy.-Taurus, Madrid, 1963. 192 pp. (TemasdeEspaña). [Sánchez Ferlosio, Ana Mạ Matute, L. Goytisolo, M. Fraile, F. García Pavón, Jesús Fernández Santos, I. Aldecoa].

18-6885. Sernova, R.-"Las novelas sobre la España contemporánea y el lector ruso".-LS, 1963, núm. 7, 179-182. [Traducciones al ruso de Dulorcs siedio, zunzunegui, Goytisolo y otros].

18-6886. Marco, J.-"En torno a la novela social española".-Ins, 1963, núm. 202.

18-6887. Elizalde, I.-“Tendenze e caratteristche della narrativa sociale spagnola".-CC, 115 (1964), 132-145. 
18-6888. VARELA JÁcome, B.-"La novela social y su mundo asocial". $-E L$, 1964 , núm. 285 .

18-6889. Berrettini, C.--Breves apuntes sobre la novelística femenina española".-Asom, 1963, núm, 3, 39-54.

18-68go. VÁzQuez Flavia, P.- "La mujer en la literatura. La imagen de la mujer en la novela actual".-Eidos, Madrid, 1964 , núm. $20,54^{-62}$.

18-6891. Baquero Goyanes, Mariano Proceso de la novela actual.-Rialp, Madrid, 1963. 220 pp. (Biblioteca del pensamiento actual). I| Atl, 1 (1963), 339-340 (Benítez Claros); $A H, \mathbf{g} \dot{0} 3$, 329-33o (García Viñó).

18-6892. RosA, J. M. DE LA-"Notas para uma introdução ao romance espanhol actual".-Esp, 1964 , núm. 2, 49-57.

18-6893. Olmos Garcia, F.- "La novela y los novelistas españoles de hoy. Una encuesta".-CuA, 1963, núm. 4, 211 237.

18-6894. WERrie, P.-“Le roman espagnol d'aujourd'hui".-TR, 1964, núm. 193, 91-101.

18-6895. András, L.-"Mai spanyol regény: mai spanyol társadalom".-Nagyvilág, 1959, $5^{82-591 .}$

18-6896. Bianchini, A.- “La nueva ola". $-T P r, 1964$, núm. 4, 247-252.

18-6897. Cirre, J. F. - “El protagonista múltiple y su papel en la reciente novela española".-PSA, 33 (1964), 159170.

18-6898. Castellet, J. M.-“La joven novela española".-Sur, 1963, núm. 284 , $4^{8-54}$.

18-6899. HoffmanN, H. - "Die Haltung des Erzählers im spanischen Roman der Gegenwart".-NS, 1963 , 352-363.

18-6goo. Baquero Goyanes, Mariano Antologia de cuentos contemporaneos. -Labor, Barcelona, 1964. xlviii +964 pp.

18-6gon. Palomo, Marfa del Pilar-La novela española en rg6x y 1962.-C.S. I.C., Madrid, 1964. 69 pp. (Cuadernos bibliográficos, 13). I| RLit, 25 (1964), 265 (Rozas).

18-69o2. Gramberg, E. J.-"Spanish fiction 1963".- BAbr, $3^{8}$ (1964), 195-139.

$V$. también núms. 5153-6, 5905.

A utores antiguos

18-69og. La historia de la Donzella Teodor. Ein spanisches Volksbuch arabischen Ursprungs. Untersuchung und krit. Ausgabe der ältesten bekannten
Fassungen von Walter Mettmann. Akad. der Wissenschaften und der Literatur, Mainz, 1962. $103 \mathrm{pp}$. || $Z R P h$, 81 (1965), 545-548 (Hilty); Ro, 86 (1965), 429 (Lecoy); RPF, $13 \quad\left(1964^{-}\right.$ 1965), 614 (Paiva Boléo); $H R, 33$ (1965), 84-85 (Place); BHS, $4^{1}$ (1964), 52-53 (Tate).

18-6904. E1 Baladro del sabio Merlín, según texto de la ed. de Burgos de 1498 . Ed. y notas de Pedro Bohigas. Ts. 2 y 3. - Selecciones Bibliófilas, Barcelona, 1960-62. 172, 224 pp. - V. núm. 1335774. II HR, 34 (1966), 66-68 (Place); BHS, 42 (1965), $4^{8-50}$ (Tate).

18-6go5. Bogdanow, F.-"The Spanish Baladro and the Conte du brait".-Ro, $8_{3}$ (1962), 383-399.

18-69o6. Scholberg, K. R.- "The structure of the Caballero Cifar". $-M L N$, 79 (1964), 112-124.

18-6907. Dutton, B., y R. M. Walker "El Libro del caballero Zifar y la lírica castellana".-Fil, 9 (1963), 53-67. 18-6go8. Piccus, J. - "Refranes y frases proverbiales en el Libro del cauallero Zifar".-NRFH, 18 (1965-66), 1-24.

18-6gog. KöNig, B.-“Amadís und seine Bibliographen. Untersuchungen zu frühen Ausgaben des Amadís de Gaula". $-R J, 14$ (1963), 294-309.

18-6910. FJelstad, Ruth Naomi - $A r$ chaisms in "Amadis de Gaula".-[Tesis, State Univ. of Iowa; resumen en $D A$, $24(1963-64), 4687]$. $153 \mathrm{pp}$.

18-6911. Amadis de Gaula, ed. E. B. Place (N. 17-5939). $\| M L N$, 8o (1965), 277-279 (Avalle Arce); $R P h, 16$ (1962$63), \quad 5^{00-502,}$ y $18 \quad\left(1964^{-6}\right), \quad 134^{-135}$ (Hamilton); $R N, 16$ (1963), 206 (Keller); $H, 47$ (1964), 195-196 (Keller); $A I A, 25$ (1965), 453-454 (Pazos); $H R$, 32 (1964), 78-79 (Rey).

18-6912. Amadis. Erstes Buch. Nach der ältesten deutschen Bearbeitung hgs. von A. von Keller.-Bibliothek d. liter. Vereins, Stuttgart, 1963. viii $+478 \mathrm{pp}$. [Reproducción de la ed. de 1857].

18-6913. Vieira de Freitas, Alfredo Amadis de Gaula. Gaula de Amadis. Ensaio acerca da infuência das novelas de cavalaria na Madeira.-Funchal, 1964. $36 \mathrm{pp}$.

18-6914. Bosch Carbonell, Marfa ÁngeLES-Estudio de "Don Olivante de Latira".-[Tesis, Univ. de Barcelona, 1963]. 18-6915. Turner, D. - "[Fernández dt] Oviedo's Claribalte: the first American novel".-RNo, 5 (1964), 65-68. 
D. de San Pedro: v. núm. 6062 .

18-6916. Scudieri RUgGieri, J.--"Un romanzo sentimentale: il Tratado notable de amor, di Juan de Cardona".RFE, $4^{6}$ (1963), 49-79. [Ca. 1545].-V. núm. $17-595^{\circ}$.

18-6917. BELIC, O.-“La novela picaresca como orden artístico".-UH, 1963, núm. $163,7 \cdot 30$.

18-6918. BELIC, OLDRICH-Spanelský pikareskni roman a realismus.-Acta Universitatis Carolinae, Praha, 1963. $23^{2}$ pp. (Philologicae monographiae, 4). II PhP, 7 (1964), 447-448 (Hampejs).

18-6919. Ortega Polaino, Lorenzo-la delincuencia en la picaresca.-Sevilla, 1964. 101 pp. $\| H, 4^{8}$ (1965), 611-612 (Laurenti).

18-6920. Batalllon, M.-“Les nouveaux chrétiens dans l'essor du roman picaresque". $-N, 4^{8} \quad(1964), 283-298$.

18-6921. Laurentr, J. L.-“Impresiones y descripciones de las ciudades españolas en las novelas picarescas del Siglo de Oro".-BBMP, 40 (1964), 309-326.

18-6922. Laurenti, J. L. - "Imágenes c impresiones de ciudades italianas en las novelas picarescas españolas del Siglo de Oro". $-R F, 76$ (1964), 334-352.

18-6923. VÁzQuez de Prada, A.-"La moralité dans le roman picaresque".-TR, 1963 , núm. $191,65-81$.

$v$. también núm. 5214 .

18-6924. Abrams, F.-“"Fue Lope de Rueda el autor del Lazarillo de Tormes?" $-H, 47$ (1964), 258-267.

18-6925. Crouch, O.-"El autor del Lazarillo. Sobre una reciente tesis".-Hf. 1963, núm. 19, 11-23.

18-6926. Rumeau, A.-"Notes sur les $\boldsymbol{L a}$ zarillo. L'édition d'Anvers, $1_{553}$, in16".-BHi, 66 (1964), 57-64.

18-6927. Rumeau, A.-"Notes au Lazarillo. Les éditions d'Anvers, $1554^{-1555}$, de $L a$ vida de Lazarillo et de La segunda parte".-BHi, 66 (1964), 257271.

18-6928. Rumeau, A.-"Notes all Lazarillo.'Des édirions d'Anvers, $1554^{-1} 555$, à celles de Milan, 1587-1615",-BHi, 66 $(1964), 272-293 .-V$. núm. 17-5957.

18-6929. BAADER, H.- "Noch einmal zur ich-Form im Lazarillo de Tormes".$R F, 7^{6} \quad(1964), 437-44^{6}$.

18-6930. Moon, H. K.-"Humor in Lazarillo de Tormes". - Brigham Young University Studies, 5 (1964), 238-241. 18-6931. Rodríguez Diéguez, J. L.-"La educación en la picaresca: el Lazari-
llo".-Rev. Española de Pedagogia, 22 (1964), 259-262.

18-6932. Morris, C. B.- "Lázaro and the squire: hombres de bien".-BHS, 41 (1964), 238-241.

18-6933. La vida de Lazarillo de Tor. mes $y$ de sus infortunios $y$ adversida. des. Ed. y notas de Carmen Castro.Taurus, Madrid, 1964. 108 pp. (Ser y iiempo. Temas de España). \|CuH, 61 (1965), 214.215 (X).

18-6934. La vida de Lazarillo de Tormes $y$ de sus fortunas $y$ adversidades. Ed. with introd. and notes by $R$. O. Jones. -Univ. Press, Manchester, 1969. xliv +89 pp. || BHS, 42 (1965), 191-192 (Reckert).

18-6935. La vida de Lazarillo de Tormes. Introd., notas y vocab. de Juan Carlos Pellegrini. 2a ed.-Huemul, Buenos Aires, 1963. 100 pp. (Clásicos Hue. mul, 1).

18-6936. Lazarillo de Tormes. Noticia prel. de J. Ruiz de Larios.-Plaza y Janés, Barcelona, 1964. 126 pp. (Clás. Plaza, 1).-V. núm. 16 44866 .

18-6937. El Lazarillo de Tormes, Adapt. de Basilio Lasala.-I.D.A.G., Madrid. Barcelona, 1964. I7 1 pp. (Col. Auri. ga).

18-6938. Vita di Lazzariglio del Torme. Ed. e premessa a cura di G. M. Berini.-Torino, 1964 . xiii +64 pp.

18-6939. La vida de Lazarillo de Tormes $y$ de sus fortunas $y$ adversidades. Trad. A. M. Battistini, introd. e commento di Biagio Dradi-Maraldi.-Forum, Forli, 1964. 107 pp. (Saper leggere, 2).

18-6940. Das Leben des Lazarillo von Tormes, Ubertr. von Helene Henze. Das Leben des Guzmán von Alfaracite von Mateo Alemán. Übertr. von Rainer Specht. Hrgs, von Horst Baader.Hanser Verlag, München, 1964. $880 \mathrm{pp}$. 18-6941. Álvarez, G., y J. Lecker-“Una transmisión del Iazarillo a la comedia holandesa".-RFE, 45 (1962), 293298. || LR, 19 (1965), 287 (Grandjean). 18-6942. BARrick, M. E. - “Three sixteenth-century printer's fillers". $-R N o$, $6(1964), 60-64$. [Sobre la $2^{\mathrm{a}}$ parte (anónima) del Lazarillo].

V. también núms. $5849,6860,715^{8}$.

18-6943. LAurenti, J. L.- "El nuevo tono religioso del Lazarillo de Juan de Luna".-ALM, 3 (1963), $107-127$.

18-6944. Laurenti, J. L.-“La técnica novelística de Juan de Luna".-CuH, $5^{8}$ (1964), 243-269. 
18-6945. LAURENTI, J. L.-“La coloración afectiva del Lazarillo de Juan de Luna a través de los diminutivos".$B B M P, 39$ (1963), 53-56.

18-6946. GLenN, R. F.-"The moral implications of $\mathrm{El}$ Abencerraje". $-M L N$, $80 \quad(1965), 202-209$.

18-6947. López Estrada, F. - "Sobre el cuento de la honra del marido defen. dida por el amante, atribuido a Rodrigo de Narváez".-RFE, 47 (1964), 331-339. [En El Abencerraje].

Montemayor: v. núm. 6079 .

18-6948. Bataillon, M.-Andrés Laguma, autor del Viaje de Turquia, a la luz de las recientes investigaciones".-ESeg, 15 (1963), 5-69.-V. núm. 13-37503.

18-6949. GiL L., y L. GiL-"Ficción y realidad en el Viaje de Turquia (Glosas y comentarios al recorrido por Grecia)".-RFE, 45 (1962), 89-16o. \|LR, 19 (1965), 86-187 (Groult).

18-6950. [LAguna, ANDrés]-Viaje a Turquia.-Aguilar, Madrid, 1964. (El globo de colores).

$V$ también núms. 5241-3.

18-6951. Hanrahan, Thomas - La mujer en la novela picaresca de Mateo Alemán.-Porrúa, Madrid, 1964. (Bibliotheca Tenanitla, 7). $\| R y F, 171$ (1965), 434-435 (Hornedo); Ins, 1964, núms. 216/7 (Moreno Báez).

18-6952. Alemán, Mateo - Guzmán de Alfarache. Ts. 2 y 4. Nueva ed.-Espasa-Calpe, Madrid, 1963. 293, 290 pp. (Clás, cast., 83).-V. núm. 17-597o.

18-6053. Alemán, Mateo-Vida del picaro Guzmán de Alfarache. Ed, de Mercedes Villalta. Pról. de E. M. Aguilera.Iberia, Barcelona, 1963. 2 ts.

18-6954. Alemán, Matro-[Vida del picaro Guzmán de Alfarache. Trad, al ruso por Evguenia Lisenko y Nadiezhda Poliak. Pról. y notas de Yuri Kornéiev.Edit. Literaria, Moscú, 1964].

V. también núm. $694 \%$.

18-6955. López de Úbeda, Francisco.-La picara Justina.-Eds. $\mathrm{R}$, La Habana, 1964. (Bibl. básica de lit. española).

18-6956. Aguilera, F.-Works by Miguel de Cervantes Saavedra in the Library of Congress (N, 16-48996). \| RLit, 25 (1964), 227 (Rozas).

18-6957. Pérez Silva, V. - “La biblioteca cervantina y caballeresca de don Juan Sedó".-BCB, 4 (1963), 390-393.

18-6958. Rosales, L.- "Icaza, cervantista". $-\mathrm{CuH}, 53$ (1963), 492-496.

18-6959. Alcalí, MANUfL-El cervantismo de Alfonso Reyes. [Discurso académico]. - Imprenta Universitaria, México, 1964. $73 \mathrm{pp}$.

18-696o. Sós, ENDre-Cervantes. - Müivelt Nép, Budapest. 1955. 166 pp.

18-6961. Rothbauer, Anton M.-Der $i n$ bekannte Cervantes. - Goverts, Stuttgart, 1963. $30 \mathrm{pp}$.

18-6962. ARbó, S. J.-Vida de Cervantes. Trad. por Manuel de Seabra.-Aster, Lisboa, 1963.

18-6963. SCHÜRR, FRIEDRICH - Cervanies. Leben und Werk des grossen Humoristen. 2. Aufl. - Francke, Bern, 1963. 162 pp. (Dalp-Taschenbücher, $37 \mathrm{D})$. -V. núm. 6-7567. I| ASNS, 202 (1965), (1965), 310-312 (Neuschäfer); $R H M$, $3^{\circ}$ (1964), 53 (Roberts); BHS, $4^{2}$ (1965), 68-69 (Trotter).

18-6964. RüegG, A.-“Zu Schürrs Cervantes".-ZRPh, 8o (1964), 478-485.

18-6965. Tomás, Mariano-Vida y desventuras de Cervantes.-Juventud, Barce lona, 1964. 167 pp. (Col. $Z$, 101).

18-6966. Pifltain, R.-"Miguel de Cervantes, soldado heroico de Lepanto".Norte, México, 1963, núm. 194.

18-6967. Iglesias Laguna, A.-“La boda de Cervantes". - $M u H, 1964$, núm. 190.

18-6968. FAgoAgA, I. DE-"Lo vasco en la vida y la obra de Cervantes".-BSV, 20 (1964), $215-237$.

18-6969. Avalle-Arce J. - "Un banquero sevillano, poeta y amigo de Cervantes" $-A H, 4^{\circ}$ (1964), 209-239.

18-697o. Manegat, Luis G.-La Barcelona de Cervantes.-Plaza y Janés, Barcelona, 1964. 231 pp. (Atlántico). $\| F H$, 2 (1964), 473 (Arasa).

18-6971. Otero, C. P.-“Cervantes e Italia: Eros, industria, socarroneria". PSA, $34 \quad$ (1964), 287-325.

18-6972. Restrepo, A. J. - "Cervantes a Santa Fe de Bogotá. Sueño-leyenda y realidad". $-B C B, 7$ (1964), 399-407.

18-6973. Starkie, W.-"Cervantes and the Gypsies".-HLQ, 26 (1963), 337-349.V. núm. 16-49021.

18-6974. Aveleyra, T. - "El humorismo de Cervantes".-ALM, 3 (1963), 128162 .

18-6975. Green, O. H. - "Realidad, voluntad y gracia en Cervantes" (N. 17$5990)$. $\| L R, 19$ (1965), 188 (Groult). 18-6976. Cortejoso, Leopoldo - Miguel de Cervantes, médico de su tiempo.Conferencias y Ensayos, Madrid, 1964 . $42 \mathrm{pp}$. 
18-6977. ZIMIC, S.-“El amante celestino y los amores entrecruzados en algunas obras cervantinas". $-B B M P$, 40 (1964), $3^{61-387}$.

18-6978. Ayala, F.- "El espacio barroco: Cervantes y Quevedo".-Ins, 1963, núm. 197 .

18-6979. Marone, G.-“Cervantes, El Greco e Velázquez".-Studi... in onore di Francesco Flora (Milano, 1969), 191200.

18-6g80. Durán, M.-“Cervantes y el realismo fluido".-Ins, 1963, núms. 200' ol.

18-6981. ReichenberGer, K. - "Cervantes und die literarischen Gattungen". GRM, 13 (1963), 233-246.

18-6g82. MANN, T. - Cervantes, Goethe, Freud (N. 17-2461). \|H H 11 (1963), 248-25o (Antonietta).

18-6983. DAMISCH, H. - "L'autre inquisition".-MF, 349 (1963), 426-432. [Cervantes y otros].

18-6984. Garcia Puertas, M.-Cervantes y la crisis del Renacimiento (N. 18 . 3532) . || NRFH, $18\left(1965^{-66}\right), 198-199$ (Avalle-Arce).

18-698 . Vianna Moog-Heróis da deca. déncia. $3^{\text {â }}$ ed. revista.-Civilização Brasileira, Rio de Janeiro, 1964. [Uno de ellos, Cervantes].

18-6986. Davies, Marian Ruth LoemLinThe individual and the bases of an ideal society in Cervantes. - [Tesis, Stanford Univ.; resumen en $D A, 25$ $\left.\left(19^{6}-6_{5}\right), \quad 1904-1905\right]$.

18-6987. Dfez de Medina, F.- "Una estatua de Cervantes".-CuH, 57 (1964), $5^{\circ 8-517 .}$

18-6988. Riley, E. L. C. - Cervantes's theory of the novel.-Clarendon Press, Oxford, 1962. $25^{6} \mathrm{pp}$. II $M P h, 62$ (1964. 65), 163-165 (Booth); BHi, 66 (1964), $172-179$ (Canavaggio); $R N, 16$ (1963), 246-25o (Green); LR, 18 (1964), 359$3^{61}$ (Groult); $R N, 16 \quad(1963), 147^{-1} 4^{8}$ (Knowles); British Journal of Aesthe. tics, 3 (1963), 262-264 (Livermore); Arb, 57 (1964), 597-598 (Molina); BHS, 4o (1963), 248-249 (Parker); $A U M L A, 20$ (1963), 401-403 (Rhodes); ACerv, 9 (1961-62), 273-276 (Sánchez).

18-6989. Fernández Gómez, C.-Vocabulario de Cervantes (N. 17-5996). \| Fil, 10 (1964), 223-23o (Lerner); $P h P, 8$ (1965), 109 (Pavliková).

18-699o. Marcus, R.-"Le lexique indoaméricain de Cervantes".- $L N L, 1963$, núm. 3, 111-114.
18-6991. Cervantes, Miguel de - Obras completas. T. 1: El Quijote, seguido del Quijote de Avellaneda. Ed., introd. y notas de $M$. de Riquer. - Planeta, Barcelona, 1969. (Clásicos Planeta).

18-6992. Cervantes, M. DE-Obras, t. 2: Obras dramáticas (N. 17-5999). \| Seg, I (1965), 434-435 (Rull).

18-6993. Cervantes, Miguel de-El relablo de las maravillas. Don Quijote. La Gitanilla. - Vergara, Barcelona, 1963. $1045 \mathrm{pp}$.

18-6994. Cervantes, Miguel de - Don Quijote de la Mancha. Versión compendiada por Clemente Cimorra. 9\% ed.-Atlántida, Buenos Aires, 1963. $14^{1}$ pp., ilustr. (Bibl. Billiken).

18-6995. Cervantes, Miguel DE - Don Quijote de la Mancha. Pról. y notas de Francisco Rodríguez Marín. Ts, 1, 5, 6, 8.-Espasa-Calpe, Madrid, 1964 $360,34^{6}, 34^{0}, 33^{8}$ pp. (Clás. cast.).

18-6996. Cervantes, Miguel de - El ingenioso hidalgo Don Quijote de la Mancha. Nueva ed., sobre los textos de $160_{5}^{-1615}$. Noticia biográfica por Luis María Plaza.-Comar, Barcelona, 1964. 859 pp., ilustr.

18-6997. Cervantes, Miguel de - Don Quijote de la Mancha, 22a ed.-EspasáCalpe, Madrid, 1964. 680 pp. (Austral, 150) -V. núm. 16-49029.

18-6998. Cervantes, Miguel DE - El ingenioso hidalgo Don Quijote de la Mancha. - Fernández, México, 1961. 562 pp.-V. núm. 17-6005.

18-6999. Cervantes, Miguel de - Don Quijote de la Mancha.-Ferma, Barcelona, 1964. (Clásicos Ferma, 6).

18-7000. Cervantes, Miguel de - $E l$ Quijote. Ilustrado por Dali. - Mateu, Barcelona, 1964 .

18-7001. Cervantes, Migufl DE - Don Quijote de la Mancha.-Edit. Nacional, Madrid, 1964. $84^{6}$ pp., ilustr. (Prosistas españoles).

18-7002. Cervantes, Miguel de - $E l$ ingenioso hidalgo Don Quijote de la Mancha. Biografía por $\mathbb{R}$. Majó Framis. Nueva ed.-J. Pérez del Hoyo, Madrid, 1963. 557 pp., ilustr.

18-7o03. Cervantes, Miguel de - El ingenioso hidalgo Don Quijote de la Mancha. Pról. de Américo Castro. $3^{\text {a }}$ ed.-Porrúa, México, 1964. xlix $+5^{86}$ pp. (Col. Sepan cuantos, 6).-V. núm. 16-49026.

18-7004. Cervantes, Miguel de - El ingenioso hidalgo Don Quijote de la 
Mancha. Notas y comentarios de A. Millares Carlo,-UTEHA, México, 1964. 2 ts.: 1026 pp., ilustr. $-V$. núm. 1126683.

18-7005. Cervantes, Miguel de - Don Quijote de la Mancha. Adaptación de Enrique Sordo y Ramón Conde.-Idag, Barcelona, 1964. 2 ts.: 154, 164 pp., ilustr. (Literatura inmortal, 2).

18-7oo6. Cervantes, Miguel de - Don Quijote de la Mancha. - Edit. Vasco Americana, Bilbao, 1963. 147 pp., ilustr. (Literatura inmortal, 2).

18-7007. Cervantes, Miguel de - El Quijote. Ed. escolar. $19^{\mathrm{a}}$ ed.-Luis Vives, Zaragoza, 1964. 312 pp.-V. núm. $16-449^{16}$.

18-7oo8. Cervantes, Miguel de - El ingenioso hidalgo Don Quijote de la Mancha. Ed. escolar, sel. por F. Ro. mero Juan. $22^{\mathrm{a}}$ ed. reformada.-Hijos de Santiago Rodríguez, Burgos, 1964. 335 pp.-V. núm. 11-28594.

18-7oog. Cervantes, Miguel de - Páginas escogidas del "Quijote".-Sel. y notas de Mariana Suárez de Alcocer.Escuela de Verano, México, 1964. 253 pp.

18-jolo. Herreros, Enrique G.-Principales aventuras de Don Quijote.-Ed. Nacional, Madrid, 1964 . 75 láms.

18-7011. Cervantes, Miguel de - Primeras aventuras de Don Quijote de la Mancha. Adapt. de M. Toledano. $4^{\text {a }}$ ed.-Juventud, Barcelona, 1964. 45 pp. $-V$. núm. 11-21227.

18-7o12. Cervantes, Miguel de - Don Quichotte. D'après la trad. de Louis Viardot.-Mame, Tours, 1963. 216 pp., ilustr.

18-7013. Cervantes, Miguel de - Don Chisciotte della Mancia. - Salani, Firenze, 1965. 2 ts. (I grandi classici).

18-7o14. Cervantes, Miguel de - Don Chisciotte della Mancia. Trad., pref. c note di Alfredo Giannini. [También contiene] Miguel de UnAmuno, Commento alla vita di Don Chisciotte. Trad., pref. e note di Carlo Candida.Dall'Oglio, Milano, 1964. 1332 pp.

18.7015. Cervantes, Miguel de - Don Chisciotte della Mancia.-Istituto Geografico De Agostini, Novara, 1964. 79 pp.

18-7o16. Cervantes, Miguel de - Don Quijote de la Mancha. Herausgegeben und neu übers. von Anton M. Rothbauer. - Goverts, Stuttgart, 1964. $137^{6}$ pD. (Gesamtausgabe, 2).
18-7017. Alencar, R. DE - "Galas, curiosidades e impurezas em luxuosa edição do D. Quixote de la Mancha".$R P, 29(1964), 207-220$. [La ed. dlescrita en el núm. 17-6019].

18-7018. MalpiQue, Cruz-D. Quixote no mundo dos ex-libris. Estruturação artística de A. M. da Mota Miranda.Associação Portuense de Ex-Libris, Porto, 1964. $112 \mathrm{pp}$.

18-7o19. SöTÉR, I.-“"Cervantes és a Don Quijote". - [En su libro] Világtájak (Budapest, 1957), pp. 33-47.

18-7o20. Cortés Ahumada, E.-"Don Quijote, o la mismidad de Cervantes".$B C B, 4 \quad(1963), 394-399$.

18-7021. Schalb-Koch, E. - "Don Quichotte et Cervantes".- $R U L, 18$ (1964), $439-445, \quad 533-542$.

18-7022. Gonthier, Denys A.-El drama psicológico del "Quijote". - Studium, Madrid, 1962. 213 pp.-V. núm. 172423. $\mid H R, 33(1965), 410-411$ (Avalle-Arce); BAbr, $3^{8}$ (1964), 54 (Durán); $H, 4^{6}$ (1963), 846-847 (Ryan); $R y C, 8$ (1963), 300-gor (Santos Merino) ; RR, 55 (1964), 289-292 (Swanson).

18-7023. Alcalá, M. - “¿Quién es Don Quijote?" - UMx, 18 (1963-64), núm. 7 .

18-7024. Cervantes, Miguel de-Az elmés nemes Don Quijote de la Mancha. [Pref. de] János Benyhe.- Uj M. Kiadó, Budapest, 1955. 2 ts. $-V$. núm. 1230259 .

18-7025. Palacín, G. B.-"El nombre del hidalgo en quien encarnó Don Quijote".-RNo, 5 (1963), núm. 1, $55^{-5} 8$.

18-7026. Romero L., A.- "Don Quijote se engendró en Argel".- $U d A$, 4o (1963), 303-313.

18-7027. Nalurm, C. O.--"Sobre la estructura del Quijote".- $P H, 8 \quad\left({ }_{1964}\right), 3^{6} 5$ $3^{8} 7$.

18-7028. Pellegrini, S.- 'L'unità del Don Chisciotte". - Belf, 19 (1964), 534 545 .

18-7029. Lloréss, V.-"Historia y ficción en el Quijote".-PSA, 28 (1963), 235' $25^{8 .}$

18-7ozo. MaezTu, Ramiro DE-Don Quijote o el amor. (Ensayos en simpatía). Ed. de A. Sánchez.-Anaya, SalamancaMadrid, 1964. $9^{8}$ pp. (Biblioteca Anaya, 43).

18-7og1. Pabón Núñez, L.- "Diez rostros del amor en El Quijote".-BACol, 14 (1964), $205-216$. 
18-7032. Aubrun, C. V.-"De la picaresque dans ses rapports avec la réalité, ou Don Quichotte et le Gentleman".Etudes Anglaises, 17 (1964), 159-162. 18-7033. Caro Baroja, J.-"El Quïjote y la concepción mágica del mundo".ROcc, 4 (1964), 158-170.

18-7034. Durán, M.-La ambigüedad en el "Quijote" (N. 17-6o34). II Hf, 1965, núm. 23, 43-46 (Harter); HAHR, 43 (1963), $588-589$ (Wilder).

18-7035. Swanson, R. A.- "The humor of Don Quixote". - $R R, 54$ (1963), 161170.

18-7o36. Cortazar, C. S. DE-“"Don Quijote, caballero cortesano?"-USF, 1963, núm. $55,61-73$.

18-7037. Monterde, Francisco-La dignidad en "Don Quijote".-Impr. Universitaria, México, 1959. 341 pp. ||$A L M$, 3 (1963), 332-335 (Ontañón de Lope). 18-7038. WALKER, R.- "Don Quijote and the novel of chivalry". - NVH, 12 (1964), 13-14, 23.

18-7039. LÁscaris, C.-"La obra de Ezequiel González Mas".- $\mathrm{CuH}, 5^{8}$ (1964), 123-127. [Autor de El "Quijote", invitación a la locura (Guayaquil, 1950)].

18-7o4o. Carbonell Basset, D. - "Don Quijote desde un punto de vista existencio-fenomenológico". - DHR, 2 (1963), 21-32.

18-7o41. Monroy, Juan Antonio-La Bi. blia en el "Quijote".-V. Suárez, Madrid, 1963. 176 pp. | RLit, 23 (1963), 288 (Rull).

18-7042. Groult, P.-"Don Quijote, mistico".-EMP, 5, 231-251.

18-7043. Descouzis, P. M.-."Don Quijo. te, catedrático de teología moral".$R F, 75$ (1963), 264-272.

18-7044. Descouzis, P. M.-"Reflejos del Concilio de Trento en el Quijote".$H, 47$ (1964), 479-484.

18-7045. Descouzis, P. M.-"Superioridad del clérigo sobre el caballero según Don Quijote".-BHi, 66 (1964), 68- $\mathbf{7}^{2}$. 18-7046. Drscouzis, P. M. - "Hacia el mundo interior del Quijote: acasos de conciencias"- $-R F, 76$ (1964), 394-404. 18-7047. Osterc, Ludovick-El pensamien. to social y politico del "Quijote".-Fds. De Andrea, México, 1963. 278 pp. (Col. Studium, 4o). || $A L M, 4$ (1964), 337342 (Bolaño e Isla); BHi, 68 (1966), 137143 (Canavaggio); CuA, ig63, núin. $4,267-270$ (de la Selva); $\boldsymbol{H}, 47$ (1964), $4^{26}$ (Stoudemire).

18-7048. Hoffman, E. L. - "Cloth and clothing in the Quijote".-KFLQ, 10 $\left(196_{3}\right), 82-98$.

18-7049. Templin, E. H.--"Labradores in the Quijote" (N. 17-6045). II BICC, 19 (1964), 599-602 (Valderrama).

18-7050. Batiza, Rodolfo-"Don Quijote" y el derecho.-Porrúa, México, 1964 . $204 \mathrm{pp}$.

18-7051. Montenegro Baca, José.-El derecho del trabajo en "El Quijote".Bolivariana, Trujillo, 1965. $132 \mathrm{pp}$.

18-7052. Gómez GALÁn, A.-"El día y la noche en el Quijote" (N. 17-6048). II LR, 19 (1965), 59 (Groult).

18-7053. Aguirre Prado, Luxs-Geografia del "Quijote".-Publicaciones Españolas, Madrid, 1963. 32 pp. (Temas españoles, 440).

18-7054. Croft CoOke, Rupert - De la mano de Don Quijote. Un viaje a través de la España de ayer y de hoy.Janés, Barcelona, 1965.271 pp., láms. (La vuelta al mundo en ochenta libros).-V. núm. 16-45996.

18-7055. Nieto Lanzos, Abelardo-Don Quijote, la Mancha y sus castillos.Cía. Bibliográfica Española, Madrid, 1966. 134 pp.

18-7056. Astrana Marín, Luis-La villa de San Clemente en el "Quijote".-Biblioteca Pública Municipal, San Clemente, 1964. 14 pp.

18-7057. Cortazar, C. S. DE, \& I. Lernik -"Notas al texto del Quijote".-Fil, $10 \quad(1964), 187-205$.

18-7058. Marasso, A.- "Claves, logogrifos y anagramas".- $R d E$, 1958, núm. 6, 531 532. [En el Quijote].

18-7059. Camera de Asarta, V.-"Consideraciones sobre un punto dudoso del Quijote".-RFE, $4^{6}$ (1963), 179-180.

18-7o6o. Palacin, G. B.-"Una enmienda indebida hecha en el Quijote".-Hf, 1965, núm. 24. 13-18.

18-7o6ı. Ricard, R.-"Sur deux phrases de Cervantes". $-L R, 17$ (1969), $159^{-1} 7^{\circ}$. [Addendum, LR, 19 (1965), 189].

18-7062. Rosenblat, A.-"Glosa cervantina. («Cada cosa engendra su semejante*)"-[En su libro] La primera visión de América (Caracas, 1965), 195-201.

18-7063. Morínigo, M. A.-"Una nota para la edición del Quijote: ¿ladrillos enrejalados o ladrillos enrelejados?"Fil, 10 (1964), $217-222$.

18-7064. Palacín, G. B.-“El pasaje más oscuro del Quijote".-DHR, $3 \quad(1964)$, $1-18$.

18-7065. Descouzis, P. M.-“Aclaración al 
Quijote: una caventura vacía», ya no vacía".-CuH, 55 (1963), 249-253.

18-7o66. Lacosra, F. C. - "E1 infinito mundo de los proverbios: Don Quijote".-USF, 1965, núm. $6_{5}, 135^{-1} 5^{2}$.

18-7067. Olsen, M.- "Los discursos de Don Quijote de la Mancha”.-Cults, 1966, núm. 39, 45-48.

18-7068. Rodrfguez Chicharro, C.-“Cide Hamete Benengeli. Dos grupos de historiadores y unos anales". - $A F, 2-3$ $(1963-64), 195^{-234}$.

18-7o69. DfAz-PLAJA, G.-"E1 retablo de macse Pedro".-Ins, 1963, núm. 204.

18-7o7o. HALFY, G.-"The narrator in Don Quijote: Maese Pedro's puppet show".-MLN, 8o (1965), $145^{-16} 6_{5}$.

18-7071. González Muela, J.-"La aventura de los batanes".--Ins, 1969, núm. 204 (suplemento).

18-7072. NeugaArd, E. J.-"The Curioso impertinente and its relationship to the Quijote".-LQ, 1966, núm. 3/4.

18-7073. Casalduero, J.-"El curioso impertinente en el Quijote de 1605 ".$C C L, 19^{64}$, núm. $85,73-75$.

18-7o74. Roux, L.-"A propos du Curioso impertinente". - RLR, 75 (1963), 173-194.

18-7075. La Barbera, ENrico Mario-las influencias italianas en la novela de "El curioso impertinente" de Cervan. tes.-V. Bonacci, Roma, 1963. 120 pp.

18-7o76. PÉREZ DE LA DEHESA, R.-"El $\mathrm{cu}$ rioso impertinente. Episodio de una crisis cultural".-Asom, 1964, núm. 2, 28-33.

18-7077. Ayala, F.-“Los dos amigos".ROcc, 10 (1965), 287-306. [El curioso impertinente de Cervantes y el de Guillén de Castro].

18-7078. Benardete, M. J.-“Los galcotes".-RHM, 31 (1965), 57-7o.

18-7o79. Rosenblat, A. - "Un episodio quijotesco [en el Inca Garcilaso]: Rodrigo Niño y los galeotes del Perú".-[En su libro] La primera visión de América (Caracas, 1965), 296-241.

18-7o80. Gutierrez, Juan Antolí-Un personaje del "Quijote" (Rocaguinarda el Bandolero). - Savia, Barcelona, 196o. $60 \mathrm{pp}$.

18-7081. Fratroni, O.--"Idilio y realidad en Sierra Morena (Quijote, I, 25)".$B L H, 1969$, núm. 5, 61-82.

18-7082. FRY, G. M.-"Symbolic action in the episode of the cave of Montesinos from Don Quijote".-H, $4^{8}$ (1965), $468-474$.
18-7083. Schirmann, J. - "The harmful foods: a curious parallel between Cervantes and Joseph Zabarra".-Etudes... Hiram Peri (Jerusalem, 1963), 140142.

18-7o84. Pabón Núñez, L. - "Sanchoo o la exaltación del pueblo español".BACol, $14 \quad$ (1964), $17-5^{8} ; \quad$ CuH, $5^{8}$ $(1964), 541-580$.

18-7085. LEÓN REY, J. A.-"'Revaluación de Sancho Panza".-BACol, 14 (1964), 59-70.

18-7o86. Lara Prado, Luis-Sancho Pan. za, exégeta-Costa-Amic, México, 1964. 200 pp., ilustr.

18-7o87. Sckommodau, H. - "Insula: $\mathbf{Z u}$ einem Abenteuer Sancho Panzas",-NS, 13 (1964), 512-525.

18-7088. Abrams, F. - “A possible Italian source of Sancho Panza's first judgment at Barataria".- $-I t, 41 \quad\left(19^{6} 4\right), 43^{8}$. $44^{2}$.

18-7o89. Piccus, J-- "La mejor pieza que comia pan en el mundo". - RNo, 5 (1964), 168-173.

18-70go. Buñuel, Miguel-Rocinante de la Mancha. - Edit. Nacional, Madrid, 1963. 160 pp., ilustr. [Libro para niños].

18-7og1. Refse, L. G.-"Cervantes and Shakespeare: a comparative study".Proceedings of the $15^{\text {th }}$ Pacific Northwest Conference on Foreign Languages (Montana State Univ., 1964), 6773.

18-7og2. Jommi, GofFredo-Realitäl der irrealen Dichtung. Don Quijote und Dante.-Rowohlt, Reinbek, 1964.155 pp.

18-7o93. Giraldr, E. N.-“Manzoni e Cervantes".-Aevum, 37 (1963), 543-552.

18-7094. Baquero Goyanes, M.-“Cervantes, Balzac y la voz del narrador".All, 1 (1963), 579-592.

18-7095. Turguenev, IVAN-Hamlet y Don Quijote.-Pub. de la Sec. de la Presidencia de la República, Managua, 1964. $26 \mathrm{pp}$. (Cuadernos darianos).

18-7og6. Verbitsky, Bernardo-Hamlet $y$ Don Quijote.-Jamcana, Buenos Aires, 1964. $13^{\circ} \mathrm{pp}$.

18-7097. Boynton, M. F.-"An Oxford Don Quixote".-H, 47 (1964), 738-750. [Cervantes $>$ Lewis Carroll].

18-7og8. Bruckner, P.-"Sigmund Freuds Privatlektüre". - Psyche, Stuttgart, 15 (1962), 881-902. [El Quijote, las Novelas ejemplares y algunas obras inglesas?. 
18-7og9. Robert, Marthe-L'ancien et le nouveau. De Don Quichotte d̀ Franz Kafka.-Grasset, Paris, 1963. 20 pp.

18-7100. Martí de Cid, Dolores-Presencia del "Quijote" en Hispanoaméri. ca.-Center of Latin American Studies, University of Kansas, $1963.15 \mathrm{pp}$.

18-7101. Aguilera-Malta, D.-"Primeras visitas de Don Quijote a América".Cuadernos de Bellas Artes, México, 1964, núm. 5, 33-40.

18-7102. Bistritsky, N.-"Don Quijote de Cipango".-OYS, 7 (1964), $115^{-11} 7$.

18-7103. Ortega Torres, J.- "El Quijote por Marco Fidel Suárez". - $B C B, 6$ (1963), 639-669.

18-7104. Ardao, A.-“El Quijole en Una muno y Ortega".-[En su libro] Filosofia de lengua española (Montevideo, $1963), 129-134$.

18-7105. Hatzantonis, E.-"Captain Sole: Don Quijote's after-image in Kazantzakis' Odyssey".-H, 46 (1963), 283-286. 18-7106. Engelbert, J. A.-“A Sancho for Saint Francis".- $H, 4^{6} \quad(1969), 287-23 \mathrm{~g}$. [Cervantes y Kazantzakis].

18-7107. Edberc, G. J.-"Don Quixote".$H, 4^{6}\left(19^{6} 3\right), 4^{2} 5^{-426}$. [Películas y ballets sobre el Quijote].

18-7108. Lobo Serna, Ciro Alfonso ¿Muchas gracias, Don Quijote!-Oropama, Ocaña, 1963. $82 \mathrm{pp}$.

18-7109. Goldaraz Campo, Fermíx--Peleas quijotescas. (El "Quijote" en verso).-Barcelona, 1964. $47^{\circ} \mathrm{pp}$.

18-7110. Román, LuIs - Don Quijote y Martin Fierro, Diálogo cuasi verosimil $y$ otros versos,-Central, Córdoba, Argentina, $19^{6} 3.15^{\circ} \mathrm{pp}$.

18-7111. Berriochoa, H. V.-"El Dr. Pa. lacio Vitery, traductor del Quijote al euskera".-BSV, 19 (1963), 285-286.

18-7112. Aveleyra Arroyo de Anda, TE. RESA-El humorismo de Cervantes en stis obras menores.-Universidad Nacional Autónoma, Fac. de Fil. y Letras, México, 1962. 232 pp. [Tesis]. || $L R$, 19 (1965), 33-34 (Borgers); $\mathrm{BHi}, 66$ (1964), 232-233 (Canavaggio); RLit, 22 (1962), 271 (Esquer Torres); BHS, 4! (1964), 68-69 (Gibbs); $H, 4^{6}$ (1963), 847 (Olivera); CuH, 57 (1964), 428429 (X).

18-7113. Cervantes, M. DE-La Galatea, ed. J. B. Avalle-Arce (N. 18-3580). ACerv, 9 (1961-62), 265-268 (Lópcz Estrada).

18-7114. Osuna, R.-“La crítica y la erndición del siglo $\mathrm{xx}$ ante $L a$ Galatea de Cervantes",-RR, $54 \quad(1963), 241^{-}$ $25 x$.

18-7115. Balbontín, J. A.-Las Novelas ejemplares de Miguel de Cervantes.Ateneo Español, México, 1963. 22 pp. 18-ך116. Cervantes, Miguel DE-Novelat ejemplares. Comentario de Sergio Fernández. 2a ed.-Porrúa, México, 1964. 3 oo pp. (Sepan cuantos..., 9).-V. núm. $17-2469$.

18-7117. Cervantes, Miguel De-Novelas ejemplares.-Eds. Club del Libro, Lima, Perú, 1964.

18-7118. Cervantes, Miguel DE-Novelas ejemplares. - Toray, Barcelona, 1964 . 468 pp. (Novelas maestras).

18-71ig. Cervantes, Miguel de-Six exemplary novels (N. 17-2475). || $M L J,{ }_{4}^{8}$ (1964), 397 (Moore).

18-7120. Ceriantes, Miguel de - Exemplarische Novellen. Die Mühen und Leiden des Persiles und der Sigismunda. Herausgegeben und neu übers. von Anton M. Rothbauer.-Goverts, Stuttgart, 1963. 1214 pp. (Gesamiaugabe, 1).

18-7121. Cervantes, Miguel De-Novelas exemplares. T. 1.-Civilização, Porto, 1964. 240 pp. (Col. Civilização).

18-7129. Cervantes, Miguel de-The de. ceitful marriage, and other exemplary novels. Transl, with a foreword by Walter Starkie.-New American Libra. ry, New York, 1963. 320 pp. (A Signel classic, CT 157). || YCL, 13 (1964), 73 (Allen).

18-7129. Ayllón, C.- "Sobre Cervantes y Lope: la novella”. $-R F, 75$ (1963), 273 . 288.

18-7124. Ayllóx, C. - "La novela corta romántica: Cervantes y Lope".-CuA, 1964. núm. 1, 218-23o.

18-712.ّ. BeLIC, O.-"Cervantes y la novela picaresca". $-P h P, 6$ (1963), 113 . 123.

18-7126. Cervantes, Miguel de-El casamiento engañoso y el Coloquio de los perros.-Ilerda, Lérida, 1964. 151 pp. 18-7127. Abrans, W.-"Una frase misteriosa de Cervantes en $E l$ coloquio de los perros".-Hf, 1963, núm. 17, 79.82. 18-7128. Sánchez-Castañfer, F.-"Un problema de estética novelistica como comentario a La española inglesa, de Cervantes".-EMP, 7, $357-3^{86}$.

18-7129. Piluso, R. V.- "La fuerza de la sangre: un análisis estructural". $-H, 47$ $(1964), 485-49^{\circ}$.

18-7130. Cervanies, Migule de-La gita- 
nilla.-Plaza y Janés, Barcelona, 1964. 99 pp. (Clásicos Plaza).

18-7131. Cervantes, Migufl de-La gitanilla y La española inglesa. Ed., est. y notas por Alfredo Malo Zarco. $5^{\text {a }}$ cd. - Ebro, Zaragoza, 1964. 134 pp. ilustr. (Biblioteca clásica Ebro, 5o).V. núm. 16-49129.

18-7132. DEFANT, A.-"El intelectualismo de Cervantes en dos novelas ejempla. res".-USF, 1963, núm. 57, 181-197. [La gitanilla y El celoso extremeño].

18-7133. Casa, F. P. - "The structural unity of El licenciado Vidriera".-BHS, $41 \quad(1964), 242-246$.

18-7134. Cervantes - Théâtre choisi. 1. Numance; Le rufian bienheureux. Trad. et introd. par Robert Marrast.Klincksieck, Paris, 1963. 328 pp. ( $T \dot{E}$. moins de l'Espagne, 5). [Texto bilingüe]. || $L R, 18$ (1964), 77-79 (Groult); PhP, 7 (1964), 204 (Hampejs).

18-7135. Cervanies, Miguel de-La Numancia. Ed., pról. y notas de F. Yndu. ráin.-Aguilar, Madrid, 1964. $120 \mathrm{pp}$. (Bibl. de iniciación hispánica). I| Seg, 1 (1965), 434-435 (Rull).

$18-7136$. Cervantes, Miguel de-El cerco de Numancia. Introd. y notas de $\mathbf{R}$. Marrast.-Anaya, Salamanca, 1961, 109 pp. || ACerv, 9 (1961-62), 282-283 (Sánchez).

18-7137. Avalle-Arce, J. B.-"Poesía, historia, imperialismo: la Numancia" (N. $\left.{ }_{17}-6087\right)$. || LR, 19 (1965), 187 (Groult).

81-7138. DoMénEch, R.-"Un montaje de Numancia y el problema de los clásicos".- $\mathrm{CuH}, 68$ (1966), 457-463.

18+7139. Canavagio, J. - "A propos de deux comedias de Cervantes". - BHi, 68 (1966), 5-29.

18-7140. AlLeN, J. J.- "The division into acts of Cervantes' Los baños de $\boldsymbol{A r}$. gel".-S, 17 (1963), 42-49.

18-7141. Cervantes, Miguel De-Comedia famosa de Pedro de Urdemalas. Ed., with prol. and notes, by Edward Nagy: -Las Américas, New York, $19_{5}^{6} \cdot{ }_{15}^{8} \mathrm{pp}$.

18-7142. Cervantes, Miguel De-El rufian dichoso. (Le rufian bienheureux). Trad. par R. Marrast.-Klincksieck, Paris, 1963. || Seg, 2 (1966), 205-206 (Rull).

18-7143. Agostini de del Río, A. - "El teatro cómico de Cervantes".-BRAE, 44 (1964), 223-307, 475-539; 45 (1965),

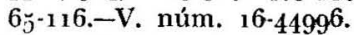

18-7144. Cervantes, Miguel De-Entremeses.-Eds. R, La Habana, 1964. (Col. Repertorio teatral).
18-7145. Cervantes, Miguel De-Seis entremeses selectos. Recopilados por Emilia Smergani. - Andò, Palermo, 1964. 187 pp.

18-7146. Cervanies, Miguel De-Interludes. Trans, and foreword by Edwin Honig. - New American Library, New York, 1963. xxvi +160 pp. (Signet books).-V. núm. 16-49145.

18-7147. CAIn, Sister MARIANA-The idea of a theatre in the "Entremeses" of Cervantes.-[Tesis, Univ, of Wisconsin; resumen en $D A, 25\left(1964^{-65}\right), 2507-$ $2508]$.

18-7148. Recouls, H. - -Un personnage des intermèdes de Cervantes, le sacristain".-RLR, $7^{6} \quad(1964), 5^{1-63}$.

18.7149. Cervantes, M. DE-Entremez do juiz dos divórcios. Trad. de Maria José de Carvalho. - Convivium, 3 (1963), núm. $10,83-89$.

18-715o. Medina Vidal, J.-Aspectos de la poesia lirica de Cervantes (N. 18 . $3589)$. II NRFH, $18(1965-66), 199 \cdot 200$ (Avalle-Arce).

18-7151. Gonzílez Olé́, F.-“Observaciones filológicas al texto del Viaje del Parnaso".-MSI, 2 (1963), 99-109.

18-フ152. Arala, F.-"El túmulo".-CuA, 1963 , núm. 4, 254-263. [El soneto "Voto a Dios, que me espanta esta gran. deza"].

18-7153. Fernández de Avellaneda, Alonso-El Quijote. $4^{\text {a }}$ ed.-Aguilar, Madrid, 1964. 594 pp. (Crisol, 28).-V. núm. 17-2494.

18-7154. TURNer, D.-"Structure and form of El Quijote apócrifo".-RNo, 4 (1969), 139-143.

18-7155. SARrail.h, J. - "Lesage, adaptateur d'Avellaneda". $-\mathrm{BHi}, 66$ (1964), $3.59-362$.

V. también núms. $5^{101}, 54^{81}, 5^{670}, 5^{846}$, $5^{849-52}, 5901,6325,6649,6860,7254$, $7652-4,7695,8140-1,8204-5$.

18-7156. VAN DYck, Rosemarie-Marcos de Obregón.-[Tesis, Univ. de Madrid; resumen en $R U M, 13$ (1964), 608]. [Espinel].

Lope de Vega: v. núms. 6644-9, 7123. 18-7157. Fernández de Ribera, Rodrico$E l$ mesón del mundo. Estudio prel., sel. Y notas de Edward Nagy. - Las Américas, New York, 1963. 186 pp. II $\mathrm{CuH}, 55$ (1963), 296-299 (Gil) .

${ }_{18} 8.7158$. Vélez de Guevara, Luis $-E i$ diablo cojuelo. [Seguido de:] La vida de Lazarillo de Tormes y de sus adtersidades $y$ fortunas.-Ramón Sopena, 
Barcelona, 1963.190 pp. (Biblioteca Sopena, 49-1).

18-7159. Vélez de Guevara, Luis - El diablo cojuelo. $3^{\text {a }}$ ed.-Espasa-Calpe; Madrid, 1963. 164 pp. (Austral, 975). 18-7160. Vélez de Guevara, Luis- $A$ sánta ördög [El diablo cojuelo]. Regény. Ford Szegö István. Atd. Benyhe János.-Europa, Budapest, 1962. 129 pp.

18-7161. Rosselli, F. - "Alcune integrazioni di glossari del Diablo cojuelo".MSI, 2 (1963), 178-222.

Quevedo: v. núms. $7891-7900$.

18-7162. Castillo Solórzano, Alonso de -La niña de los embustes.-Aguilar, Madrid, $1964.55^{\circ}$ pp. (Col. Extra, 21).

18-7163. Montero Padilia, J:-“Jerónimo de Alcalá y la novela picaresca".ESeg, 15 (1963), 259-272.

18-7164. Cortés de Tolosa, Juan-Lazarillo de Manzanares.-Libros Bolívar, Barcelona, 1963. 154 pp. I| Conv, 31 (1963), 762-763 (Boni).

18-7165. Pascual Merino, Olga-las novelas de doña Maria de Zayas y Sotomayor. - [Tesis, Univ. de Barcelona, $1963]$.

18-7166. ZaYAs, MARía DE - A shameful revenge and other stories. Transl. by John Sturrock. - Folio Soc., London, 1963 .

18-7167. Senabre Sempere, R.-“La fuente de una novela de doña María de Zayas".-RFE, $4^{6}$ (1963), 163-172. [Lope de Vega].

18-7168. HAMMOND, J. H.-“Substitutions in the works of Francisco Santos".The South Central Bull., Tulsa, 1963, núm. 4, 41-45.

18-7169. Mercadier, G.-“¿Cuándo nació Diego de Torres Villarroel?"-Ins, 1963, núm. 197. [En 1694].

18-717o. Berenguer Carisomo, Arturo El doctor Diego de Torres Villarroel o el picaro universitario. - Esnaola, Buenos Aires, 1964. 89 pp.

18-7171. Placer, G.-"Honras fúnebres de Torres Villarroel".-EM, 20 (1964), $9^{1-}$ 98.

18-7172. SEboLd, R. P.-"Mixtificación y estructura picarescas en la Vida de Torres Villarroel".-Ins, 1963, núm. 204.

18-7173. Torres Villarroel, Diego DEVida. Pról. y notas de Federico de Onís.--Espasa-Calpe, Madrid, 1964. $24^{8}$ pp. (Clás. cast., 7).

18-7174. Gutiérrez Sesma, Julio-la me. dicina y los médicos en la vida y en la obra literaria del $P$. José Francisco de Isla.-[Tesis, Univ. de Madrid; resumen en $R U M, 12$ ( 1963 ), 976-978].

18-7175. EzQuerra Abadía, R.-“"Obras y papeles perdidos del Padre Isla".EMP, 7, 417-446.

18-7176. Pérez Picón, C. - "El P. Isla, vascófilo. Un epistolario inédito". MisCo, 42 (1964), 183-301; 43 (1965), $342-505 .|| B S V, 21 \quad(1965), 116-117$ (Arocena).

18-־177. IsLa, José Francisco de - Fray Gerundio de Campazas. Introd. y notas de R. P. Sebold.-Espasa-Calpe, Madrid, $1960-1964.4$ ts.: xcviii +188 , $320, \mathrm{xx}+196,300 \mathrm{pp}$. (Clás. cast., 148-151). || $A O, 13(1963), 345-353 ; 14$ (1964), 273-276 (Caso González); $R R$, 55 (1964), 132-133 (Effross); BHi, 66 (1964), 429-431 (Guinard); RLit, 20 (1961), 445 (Pinedo); BHi, 65 (1969), $3^{87-38}$ I (Sarrailh).

Autores modernos

18-7178. Herrero, J.-"El testimonio del Padre Coloma sobre Fernán Caballero".-BHS, 41 (1964), 40-5o.

18-7179. Montesinos, José F.-Fernán Caballero. Ensayo de justificación.-E1 Colegio de México, México; Univ. of California, Berkeley, 1961. xvi $+{ }_{181}$ pp. $M P h, 61 \quad(1963-64), 320-321$ (Correa); $B A b r, 37$ (1963), 59 (DeCoster); $H A H R, 43$ (1969), 586 (Dobrian); HR, 31 (1963), 367-37o (Hafter); $B H i, 65$ (1963), 172-173 (Le Bouill); $M L N, 79$ (1964), 214-216 (López Morillas); $R H M, 29$ (1963), 187-188 (Peñuelas); $H, 4^{6}$ (1963), 169 (Qualia); $P S A, 28$ (1963), 206-210 (Sobejano).

18-7180. Fernán Caballero-la gaviota $5^{\text {a }}$ ed.-Espasa-Calpe, Madrid, 1964. $3^{64}$ pp. (Austral, 364).-V. núm. 16-49163. 18-7181. García De Dini, E.- "Patriotismo y costumbrismo de Estébanez Calderón".-MSI, 1964 , núm. $8,85^{-100}$.

18-7182. Estébanez Caloerón, Serafín La Andalucia de Estébanez Calderón. (Antologia). Recopilación por Jorge Campos.-Taurus, Madrid, 1964. $14^{2}$ pp. (Temas de España).

18-7183. Estébanez Calderón, Serafín Cristianos y moriscos. Ed., pról. y notas de F. Buendia.-Aguilar, Madrid, 1964. (Bibl. de iniciación hispánica).

18-7̧184. Sánchez de Palacios, M.-Mesonero Romanos. Estudio y antologia.Cía. Bibliográfica Española, Madrid, 
1963. 206 pp. (Un autor en un libro). |i Rlit, 26 (1964), 237 (Romero).

18-7.185. MEsonero Romanos, Ramón Escenas matritenses, $3^{\text {a }}$ ed.-Espasa.Calpe, Madrid, 1964. 200 pp. (Austral, 283).

18-7186. Caldera, E.-“Il problema del vero nelle Escenas matritenses".-MSI, 1964 , núm. 8, 101-121.

18-7187. Barrón, C. G.-"Antonio Alca. la-Galiano y la Fontana de Oro".-H, (1964), 91-94. [Mesonero, Valera, Gal(iós].

V. también núm. 5866 .

18-7188. CANo, J. L.-"Don Juan Valera en el Brasil".-Rey, de Cultura Bra. sileña, 2 (1969), 131-137; СuA, 1963, núm. $5,279-284$.

18-7189. Marfas, J.-- "Juan Valera. Un camino. Entendamos a Hispanoamérica”. -Lect, 158 (1964), 116-122.

18-719o. TORre, Guillermo DF - Tres conceptos de la literatura hispanoamericana. - Losada, Buenos Aires, 1969. (Biblioteca de estudios literarios). [Valera, Clarín, Unamuno]. \| $B A b r, 39$ (1965), 66 (Bleznick); PSA, 39 (1965), 213-217 (Sobejano).

18-7191. DeCoster, C. C.-"Valera and Andalucia" (N. 17-6109). || BlCC, 19 $\left(19^{6} 4\right), 37^{6-377}$ (Valderrama Andrade).

18-7192. Valera, Juan - Andalusische Schnurren. Übers. von Susanne Felkau. -Langewiesche - Brandt, Ebenhausen München, $196_{4} .65 \mathrm{pp}$.

18-7193. Echínove, J. DE-"La fe de Juan Valera y Las ilusiones del doctor Faustino".-CuH, $5^{6}$ (1963), 551-561.

18-7194. VALERA, JuAN-Juanita la Larga. Introd., notas y vocab. de Leda Schiavo y Elda Artigas.-Huemul, Buenos Aires, 1964. 199 pp. (Clásicos Huemul, 25) .

18-7195. Valera, Juan - Pepita Jiménez. Introd., notas y vocab. de Elda Artigas y Leda Schiavo. - Huemul, Buenos Aires, 1964. 195 pp. (Clásicos Huemul, 33).

18-7196. PageArd, R.-"Pepita Jiménez en France" (N. 17-6114). ||$L R, 19$ (1965), 74 (Groult).

18-7197. DECoster, C. C.-“Juan Valera et Ernest Mériméc: leur correspondance inédite".-BHi, 66 (1964), 91-105.

V. también núm. 7187 .

18-7198. MCClendon, BarnetT AdDisonThe life and works of Pedro Antonio de Alarcón.-[Tesis, Univ. of Nebraska; resumen en $D A, 24 \quad(1963-64), 3340]$. $266 \mathrm{pp}$.

18-7199. Alarcón, Pedro Antonio de El capitán Veneno. Introd., notas y vocabulario de Clara Passafari de Gutiérrez.-Huemul. Buenos Aires, 1963. 122 pp. (Clósicos Huemul).

18-7200. Winslow, R. W.-"The distinction of structure in Alarcón's El sombrero de tres picos and $\mathrm{El}$ capitán Veneno".- $-H, 46$ (1963), 715-721.

18-7201. Alarcón, Pedro Antonio de Der Dreispitz. Übertr. von Helene Weyl.-Insel, Frankfurt, 1963. 78 pp. (Insel-Bucherei, 223).-V. núm. 8-13086. 18-7202. MANcini, G.-"Qualche considerazioni su $E l$ niño de la bola di Pedro Antonio de Alarcón".-MSI, 2 (1963), $15^{2-169 .}$

V. también núm. 6753 .

18-7203. Montesinos, José F. - Pereda o la novela idilio.-El Colegio de México, México; University of California, Berkeley, 1961. viii + 311 pp. \|UMx, 16 (1961-62), núm. 10 (Alvarez); RHM, 29 (1963), 188 (Bleznick); BHi, 65 (1963), 174 (Le Bouill); $M P h, 61$ (1963-64), 321-322 (Correa); BAbr, 37 (1963), 59 (DeCoster); HR, 31 (1969), $3^{6} 7.370$ (Hafter); $H, 4^{6} \quad(1963), 439$ (Hartsook); MLN, 79 (1964), 216-219 (López Morillas); $L R, 17$ (1963), 356$3^{60}$ (Ricard); PSA, 29 (1969), 326-327 (Sobejano).

18-7204. Carraceno, Daniel - Pereda.Cía. Bibliográfica Española, Madrid, 1964. 280 pp. (Un autor en un libro). 18-7205. Pereda, José María de-Escenas montañesas. - Aguilar, Madrid, 1963. 488 pp. (Crisol, o19) . || Bro, 80 (1965), $542-543$ (Maia).

18-7206. Armas Ayala, A. - "La CasaMuseo Pérez Galdós". - $M u H, 1964$, núm. 196 .

18-7207. Armas Arala, A.-"Galdós editor'.-Asom, 1963, núm. 1, 37-51.

18-7208. RicAro, Robert - Aspects de Galdós,-P.U.F., Paris, 1963. 105 pp. II LR, 19 (1965), 194-195 (Groult).

18-7209. Montesinos, J. F.-“Galdós en busca de la novela".-Ins, 1963, núrn. 202.

18-7210. RiGARD, R.-Galdós et ses romans (N. 18-3614). \|HR, 31 (1963), 192 (Correa); LR, 19 (1965), 193-194 (Gottigny); RHM, 29 (1963), \&o (Jaimes-Freyre); $R R, \quad 54$ (1963), $147^{-149}$ (Livingstone); $S, \quad 17$ (1963), 230-234 (Schraibman). 
18-7211. Correa, G.--Pérez Galdós y su concepción del novelar". - BICC, 19 (1964), 99-105.

18-7212. ÁnGeles, J.- “Baroja y Galdós. Un ensayo de diferenciación".-RLit, $23(1969), 49-64$.

18-7213. Corres, G.--"El simbolismo mitico en las novelas de Pérez Galdós".$B I C C, 18$ (1963), 428-444.

18-7214. Correa, Gustaro-El simbolismo religioso en las novelas de Pérez Gal. dós. - Gredos, Madrid, 1962. $280 \mathrm{pp}$. (BRH). || CD, 177 (1964), 162-163 (Alvarez Turienzo); $B H S, 4^{1} \quad(1964)$, 119120 (Brooks); $H, 46$ (1969), 664-665 (Chamberlin); CL, 16 (1964), 184-186 (Hafter); $R y C, 8$ (1963), 606.6o7 (Lopez Montenegro); $R y F, 168$ (1963), 389-39o (Micó Buchón); BAbr, 37 (1963), 431-432 (Regalado).

18-7215. Andrade Alfieri, G, y J. J. AlFIERI-"EI lenguaje familiar de Pćrez Galdós".-Hf, 1964, núm. 22, 27-73.

18-7216. Chamberlin, V. A.-“The mule. tilla... [en Galdós]" (N. 17-2535). II $B I C C, \quad 19$ (1964), $3^{80-3^{81}}$ (Valderrama Andrade).

18-7217. Guignet, T.-Le discours burlesque chez Pérez Galdós,-[Tesis, Univ. dc París, 1962].

18-7218. RICARD, R.-“Trois mots du vocabulaire de Galdós: cebolla, araña et barbero". - AION-R, 5 (1963), 173175 .

18-7219. Schraibman, J.-Dreams in the novels of Galdós (N. 17-6141). $\| R R$, 55 (1964), 67-68 (Bell); LR, 17 (1963), 397-398 (Borgers).

18-7220. SHOEMAKER, W. H.-Los prólogos de Galdós (N. 18-3620). $\| B A b r$, 38 (1964), 55 (Bleznick).

18-7221. RICARD, R.-“La *segunda conversión, en las novelas de Galdós".ROcc, 4 (1964), 114-118.

18-7222. Delporte, ANNIE - La peinture de la misère dans les romans de Galdós.-[Tesis, Univ. de París, 1962].

18-7223. Major, Harrison Elbert - El tema de caridad en la obra de Galdós.-[Tesis, Univ. de Madrid; resumen en $R U M, 12$ (1963), $766-767]$.

18-7224. MACK, Michèle - L'usure dans les romans de Benito Pérez Galdós.[Tesis, Univ. de París, 1963].

18-7225. Bermúdez Cárdenas, Daisy MaRINA-El niño en la novela galdosiana. - [Tesis, Univ. de Madrid; resumen en RUM, 12 (1963), 956-958].

18-7226. Gutiérrez Cortés, Celia-Algu- nos personajes femeninos burgueses en las novelas de Benito Pérez Galdós.Tesis, Universidad Nacional Autónoma, México, 1963. 110 pp.

18-7227. Jourdan, Pierre-Le personnage de José Ido del Sagrario dans l'cuvre de Pérez Galdós.-[Tesis, Univ. de $\mathbf{P a -}$ rís, 1962].

18-7228. NAGY, E.-“Clavellina, una obra inédita de Galdós”. - H, 47 (1964), 183 .

18-7229. Pérez Galdós, Benrro-El amigo Manso. Ed by Denah Lida. - Oxford Lniv. Press, London-New York, $1966_{3}$. $3^{84}$ pp. (Oxford texts). $\| H, 47$ (Ig64), 210-211 (Flynn).

18-723o. Pérez Galdós, Benito - Doĩa Perfecta. Trad. de l'espagnol par Robert Marrast. Introd. de María Pérez Galdós. Préface de Max Aub. - Les Editeurs Français Réunis, Paris, 1963 . $280 \mathrm{pp}$.

18-7231. Brown, D. F. - "An Argentine Doña Perfecta: Galdós and Manuel Gálvez". $-H, 47$ (1964), 282-287.

18-7232. WERER, R. J.- "Galdós and Orbajosa".-HR, 3l (1963), 348-349.

18-7233. TAIB, Nicole-Comparaison entre "Doña Perfecta" et "Gloria".-[Tesis, Univ. de París, 1963].

18-7234. Pérez Galdós, BEnito-Gloria.Hernando, Madrid, 1963. 2 ts.

18-7235. Pérez Galdós, Benito - La de Bringas.-Hernando, Madrid, 1963. 275 pp.-V. núm. 8-11827.

18-7236. Chamberlin, V. A. - "Galdós" chromatic symbolism key in Lo prohibido". $-H R, 32$ (1964), $109 \cdot 117$.

18-7237. Mariani, Claude - Les procédés de style dans "Fortunata y Jacinta" de Pérez Galdos.-[Tesis, Univ. de París, $1963]$.

18-7238. Cadiot, Evelyne-La famille espagnole d'après deux romans de Galdós: "Fortunata y Jacinta" et "Angel Guerra".-[Tesis, Univ. de París, 1962]. 18-7239. Pérez Galdós, Benito - Miau. Transl. by J. M. Cohen.-Methuen \& Co., London; Penguin Books, Baltimore, 1963. $311 \mathrm{pp}$.

18-7240. Pérez Galdós, Benito - La incógnita. Nota prel. de F. C. Sáinz de Robles.-Aguilar, Madrid, 1963. $44^{8} \mathrm{pp}$. (Crisol, 371).-V. núm. 9-14388.

18-7241. Russell, R. H.-"La óptica del novelista en La incógnita y Realidad". - Fil, $10(1964), 179^{-185}$.

18-7242. Sobejano, G.-"Forma literaria y sensibilidad social en La incógnita y 
Realidad de Galdós".-RHM, $3^{\circ}$ (1964), 89-107.

18-7243. Pérez Galdós, Benito - Realidad. Nota prel. de F. C. Sáinz de Robles.-Aguilar, Madrid, 1962. $39^{8} \mathrm{pp}$. (Crisol, 375).-V. núm. 8-11829.

18-7244. Pérez Galdós, Bentro-la loca de la casa.-Dédalo, Madrid, 1963. 39 pp. (Novelas y cuentos).

18-7245. Russell, RoBert Hilton - The "figura evangélica" in three novels of Pérez Galdos: "Nazarin", "Halma" and "Misericordia".-[Tesis, Harvard Lniv., $19^{6} 3$ ].

18-7246. Rivfra Rivas, Carmen-Galdós a través de "Misericordia". - [Tesis, Univ. de Salamanca, 1963].

18-7247. Chamberlin, V. A.-."The significance of the name Almudena in Galdós' Misericordia'.- $H, 47$ (1964), 491496.

18-7248. Casalduero, J. - "Galdós: de Morton a Almudena". - MLN, 79 (1964), $181-187$.

18-7249. Correa, G.-"El sentido de lo hispánico en El caballero encantado de Pérez Galdós y la generación del 98 ". -BICC, 18 (1963), 14-28.

18-7250. Pérfz Galdós, Benito - Obras completas. Nueva ed. Tomos 1 y 2 : Episodios nacionales.-Aguilar, Madrid, 1964. (Obras eternas). - V. núm. 1337621 .

18-7251. HinterhäLSER, Hans-Los "Epl. sodios nacionales" de Benito Pérez Galdós. Trad. de José Escobar.-Gredos, Madrid, 1963.398 pp. $(B R H) .-$ V. núm. 18-3629. Ins, 1963, núm. 199 (Latorre); CuH, 61 (1965), 436-441 (Rodríguez); Asom, 1964, núm. 3, 107-108 (Zuleta).

18-7252. Rodríguez, Alfred - Introduc. tion to the "Episodios nacionales" of Benito Pérez Galdós. - [Tesis, Brown Univ.; resumen en $D A, 24$ (1963-64), $3757-375^{8}$ ]. $261 \mathrm{pp}$.

18-7253. Dennis, WARD Haldan-Characterization in the first series of the "Episodios nacionales" of Benito Pérez Galdós.-[Tesis, Columbia Univ.; resumen en $\left.D A, 26(1965-66), 4^{6} 55\right]$.

18-7254. Pérez Morales, África-El ceruantismo de Galdós en la primera serie de sus "Episodios nacionales". [Tesis, Univ, de Murcia, 1969].

18-7255. Vilmeuf, Bernard-Les personnages féminins dans la première séric des "Épisodes nationaux" de Benito Pérez Galdós.-[Tesis, Paris, 1962].
18-7256. Pérez Galdós, Bentro - Trafalgar. Pról. de Luis Araujo Costa.-Hernando, Madrid, 1963. xix $+267 \mathrm{pp}$.

$18-7^{2} 57$. LARREA, E. M.-“Épica y novela en Zaragoza".-RHM, 3o (1964), 261 . 270 .

18- $7^{2} 5^{8}$. Ronrfgufz, A.-“Galdós' use of the classics in Zaragoza”. - MLN, 79 (1964), 211-213.

18-7259. Rodrfgeez, A. - "Shakespeare, Galdós y Zaragoza".-CuH, $5^{6}$ (1963), $89-98$.

18-7260. Pírez Galdós, Benito-El terror de 1824.-Hernando, Madrid, 1963. 289 $\mathrm{Pp}$.

18-7261. PÉRez Galdós, Benito-Zumalacúrregui.-Hernando, Madrid, 1963. 299 pp.

18-7262. Rodrfguez Batllori, F. - “Galdós, poeta".-PE, 1963, núm. 92, 15-20. 18-7263. Schraibman, J.-"Poemas inéditos de Galdós".-RHM, 30 (1964), 354372 .

18-7264. Schrabman, J.-“Galdós, colaborador de El Ómnibus. Recopilación, prólogo y notas". - AEAtl, 9 (1963), 289-334.

18-7265. SHofmAKer, W. - "Una amistad literaria: Ia correspondencia epistolar entre Galdós y Narciso Oller". $-B A B L$, $3^{\circ} \quad(1963-64), 247-306$.

18-7266. NUEZ, S. DE LA - "Unamuno y Galdós en unas cartas". - Ins, 1964 , núms. $216 / 7$.

V. también núms. $5120,5866,7178,7384$. 18-7267. SAntos, D.-“Macías Picavea, novelista de la Regeneración”.-EL, 1963 , núms. $272 / 3$.

Coloma: v. núm. $7^{187}$.

18-7268. Sánchez, R. G.-"Clarín y el romanticismo teatral: examen de una afición".-HR, 31 (1963), 216-228. || $L R$, $19\left(19^{6}\right), 293^{-294}$ (Simon).

18-7269. BÉCARUD, JEAN-“La Regenta” de Clarin y la Restauración. Trad. de Teresa García-Sabell. - Taurus, Madrid, 1964. $4^{6} \mathrm{pp}$. (Cuadernos Taurus). II AH, 1964, 91-92 (Pino).

18-7270. DuRand, F. - "Characterization in La Regenta: point of view and theme".-BHS, 41 (1964), 86-100.

18- 727 1. FerReras, J. I.-"La Regenta: ante un nuevo método". - LNL, 1964, núm. 2, $15-41$.

18-7272. Fernández Avello, Manufl Algo sobre Clarin y sus "Paliques".Inst. de Ests. Asturianos, Oviedo, 1963. $4^{\circ}$ pp. $\| H, 47 \quad(1964), 870$ (Kronik) 18-7253. DE FilipPo, Luigi - Leopoldo 
Alas "Clarin", critico letterario.-Roma, 1964. $78 \mathrm{pp}$.

V. también núms. 5120, 5868, 7190.

18-7274. Pianca, A. H. - "Emilia Pardo Bazán ¿realista o idealista?" - PH, 8 (1964), 429-441.

18-7275. Bergaza González, F.--"La Pardo Bazán y el naturalismo".-EL, 196 núm. 295.

18-7275. KIRBY, Harry LeE, JR.-Evolution of thought in the critical writings and novels of Emilia Pardo Bazan.[Tesis, Univ. of Illinois; resumen en DA, $\left.24\left(19^{6}-64\right), 299\right] .272 \mathrm{pp}$.

18-7277. GILES, M. E.--"Impressionist techniques in... Emilia Pardo Bazán" (N. $17-6187)$. I| BICC, 19 (1964), 609 (Valderrama Andrade).

18-7278. Torres Martfnez, Adriana-Los personajes femeninos en las novelas de doña Emilia Pardo Bazán. - [Tesis, Univ. de Murcia, 1963].

18-7279. KIRBY, H. L., JR.-“Pardo Bazán, Darwinism and La madre naturaleza". $-H, 47$ (1964), 733-737.

18-7280. Pardo Bazán, Emilia-la sirena negra. La piedra angular. $5^{\text {a }}$ ed.-Agui. lar, Madrid, 1964. 496 pp. (Crisol, 6).

V. también núms, 5120, $615^{2}$.

18- 728 I. Palacio Valdés, Armando-Jose $5^{\text {a }}$ ed. - Espasa-Calpe, Madrid, 1963. 151 pp. (Austral).-V. núm. 12-33687. 18-7282. Palacio Valdés, Armando - La novela de un novelista. $9^{\text {a }}$ ed.-Losada, Buenos Aires, 1963. 26o pp. (Contemporánea, 45).-V. núm. 16-45076.

18- 7283 . Palacio Valdés, Armando - Riverita. $6^{\text {a }}$ ed.-Espasa-Calpe, Madrid, 1963. 230 pp. (Austral, 189).-V. núm. $11-28705$.

18-7284. Palacio Valdés, Armando-Santa Rogelia.-Dédalo, Madrid, $1964.7^{6}$ pp. (Nozelas y cuentos).

Unamuno: v. núms. $8098,8102-29$.

Ganivet: v. núms. $7595^{-6}$.

18-7285. Betoret París, E. - "Valencian professional types in the works of $\mathrm{V}^{\prime} \mathrm{i}$. cente Blasco Ibáñez". - KFLQ, 11 (1964), 61-7o.

18-7286. Blasco IbÁÑez, Vicente-La $b a$ rraca. $6^{a}$ ed.-Espasa-Calpe, Buenos Aires, 1964. 146 pp. (Austral, 351).

18-7287. Blasco IbÁÑez, Vicente-La barraca.-Eds. R, La Habana, 1964. (Col. Biblioteca del pueblo).

18-7288. Blasco IbÁÑez, ViCENTE-La horda.-Planeta, Barcelona, 1963. 314 pp. (Autores españoles contemporáneos).V. núm. 17-2577.
18-7289. Blasco Ibáíez, Vicente - Tres cuentos. Choisis et annotés par R. J. Michel.-Belin, [Paris, 1969]. $4^{8}$ pp. (Cultura y literatura hispanicas). LNL, 1964, núm. 1, 129 (Pistre).

18-72go. Blasco Ibáñez, Vicente-En el pais del arte.-Planeta, Barcelona, 1963. 287 pp. (Autores españoles contemporáneos).

V. también núm. 6873 .

18-7291. Rubia Barcia, J. - A bibliography and iconography of Valle-Inclán (17-2586). || Hf, 1964, núm. 20, 69-71 (Boudreau); $\mathrm{BHi}, 65$ (1963), $176-178$ (Devoto).

18-7292. Garcfa Pavón, F.-"En el tínglado de la eterna farsa". $-E L, 1965$, núms. 320/1. [Valle-Inclán].

18-7293. AmézAGA, E. - "Valle-Inclán". [En el vol. colectivo] Sobre la genera. ción del 98 (San Sebastián, 1963), 91 102.

18-7291. Abirdched, R.-"Connaisance de Valle-Inclán".-Études, $3^{17} \quad(1963), 3^{86-}$ 389 .

18-7295. Rivas Xerif, C.--“Apuntes para un retrato de Valle-Inclán".-Libros Selectos, México, 1964 , núm. 20.

18-j296. Carballo Calero, R.- "A temática galega na obra de Valle-Inclán".Grial, 1964, 1-16.

18-7297. Martínez del Portal, M. - "Lo galaico en Valle-Inclán". - $A U M, 21$ (1962-69), 89-93.

18-7298. NAYA PÉREZ, J.-“Valle-Inclán y Murguia”.-BAG, 29 (1959), 50-ร̆3.

18-7299. Andrade, R. - "Mascarilla de Valle-Inclán”.-CCL, $196_{5}^{5}$, núm. 98, 8788.

18-7300. Alcoverro, T. - "Valle-Inclán, redivivo".-EL, 1964 , núm. 285 .

18-73or. Worms, J.-"Valle-Inclán, l'homme, l'œuvre".-Bref, Paris, ı963, núm. 64.

18-7302. Russell, D. I.-"El penacho lirico de Valle Inclán”-Asom, 19 (1963). $3^{0-40 .}$

18-7303. Follex, T. - "Valle Inclán: a comparative study in modernismo".NVH, 12 (1964), 10-13.

18.7304. Flynn, G. C.- "The Bagatela of Ramón del Valle Inclán”. - $H R, 3^{2}$ (1964), 135-141. [Y versión española en $A P C H, 281-287]$.

18-7305. ArmiJo, R.- "Los dos Valle-Inclán”.-CultS, 1964, núm. 33, 97-100.

18-7306. MAREY, J. - "Du chroniqueur Zugasti à Valle-Inclán, romancier".$L N L, 1964$, núm. 2, 48-59. 
18-7307. Callan, R. J. - "Satire in the Sonatas of Valle-Inclán".- MLQ, 25 (1964), 330-337.

18-7308. Smith, V. - "Dandy elements in the Marqués of Bradomin".-HR, 32 $\left(19^{6}\right), 34^{\circ}-35^{\circ}$.

18-7309. MAREY, J. - "Valle-Inclán et le cycle carliste". $-E, 19^{64}$, núms. $4^{19 / 20}$, $61-71$.

18-7310. VAlLe INGLÁN, RAMÓN DEL-Cara de plata. $2^{a}$ ed.-Espasa-Calpe, Madrid, 1964. 138 pp. (Austral, 651). V. núm. $4-4778$.

18-7311. VALle-INCLÁN, RaMón DEL-Tíano Banderas. $6^{\mathrm{a}}$ ed. - Espasa-Calpe, Madrid, $19^{64} .15^{8}$ pp. (Austral, 105). -V. núm. 17-6215.

18-7312. MicheL, JOSEPH-"La yuxtaposición de La gloria de Don Ramiro y Tirano Banderas". - Texas Western College's Publications, 1964.

18-7319. Barco Terdel, E.-"América en Valle-Inclán". - CuH, 53 (1963), 120 131.-V. núm. 16-45088.

18-7314. S.Mith, V. A.-"Fin de un revolucionario y su conexión con el ciclo ibérico".-RLit, 26 (1964), 61-88.

18-7315. Marrast, R.- "Valle-Inclán, dramaturge engagé". - Bref, Paris, 1969 , núm. 64 .

18-73:6. Brooks, J. L.-“Los dramas de Valle-Inclán”,-EMP, 7, $177-198$.

18-7317. Otero Seco, A.-"Sobre ValleInclán y el esperpento".-Asom, ig64, núm. 2, 15-27.

18-7318. Hormigón, A.-"Notas a la puesta en escena de dos esperpentos [de Valle-Inclán]". - $P A, 19^{6} 4$, núm. $5^{2}$, $50-53$.

18-7319. Valle Inclán, Ramón del-Divinas palabras, $2^{\text {a }}$ ed.-Espasa-Calpe, Ma. drid, 1964. 197 pp. (Austral, 1320).V. núm. 17-2608.

18-7320 MARRAST, R. - "Algunas llaves -para Divinas palabras". - PA, 1963, núm. $4^{6,} 42-49$.

18-7321. Spock, R. J.--"Valle-Inclán".-H, 47 (1964), $184-185$. [Divinas palabras en México].

18-\%322. García LORA, J.--"Alfombra mágica del teatro mejicano".-Ins, 1964, núms. 212/3. [Divinas palabras].

18-7323. Phillips, A. W.- "El esperpento de Los cuernos de don Friolera". $H u N L, 5 \quad(1964), 309-322$.

18-7324. VAlle-INGLÁN, Ramón DEL-Mar tes de carnaval.-Espasa-Calpe, Madrid, 1964. 232 pp. (Austral, 1337).

18-7325. Valle-INCLÁn, Ramón del-Cla. ves líricas, $2^{\mathrm{a}}$ ed. - Espasa-Calpe, Madrid, 1964. 160 pp. (Austral, 621).

18-7326. Speratti Piñero, E. S.-"Los últimos artículos de Valle-Inclán".-APCH, 455462 .

18-7327. Marey, J. - "Une interview de Valle Inclán au journal Le Temps".$L N L, 1964$, núm. 2, 6o-63.

r. también núm. 7335 .

18-7328. Pérez Lugín, Alejandro-la casa de la Troya. Estudiantina. 68? ed.Gali, Santiago de Compostela, 1964 . 275 pp. - V. núm, 12-33705.

18-7329. Nallim, C. O. - "Evocación de Pío Baroja".-RLMo, 3 (1964), 45-55.

18-733o. SÁinz de Robles, F. C. - "¿Don Pío? Tan vivo que ahí está..."-Correspondencia Diplomática, Madrid, 1963 , núm. 1.

18-7331. ARrifTA, G.-"Recordando a un maestro, Baroja”. - IAL, 1964, núms. $187 / 188$.

18-7332. Arió, Sfrastián Juan-Pio Baroja y su tiempo. - Planeta, Barcelona, 1963. 846 pp., láms. (Hombre y época). \|EL, 1965, núm. 909 (Fernández Asís); Ins, ı964, núms. 212/3 (MarraLópez); Asom, 1965, núm. 3, 75-77 (Otero Seco); CuH, $59 \quad(1964), 477$ (R.).

18-7333. BaEzA, F.-Baroja y su mundo (N. $18-3689$ ). || Map, 1963, núm. 1, 293. 294 (Echevarria).

18-7334- Olstad, C. - "Baroja and Picasso".-RNo, 5 (1964), $124-127$.

18-7335. Gil, I. M.-"De Baroja a ValleInclán".-CuH, 6o (1964), 36-44.

18-7336. Peña Santiago, L. P.-"E1 vasco en la obra de Pio Baroja".-[En el vol. colectivo] Sobre la generación del 98 (San Sebastiain, 1963), 41-54.

18-7337. Azeez Butt, A. - La visión del exiranjero en la obra de don Pio Baroja.-[Tesis, Univ. de Madrid; resumen en $R U M, 12$ (1963), $753-754]$.

18-7338. Cancioti, G.- "Pio Baroja, osservatore del costume italiano".-Con $3^{2} \quad\left(19^{64}\right), 49^{8-503}$.

18-7339. Ebanks, Gerardo Mack - Las ideas de Baroja.-[Tesis, Univ. de Madrid; resumen en $R U M, 12$ (1963), 757 $\left.75^{8}\right]$.

18-7340. Iglisias, Carmen-El pensamiento de Pio Baroja. Ideas centrales,-Robredo, México, 1963. 187 pp. (Col. Clásicos y modernos).-V. núm. 17-2628. || $A L M, 3$ (1963), 342-346 (Abreu Gómez); $M L J, 49$ (1965), 70-72 (Borenstein); $B A b r, 3^{8}$ (1964), 293 (Ferrer); 
Ins, 1964, núm. 211 (Marra-López); RHM, 29 (1963), 302-304 (Zardoya).

18-7341. Alberich, J.-"Algunas observaciones sobre el estilo de Pío Baroja".BHS, $4^{1}(1964), 169-18 \tilde{5}$.

18-7342. Nallim, C. O. - "Alcances del mundo novelístico de Pío Baroja”. APCH, 375-383.

18-7343. SLADE, TODD H. - Contribución al estudio del lenguaje coloquial en la novela de Pio Baroja. - [Tesis de la Universidad de Madrid; resumen en RUM, 14 (1965), 233-235].

18-7344. Campoy, Antonio Manuel-Pio Baroja. - Cía. Bibliográfica Española, Madrid, $1963.196 \mathrm{pp}$. (Col. Un autor en un libro). [Estudio y antología].

18-7345. BarojA, Pío - Aventures, inventions et mystifications de silvestre $\boldsymbol{P a}$. radox. Trad. par P. Guenoun. - Les Editeurs Français Réunis, Paris, 1963. 18-7346. Baroja, Plo-Camino de perfec. ción. (Pasión mistica). - Las Américas, New York, 1962. 208 pp.

18-7947. Baroja, Pio-Camino de perfec. ción. Pasión mistica. Pról y notas de J. Uribe Echevarría.-Ed. Universitaria, Santiago de Chile, 1963. 3o6 pp.-V. núm. $11-2674^{6}$.

18-7348. Baroja, Pfo-Chemin de perfec. tion. Trad. par R. Marrast. Introd. par J. Corrales-Egea.-Les Éditeurs Fran. çais Réunis, Paris, 1964.

18-7349. Solotorersky, M. - "Notas para el estudio intrínseco comparativo de Camino de perfección y La voluntad". $-B d F S, 15$ (1963), 111-164.

18-735o. Baroja, Pío - Fantasias vascas. $4^{\mathrm{a}}$ ed.-Espasa-Calpe, Madrid, $1964 \cdot 14^{6}$ pp. (Austral, 230).

18-7351. Baroja, Pfo-El gran torbellino del mundo. $3^{\text {a }}$ ed.-Espasa-Calpe, Madrid, 1964. 256 pp. (Austral, 256).

18-7352. Baroja, Pío-Las inquietudes de Shanti Andia. $4^{\text {a }}$ ed.-Aguilar, Madrid, 1964. 504 pp. (Crisol, 3og).-V. núm. $17-2637$.

18-7353. BArojA, Pío - La leyenda de Jaun de Alzate. $4^{\text {a }}$ ed.-Espasa-Calpe, Madrid, 1964. 147 pp. (Austral, 177).

18-7354. Flores Arroyuelo, F. J. -- "La lucha por la vida desde dentro". Mont, 1962, núm. 40, 4⿻17.

18-7355. Baroja, Pfo - El mayorazgo de Labraz. $3^{\text {a }}$ ed.-Espasa-Calpe, Madrid, 1964. $\$ 62$ pp. (Austral, 377).

18-7356. Baroja, Pfo-El mundo es ansi. $3^{3}$ ed. - Espasa-Calpe, Madrid, 1964 . $15^{2}$ pp. (Austral, 331).
18-7357. Baroja, Ṕo-Los pilotos de altura. $3^{\text {a }}$ ed.-Aguilar, Madrid, $19^{64} \cdot 44^{6}$ pp. (Crisol, 296).-V. núm. 14-41450.

18-7358. Baroja, P.-Zalacaín el aventurero, présenté par B. Sesé (N. 176263). || RLit, 22 (1962), 284 (Romero).

18-7359. Di Blasi, Daniel - A critical study of the essays and other nonfiction of Pio Baroja.-[Tesis, Columbia Univ; resumen en $D A, 24$ (1963-64), 3334-3335]. $34^{6}$ pp.

V. también núm. 7212 .

Azorín: v. núms. $6873,7349,8197-9$.

18-7360. León, Ricardo-Humos de rey. -Dédalo, Madrid, 1963. 56 pp. (Nove. las y cuentos).

18-7361. León, Ricardo-Las siete vidas de Tomás Portolés.-Dédalo, Madrid, 1964. 56 pp. (Novelas y cuentos).

Concha Espina: v. núm. 6873.

18-7362. Muelas, F.-"Mínima ojeada en el umbral de Gabriel Miró". - $E L$, 1964 , núm. 298.

18-7363. Cordua, C.- "Intensidad y entereza en la obra de Gabriel Miró".$A U C h, 122 \quad(1964), 144^{-166 .}$

18-7364. Barberá, E.-"El testimonio del artista en la obra de Gabriel Miró".RLMo, 3 (1964), 91-94.

18-7365. Umbral, F.-“Gabriel Miró, ¿del que nada aprendimos?"-Agora, 1964, núms. $85 / 93$.

18-7366. Miró, Gabriel - Figuras de la pasión del Señor.-Eds. R, La Habana, 1964. (Bibl. básica de lit. española).

V. también núm. $5^{866}$.

18- $\boldsymbol{7 3}^{6} \overline{7}$. Rivas-Xerif, C.-“Ramón Pérez de Ayala". - Libros Selectos, México, 1964, núm. 21.

18-7368. Rivas Andrés, V. - "Pérez de Ayala con perspectiva". - $H D, 1962$, 708-713.

18-7369. LÁzAro, A. - "Recordando la muerte de Pérez de Ayala".-LT, 1964 , nưm. $47,145^{-1} 5^{\circ}$.

18-7370. TORre, G. DE-“El universo novelesco de Pérez de Ayala".-Asom, 20 (1964), núm. 1, 13-21.

18-7371. Uriarte, F.- "Temas y problemas de dos novelistas: Hesse y Pérez de Ayala".-Map, 1963, núm. 1, 262 271 .

18-7372. ReINinK, K. W.-Algunos aspectos... de la obra de Pérez de Ayala (N. 16-45118). $Z R P h, 80 \quad(1964), 4^{05}$ 407 (Siebenmann).-V. núm. 17-2654.

18-7373. Hartsook, J. H.-"Literary tradition as form in Pérez de Ayala".RNo, 6 (1964), 21-25. 
18-7374. TORRE, G. DE - "Dos conceptos del amor en Pérez de Ayala: edenismo y donjuanismo". - Daülar, 1964, núm. $100,248-253$.

18-7375. Pérez de Ayala, Ramón-Belarmino und Apolonio. Ubers. von W Muster. - Fischer, Frankfurt/München, 1964. 289 pp. (Fischer Bücherei, 633).V. núm. 16-45120.

18-7376. Weber, F.- "Relativity and the novel: Pérez de Ayala's Belarmino $v$ Apolonio".-PhQ, 43 (1964), 253-2ך1.

18-7377. PÉrez de AYAIA, Ramón-Tigre Juan. El curandero de su honra.-Las Américas, New York, 1964. 267 pp.

18-7378. Dobrian, W. A. - "Development and evolution in Pérez de Ayala's $T i$ gre Juan".-[En:] B. SLote (ed.), Literature and socicty (Lincoln, Nebraska, 1964), $187-201$.

18-7379. Díez de Revenga Torres, Maria J.-El cuento y la noréla corta en Ramón Pérez de Ayala.-[Tesis, Univ. de Murcia, 1963].

18-7380. Rodrfcuez Monescillo, E. - "El mundo helénico de Ramón Pérez de Ayala".-Actas del II Congreso español de estudios clás. (Madrid, 1964), 5̃10521.

18-7381. Pérez de Ayala, Ramón - Pequeños ensayos. Ed. recogida y ordenada por J. García Mercadal.-Biblioteca Nueva, Madrid, 1969. $311 \mathrm{pp}$.

18-7382. Pérez de Ayala, RaMón-Tabla rasa.-Bullón, Madrid, 1963. 244 pp. (Generaciones juntas).

18-7383. PÉrez de Ayala, RAMón-Tributo a Inglaterra. Recopilac. y pról. de J. Garcia Mercadal-Aguilar, Madrid, 1963. 502 pp. (Ensayistas hisp.). 18.7384. Schraibman, J.- "Cartas inéditas de Pérez de Ayala a Galdós".-Hf, 1963 , núm. 17, 83103 .

18-7385. Hornedo, R. M. DE-"Pérez de Ayala y Gómez de la Serna".-Hum, 15 (1963), $181 \cdot 188$.

V. también núms. $5^{866}, 8184$.

18-7386. Cano, J. L. - "Rafael CansinosAsséns".-Asom, 1964, núm. 3, 82-84.

18-7387. Dfaz-Plaja, G.-"La letra y el instante",-Dest, 18 julio 1964. [Sobre R. Cansinos-Asséns].

18-7388. Dirgo, G. - "Cansinos-Asséns". -IAL, 1964, núms. 187/8; PEsp, 1964, núm. 139 .

18-7389. Quiñones, F. - "R. Cansinos-Asséns". $-E L, 1964$, núm. $29 \%$.

18-739o. Tiempo, C. - "Rafael CansinosAsséns".-CCL, 1963 , núm. 72, 62-69.
18-7391. Viñuelas, A. de-“Rafael Cansinos-Asséns o la vocación literaria”.PSA, 34 (1964), 366-368.

18-7392. Flint, W.-Sounds in the Obra literaria of José Gutiérrez-Solana". bHS, 40 (1963), 40-44.

18-7393. González Ruano, C.-“José Gutiérrez Solana".-Azor, 1962, núm. 9.

18-7394. Flint, W. - "Wax figures and mannequins in Solana".- $H, 4^{6}$ (1963), $74^{0-747}$.

18-7395. "Wenceslao Fernández Flórez". -EL, 1964, núm. 254. [Número de homenaje].

18-7396. Allvarez de Menina-Bocos, C."Wenceslao Fernández-Flórez". - NEt, $1964,268-269$.

18-7397. Fernández Flórfz, WencleslauEl malvado Carabel.-Planeta, Barcelona, 1964. 251 pp. (Autores españoles contemporáneos). $-V$. núm. 14-41457.

18-7398. Rodrfguez Panigua, E. - "Las humanidades clásicas en La vida nueva de Pedrito de Andia [de R. Sánchez Mazas]".-Actas del II Congreso espanol de estudios clás. (Madrid, 1964), $521-531$.

18-7399. Chacel, RosA - Teresa.-Aguilar, Madrid, 1963. 354 pp. (Col. literaria). 18-7400. Durán, M.-“Max Aub o la vocación de escritor".-PSA, 31 (1963), $125 \cdot 13^{8}$.

18-7401. AUB, MAX-San Juan.-PA, 1964, núm. $5^{2}$ [Con una nota del autor, una bibliografía de sus obras, y artículos de J. R. Marra López, J. M. de Quinto $\mathrm{y}$ Alfonso Sastre].

18-7402. AUB, M.-Las buenas intenciones (N. 10-21363). \| CCL, 1965, núm. 92, 89 (Demayo).

18-7403. Aub, Max-Campo del Moro.Joaquín Mortiz, México, 1963. 256 pp.

18-7404. Aub, Max-Die Schuld der ersten Anglers. Erzählungen. Dt. von Hildegard Baumgart u. Gustav Siebenmann.-Piper, München, 1963. $74 \mathrm{pp}$. (Piper-Bücherei, 177).

18-74\%5. Agostini DE DEL Rfo, A.-"Los cuentos de Max Aub". - RHM, 29 (1963), 62-63.

18.7406. Bosch, R.-"El teatro de Max Aub".-Hf, 1963, núm. 19, 25-36.

18-74\%7. Umbral, F.- "Iras y templanzas de Juan Antonio de Zunzunegui".CuH, $5^{8}$ (1964), 399*401.

18-7408. Colchero Rozas, Carlos - Humor, ambiente, personajes $e$ influencia de la picaresca en la novela de Juan Antonio de Zunzunegui.-[Tesis, Uni- 
versidad Nacional Autónoma, México, 1963]. 118 pp.

18-7409. RAY, G. B.- "Notes on a source for Juan Antonio de Zunzunegui".$H R, 32$ (1964), $157-163$.

18-7410. Zunzunegui, Juan Antonio deBajo mi cielo metalúrgico. - Librería Arturo, Bilbao, 1963. $25^{\circ} \mathrm{pp}$., láms. (El cofre bilbaino, 6).

18-7411. Zunzunegli, Juan Antonio de El chiłlichandle.-Samarán, Barcelona, 1963. 419 pp. NT, 21 (1969), 599-601 (Somoza).

18-7412. Zunzunegur, Juan Antonio DEEl chiplichandle. Las ratas del barco. La úlcera.-Editoral Vergara, Barcelona, 1963. 1006 pp. +19 láms. (Caudal y cauce).

18-7419. Zunzunegui, Juan Antonio deChiripi.-Bullón, Madrid, 1963. 342 pp. (Generaciones juntas).

18-7414. Zunzunegui, JUan Antonio DE Don Isidoro $y$ sus limites. - Noguer, Barcelona, 1963. 312 pp. If EL, 1964, núm. 289 (A. L.); $R y F, 171 \quad(1965)$, 434 (Hornedo); Res, 1 (1964), $185^{-1} 87$ (Marcos).

18-7415. Zunzlnegu, Juan Antonio DELas ratas del barco. - Bullón, Madrid, 1963. 394 pp. (Generaciones juntas).

18-7416. Zunzunegei, Juan Antonio de -La toz de la sangre.-Dédalo, Madrid, 1963. $4^{8}$ pp. (Novelas y cuentos).

V. también núm. 6889 .

18-7417. Marr.t-López, J. R.-“Ramón J. Sender, novelista español".-Ins, 1964, núm. 209.

18-7418. SENDER, RAMóN-Crónica del alba.-Las Anicricas, New York, 1963. 2 ts. $-V$. núm. $17^{-6905}$. $\| H, 4^{8}(1965)$, $179 \cdot 180$ (Olstad).

18-7419. Sender, RaMón J. - Cronaca dell'alba. Ippogrifo violento. Villa Giulietta. Trad. di L. Orioli-Einaudi, Torino, 1964 . viii $+393 \mathrm{pp}$.

18-7420. Olstad, C.- "The rebel in Scnder's Ei lugar del hombre".- H, 47 (1964), $95-99$.

18-7421. Sender, Ramón-Mosén Millán. Ed. by Robert M. Duncan. - D. C. Heath, Boston, 1964. xv+111 pp. । $M L J, 4^{8}$ (1961), $53^{8}$ (Sánchez); $H, 47$ (1964), 678-679 (Vilas).

18-7422. Sender, RAmón-Tales of Cibola. Transl. by Florence Sender, Elinor Randall \& Morse Manley.-Las Américas, New York, $1964.3^{83}$ pp. $\| H, 4^{8}$ (1965), 940 (Olstad).

18-7423. SENDER, RAMÓN - Requiem für einen spanichen Landmann. Übertr. von Walter Boehlich. - Suhrkamp, Frankfurt, 1964. 104 pp. (Bibliothek Suhrkamp, 133).

18-7424. Marra López, J. R.-"En Palma, con Camilo José Cela". - Ins, 1964, núm, 208.

18-7425. MARra-López, J. R.-"El acelismo" de Camilo José Cela".-Ins, 1964, núm. 215.

18-7426. Oguiza, T.- "Dos aspectos de la obra de Camilo José Cela".- $\mathrm{CuH}$, 60 (1964), 219-23o.

18-7427. Ferrer, O. P.-El sistema estético de Cela (N. 17-6320). || S, 17 (1963), 64-66 (Suárez-Llanos).

18-7428. Polo García, Victorino-Análi. sis estilístico de Camilo José Cela.[Tesis, Univ. de Murcia, 1963].

18-7429. Polo García, V.-"El diminutivo en C. J. Cela".-Mont, 1963, núm. $4^{1,} 4^{-16 .}$

18-7430. Cela, Camilo José-la familia de Pascual Duarte. Con 41 maderas escogidas por Jaume Pla.-Ios Papeles de Son Armadans, Palma de Mallorca, 1964. 108 pp. ilustr.

18-7431. Cela, Camilo José-[la familia de Pascual Duarte. Trad. al polaco por Zofia Szleyen].-Warszawa, ${ }^{1963}$.

18-7432. Beck, M. A.-"Nuevo encuentro con La familia de Pascual Duarte".RHM, 3० (1964), 279-298.

18-7433. ORTEGA, José- "La colmena" de Camilo José Cela: contenido y expre. sión.-[Tesis, Ohio State Univ.; resu. men en $\left.D A, 25 \quad\left(1964^{-6}\right), 4^{83}\right]$.

18-7434. Cella, Camilo José-Der Bienenkorb. Ubers. von Gerda Theile-Bruhns. -Walter, Olten-Freiburg/Br., 1964. 329 pp.

18-7435. Cela, Camilo José-Las compañias convenientes $y$ otros fingimientos $y$ cegueras.-Destino, Barcelona, 1963. 285 pp. || $E L, 1964$, núm. 293 (Iglesias Laguna); NT, 1964, 123-125 (Somoza).

18-7436. Cela, Camilo José - Garito de hospicianos.-Noguer, Barcelona, 1963. 360 pp., láms. (El espejo y la pluma). i| $E L, 19^{64}$, núm. 284 (Umbral).

18-7437. Cela, Camlo José-Nuevas andanzas y desventuras de Lazarillo de Tormes. $8^{\text {a }}$ ed. - Noguer, Barcelona, 1963. 24. pp. (Galeria literaria). - V. núm. 10-23934.

18-7438. Cela, Camilo José-Once cuentos de fuitbol.-Edit. Nacional, Madrid, 1963. 81 pp., ilustr. Agora, 1963-64, 
núms. 85-93 (Umbral); Map, 4 (1965), 239-242 (Uribe Echevarría).

18-7439. Cela, Camilo José - Toreo de salón. Farsa con acompañamiento de clamor y murga.-Lumen, Barcelona, 1963. Sin paginación, ilustr. || Ins, 1964, núms, 212/3 (Marra-López); CuH, 58 (1964), 232 (Tijeras); EL, 1964, núm. 284 (Umbral).

18-7440. Cela, Camilo José-Pisando la dudosa luz del dia. Poemas de una adolescencia cruel. $3^{\text {a }}$ ed.-Papeles de Son Armandans, Palma de Mallorca, 1963. (Col. Juan Ruiz, 10).-V. núm. 16-49368. || PSA, 31 (1963), 213-215 (de Luis); PEsp, 1964, núm. 136 (Fernán. dez Molina).

18-7441. Cela, Camilo José-Viaje a la Alcarria. $4^{\text {a }}$ ed.-Espasa-Calpe, Madrid, 1964. 163 pp. (Austral, 1141).-V. núm. $17-2707$.

18-7442. Gramberg, E. J. - "José María Gironella, ¿novelista?" - CCL, 1963, núm. $79,62-68$.

18-7443. NúÑEZ, L.- "Un Gironella distinto".-NT, 19 (1963), 794-796.

18-7444. Oliveira, Z. DE-"A guerra civil espanhola: Gironella e Soler",-Lumen, 34 (1964), 860-865.

18-7445. Gironella, José María-Los cipreses creen en Dios. $37^{\mathrm{a}}-4^{6^{\mathrm{a}}}$ eds. Planeta, Barcelona, $1963^{-64}$. 870 pp. (Ómnibus, 5).-V. núm. 17-2714.

18-7446. Gironella, José María-Un miillón de muertos. $7^{\mathrm{a}-10^{\mathrm{a}}}$ eds.-Planeta, Barcelona, 1963-64. 819 pp. (Ómnibus). -V. núm. 17-2719.

18-7447. Gironella, José María-Un nillion de morts. Trad. de Paul Werrie. -Plon, Paris, s. a. 2 ts.: 408, $37^{6} \mathrm{pp}$. (Feux croissés).

18-7448. Gironella, José María - One million dead.-Doubleday, New York, 1963. 684 pp.

18-7449. Grronella, José Marfa - Reif auf Olivenbluten. Übertr. von Dietrich Niebuhr.-List, München, 1963. 727 pp. \|WeW, 19 (1964), $33^{6}$ (Schöne).

18-745o. Gironella, José María-Mujer, levántate $y$ anda. ${ }^{a}-3^{a}$ eds.-Plancta, Barcelona, 1963. 168 pp. (Autores españoles contemporáneos). \| $P E, 1963$, núm. 81, 192-133 (Murciano); NT, 19 (1969), 793-797 (Núñez); $E L, \quad 1969$, núm. 262 (Rodriguez Alcalde).

18-7451. Grronella, José María - Personas, ideas, mares.-Planeta, Barcclona, 1963. 408 pp. (Autores españoles contemporáneos). || EL, s964, núm. 287
(Iglesias Laguna); $P E$, 1964 , núm. 96, 125-126 (Murciano); CuH, 59 (1964), 478.479 (R.).

18-7452. MostazA, B.-“Carmen Laforet, la novclista introspcctiva". - LEsp, 7 (1964), $180-18_{5}$.

18-7453. LAFORet, CaRMen - Tres pasos fuera del tiempo. La insolación. $3^{\mathrm{a}} \mathrm{ed}$. - Planeta, Barcelona, 1963. $3^{65} \mathrm{pp}$. (Autores españoles contemporáneos).

18-7454. Garcia-Viñó, M.-“La subjetividad de Ana María Matute". $P E$, 1964, núms, $99 / 100,36-39$.

18-7455. WeItzNer, Margarft Elizabetì -The novelistic world of Ana Maria Matute: $A$ pessimistic vision of life.[Tesis, Univ. of Wisconsin; resumen en $\left.D A, 24(1963-64), 2491-249^{2}\right], 286$ pp.

18-7456. Romero, L.-“Ana Maria Matute frente a sus personajes".-Dest, 18 julio 1964 .

18-7457. Matute, Ana Marfa-Fiesta al Noroeste, $3^{\text {a }}$ ed. - Destino, Barcciona, 1963. $130 \mathrm{pp}$. (Áncora y delfin).-V. núm. 16-45161. $\| R y F, 173$ (1966), 328 (Castro y Delgado); Hum, 16 (ig64), 84 (Vegas González).

18-7458. Matute, A. M.-Libro de juegos para los niños de los otros (N. 17-6341). || $\mathrm{CuH}, 5^{8}\left(\mathrm{1}^{6} 64\right), 45^{8}$ (Grande).

V. también núm. $688_{4}$.

18-7459. DELANo, L. K.-"Sensory images in the Galician novels of Elena Quiroga".-KFLQ, 1o (1963), 59-68.

18-7460. Quiroga, ElenA - Eine Stunde der Wahrheit.-O. Müller Verl., Salzburg, 1963. 243 pp. I| WeW, 19 (1964), 153 (Reitz).

18-7461. Quiroga, Elena - Le bras du vent. Trad. par Maurice-Alex Dumont. -Casterman, Paris, 1963. 259 pp.

Dolores Medio: v. núm. 6889 .

18-7462. Mostaza, B. - "Miguel Delibes, el novelista del realismo profundo".LEsp, 6 (1963), núm. 75.

18-7463. García-Vı̃̃ó, M.--"Miguel Delibes, entre la primera y la segunda naturaleza".-PE, 1964, núm. 95, 26-41.

i 8-7464. Deribes, Mrguel - Tagebuch eines Jägers. Ubers. von Susanne Felkau. -Bachem, Köln, 1964. 216 pp. \|WeW', 19 (1964), $34^{8}$ (Baldus).

I 8-7465. Delibes, Miguel-El camino. Ed. by P. Polack.-Harrap, London, 1963 . $286 \mathrm{pp}$. \|N NVH, 12 (1964), 29-30 (R. C. H.); BHS, $4^{1}(1964), 266$ (Shaw). 18-7466. Johnson, E. A., JR.-"Miguel De- 
libes, $E l$ camino. A way of life". $-\boldsymbol{H}$, $4^{6} \quad(1963), 74^{8-75^{2}}$.

18-7467. Delibes, Miguel-La caza de la perdiz roja.-Lumen, Barcelona, 1963 . 20 hojas+16 láms. I| $E L, 1963$, núm. 263 (A. A.); CuH, 58 (1964), 458-459 (Grande); $P E$, 1963, núm. 84, 99-100 (Umbral).

18-7468. Delibes, Miguel - La fenille rouge. Trad. par Maurice Edgar Coindreau.-Gallimard, Paris, 1963. $221 \mathrm{pp}$. (Du monde entier).

18-7469. Delibes, Miguel-Europa: parada y fonda.-Edics. Cid, Madrid, 1963 206 pp. (Col. Altor). $\| N T, 1964,132-$ 193 (G. G. V.).

18-747o. Aldecoa, IgNacio-Mit dem Ostwind, Aus dem Spanischen von Annelies von Benda.-J. P. Bachem, Köln, 1963. ${ }_{25}^{6} \mathrm{pp}$. \|W WeW, 19 (1964), $15^{\circ}$ (Schöne).

18-7471. AldecoA, Ignacio-El Pais Vasco.-Noguer, Barcelona, 1963. 128 pp., láms., mapas. (Andar y ver). $\| E L$, 1964, núm. 290 (A. L.).

V. también núm. $688_{4}$.

18-7472. Riley, E. C.--"Sobre el arte de Sánchez Ferlosio: aspectos de El Jarama".-Fil, 9 (1969), 201-221.

18-7473. Sánchez Ferlosio, Rafael - $l l$ Jarama. Trad. di Raffaella Solmi--Einaudi, Torino, 1963. 355 pp. $\| C C$, 115 (1964), 166-167 (de Gennaro).

V. también núm. $688_{4}$.

18-7474. Martínez Cachero, J. M. - "El novelista Juan Goytisolo". - PSA, 32 (1964), $125^{-160 .}$

18-7475. Werrie, P.- "Le cas de M. Juan Goytisolo".-TR, 1964, núm. 204, 141. 147 .

18-7476. Schwartz, K. - "The novels of Juan Goytisolo". $-H, 47 \quad(1964), 302$ 308 .

18-7477. Gormsolo, J.-La Chanca (N. 17.6354). I| PSA, 33 (1964), 118-121 (Sobejano).

18-7478. Goytisolo, Juan-“La Chanca". - Les Temps Modernes, Paris, 18 (1963), $1345^{-1} 3^{80}$.

18-7479. Goytisolo, JuAn - La Chanca, précédé de Terre de Nijar. Trad. par Robert Marrast. - Gallimard, Paris, 1964. 234 pp. (Du monde entier). II Études, Paris, juillet-août 1964, $152-153$ (Louis-Chevrillon).

18-7480. Goytisolo, JuAN-Danses d'été. Trad. par M. E. Coindreau.-Gallimard, Paris, 1964. $23^{8}$ pp. (Du monde entier). II NRF, $12 \quad(1964), 1 \check{5}^{2-153}$
(Blanzat); Études, juillet-août 1964, 153 (Louis-Chevrillon).

18-7481. Goytrolo, JuAn-Luto no Pa. raiso.-Portugália, Lisboa, 1964. (Col. contemporânea).

V. también núm, 6889 .

18-7482. MostazA, B.-“José Luis Castillo Puche, novelador del testimonio". LEsp, 7 (1964), $445-45^{\circ}$.

18-7483. Castillo Puche, J. L.-Paralelo 40.-Destino, Barcelona, 1963. $47^{6} \mathrm{pp}$. II Res, 1 (1964), 31-33 (Marcos); ins, 1969 , núms. 200/01 (Marra-López); $A I 1$, 1963, núm. 119, 326-327 (Ortiz Sánchez); Asom, 1965, núm. 2, 83-88 (Peñuelas); $H, 49$ (1966), 169 (Peñuelas); $E L, 1963$, núm. 268 (Pérez Piedra); $T R$, 1964, núm. 95, 150-151 (Rosa); CuH, $5^{6}$ (1963), 679-682 (Tijeras); Agora, 1969, núms. $83 / 84$ (Umbral).

18-7484. Castillo Puche, José Luis-Oro blanco. (Las pastores vascos en Estados Unidos).-Madrid, 1963. 455 pp. (Col. Altor). \| NT, 20 (1963), núm. 11, 334 (G. G. V.); $H, 4^{8}$ (1965), 182-183 (Sánchez); $B S V, 19$ (1963), 389-291 (Zumalde).

\section{PROSA VARIA}

18-7485. Beneyto Pérez, J. - “Ejemplos, imágenes $y$ esquemas en la construcción política medieval".-EMP, $5,35^{\text {- }}$ 359

18-7486. Gonzílez Olmedo, F. - "Introducción al estudio de la predicación española".- $R y F, 169$ (1964), 143-154.

18-7487. Simón Díaz, José-Impresos del xvi: Historia.-C.S.I.C., Madrid, 1964. 32 pp. (Cuadernos bibliográficos, $1_{5}$ ). 18-7488. Vilar, P.--"Les primitifs espagnols de la pensée économique, quantttativisme et bullionisme".- $\mathrm{BHi}, 6_{4}$ bis (1962), 261-284.

18-7489. Ridruejo Alonso, Pedro-la noción de constitución histórica en el pensamiento politico español del siglo xviii.-[Tesis, Univ. de Madrid; resumen en $R U M, 13$ (1964), 881-882].

18-7490. Fernández de la Mora, GonzaLo-Pensamiento español 1963. De Azorin a Zubiri.-Rialp, Madrid, 1964. 276 pp. \| EstF, 14 (1965), 220-221 (X).

18-7491. Commlas, José Luis-La teoria del régimen liberal español.-Inst. de Ests, Políticos, Madrid, 1962. $174 \mathrm{pp}$. [Donoso Cortés, Bravo Murillo, Cánovas]. If $R y F, 169$ (1964), 209-210 (Saenz de Santa María). 
18-7492. IrIARTf, JOAQUíN-Nuevos pensares. Teoria, historia, critica.-Razón y Fe, Madrid, 1963. xv + 625 pp. (Bi. blioteca de filosofia y pedagogia).

A utores antiguos

18-7493. Crónica seudo isidoriana. Ed. e indices preparados por Antonio Benito Vidal.-Valencia, 1961. (Textos medievales, 5 ).

18-7494. Віsнко, C. J. - "The liturgical context of Fernando I's last days".-HS, 17 (1964), 47-59. [En la Historia silense].

18-7 t95. Ś́nchrz-Albornoz, C.-"De nuevo sobre la crónica de Alfonso III y sobre la llamada Historia silense".CuHE, 1969, 292-371. - V. núm. 1125471 .

18-7496. Lomax, D. W.-"The authorship of the Chronique latine des rois de Castille".-BHS, 40 (1969), $205-211$.

18-7497. Ferrari, A.-"Artificios septenarios en la Chronica Adefonsi Imperatoris y Poema de Almería".-BAH, 153 (1963), 19-68. || $M A, 7^{2}$ (1966), $5^{87-588}$ (Gautier-Dalché).

18-7498. Ferrari, A.-"El cluniacense Pedro de Poitiers y la Chronica Adefonsi imperatoris y Poema de Almería". $-B A H, 153$ (1963), 153-204.

18-7499. Castro, M. DE-"Las ideas políticas y la formación del príncipe en el De preconiis Hispaniae de Fr. Juan Gil de Zamora".-HM, 22 (1963), $5^{\circ 7}$ 541 .

18-7500. Crónica de San Juan de la Pe$\tilde{n} a$. Versión latina $\mathbf{e}$ índices prepara. dos por Antonio Ubieto Arteta.-Va. lencia, 1961. 277 pp. (Textos medieva. les, 4).

V. tambićn núm. 6472 .

18-7501. Babín, M. T.-Homenaje a Alfonso $X$ el Sabio".-Educación, San Juan, Puerto Rico, 1964, núm. 11, 86. 96.

18-7502. MetrmanN, W. - "Stand und Aufgaben der alfonsinischen Forschungen".- $R J, 14$ (1963), 269-293.

18-ión. Ballesteros Beretta, AntonioAlfonso $X$ el Sabio.-Salvat, Barcelona, 1963. 1174 pp., ilustr. || Ins, 1964, núm. 215 (Cano); BHS, $4^{1} \quad\left(19^{6} 4\right), 188$. 189 (Lomax).

18-7504. Llampayas, J.-Alfonso X.-Dédalo, Madrid, $1963 . \quad 5^{6}$ pp. (Noñelas y cuentos).

18-7505. Torres Fontrs, J.-Documentos de Alfonso $\mathrm{X}$ el Sabio.-Murcia, 1969. 1xx + 111 pp., ilustr. $A I A, 24$ (1964). 480-48i (Meseguer Fernández.).

18-7506. Valdeavellano, L. G. De-"Los días penosos del Rey Sabio".-Residencia, diciembre de 1963 .

18-7507. Catalán, Diego-De Alfonso $\mathrm{X}$ al Conde de Barcelos. Caatro estudios sobre el nacimiento de la historiografia romance en Castilla y Portugal.Gredos, Madrid, 1962. 454 pp. (Semi. nario Menéndez Pidal). || BHS, 4o (1963), 182-183 (Lomax); HR, 33 (1965), $68-71$ (Tate); $N, 4^{8}$ (1964), $267-268$ (Van Praag).

18-7508. Rubio, F.- "Nuevo avance en la publicación de la General estoria de Alfonso el Sabio". - CD, 176 (1963), $107-118$.

18-7509. Gómfz Pérez, J.-"Elaboración de la Primera crónica general de España y su transmisión manuscrita".Scrip, 17 (1963), núm. 2.

18-7510. AGuilfra, M.-"Séptimo centenario de las Siete Partidas".-BACol, 13 (1963), $241-257$.

18-7511. Cerda Ruiz-Funes, Joaquín Consideraciones sobre el hombre y sus derechos en las "Partidas" de Alfonso el Sabio.-Universidad, Murcia, 1969. $5.5 \mathrm{pp}$

18-7512. Valdeavellano, L. G. de-"Las Partidas y los orígenes medievales del juicio de residencia". - $\boldsymbol{B A H}, 153$ (1963), 204-246.

18-7513. FrankL, V.- "Hernán Cortés y la tradición de las Siete Partidas".-RHA, 1962, núms. 53/54, 9-74.

18-7514. Alfonso X, el Sabio-libro de las cruzes. Ed. de Lloyd Kasten y L. B. Kiddle. Pról. de J. A. Sánchez Pèrez.C.S.I.C., Inst. Miguel de Cervantes, Madrid, 1961. xlviii + 173 pp. $\| A I A, 25$ (1965), 453 (Castro); RPh, $17 \quad(1963$ 64), 498-502 (Gimeno Casalduero); LR, 18 (1964), 386-387 (Groult); BICC, 18 (1963), 213-214 (Montes); RFE, 44 (1961), 460-461 (Sánchez Alonso).

r. también núms. $543^{1}, 544^{6}$.

18-755. Catalán, D.-“La Estoria de los reves del Señorio de Africa del maestro Gilberto o Sujulberto. Una obra del siglo xiII perdida". $-R P h, 17$ (196364), $34^{6-353}$.

Historia troyana: v. núm. 4893 .

187516. WeAver, Billy Rupert - The forms and usage of the personal pronouns in "Castigos e documentos para bien vivir ordenados por el rey don 
Sancho $I V^{\prime \prime} \cdot-[$ Tesis, Univ. of Wisconsin; resumen en $D A, 24$ (1963-64), 3743]. 236 pp.

18-7517. Libro del consejo e de los consejeros, por Maese Pedro. Ed. de Agapito Rey. - Libreria General, Zaragoza, 1962. 84 pp. (Bibl. del hispanista, 5). -V. núm. 14-41512. \| RLit, 23 (1963), 273 (Fradejas); H, $46(1963), 193$ (London); $B H S, 4 l$ (1964), 66-67 (Michael). 18-7518. MetrmanN, W. - "Neues zur Uberlieferungsgeschichte der sogenannten Bocados de oro". $-F F S, 115^{-1} 3^{2}$. II $Z R P h, 80 \quad(1964), 569$ (Hatzfeld).

18-7519. Lomax, D. W.-"The date of don Juan Manuel's death".-BHS, 4o (1963), 174 .

18-7520. Juan Manuel, Don-Libro del Conde Lucanor. Selección.-La Mandrágora, Buenos Aires, 1963. 157 pp. (Bolsi-clásicos, 1).

18-7521. Scholberg, K. R.-“'Sobre el estilo del Conde Lucanor". - KFLQ, 9 (1963), núm. 4.

18-7522. Várvaro, A.-“La cornice del Conde Lucanor".-SLSp, 187-195.

18-7523. SEgre, C.- "Negromanzia e in. gratitudine (Juan Manuel, il Novelli. no, Ludovico Ariosto)". - $M M D, 2$, $635-658$

18-7524. Guillén de Segovia, Pedro-La gaya ciencia. Transcripción de O. J. Tuulio. Introd., vocabularios e índices por J. M. Casas Homs.-C.S.J.C., Madrid, 1962. 2 ts.: lxxvii + 223, 315 pp. (Clásicos hispanos). \|| Map, 1963, núm. 1, 306-308 (Ferreccio); LR, 19 $\left(16_{5}\right), \quad 3^{1-32}$ (Groult); RLit, 22 (1962), 267 (Quilis); SCL, 16 (1965), $\begin{array}{lllll}436-437 & \text { (Sala); } N, 4^{8} \quad(1964), & 87-88\end{array}$ (Van Praag).

18-7525. Alvarfz Delgado, J. - "Alonso de Palencia (1423-1492) y la historia de Canarias".-AEAtl, 9 (1963), $5^{1-79}$.

Rodríguez de Almela: v. núm. 6490 .

18-7526. Nonell, Carolina-Fortún García de Ercilla y su tratado "De la guerra y el duelo".-Junta de Cultura de Vizcaya, Bilbao, 1963. 245 pp.

18-7527. Cione, Edmondo-Juan de Valdés: la sua vita $e$ il suo pensiero religioso. $2^{\text {a }}$ ed.-F. Fiorentino, Napoli, 1963. 225 pp. (Coll. di studi e testi di letteratura, 7). \|J Journ. Hist. of Philosophy, 2 (1964), 259-260 (Fuhrmann); $C T$, 1965 , núm. 29o, 134-135 (Hernández); HS, 15 (1962), 477-478 (S. G. G.).

18-7528. VALDÉs, JUAN DE-Diálogo de la
lengua.-Espasa-Calpe, Madrid, 1964. 288 pp. (Clás. cast., 86).

18-7529. VAldés, JUAN DE-Diálogo de la lengua. $4^{\text {a }}$ ed.-Espasa-Calpe, Madrid, 1964. 140 pp. (Austral, 216).

Hurtado de Mendoza: v. núms. 6074-6.

Mármol Carvajal: v. núm. 6075.

Luis de León: v. núm. 7882.

18-7530. Barbadillo, Manuel - Pacheco, su tierra y su tiempo.-Ed. Jerez Industrial, Jerez, 1963.195 pp., láms. II RLit, 23 (1969), 287 (Morales).

18-7531. BARberá, C.-"E1 Padre José de Sigüenza como crítico de arte de las pinturas del monasterio del Escorial". $-C D, 177$ (1964), 86-99.

18-7532. SIGÜENZA, José DE-Historia de la fundación del monasterio del Escorial. Pról. de F. C. Sainz de Robles. -Aguilar, Madrid, 1969. $47^{\circ}$ pp., ilustr. (Col. Evocación y memorias). If $C D$, 117 (1964), $14^{8}$ (Diez del Río); $R A M$, 41 (1965), 505 (Kirchmeyer).

18-7533. Moncada, Francisco de-Expedición de catalanes a Grecia. Adaptación de José Miguel Velloso-Aguilar, Madrid, I96g. 125 pp., ilustr. (El globo de colores).

López Pinciano: v. núm. 5839 .

Tamayo de Vargas: v. núm. 5181 .

18-7534. Selic, K. L.-“Una nota su Dante nella Spagna del secolo diciassettcsimo".-Cono, 3o (1962), 478-479. [BaItasar de Vitoria].

Quevedo: v. núms. 7901-2.

18-7535. Heger, K.-Baltasar Gracián (N. 17-2922). $\mid$ AHSI, 34 (1965), 171 (Batllori); RHM, 3o (1964), 148 (Pollin). 18-7536. Krauss, WERNER-El sentido de la vida según Baltasar Gracian. Trad. de Ricardo Estarriol._Rialp, Madrid, 1963. 304 pp. (Biblioteca del pensa. miento actual).

18-7537. Aranguren, J. L.--"La morale de Gracián".-RMM, 68 (1963), 281 301.-V. núm. 14:41542.

18-7538. Novo, Salvador-“Frutos de la amistad. La amistad en Gracián". Sembradores de Amistad, Monterrey, 18 (1963), núm. 141, 2-4.

18-7539. Batllori, M.- "La agudeza de Gracián y la retórica jesuítica”. $A P C H, 57-6 \mathrm{~g}$.

18-754o. Salas, X. DE-“El Giorgione en Gracián".-EMP, 6, 547-556.

18-7541. Ferrer, O. P. - "A propósito de una interpretación del título del Oráculo manual de Baltasar Gracián". $-H f, 1963$, núm. 19, 61-62. 
18-7542. ViqueIrA, J. M.-“Notas portuguesas en la obra de Gracián”. $-A B P$, 5 (1962), 6-39-V. núm. 17-2832.

18-7543. Camón Aznar, J.- "De Baltasar Gracián a Francisco de Goya".-Ambos Mundos, México, 1 (1962), núm. 4, $79^{-80}$.

Autores modernos

18-7544. Otero Pedrayo, R.-“Coordenadas históricas de la vida del P. Feijoo”. $-B B M P, 40 \quad(1964), 183-197$.

18-7545. Ceñal, R.-"Feijoo, hombre de Ia Ilustración".-ROcc, 7 (1964), 313 334 .

18-7546. Carballo Calfro, R.-“Feixó e a razón borbónica".-Grial, 1964, 409418 .

18-7547. Otero Pedrayo, R.-"Na procura do intimo Mestre Feixóo".-Grial, $1964,159-168$.

18-7548. Colombás, G. M.-"Feijoo y el lulismo".-ELu, 7 (1963), 113-130.

18-7549. Feijóo, Bhito Jerónimo-Ideas literarias. Sel. de J. Vila Selma.-Publicaciones Españolas, Madrid, 1963. $43^{8}$ pp. (El libro para todos). || EL, $39^{64}$, núm. 289 (Fernández Pousa); UdA, $4^{1}$ (1964), 331-332 (Péxez Botero).

18-755o. Fernández y Gonzílez, A. R."Ideas estéticas y juicios críticos del P. Feijoo en torno a la problemática del teatro del siglo xvin", $-B B M P$, $4^{\circ}$ (1964), 19-35.

18-7551. SAmoni, C.-"I concetti di gusto e di no sé qué nel Padre Feijoo e la poctica del Muratori".-GSLI, 81 $(1964), 117-124$.

18-7552. Gamallo y Fierros, D. - "La poesía de Feijoo".-BBMP, 4o (1964), $117-165$.

18-75.j3. SAN EMetFrio Y Cobo, M.-"La estética musical del P. Feijoo".-BBMP, 4o $(1964), 99-116$.

18-7554. Yelo Templado, A.-"Feijóo y la música sagrada".-Yermo, 2 (1964), $267 \cdot 279$.

18-7555. Сobo Barquero, J. J.-“El P. Feijoo y las artes del diseño",-BBMP, $40(1964), 167-181$.

18-7556. Muñiz Martín, M. E.-"Feijóo y Asturias".-BIEA, 17 (1963), núm. $5^{\circ}$, 39-74. [Publica tres cartas inéditas].

18-7557. LApoInte, JacQues - Francisco Bacon en la obra del P. Feijoo.-[Tesis, Univ. de Madrid; resumen en RUM, 13 (1964), 594].
18-7558. Cruz, S.-“Feijoo y Lizardi".CCL, 1964, núm. 88, 91-93.

Campomanes: v. núm. 7908.

18-7559. Eximeno, Antonio-"Textos [sobre estética]”. Est. y sel. por J. Espinós Orlando. - RIEs, 21 (1963), 375391 .

18-7560. Garcla de Parenes Aued, GusTAvo-El pensamiento de don Lorenzo Hervás y Panduro. Su significación en las ciencias del espiritu.-[Tesis, Univ. de Madrid; resumen en RUM, 12 (1963), 789-79o].

Jovellanos: v. núms. 7918-20.

Martínez Marina: v, núm. 7919 .

Forner: v. núm. 5934.

18-7561. Espoz y Mina, F.-Memorias (N. $17-6546) . \| P h Q, 43(1964), 521$ (King).

Alcalá Galiano: v. núm. 7187 .

18-7562. Miraflores, MARQuÉs DE - Memorias del reinado de Isabel II. Ed. y est. prel. de Manuel Fernández Suárez.-Atlas, Madrid, 1964. 3 ts.: xxiv + $35^{\circ}, 498,490$ pp. (BAE, 172-174).

18-7563. Lozano, M.-"Teoría de la sociedad según De Bonald y Danoso Cortés",-REE, 19 (1963), 335-402.

18-7564. SUÁrez, FEDERICO-Introducción a Donoso Cortés.-Rialp, Madrid, 1964. 273 pp. (Col. Naturaleza e historia, 9). i) RLit, 25 (1964), 234.236 (Benitez Claros); $T R, 1964$, núm. 197, 144.146 (Brierre); $A H, 1964$, núms. 126/7, $19^{6-198}$ (Madrazo y Madrazo); REP, 1964, núm. 138, 256 (Morodo); EstF, 14 (1965), 416 (Riezu).

18-7565. Schmitr, CARL - Interpretación europea de Donoso Cortés. Trad. de Francisco de Asís Caballero, pról, de Ángel López Amo. - Rialp, Madrid, 1963. 137 pp. (Biblioteca del pensamiento español). - V. núms. 8-19243, 8-13252.

18-7566. Donoso CorTÉs, JuAn-Il potere cristiano. Trad. L. Cipriani-Panunzio. -Marcelliana, Brescia, 1964. 374 pp.

V. también núms. 5934, 7491.

18-7567. Durán NoGUer, JUAN-Tributo de Vich a Balmes.-Patronato de Estudios Ausonenses, Vich, 1963. 28 pp., láms. [Separata de Ausa, núms. $45 \mathrm{y}$ $46]$.

I 8-7568. Muñoz VÁzQuez, A.-“La cuestión del principio y fundamento en la filosofía de Balmes". $-H u N L, 4$ (1963), 97-113.

18-7569. Amrgo, C.-."Introducción a la psicología de Balmes”. - VyV, 1964, núm. 85 . 
18-7570. JMménez Quílfz, Manuel - Vi. gencia del pensamiento periodistico de Balmes en la era de la información es. pacial.-Magerit, Madrid, $1964.35 \mathrm{pp}$. 18-7571. Sainz de Robles, F. C.-Balmes. Estudio y antologia.-Cía. Bibliográfica Española, Madrid, 1964. 222 pp. (Un autor en un libro).

18-7572. BALMES, JAMre-El criterio. $9^{\text {a }}$ ed.-Espasa-Calpe, Madrid, 1964. 262 pp. (Austral, 71).-V. núm. 16-49524.

Larra: v. núms. $7927-31$.

18-7573. BONEU FARRÉ, E. J.-"Castelar y la fórmula de progreso".-REP, 1962, núm. 124, 99-132.

V. también núm. 7922 .

Giner: v. núm. 6222.

18-7574. Azcárate, P. DE-"El idcario político de Gumersindo de Azcárate".ROcc, 2 (1963), 285-3o7.

18-7575. Tzitsikas, Helene-Las obras literarias de Santiago Ramón y Cajal: el tema de la voluntad.-[Tesis, Northwestern Univ; resumen en $D A, 24$ $(1963-64), 3734]$.

18-7576. Ramón Y Cajal, Santiago Guentos de vacaciones. $5^{\text {at }}$ ed.-EspasaCalpe, Madrid, 1964. 290 pp. (Austral, 241).

18-7577. Ramóx y Cajal, Saxtiago-Los tónicos de la voluntad. 8? ed.-EspasaCalpe, Madrid, 1963. 201 pp. (Austral, 227).-V. núm, 11-28829.

18-7578. Río, A. DEL-"El sentido integrador en la obra de Menéndez Pelayo".HDA, 3, 185-219. | ZRPh, 80 (1964), 585 (Kröll) .

18-7579. Laf́n Evtralco, P.-"Menéndez Pelayo y el mundo clásico". - Map, 1963 , núm 1, 56-68; $M P, 1963-64$, núms. $437 / 4^{\circ}, \quad 28 \check{3}-303$.

18-7580. Herkíndez V'ista, E.-"Los escritores hispanorromanos: prejuicio $y$ juicio estético de Menéndez Pelayo".RLit, 26 (1964), 5-33.

18-7581. VENY ROCA, M.-"El Escorial y Menéndez Pelayo".-NEt, 1963, núms. $26 / 27,147^{-1} \check{5}^{2}$.

18-7582. Fuente, A. DF $\mathrm{x}$ A - Menéndez Pelayo y Jaén".-BIEG, 8 (1962), 9* 185.

18-7583. Menéndez Pfrayo, M.-Antologia general (N. 12-3405o). || Fin, 1963. núm. $37,81-85$ (Lira).

18-7584. Menéndez Pelayo, MarcelinoLa filosofia española. Sel. y cstudio prel. de C. Láscaris. $2^{\mathrm{a}}$ ed.-Rialp, Madrid, 1964. 468 pp. (Bibl. del pensamiento actual).-V. núm. 10-21616.
18-7585. Menéndez Pelayo, MarcelinoDiscursos, 2a ed. - Espasa-Calpe, Madrid, 1964. 182 pp. (Clás. cast., 140).V. núm. 12-34052.

18-7586. López Estrada, F.-"Epistolario de Menéndez Pelayo: sus cartas a Servando Arboli".-RLMo, 3 (1964), 839o.-Y. núm. 14-39572.

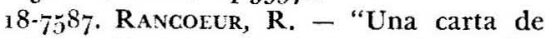
Dom Guépin a Menéndez Pelayo".Yermo, 1 (1963), 223-23o.

V. también núms. $4296,8_{14} 8$.

18-7588. Lerroux, Ale Jandro-Mis memorias.-A. Aguado, Madrid, 1963. $65^{2}$ pp.

Unamuno: v. núms. 7014, 7104, 8081, $813^{0}-43$.

18-7589. Conde Gargollo, E. - "Āngel Ganivet y su destino histórico".-CuH, $58(1964), 51-71$.

18-7590. Herrero, J.- "Ganivet y su Canciller en Amberes".-RHM, 30 (1964), $271-278$.

18-7591. Ganivet, Ángel-Idearium espapañol-Aguilar, Madrid, 1964. 144 pp. (Ensayistas hispanicos). \|USF, 1964, núm. 6o, 368-369 (Rivacoba).

18-7592. Ganivet, Angel-Ideario. Sel. de García Mercadal. Pról. de E. Gascó Contell. - Afrodisio Aguado, Madrid, 1964. 372 pp. (Clásicos y maestros).

18-7593. Ganint, Ánger-Le génie de l'Espagne. [Idearium español, El porvenir de España]. Trad. par Robert Pellet. - Les Eds. du Scorpion, Paris, 1964 .

18-7594. SHaw, D. L.-“Ganivet's España filosófica contemporánea..." (N. 14. $4^{1560)}$. II BICC, $19(1964), 3^{67}$ (Valderrama Andrade).

18-7595. Agudiez, J. V.-“Introducción a las novelas de Ángel Ganivet".-DHR, 2 (1963), 33-47.

18-7596. VENDROUX, JACQUelne-L'utopie satirique chez Ganivet d'après "La conquista del reino de Maya".-[Diplôme d'études supéricures, Univ. de Paris, $1955]$.

18-7597. Ollyar Bertrand, Rafael-Prat de la Riba.-Aedos, Barcelona, 1964. 425 pp. (Biblioteca biográfica Aedos).

Azorín: v. núms. 8200-5.

18-7598. Carro, V. - "El Ramiro de Maeztu que yo conocí". $-P E$, núm. 102, $78-92$.

18-7599. Wrlson, F. G. - "Ramiro de Maeztu: crítico de la revolución".$P E$, 1964, núms, $97 / 98,66-85$.

V. también núms. $5^{8} 5^{1}, 7030$. 
18-7600. Zamacois, EduARdo-Un hombre que se va... (Memorias).-AHR, Barcelona, 1964. $5^{10}$ pp. (Col. 4 al año).

18-7601. Díaz de CFrio, F.-"Vuelve Eugenio d'Ors, 1882-1954". - Pens, 20 $(1964), 449-466$.

18-7602. Arcay, L. A.-“Eugenio d'Ors". -Azor, 1964, núm. 17 .

18-7603. Riera Claville, Manufl-Eatgenio d'Ors y la unidad moral de Europa--Academia del Faro de San Cristóbal, Barcelona, 1963. 19 pp.

18-7604. Vitrer, M.-“La filosofía de Eugenio d'Ors".-[En su libro] Valoracio. nes, t. 2 (La Habana, 1961), pp. $264_{4}$ 274 .

18-7605. Zapatero, J. C.-"El Escorial y cl pensamiento de Eugenio d'Ors".NEt, 1969, núms. 26/27, 162-168.

18-7606. Rojo PÉrez, Erundino-La ciencia de la cultura. Teoria historiológica de Eugenio d'Ors.-Juan Flors, Barcelona, 1963. 28 pp. IS Salm, $11(1964)$, $603-604$ (Flórez); EstF, 13 (1964), 657 (Montull).

18-7607. D'ORS, EUGENIO-Introducción a la critica de arte. - Aguilar, Madrid. 1963. $14^{8} \mathrm{pp}$.

18-7608. D'Ors, Eugenio - Lo barroco.Aguilar, Madrid, 1964. 162 pp.

18-76og. D'Ors, Eugenio - Goya, Picasso. Zabaleta.-Aguilar, Madrid, 1964. 176 pp. II $B C B, 8$ (1965), 1673-77 (Cortés).

$\checkmark$. también núms, 5336, 5344-5, 5347, 6268,7614 .

Pérez de Ayala: v. núms. 7381-3, 8184 . 18-76ı. ROA, R.-"Filósofo en entredicho".-[En su libro] Retorno a la alborada (La Habana, 1964), t. 1, pr. $442-454$. [Ortega y Gasset].

18-7611. Ortega y Gasset, Manuel-Ni. ñez y mocedad de Ortega.-Clave, Madrid, 1964. 105 pp., ilustr.

18-7612. Zambrano, M. - "Un frustrado Pliego de cordel de Ortega y Gasset".$P S A, 30 \quad$ (1963), 187-196.

18-7613. GuY, Alain - Ortega y Gasset, critique d'Aristote. L'ambiguïté du mode de pensée péripatéticien jugé par le ratio-vitalisme.-Privat, Toulousc, 1963.204 pp. $\| C D, 117$ (1964), $15^{8}$ (Alvarez Turienzo); REG, 77 (1964), 612 (Aubenque); Arb, $5^{8}$ (1964), 102.104 (Caravaca); Ins, 1964, núm. 207 (Carpintero); Rev. Thomiste, 66 (1966), 130-132 (Courtés); Yermo, 3 $(1965), 42$ (I. M. G.); $B H i, 65$ (1963), 426 (Llinarès).

18-7614. Qüestions de filosofia. Camis.
Sartre - Ortega - d'Ors - Torres - Descartes - Llull... - Edit. Franciscana, Barcelona, 1964. 149 pp. (Criterion, 21).

18-7615. Olasagasti, T. - "La pregunta biográfica. Heidegger y Ortega".-PSA, $33(1964), 243-266$.

18-7616. RAmírez, S.-Ortega y el núcleo de su filosofia (N. 16-45335). \| Pens, 19 (1963), 503-504 (Martinez).

18-7617. Martins Prata, Francisco XaVIER P.-Dialéctica da razão vital (intuição originária de José Ortega y Gas. set). - Morais, Lisboa, 1962. $4^{\text {oo }} \mathrm{pp}$. (Col. Cultura) . II Ocid, 7o (1966), 120121 (Pinharanda Gomes); ROcc, 4 (1964), 369-371 (Vita).

18-7618. Karieva-Ugrinovich, V. B.- [“El carácter reaccionario de la concepción del hombre en la filosofía de Ortega y Gasset'].-Filos. Nauki, 1964, núm. $6,119-126$.

18-7619. Gaete, Arturo-El sistema maduro de Ortega.-Fabril Editora, Buenos Aires, 1962. 290 pp. (Col. Idea del hombre). || PhM, 1964, núm. 29, 66 (Ceriotto) ; CyF, 21 (1965), 3-7 (Edwards); Pens, 20 (1964), 237-238 (Gómez. Caffarena).

18-7620. Rodríguez HuÉscar, A.-"El concepto central del perspectivismo orte. guiano". - Diálogos, Univ. de Puerto Rico, 1 (1964), núm. 1, 69-79.

18-7621. Merino, L.- "La vida humana, el mundo y el ser fundamental en Ortega".-RevFil, 23 (1964), 51-78.

18-7622. Goyenechea, Francisco-Lo individual y lo social en la filosofia de Ortega y Gasset.-Pas-Verlag, Zürich, 1964 .

18-7623. Agulla, J. C.- "La contribución de Ortega a la teoría sociológica".$H u, 5$ (1962), 166-168.

18- 7624 . Gonzál.ez Caminero, N.-“Metafísica de la realidad radical y sociología de la cultura en el último Ortega y Gasset".-Pens, $20(1964), 173$. 204 .

18-7625. Abellán, J. L. - "Ortega y el aristocraticismo burgués".-BISD, 1964 , núm. 32, $165^{-174}$.

18-7626. Levi, S.-["La teoría de Ortega y Gasset sobre la élite, apología de la oligarquía financiera"']. - Filosofika Misl, 13 (1963), 334-344. [En búlgaro]. 18-7627. Levi, S.-["La filosofía de la historia según Ortega y Gasset"].-Izvestija Inst. po Filozofija, Sofija, 8 (1969), 201225. [En búlgaro]. 
18-7628. Hifrro SÁnchez-Pescador, José -El derecho en Ortega.-[Tesis, Univ. de Madrid; resumen en $R U M, 13$ $\left.(1964), 749-75^{\circ}\right]$.

18-7629. López MENDEL, Jesús-Ortega en el pensamiento juridico contemporáneo. -Eds. del Movimiento, Madrid, 1963. 147 pp.

18-763o. Giusso, Rubén Oscar-El pensamiento estético de Ortega. - [Tesis, Univ. de Madrid; resumen en RUM, $13(1964), 576]$.

18-7631. WEBER, F. - "An approach to Ortega's idea of culture: the concept of literary genre".- $H R, 32$ (1964), 142156.

18-76g2. Young D., Claudr-El concepto de educación en José Ortega y Gasset.-[Tesis, Univ, de Madrid; resumen en $R U M, 13(1964), 581]$.

18-7633. Corrigan, R. - “La misión pedagógica de José Ortega y Gasset".APCH, 231-237.

18-7634. Corrigan, R. - "José Ortega y Gasset: master teacher". - KFLQ, 10 (1963), $129-132$.

18-7635. Marfas, J.-“"Ortega ante el paisaje español".-Lect, $159 \quad(1964), 123$ 127.

18-7636. González Caminero, N. - "El Ortega póstumo".-AION-R, 5 (1963), $127^{-1} 7^{2}$.

18-7637. Ortega y Gasset, José - Obras completas. T. 4. $7^{\text {a }}$ ed.-Revista de Occidente, Madrid, 1964. 560 pp.-V. núm. 17-6498. || Era, ${ }_{16}(1964), \quad 590-592$ (Bernard-Maitre).

18-7638. ORTEgA Y GASSET, José - Obras completas. T. 5. $6^{\mathrm{a}}$ ed.-Rev. de Occi dente, Madrid, 1964. 636 pp.-V. núm. 17-2892.

18-7639. Ortega y Gasset, José - Obras completas. T. 7. $2^{3}$ ed.-Rev. de Occidente, Madrid, 1964.580 pp.-V. núm. 17-2893.

18-7640. Ortega y Gasset, José-La disumanizzazione dell'arte. 'Trad. di S. Battaglia.-Edizioni di Ethica, Forli, 1964 . $5^{1}$ pp. II IS, $4^{8}$ (1965), 353 (Rossi). 18-7641. ORTEGA Y Gasset, José-Gott in Sicht.-Deutsche Verlags-Anstalt, Stuttgart, 1964. 180 pp. \|W WeW, 19 (1964), 301-302 (Mühlberger).

18-7642. ORTEGA Y GASSET, José-En torno a Galileo.-Espasa-Calpe, Madrid, 1964. $24^{\circ}$ pp. (Austral, 1365). $\| A r A$, 59 (1965), 268 (Dominguez); $R y F, 173$ (1966), 659-66o (Micó Buchón).

18-7643. ORTEGA Y GASSET, José-Espiritu de la letra. - Espasa-Calpe, Madrid, 1964. 218 pp. (Austral, 1370). \| ArA, 59 (1965), 267 (Dominguez).

18-7644. ORtega y Gasset, JosÉ-El espectador. 2 a ed.-Rev, de Occidente, Madrid, $1963-64.2$ ts.: 236, 180 pp. (El arquero).-V. núm. 16-49597.

18-7645. ORTEGA Y GASSET, José-Estudios sobre el amor.-Espasa-Calpe, Madrid, 1964. 234 pp. (Austral, 1338).

18-7646. ORTEGA Y GASSET, José-Estudios sobre el amor, $15^{\text {a }}$ ed.-Revista de Occidente, Madrid, 1964. 6o pp. (El arquero).-V. núm. 18-3848. \|BAbr, 39 $(1965), 201$ (Silverman).

18-7647. Ortega y Gasset, José-El hombre y la gente. $4^{\mathrm{a}}$ ed.-Rev. de Occi dente, Madrid, 1964.2 ts.: 188,216 pp. (El arquero).-V. núm. 17-6506.

18-7648. ORtega Y Gasset, Josḱ-Ideas y creencias. $7^{\text {a }}$ ed. - Espasa-Calpe, Madrid, 1964. 209 pp. (Austral, 151).-V. núm. 16-45366.

18-7649. Ortega X Gasset, José-Meditación del pueblo joven.-Espasa-Calpe, Madrid, 1964. 164 pp. (Austral, 1354). 18-7650. Ortega y Gasset, José-Meditación de la técnica. $5^{\mathrm{a}}$ ed.-Rev. de Occidente, Madrid, 1964. 168 pp. (El arquero).-V. núm. 16-49604. $A r A, 59$ (1965), 266-267 (Domínguez); $R y F, 173$ (1966), 66o (Micó Buchón).

18- 7651 . Ortega y Gasset, José-Medilación de la técnica.-Espasa-Calpe, Madrid, 1964. 142 pp. (Austral, 1360).

18- 7652 . ORTEgA X GASSET, José-Medilaciones del "Quijote". $7^{\text {a }}$ ed. - Revista de Occidente, Madrid, 1963. 208 pp. (Col. El arquero).-V. núm. 16-49607.

18-7653. ORTEgA y GAsset, José-Meditaciones del "Quijote". Ideas sobre la novela. - Espasa-Calpe, Madrid, 1964. 214 pp. (Austral, 1350).

18-7654. ORTega x GASSET, JosÉ-Meditations on Quixote. Transl. by Evelyn Rugg and Diego Marín.-W. W. Norton, New York, 1963. 192 pp.

18-7655. Ortega y Gasset, José-Mocedades. 6 ${ }^{\text {a }}$ ed. - Espasa-Calpe, Madrid, 1964. 156 pp. (Austral, 201).

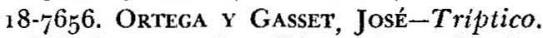
Mirabeau o el politico. Kant. Goethe. $5^{3}$ ed.-Espasa-Calpe, Madrid, 1964 . 178 pp. (Austral, 181).-V. núm. 1441596.

18-7657. Ortega y Gasset, José-El tema de nuestro tiempo. 11a ed.-EspasaCalpe, Madrid, 1964. 156 pp. (Austral, 11).-V. núm. 17-2904. 
18-7658. Ortega y Gasset, José-La rebelión de las masas, $16^{\mathrm{a}}$ ed.-Espasa-Calpe, Madrid, 1964. 213 pp. (Austral, 1).-V. núm. 17-2902.

18-7659. Ortega x Gasset, José - Notas. $9^{\text {a }}$ ed.-Espasa Calpe, Madrid, 1964. 158 pp. (Austral, 45).-V. núm. 1024094 .

18-7660. Ortega y Gasset, J.-Una inter. pretación de la historia universal (N. $\left.17-65^{11}\right)$. \| ROcc, $5 \quad\left(19^{64}\right), 35^{6-357}$ (Toynbee).

18-7661. Ortega Y Gasset, José - Velázquez. $5^{\text {a }}$ ed.-Revista de Occidente, Madrid, $1963.10_{5}$ ilustr. y $65^{\circ}$ pp.-V. núm. $17-2907$.

18-76062. ORTEGA Y GASSET, JosÉ-Velázquez. $4^{\text {a }}$ ed.-Rev. de Occidente, Madrid, 1963. $25^{\circ}$ pp. (Col. El arquero).V. núm. 14-41597.

18- 7663 . "Epistolario de Ortega con $\mathrm{Ma}$ ragall".-ROcc, 6 (1964), $261-271$.

18-7664. "Epistolario entre Unamuno $y$ Ortega".-ROcc, 7 (1964), 3-28.

V. también núms. 5409, 5866, 7104, 8036-7.

18-7665. Cataluña al doctor Marañón. In memoriam. - Diputación Provincial, Barcelona, 1964. viii +215 pp., ilustr. [ 32 colaboraciones].

18-7666. GüELL, C.-“"Marañón y nuestra tarea colectiva".-CuD, 1964 , núm. 7 .

18-7667. Marañón, Gregorio-Amiel. 10 a ed.-Espasa-Calpe, Madrid, 1964. $23^{\circ}$ pp. (Austral, 408).-V. núm. $17-65^{27}$.

18-7668. Marañón, Gregorio-El empecinado visto por un inglés. $5^{\text {a }}$ ed.-Espasa-Calpe, Madrid, 1964. ${ }^{1} 5^{8}$ pp. (Austral, 36o).-V. núm. 14-39504.

18-7669. Marañón, Gregorio-Raiz y decoro de España. $3^{\text {à }}$ ed.-Espasa-Calpe, Madrid, 1964. 160 pp. (Austral, 1111). -V. núm. 16-45429.

18-767o. Marañón, Gregorio - Tiberio. Historia de un resentimiento. $9^{\mathrm{a}}$ ed.Espasa-Calpe, Madrid, 1963. 317 pp. (Grandes biografias).-V. núm. 17-2928.

V. también núm. 5913.

18-7671. Russell, P. E. - "Don Alberto Jiménez (1883-1964)".-BHS, 41 (1964), $247^{-248}$.

Bergamín: v. núms. 8246-7.

18-7672. Guy, A.- "La théorie de la «religation selon Xavier Zubiri".-BHi, 66 (1964), 391-395.

18-7673. ZaragüetA, J.-“Una obra de Javier Zubiri".-RevFil, 21 (1962), $255^{-}$ 279 .

18-7674. Nó́ Ceballos, F. S. C. - "Idea zubiriana del hombre". - $\mathrm{CuH}$, 6o (1964), 419.430.

18-7675. Artola, J. M.-"En torno a Sobre la esencia de Javier Zubiri".-Es. tudios Filosóficos, 12 (1963), 297-332. 18-7676. Laín Entralgo, Pedro-La espera y la esperanza. $3^{\mathrm{a}}$ ed.--Revista de Occidente, Madrid, 1963. 620 pp. $-\mathrm{V}$. núm. 14-39508. || Asom, 1965, núm. 1, 86-89 (Zavala).

18-7677. Laín Entralgo, P. - Teoria $y$ realidad del otro (N. 17-6533). II Era, 16 (1964), 718-719 (Bernard-Maitre).

18-7678. Toledo PizA, D. R. DE-“Encontro com Julián Marías".-Rev. Brasi. leira de Filosofia, 12 (1962), 229-232.

18-7679. Vilar, S. - "Julián Marías and the intelligentsia in Spain".-BAbr, 37 (1963), $252-260$.

18-7680. Iglesias, I.--"Marías o la fe en el liberalismo".-MN, 1963, núm. 9, $69-71$.

18-7681. Blanco Amor, J.--"España como tarea en Julián Marías".-CuH, 53 (1963), $543-55^{\circ}$.

18-7682. Marías, Julí́n - Los españoles. $2^{\mathrm{a}}$ ed.-Revista de Occidente, Madrid, 1963. 360 pp. - V. núm. 17-6537. il RHM, 3o (1964), 144 (Pollin); $B H i$, 66 (1964), 467-469 (Ricard).

18-7683. Marías, Julián-Filosofía espa. ñola actual. $4^{\text {a }}$ ed. - Espasa-Calpe, Madrid, 1963. 200 pp. (Austral, 804).-V. núm. $12-30462$.

18-7684. Marfas, Julián-El tiempo que ni vuelve ni tropieza.-Edhasa, Barcelona, 1964. $236 \mathrm{pp}$. (El puente). $\| B A b r$, 39 (1965), $33^{2}$ (Beerman); Ins, 1964, núm. 215 (Cano); CCL, 1964, núm. 91, 87-88 (Iglesias).

18-768 . Ferrater Mora, José-Tres mundos: Cataluña, España, Europa.-Edhasa, Barcelona, 1963. 193 pp. (El puente). \| CCL, 1964, núm. $85,82-83$ (Olaso); $R O C c, 7$ (1964), 250-251 (Scuderi).

\section{LITERATURA RELIGIOSA}

18-7686. Corrientes espirituales en la España del siglo xvi. Trabajos del II Congreso de Espiritualidad. - Juan Flors, Barcelona; Universidad Pontificia, Salamanca, 1963 . viii $+5^{67}$ pp. II Salm, 10 (1963), 479-48o (Jiménez Duque).

18-7687. Valbuena Prat, Angel - Estudios de literatura religiosa española. Epoca medieval y Edad de Oro.-Afrodisio Aguado, Madrid, 1964. 282 pp. (Col. Clásicos y maestros).-- V. núm. 12 - 
33876. || RLit, 26 (1964), 207 (Garrido Gallardo); PEsp, 1964, núm. 142 (Murciano).

18-7688.-Ortiz EchagüE, José - España mistica. $4^{\text {a }}$ ed.-Madrid, 1964 .

18-7689. CoRuña, S. DE LA-“En torno a los místicos".-NG, 10 (1963), 81-94.

18-76go. Peters, C., \& A. Ruiz-"I mistici spagnoli".-[En] Il pensiero della Rinascenza e della Riforma, t. 9 (Milano, 1964), 2329-2446.

18-7691. Jiménez DuQue, Baldomero Teología de la mistica.-Ed. Católica, Madrid, 1963. 526 pp. (BAC, 225). $R A M, 40$ (1964), 357-36o (Gensac).

18-7692. Zolla, Elémire (ed.)-I mistici. -Garzanti, Milano, 1963. 1620 pp. \|EC, 15 (1964), 466-467 (Cruz).

18-7693. GILMONT, J. F.-Les écrits spirituels des premiers jésuites (N. 17-6559). I| Rev. d'Hist. de l'Église de France, 19 (1963) , 117-119 (Bernard-Maitre); $R E$, 23 (1964), 324-325 (Fortunato de J. Sacramentado); RHE, 59 (1964), 344-345 (Ruysschaert); GuL, $3^{6}$ (1963), 395-396 (Silberer); HJ, 85 (1965), 206-207 (Zeeden).

18-7694. Saco Alarcón, J. - "Espiritualidad sacerdotal en los jesuitas españoles del siglo xvir".-MisCo, 39 (1963), 209-296; 4o (1963), 81-204.

18-7695. Przywara, ERICH-Teologúmeno español. Trad. de A. López Quintas.Guadarrama, Madrid, 1962. $188 \mathrm{pp}$. [San Ignacio, Santa Teresa, San Juan de la Cruz, Cervantes].-V. núm. 1128973. $\| C D, 175$ (1962), 777 (García Merino); $R y F, 170$ (1964), 515-516 (Iturrioz); RAM, 41 (1965), 229-230 (Kirchmeyer); $E M, 19$ (1963), $145^{-1} 4^{8}$ (Tourón).

18-76g6. Baraut, C.-"Les fonts franciscanes dels escrits de Garcias de Cisneros".-AMon, 9 (1962), 65-78.

18-7697. Marín Martínez, T.-"E1 Calalogus sanctorum episcoporum del obispo Bernal Díaz de Luco". - HS, 16 (1963), $373-45^{8}$.

18- 7698 . Ros, F. DE-“Alonso de Madrid et Louis de Blois".-LR, 17 (1963), $111-121$.

18-7699. León, Pablo de-Guía del cielo. Est. prel. y ed. de Vicente Beltrán de Heredia.-Flors, Barcelona, 1963. xviii 630 pp. (Espirituales españoles, 11). RLit, 23 (1963), 284-285 (Díez Taboada); VyV, 22 (1964), 741 (Meseguer).

18-7700. Barrado Manzano, A.-“"La casa donde nació San Pedro de Alcántara, convertida en iglesia".-AIA, 23 (1969), $267-298$.

18-7701. Pedro de Alcántara, San - Le chemin secret de l'oraison. Adaptation française du Tratado de la oración par W. Bédard et L. Poirier.-[Paris, $1963 \%$. II $R A M, 4^{\circ}$ (1964), 120-121 (Gensac). 18-7702. Jones, W. B.-Constantino Ponce de la Fuente: the problem of protestant influence in sixteenth-century Spain.-[Tesis, Vanderbilt Univ., 1964]. 18-7703. Ávila, Juan de-Avisos y reglas cristianas sobre aquel verso de David: "Audi, filia". Introd. y ed. de L. Sala Balust. Apéndice con textos de Pedro Fernández de Córdoba, Juan de la Peña y Juan de Ávila.-Juan Flors, Barcelona, 1963. xii +347 pp. (Espirituales españoles, 10). U Man, 35 (1969), 358359 (Arias); EM, 19 (1963), 358-359 (Diaz); VyV, 22 (1964), 741 (Meseguer); RyF, 169 (1964), 211 (Puig); RLit, 23 (1963), 283 (Rozas); NG, 11 (1964), 161162 (Santiago de la Coruña).

18-7704. Navarro Santos, Jesús-La reforma de la Iglesia en los escritos del maestro Avila. Su enfoque teológico.Facultad de Teología, Granada, 1964 . $\mathbf{x v}+367 \mathrm{pp}$

18-7705. VÁzQuez, M. - "Fray Luis de Granada en Portugal".-LFr, 17 (1964), 9-22.

18-7706. Oechslin, Raphael Louis-Louis of Granada.-Herder \& Herder, New York, 1963. 142 pp. - V. núm. 1024159.

18-7707. GonzÁlez-Bardallana, N. - "El ministro de la palabra, según la doctrina de fray Luis de Granada". $R E T, 23$ (1963), 61-75.

18-7708. Granada, LuIs DE-Historia de Sor Maria de la Visitación y sermón de las caidas públicas.-J. Flors, Barcelona, 1962. 430 pp. \| $M C, 71$ (1963), 291-293 (Julio Félix del Niño Jesús); $E M, \quad 19$ (1969), 179-180 (Medina Zahara); $V y V, 22$ (1964), 740 (Meseguer); RLit, 22 (1962), 268-269 (Rozas).

18-7709. Tellechea Idígoras, J. I. - "La biblioteca del arzobispo Carranza”. $H S, 16$ (1963), 459-499.

18-7710. Tellechea Idígoras, J. IgnacioFray Bartolomé de Carranza. Documentos históricos. Pról. de G. Marañón. T. 1: Recusación del Inquisidor general Valdés. T. 2 [dos partes]: Testificaciones de cargo.-Real Academia de la Historia, Madrid, 1962-63. (Archivo documental español, 18, 19). 
18-7711. Tellechea, J. I.-"El obispo de León, D. Andrés Cuesta, y el proceso de Carranza".-ALeon, 1962, núm. 31, $59-83$.

V. también núm. 6829 .

18-7712. Elizalde, Ignacio-San Ignacio de Loyola.-Sánchez Rodrigo, Plasencia, 1963. $140 \mathrm{pp}$. (Hijos ilustres de España, 31).

18-7713. Bottereau, G.- "Un portrait de S. Ignace de Loyola”.-RAM, 39 (1963), 419-432.

18-7714. Momfrgue, M. - "Un point de vue sur l'itinéraire d'Ignace de Loyola". - Prière et Vie, Toulouse, 137 (1962), 40 $7-412$.

18-7715. Silos, L. R.- "Cardoner in the life of Saint Ignatius of Loyola”.-AHSI, 33 (1964), 3-43.

18-7716. Gulllermou, Alain - San Ignacio de Loyola y la Compañía de Jesús. Trad. de Isabel Llacer.-Aguilar, Madrid, 1963. 232 pp. (Hombres de espiritu).-V. núm. 17-3029.

18-7717. Petri, Laura - Ignatius Loyola. En bok om att hjälpa själar. Inledning av Gunnar Hillerdal.-Natur och Kultur, Stockholm, 1963. 305 pp.

18-7718. Pöschl, Matthias-Ignatius von Loyola.-L. Auer, Donauwörth, 1963 . 88 pp.

18-7719. Bainton, R. H. - "St. Ignatius Loyola's methods of religious teaching". -[En sus] Studies on the Reformation (Boston, 1963), 242-247.

18-7720. IPARRAGUiRre, I. - Répertoire de spiritualité ignatienne (N. 17-6661). U Rev. d'Hist. de l'Église de France, 49 (1963), 117-119 (Bernard-Maitre); ReSR, 51 (1969), 330-331 (de Certeau); Sciences Eccl., 15 (1963), 308-309 (Cusson); $R E, 23$ (1964), 325 (Fortunato de Jesús Sacramentado); $R A M, 39$ (1963), 116-117 (Gensac); CHR, $4^{8}$ (1962-63), 514-515 (Larkin); BHS, 40 (1963), 56-57 (McClelland); RHE, 59 (1964), 345 (Ruysschaert); GuL, 36 (1963), 395-396 (Silberer).

18-7721. Gutbert, JosePh DE-[La espiritualidad de San Ignacio].-Chuô Shuppansha, Tokyo, 1963. 267 pp.

18-7722. Labourdette, M. M.-“Spiritualité ignatienne"".-Rev. Thomiste, $6_{4}$ (1963), 628-631.

18-7723. Maruca, Dominicus - Instruments in the hand of God. A study in the spirituality of St. Ignatius Loyola. -Universitas Gregoriana, Roma, 1963. 8o pp.
18-7724. Penning de Vries, Pift-Ignatius of de spiritualiteit der Jezuïeten. -Lannoo, Tielt-Den Haag, 1964. 200 pp. || AHSI, $33(1964), 365-366$ (Iparraguirre); $O G E, 38$ (1964), 439-440 (L. M).

18-7725. Iparraguirre, Ignacio - Tracce ignaziane per un impegno cristiano. Itinerario dello spirito. Trad. di Enzo Farinella. - Ảncora, Milano; Cenacolo, Brescia, 1963. 211 pp.

18-7726. Junco, A.- "El San Ignacio desconocido: otro Francisco de Asís". Abs, 28 (1964), $15^{8-169 .}$

$18-7 \% 2 \%$. MARXer, Fridolin - Die inneren geistlichen Sinne. Ein Beitrag zur Deutung ignatianischer Mystik. - Herder, Freiburg, 1963. 208 pp. \| RAM, 40 (1964), $375-376$ (de Gensac); AHSI, 33 (1964), 362-364 (Iparraguirre); Scholastik, $4^{\circ}$ (1965), 316-317 (Winkes).

18-7728. RAHNER, K. - "De ignatiaanse mystick van de beaming der wereld".[En] Nieuwe theologische verkenningstochten (Haarlem, 1961), 189-211.

18-7729. Guerrero, E. - "San Ignacio de Loyola y espíritu ecuménico".-Cris, 21 (1964), 248-249.

18-7730. Sola, J.-"Przywara. Su teologia de la Pasión".-RE, 23 (1964), 210. 228. [Sobre San Ignacio].

18-7731. UllmanN, W. H. - "Obduziert wurde: Ignatius von Loyola".-Medizi. nische Welt, Stuttgart, 1969, $175^{8-}$ 1763 .

18-7732. RHeinfelder, H. - "Ignatius of Loyola and Martin Luther in modern German criticism". - LHC, 29o291. [Y versión portuguesa, Symposium, 5 (1963), 72-87].-V. núms. 14-41640, 176677 .

18-7733. Achútegur, P. S.-"San Ignacio de Loyola y nuestros hermanos separados".-Christus, México, 1963, núm. 28, $55^{1-5} 57$.

18-7734. Schnemer, B.-"La devozione di S. Ignazio di Loyola verso la Chiesa". - [En] Sentire Ecclesiam, I (Roma, 1964), 505-560.

18-7735. LeWIs, J.-Le gouvernement spirituel selon $S$. Ignace (N. 17-6696). II Salm, 10 (1963), 481 (Adolfo de la Madre de Dios); CC, 1 (1963), $157^{-1} 5^{8}$ (Dumeige); Angelicum, 40 (1963), 131 (Huerga); RyF, 167 (1963), 203 (J. A. S.); $E E, 3^{8}$ (1963), 505-506 (J. M. V.); Antonianum, $3^{8}$ (1963), 123 (Lasic); Z. f. Kath. Theol, 85 (1969), 108 (N.); Gr, 45 (1964), 582-583 (Örsy). 
18-7736. Iparraguirre, I. - "Boletín de Ejercicios ignacianos (1963)". - Man, $3^{6}$ (1964), 347-362.-V. núm. 18-39o8.

18-7737. IGNAcio de Loyola-Obras completas. Ed. manual. Transcripción, introd. y notas de Ignacio Iparraguirre. Autobiografia de S. Ignacio ed. y anotada por Cándido de Dalmases. $2^{\text {a }}$ ed., corr. y aum. - Ed. Católica, Madrid, 1963. xiii +1021 pp. $(B A C)$.-V. núm. 9-1567o. || Stromata, $21(1965), 661-662$ (Fiorito); $A T G, 27$ (1964), 389-39o (Segovia).

18-7738. Ignatius Loyola, Saint - The spiritual exercises. New transl. based on studies in the language of the autograph.-St. Paul Publications, Allabay, Bombay, 1963. 173 pp.

18-7739. Ignatius Loyola, SAINT - The spiritual exercises. Transl. by A. Mottola, introd. by R. W. Gleason.-Doubleday, New York, 1964. 200 pp. (Ima. ge books).

18-7740. Encinas, Antonio - Los Ejerci. cios espirituales de San Ignacio. $4^{\text {a }}$ ed. -Sal Terrae, Santander, 1964. 1059 pp.-V. núm. 12-33939.

18-7741. Hernández García, Eusebio Ejercicios ignacianos completos segin las técnicas últimas de San Ignacio. T. 1: Meditaciones $y$ contemplaciones. $3^{\mathrm{a}}$ ed.-Pontificia Universitas Comillensis, Santander, 1963. xi +983 pp. $\| C D$, 177 (1964), 173 (de la Calle).

18-7742. HARV,ANeK, Robert F. (ed.) -Proceedings of the Institute on the Contemporary Thought and the "Spiritual exercices" of St. Ignatius of Loyola.Loyola Univ., Chicago, 1963. $88 \mathrm{pp}$.

18-7743. Calveras, J. - "Más precisiones sobre la cronología del autógrafo de los Ejercicios".-AHSI, 32 (1963), 322328.

18-7744. Evarn, A.-“S. Ignace et Rosmini: une page peu connue de l'histoire des Exercices au xuxe siècle".$R A M, 39$ (1963), $4^{6} 5480$.

18-7745. SciaccA, M. F.-"Di una intexpretazione dialettica degli Esercizi spirituali di S. Ignazio di Loyola".-[En] Studi sulla filosofia moderna (Milano, 1964$), 67-70$.

18-7746. Pettr, M. - "Evangelios de la infancia y Ejercicios espirituales de San Ignacio".-CyF, 20 (1964), 469480.

18-7747. Domene, Jesús Francisco-Elementos teológicos en los "Ejercicios". Relación "gracia-método-director" a la luz de la teologia espiritual.-Manresa House, Taichung; Sal Terrae, Santander, 1963. 198 pp. $\| C y F, 21$ (1965), 8-9 (Fiorito); AHSI, 33 (1964), 366 (Iparraguirre).

18-7748. AlEU, J.-“La epistemología sobrenatural en los Ejercicios de San Ignacio".- $R E, 23$ (1964), 424-441.

18-m749. Meissner, W. W.-"Psychological notes on the Spiritual exercises. An analysis of the interaction of nature and grace using recent developments in psychoanalytic ego-psychology". $W L, 9^{2}$ (1963), 349-366; 93 (1964), $3^{1-}$ $58,165-191$.

18-7750. Marín, F.-“Aportaciones bíblicas a la contemplación del Reino".Man, 35 (1963), 333-342.

18-7751. Marín, F. - "Fondo escriturario del principio y fundamento". - Man, 35 (1963), 241-250.

18-7752. Solaguren, C. - "La cristología del P. Teilhard de Chardin y el principio y fundamento de San Ignacio".Man, 35 (1963), 5-47.

18-7753. Fiorito, M. A.-“Apuntes para una teología del discernimiento de espiritus".-CyF, 19 (1963), 401-417; 20 (1964), 93-123. II AHSI, 33 (1964), 365 (Iparraguirre).

18-7754. O'Connor, T. R.-“The Ignatian Exercises and the liturgical kerygma". - [En] Liturgy for the people. Essays in honor of Gerald Ellard $S . I$. (Milwaukee, 1963), 38-54.

18-7755. FEsSARD, G.-“Le fondement de l'herméneutique selon la XIIIe règle d'orthodoxie des Exercices spirituels".Archivio di Filosofia, 1963, 203-219.

18-7756. LewINE, M.- "The source of Rubens' Miracles of St. Ignatius".-Art Bull., New York, 45 (1963), 143-147. V. también núms. 7695,8003 .

18-7757. S. Francisco de Xavier, apóstolo das Indias. Memória do passado, 24 de janeiro-24 de fevereiro 1963.-Junta de Investigações de Ultramar, Lis. boa, 1963. $172 \mathrm{pp}$.

18-7758. Xavier acordado.-Missões, Lisboa, 1969, núm. 2; 32 pp. [Núm. dedicado a San Francisco Javier].

18-7759. Schurhammer, Georg - Franz Xaver. Sein Leben und seine Zeit. 2. Bd.: Asien (154I-1552). 1. Halbband: Indien und Indonesien (154I-I547).Herder, Freiburg, 1963. xxx $+85^{2} \mathrm{pp}$. -V. núm. 10-2415o. || GuL, 37 (1964), 395 (Ammann); Nyt fra Historien, 15 $(1964), 114$ (B. B.); Neue Z. f. Mis. 
sionswiss., 20 (1964), 286-292 (Beckmann); AHSI, 33 (1964), 127-130, $85^{2}$ (Boxer); RHE, 60 (1965), $55^{2-554}$ (Combaluzier); Streven, 17 (1964), 1011 (Dierickx); Intern. Rev. of Miss., 54 (1965), 377-378 (Enklaar); Nederl. Theol. Tijdschrift, 19 (1965), 428-429 (Enklaar); Z. f. Kathol. Theol., 87 (1965), 483-484 (Fröhlich); Credo, $4^{6}$ (1965), 136-197 (Gerlach); Z. f. Missionswiss., $4^{8}$ (1964), $15^{1-15^{2}}$ (Glazik); $S Z, \quad 174 \quad(1964), \quad 236-237$ (Hetling); OGE, $3^{8}$ (1964), $216-218$ (L. M.); Se. lec, de Libros, 1 (1964), 284-289 (Llorca); Bro, 79 (1964), 503-504 (Mauricio); NRTh, 86 (1964), 1238-1239 (Mols); Kerk en Missie, 44 (1964), 164 (Parein); Gr, 45 (1964), 657-66o (Schnei. der); $A T G, 27$ (1964), $44^{10-411}$ (Sotomayor); $C_{y} F, 20$ (1964), 332-333 (X); Humboldt, 1964, núm. 19, 76 (X).

18-7760. Schurhammer, Georg-Die Zeitgenössischen Quellen zur Geschichte Portugiesischasiens und seiner Nach barländer zur Zeit des $\mathrm{Hl}$. Franz Xaver $\left(153^{8-1552)}\right.$.-Inst. Historicum, Roma, 1962. xxx + 653 pp. (B. inst. Historici, 20). I| $R y F, 173$ (1966), 655 . $6_{5}^{8}$ (Echánove).

18-7761. Fernandes, José Vicente BaLDOMERo - Jivit $S$. Francisco Xavierachem. - Dias Sapeco, Santa Cruz, Goa, 1964. 112 pp., ilustr.

18-7 762 . Jorge, ENRIQUe - Vida popular de San Francisco Javier. $2^{3}$ ed.-Misión Anking, Palencia, 1964. 143 pp.

18-7763. Montguerre, Jean-Marc - $s t$. Francis Xavier.-Doubleday, New York, 1963. 165 pp. - V. núm. 17-6772.

18-7764. Petrini, Enzo-Il corsaro di Dio (San Francesco Saverio). - La Scuola, Brescia, 1953. 144 pp., ilustr.-V. núm. $11-25616$.

18-7765. Goncet, O.-"François Xavier et le Japon".-TR, 1962, núm. 178, 47-58. V. también núm. 5536 .

18-7766. Saint-Paulien, J.-San Francisco de Borja, el expiador.-Eds. Paulinas, Bilbao, 1963. 320 pp.-V. núm. 17-6757. 18-7767. Lucas-Dubreton, J.-Les Borgia. -Le Livre Club du Libraire, Paris, 1962. 338 pp. [San Francisco de Borja,

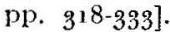

18-7768. Suau, Pedro - Historia de $S$. Francisco de Borja, tercer general de la Compañia de Jesús (1510-1572). Trad. por Amelia del Purísimo Corazón.-Hechos y Dichos, Zaragoza, 1963 . $455 \mathrm{pp}$.
18-7769. Ezpeleta, M.-“E1 diario espiritual de San Francisco de Borja".Man, 35 (1963), 121-132.

18-7770. Dicken, ERIC WILliam T.-The crucible of love: A study of the mysti. cism of St. Teresa of Jesus and St. John of the Cross.-Sheed \& Ward, New York; Darton, London, 1963. 548 pp., ilustr. || $A r A, 59$ (1965), 98-99 (Cilleruelo); EC, 15 (1964), 472-474 (Edwards); BHi, $66 \quad(1964), \quad 418-422$ (Ricard); $L R, 19$ (1965), $141-142$ (Vermeylen); Month, 217 (1964), 121-122 (Walsh); TLS, Jan. 91964 (X).

18-7771. Steinmand, Anne E.-Carmel vivant. Préface de Jean-Pierre de la Trinité.-Éds. Saint Paul, Paris, 1963. 383 pp. $M C, 7^{2}$ (1964), 6o1-604 (Simeón de la $S$. Familia).

18-77テ2. MúJicA, E. - “De la mano de Santa Teresa". $-U d A, 40$ (1963), 540547. [Santa Teresa y San Juan].

18-7773. Krrven, J. - "Du nouveau sur Thomas de Jésus. L'avènement de la mystique des lumières en Espagne $(1601-1607)$ ". $-B H i, 64$ bis (1962), 113135. [Santa Teresa y San Juan de la Cruz]. II LR, $19 \quad(1965), \quad 146-147$ (Groult).

18-7774. Leroy, O.-Sainte Thérèse d'Avila (N. 17-6581). \| RyF, 169 (1964), 99 (Jorge); Pev. Thomiste, Paris, 64 (1964), 335.336 (M. L.); RAM, 39 (1963), 261. 268 (Olphe-Galliard); NRTh, 86 (1964), 87 (Thiry); Rev. Nouvelle, Bruxelles, 39 (1964), 109 (Vandenbrouke); $C y F, 19$ (1963), $530-531$ (X).

18-7775. Thomas, Fr., \& Fr. Gabriel Saint Teresa of Avila. Studies in her life, doctrine and times.-Clonmore \&c Reynolds, Dublin; Burns \& Oates, London, 1963. 249 pp. || EC, 15 (1963), $474-475$ (Fiachra).

18-7776. García y Ortiz de Taranco, F. M.-"Santa Teresa en la crisis del Renacimiento".-[En] Santa Teresa en el IV centenario de la reforma carmelitana (Barcelona, 1963), 97-111.

18-7777. Criado de Val, M.-"Santa Te. resa de Jesús en la gran polémica española: mística frente a picaresca".$R E, 22$ (1963), 376-384.

18-7778. VACA, C.- "La personalidad de Santa Teresa".-RE, 22 (1963), 225237.

18-7779. Nazario de Santa Teresa-“El espíritu teresiano desde una antropologia de la infancia y de la juventud". $-R E, 22$ (1963), 462-481. 
18-7780. Santa Ellalia, Mary G. - Inquieta y andariega. (Santa Teresa de Jesús).-Propaganda Popular Católica, Madrid, 1964. 96 pp. (Lo imposible). 18-7781. Comas, A.- "Fémina inquieta y andariega".-CuH, 53 (1963), 509-5口о. 18-7782. Teresa de Jesús. IV centenario de la Reforma teresiana. - G. Gibert, Tarragona, 1969. 17 hojas, grabs.

18-7783. Santa Teresa. En el IV centenario de la Reforma carmelitana. Ciclo de conferencias en la Universidad de Barcelona, - Universidad, Barcelona, 1963. 119 pp., láms.

18-7784. JUAN Bosco de Jesús-“Congreso nacional de espiritualidad teresiana. (IV Centenario de la Reforma teresiana). Madrid, 16-2o de abril de 1963".-RE, $23(1964), 310-316$.

18-7785. Vázquez de Prada, V.-"La reforma teresiana y la España de su tiempo".-[En] Santa Teresa en el IV centenario de la reforma carmelitana (Barcelona, 1969), 79-96.

18-7786. SAGgI, L. - "Questioni connesse con la riforma teresiana".-Carmelus, 11 (ig64), 161-184.

18-7787. García Villoslada, R. - "Santa Teresa de Jesús y la Contrarreforma católica".-Carmelus, 1o (1963), 231-262.

18-7788. ÁlAmo SALAZAR, A.-“'Antorchas espirituales en la huella de Teresa de Jesús en Palencia"-Publ. de la Inst. Tello Téllez, Palencia, 1963, núm. 23 , 1-20.-V. núm. $17-6591$.

18-7789. EFrÉn de lA MAdre de Dios--"El ideal de Santa Teresa en la fundación de San José". - Carmelus, 10 (1963), 206-23o.

18-7790. Poveda ARIÑo, J. M.-"Enfermedades y misticismo en Santa Tere$\mathrm{sa}^{\prime},-R E, 22$ (1963), $25^{1-266 .}$

18-7791. Fernández Ruiz, C. - "Medicina y médicos en la vida y obra de $S^{\text {a }} \mathrm{Te}$ resa de Jesús",- $R E, 23$ (1964), 186 2og.-V. núm. 18-3949.

18-7792. López IвоR, J. J.--“Ideas de Santa 'Teresa sobre la melancolía". $-R E$, 22 (1963), 432-443.

18-7793. EFRÉN DE LA MAdRE DE DIOS "Teresa de Jesús, sentido de adaptación".-RE, 22 (1963), 267-283.

18-7794. Eulogio de San Juan de la Cruz - "Principios teológicos fundamentales en la doctrina teresiana". - RE, 22 (1963), $521-577$.

18-7795. Morales Oliver, L.-“La espiritualidad de Santa Teresa".-[En] Santa Teresa en el IV centenario de la reforma carmelitana (Barcelona, 1963), $63-77$.

18-7796. EFrÉn dE LA MAdRE DE DIOS"Doctrina y vivencia de Santa Teresa sobre el misterio de la Santísima Trinidad".-RE, 22 (1963), 756-772.

18-7797. Fortunato de Jesús SACramenTADO-"Doctrina teresiana del amor de Dios".-RE, 22 (1963), 6o9-636.

18-7798. Bursson, MARIE - Présence du Christ dans l'auvre de sainte Thérèse.[Tesis, Univ. de París; resumen en AUP, 34 (1964), 248-249].

18-7799. Enrique del Sagrado Corazón - "Doctrina y vivencia de Santa Teresa sobre el misterio de Cristo". $-R E$, 22 (1963), 773-812.

18-7800. Rodríguez, L.-"Cristo en el centro del alma según San Agustín y Santa Teresa".-RE, 23 (1964), 171-185.

18-7801. Caipánaga, V.-"La Iglesia en el itinerario espiritual de San Agustín y Santa Teresa de Jesús".-Aug, 8 (1963), 201-222.

18-7802. Segundo dE Jesús-“Doctrina teresiana del amor al prójimo".- $R E, 22$ $\left(19^{6}\right), 637-667$.

18-7803. RoF Carballo, J.-"La estructura del alma según Santa Teresa".$R E, 22$ (1963), 413-431.

18-j804. Santiago de SAN José-"La esperanza como virtud y como actitud en la doctrina de Santa Teresa".-RE, 22 (1963), 668-68o.

18- 7805 . Ortega, A. A.- "La espiritualidad teresiana en su situación histórica".-RE, 22 (1963), $578-5^{84}$.

18-7806. Muñoz Alonso, A.-"La espiritualidad seglar y Teresa de Jesús".Aug, 8 (1963), 459-474.

18-7807. Adolfo de la Madre de Dios-"Vista panorámica de la vida espiritual según Santa Teresa".-RE, 22 (1963), $5^{8} 5-608$.

18-7808. Srnnige-BreEd, A. - "Evolución normal y unitaria del yo teresiano a la luz de su vida interior". - $R E, 22$ (1963), 239-250.

18-7809. Efrén de la MAdre de Dios-"Vida interior del carmelita descalzo en la mente de Santa Teresa".- $R E$, 21 (1962), 447-463.

18-7810. BLAs de Jesús - "Verdadera humildad. En los fundamentos de la ascética teresiana".- $R E, 22$ (1963), 681722.

18-7811. Adolfo dE LA MAdRe DE DIOS"Sintesis teresiana sobre contemplación adquirida".- $R E, 22$ (1963), $723-735$. 
18-7812. Santa Teresa, maestra di orazione.-Istituto di Spiritualità dei Carmeliti Scalzi, Roma, 1963. 280 pp. EC, 14 (1963), $487-4^{88}$ (Roberto di S. Teresa del B. Gesù); CC, 116 (1965), $3^{81-382}$ (Schiavone).

18-7813. JMḾ́nez-DUQUe, BALDOMERo-El espiritu apostólico de Santa Teresa.Edit. Ángeles de las Misiones, Bérriz, 1963. $\times$ iii $+1{ }^{2} 2 \mathrm{pp}$.

18-7814. Roldán, A.-“La misión de Santa Teresa en la Iglesia a la luz de la hagiotipologia".-RE, 22 (1963), 284. 347 .

18-7815. Emmanuel de la Vierge - "Disposiciones interiores del religioso apóstol en el pensamiento teresiano". $-R E$, 22 (1963), 834-847.

18-7816. Efrén de LA Madre de Dios "Pensamiento de Santa Teresa sobre ei apostolado de los carmelitas descalzos"-RE, 22 (1963), 30-45.

18-7817. Jiménez DUQUe, B.-"El sacerdote jegún Santa Teresa".- RE, 22 (1963), 813.833 .

18-7818. SÁNchez BeAto, C. - "Gobernar educando. Rasgos del genio pedagógico de Santa Teresa".-RE, 22 (1963), 444161 .

18-7819. Muñoz Alonso, A. - "Prospectivas teresianas en dos temas de actualidad filosófica".-Aug, 8 (1969), 297320.

18-7720. Muñoz Alonso, A. - "Concepto del mundo y de las cosas en Teresa de Jesús".-RE, 22 (1969), 489-498.

18-7821. Castro y Calvo, J. M.-“Teresa de Avila, o el realismo militante".[En] Santa Teresa en el IV centenario de la reforma carmelitana (Barcelona, 1963), 9-37.

18-7822. SEBASTIAN, V.-An introduction to the writings of Saint Teresa.-Regnery, Chicago, 1963. $135 \mathrm{pp}$.

18-7829. CONDE, C. - "Sobre la escritura de Santa Teresa y su amor a las letras". $-R E, 22$ (1963), 348-358.

18-7824. Florisoone, M. - "Estética de Santa Teresa".-RE, 22 (1963), 482. 488.

18-7825. Ferrer Canales, J. - "Estilo de Santa Teresa".-CLAJ, 6 (1963), $205^{-}$ 209.

18-7826. Bertini, G. M.-“Nota sul linguaggio di Caterina da Siena e di Teresa d'Avila".-Studi... Francesco Flora (Milano, 1963), 175-19o.

18-7827. BernabÉU Barrachina, F.-“Aspectos vulgares del estilo literario te- resiano $y$ sus posibles razones". $-R E$, 22 (1963), 359-375.

18-7828. IzQuierdo LuQue, María MagnaLENA-Santa Teresa de Jesús. Metriforas y simbolos. Enfermedades y muerte, por Manuel Izquierdo Hernández. Pról. de Azorín.-Autor, Madrid, 1969. 145 pp.-V. núm. 16-4908. || Ins, 1964, núm. 208 (Campos); RAM, 4o (1964), 234235 (Ricard).

18-7829. Teresa de Jesús, Santa - Obras completas. Ed., introd. y notas por el P. Isidoro de San José.-Espiritualidad, Madrid, 1963. xiii+2271 pp. || $R E, 22$ (1963), 205-206 (Alberto de la Virgen del Carmen).

18-783o. Teresa de Jesús, Santa-Oeuüres complètes. Édition du IV centenaire. T. 1: Ma vie; T. 2: Les fondations, Le chemin de la perfection, Exclamations, Avis, Pensées sur le "Cantique des can. tiques”, Le chateau intérieur, Poésies. -Fayard, Paris, 1962. \|NRTh, 86 (1964), 87-88 (Fisch); Etudes, Paris, 318 (1969), núms. $7 / 8,140$ (H. H.). Et $C, 33$ (1965), 193-194 (M. A.).

18-7831. Teresa de Jesús, Santa - Libro de su vida. Ed. de Isidoro de San José.-Edit. de Espiritualidad, Madrid, 1963.391 pp.

18-7832. Teresa of Jesus, SAInT - The way of perfection. Transl. by a Benedictine of Stanbrook, rev. by B. Zinımerman.-Newman Press, Westminster, England, 1963. xxxii +243 pp. - V. núm. $17-2968$.

18-7833. Tomás de la Cruz-"Santa Teresa y la polémica de la oración mental. Sentido polémico del Camino de perfección".-[En] Santa Teresa en el IV centenario de la reforma carmelitana (Barcelona, 1963), 39-61.

18-7834. Ildefonso, P.-Florecillas de San. ta Teresa.-Eds. Paulinas, Bogotá, $19^{6} 3$. $252 \mathrm{pp}$.

18-78,35. Teresa de Jesús, Santa-Epistolario. Ed. por el P. Isidoro de San José. - Espiritualidad, Madrid, 1963. 882 pp. (Bibl. popular carmelitana).

18-7896. Prijatel, F.- "La antinomia conciencia del propio valer/humildad en el epistolario teresiano". $-M C, 71$ (1969), $213 \cdot 254$.

18-7837. Riopérez y Milá, S.-"Santa Teresa de Jesús, vista por Azorin",-RE, 22 (1969), 408-412.

18-7838. Azorfn-"Ventana a Santa Teresa".-RE, 22 (1963), 399-407.

V. también núms. $5321,657^{-1}, 7695$. 
18-7839. Srmeón de la Sagrada Familia - "Ediciones italianas de San Juan de la Cruz en los últimos cincuenta años”. $-M C, 21$ (1963), 271-277.

18- 78 o. Bruno de Jésus Marie - Saint Jean de la Croix (N. 17-6629). || RAM, 39 (1963), 261-268 (Olphe-Galliard); Man, 36 (1964), $3^{66}$ (Solá).

18- 7841 . Bruno di Gesù Maria-San Giovanni della Croce. - Ancora, Milano, $19^{6} 3.5^{\circ 1}$ pp. ||$C C, 116$ (1965), 163164 (De Gennaro).

18-7842. PEERS, E. AlLison - Spirit of flame: A study of St. John of the Cross. gth reprint. - S.C.M. Press, London, 1961. 170 pp.

18-7843. Balthasar, H. U. von - "Juan de la Cruz". - [En] Herrlichkeit: eine theologische .̈sthetik, t. 2 (Einsiedeln, 1962), pp. 465-531.

18-7844. Paroissin, M. E.-Art et humanisme biblique.-Debresse, Paris, 1955. xviii + 520 pp. [Incluye a San Juan].

18- 7845 . Helfer, James Stone-Mysticism and revelation: a study in the particularity of mysticism.-[Tesis, Princeton University; resumen en $D A, 24$ (1963. 64), 413-414]. 276 pp. [Mística hindú, Plotino y San Juan de la Cruz].

18-7846. WERBLoWSKY, R. J. Z.-["E1 rechazo místico de las iluminaciones misticas. Sobre el misticismo no-cognoscitivo de San Juan de la Cruz"].Iyyun, 14 (1963), 205-212; 15 (1964), $375-376$. [En hebreo; resumen en inglés].

18-7847. Pellé-Douñl, Yvonne-San Juan de la Cruz y la noche mistica. Trad. de Luis Hernández Alfonso.-Aguilar, Madrid, 1963. 216 pp., láms. (Hombres de espiritu). || Alcor, Asunción, 1964, núm. 31 (Figueira).

18- 7848 . Giuseppe V. Dell'Eucaristia "La fonte nella notte"--Riv. di Vita Spirituale, 16 (1962), 393-425.

18-7849. Cambon, G.-"Immediacies and distances". - Poetry, Chicago, March 1960. [San Juan de la Cruz].

18-7850. SAlas VIÚ, V.-"De amor en la frontera. El amor divino en San Juar de la Cruz".-CuH, $5^{6} \quad(1963), 345^{-}$ 359 .

18-7851. Laureano DE LA INMACulada "El desposorio espiritual, según San Juan de la Cruz". $-M C, 71$ (1963), $155^{\circ}$ 212.

18-7852. Eulogio de San Juan de la Cruz - La transformación total del alma en Dios según S. Juan de la Cruz.-Edit. de Espiritualidad, Madrid, 1963. $35^{\circ}$ pp.

18-7853. Leroy, O.-“"S. Jean de la Croix en face du miracle".-RAM, 39 (1963), $433-464$.

18-7854. Fernández Ulloa, Ana FranCISCA-La soledad en la obra de San Juan de la Cruz.-[Tesis, Univ. de Madrid; resumen en $R U M, 12$ (1963), 744-745].

18-7855. Nazario de SANTA Teresa-La música callada. Invitación al silencio. $2^{\text {a }}$ ed.-Unitas, México, 1960. 204 pp. 18-78 5 6. Nazario de Santa Terfa-Des. nudez: lo mistioo y lo literario en San Juan de la Cruz.-Polis, México, 1961. 18- 7857 . Suárez, GrRmán - La religiosa perfecta, segin San Juan de la Cruz.Studium, Madrid, 1962. 255 pp. || Aug, 8 (1963), 271.272 (Armas); RyC, 8 (1963), 614 (Camblor); $E C, 14$ (1963), 489-49o (E. de la V. del Carmen); $M C$, 72 (1964), 611 (Miguel A. de Santa Teresa) .

18-7858. Miranda, V.-"Da poesia de S. João da Cruz".-Lumen, 25 (1961), 234. 240 .

18-7859. Orozco Díaz, E.-"Poesía tradicional carmelitana. (Notas para una introducción a la lírica de San Juan de la Cruz)".-EMP, 6, 407-446.

18-7860. SPEndrR, S.- "The most ecstatic poetry ever written".-New Republic, June 1959 .

18-7861. Luis Alberto del Niño Jesús "San Juan de la Cruz: belleza y amor". -Reú. de la Asoc. Escuela de Derecho, Quito, 1958, núm. 12, 24-32.

18-7862. Vallejo y Franco de Espés, AlFonso-La poesia de San Juan de la Cruz en la versión de Roy Campbell.[Tesis, Univ. de Zaragoza, infor]

18-7863. JUAN de la CRUz, SAN-Poesias completas, $2^{\mathbf{a}}$ ed. - Aguilar, Madrid, 1963. 430 pp. (Crisol, 171 bis). - V. núm. 14-39536.

18-7864. Juan de ta Cruz, San - Les cantiques spirituels. Trad. en vers par Cyprien de la Nativité de la Vierge.Maeght, Paris, 1963. 71 pp., ilustr. [Ed. bilingüe].-V. núm. 16-49768.

18-7865. Eulogio de la Virgen del CarMEN-"Estructura literaria del Cántico espiritual, Bases para su exégesis científica". $-M C, 68$ (1960), 383-414.

18-7866. Nazario de Santa Teresa-Lo que cabe en un verso [Cántico espiritual, 3:3].--Inst. de Cultura Hispánica, Santo Domingo, 1957. 131 pp. 
18-7867. Fernández, A. F.-“Análisis ideológico de las Coplas hechas sobre un éxtasis de alta contemplación de San Juan de la Cruz". - RFCR, 1961, núm. 10 .

18-7868. Huerga, A. - "¿Nuevos escritos de San Juan de la Cruz?"-Angelicum, Roma, 34 (1962), 181-203.

18-7869. Federico de SAN JUAN de LA CRUZ-“Avisos falsamente atribuidos a San Juan de la Cruz".-RE, 22 (1963), $137-168$.

18-7870. Ulanov, B. - "Shakespeare and Saint John of the Cross: de contemptu mundi". - [En] Sources and resources (Westminster, Md., 1960), $1_{5}$ 0-187.

V. también núms. $5958,7695,7770-3$.

18-7871. Monasterio, JoAQUín - Estructura sacramental. Espiritualiáad del $P$. La Puente--C.S.I.C., Madrid, 1962. $25^{6}$ pp. - V. núm. 17-6789. \| Man, $3^{6}$ (1964), 365 (Abad); CD, $177 \quad$ (1964), 785-786 (Folgado); AHSI, 34 (1965), 348-349 (Iparraguirre).

18-7872. Palma, LuIS DE LA-Obras com. completas (N. 17-3065). || AHSI, 33 $(1964), 135^{-136}$ (Iparraguirre).

18-7873. PALMa, Luis DE LA-Historia de la Sagrada Pasión sacada de los cuatro Evangelios, $11^{\text {a }}$ ed.-Apostolado de la Prensa, Madrid, 1963. $53^{8} \mathrm{pp}$.

V. también núm. 5321 .

\section{AUTORES Y OBRAS DE GENEROS DIVERSOS}

18-7874. Guy, Alain-Fray Luis de León. Trad. Alberto J. Vaccaro. - Columba, Buenos Aires, 1963. 91 pp. (Hombres inquietos, 6).--V. núm. 17-6801. || $C D$, 177 (1964), 158-159 (Alvarez Turienzo); Sap, 19 (1964), 230-231 (Caturelli); $R y F, \quad 169$ (1964), $557-558$ (Roldán).

18-7875. Lorenzo, Pedro de - Fray Luis de León.-Nuevas Editoriales Unidas, Madrid, $1964.296 \mathrm{pp}$. (Genio y figura, 3). \|EL, 1964, núm. 296 (Rincón).

18-7876. Torres Yagüe, Federico - Fray Luis de León.-Cía. Bibliográfica Española, Madrid, 1964. 200 pp. (Un autor en un libro).

18-7877. Serrano Plaja, A.-“El *ansia de armonía o sson eternos en Juan de Herrera y fray Luis de León".CuH, 53 (1963), 29-40. \|LR, 19 (1965), 142 (Groult).

18-7878. Soons, A.-"Poesía y taracea. Las odas de fray Luis de León". - $H$, 1964 , núm. 20, 1-4.

18-7879. Montoliu, M. DE-“Un tema estoico en la lírica de fray Luis de León".-EMP, 4, 461-467.-V. núm. 10-21580.

18-788o. Granados, G. R.-"El desasosiego en la poesía de fray Luis de León". -Cults, 1964, núm. 32, 8o-83.

18-7881. Müller-Bochat, E.-“Zur Ode an Salinas von Luis de León".-ASNS, 201 (1964), 40-43.

18-7882. LEÓN, FRAY LuIS DE-la perfecta casada. Exposición del Cantar de los Cantares, de Salomón. $9^{\mathrm{a}}$ ed.-Aguilar, Madrid, 1964. $45^{1} \mathrm{pp}$. (Crisol, 10). -V. núm. 14-41648.

18-7883. Arkin, A. H.-"La influencia de la exégesis hebrea en los comentarios biblicos de fray Luis de León".Sef, 24 (1964), 276-287; OYS, 7 (1964), xxix-xxxi.-V. núm. 17-6806.

$18-7884$. LEÓn, FRAY LUIS DE-De legibus - Tratado de las leyes (1571). Ed. crít. bilingüe de Luciano Pereña. C.S.I.C., Madrid, 1963. lxxxviii $+13^{8}$ pp. $\| C D, 177$ (1964), $3^{86}$ (Álvarez Turienzo); $A u g, 9$ (1964), 428 (Armas); AIA, 24 (1964), 474-475 (Barrado); Sef, 25 (1965), 131-132 (Cantera); Anlonianum, 40 (1965), 131-132 (Capobianco); RLit, 24 (1963), 254 (Rull); Salm, 11 (1964), 586-587 (Sobradillo); Arb, 59 (1964), 274-278 (Truyol).

$\checkmark$. también núm. 6015 .

18-788. Masferrer Cantó, S.-Francisco de Quevedo. Relato de la vida del gran escritor, poeta y filósofo. $4^{\text {a }}$ ed.-Ara. luce, Barcelona, 1963. 144 pp., láms. (Los grandes hechos de los grandes hombres).

18-7886. Serrano Poncela, S.- "Los cnemigos de Quevedo".-AF, 2-3 (1963 $64), 235^{-251 .}$

18-7887. Quevedo, Francisco DE - Obras completas. Ed., introd., bibliografia y notas de José Manuel Blecua. T. 1: Poesia original. - Planeta, Barcelona, 1963. cl + 1461 pp. (Clásicos Planeta, 4). $\| R N, 18(1965), 254-255$ (Kossoff); $R J, \quad 14$ (1964), $3^{86-388}$ (Pring-Mill); H, 47 (1964), 868 (Rey); RLit, 24 (1963), 252-254 (Rozas); BAbr, $3^{8}$ (1964), -412 (Silverman); Ins, 1964, núm. $206(\mathrm{X}) ; \quad T L S$, April 16, 1964 (X).

18-7888. Lida R.-“Quevedo y su Espana antigua".-RPh, 17 (1963-64), 253 271. I| $B I C C, 20$ (1965), 174 (Montes). 
18-788g. Glaser, E.-“Quevedo versus Pérez de Montalvín..." (N. 16-498;6). II $B I C C, 19 \quad(1964), 36_{5}^{5}$ (Valderrama Andrade).

18-78go. Berstras, H. N.-"Three expressions of cuckoldry in Quevedo" (N. 16.45531). || BICC, $19(1964), 36_{5}-3^{66}$ (Valderrama Andrade).

18-7891. Quevedo, Francisco DE-Narra. zioni $e$ fantasie satiriche: La vita del Buscón. Sogni. L'ora di tutti. Trad. di Cesco Vian.-Il Club del Libro, Milano, $1963.518 \mathrm{pp}$.

18-7892. QUevedo, Francisco DE-Historia de la vida del Buscón. Introd. de C. O. Nallim, - Ateneo, México, 1964 . $154 \mathrm{pp}$.

18-7893. Quevedo, Francisco DE - Historia de la vida del Buscón, $9^{\text {a }}$ ed.-Espasa-Calpe, Madrid, $1964.14^{8} \mathrm{pp}$. (Austral, 24).-V. núm. 17-6822.

18-7894. Quevedo, F. DE-The Scavenger, tr. H. A. Harter (N. 17-6823). RHM, 30 (1964), 151 (de del Río).

18-7895. Quevedo, Francisco de - Der abenteuerliche Buscón oder Leben und Taten des weitbeschrieenen Glucksrit. ters Don Pablos aus Segovia. Übers. von I. C. Artmann. - Insel, Frankfurt, Ig6. $208 \mathrm{pp}$.

18-7896. IVentosch, H. - "Onomastic invention in the Buscon" (N. 17-9089). I! BiCC, 19 (1964), 372-373 (Valderra. na Andrade).

18-7897. Randall, D. B. J.- "The classical ending of Quevedo's Buscón".$H R, 32(1964), 101+108$.

18-7898. Pricf, R. M.- "Quevedo's satire on the use of words in the Sueños".$M L N, 79(1964), 169-180$.

18-7899. Quevedo, Francrsco de-lisions. Transl. by Sir Robert L'Estrange. Introd. by J. M. Cohen.-Centaur Press, Fontwell (Sussex); Southern Illinois Univ. Press, Carbondale, 1963. 146 P.

18-79o0. Vázquiz de Castro, Isabel-Es. tilistica y sintaxis en "La hora de to. dos".-[Tesis, Univ. de Madrid, 1958].

18-7901. Crosby, J. O.-The sources of the text of Quevedo's "Politica de Dios" (N. 17-3095). I| RR, 54 (1963), 57-6. (Del Piero y Craddock); $M L N$, 79 (1964), 559-561 (Lida); RLit, 26 (1964), 210-211 (Romero).

18-7902. López Grigera, L.-“'Un problema bibliográfico en Quevedo: La cuna y la sepultura".-Fil, $10(1964), 207$ 215 . 18-79o3. Castanien, D. G.-“Three Spanish translations of Epictetus". $-S P h, 61$ $(1964), 616-626$. [El Brocense, Gonzalo Correas, Quevedo].

18-79o4. Castanien, D. - “Quevedo's version of Epictetus' Encheiridion”.-S, 18 (1964), 68-78.

18-7905. Rothe, ArNold - Seneca und Quevedo. Untersuchungen zu den Frühschriften Quevedos.-[Tesis, Univ. de Colonia, 1964].

18-79o6. ETtinghausen, H. - "Quevedo marginalia: his copy of Florus's $E p i$. tome".-MLR, 59 (1964), 391-398.

$\checkmark$. también núms. $5^{84} 6,5^{848}, 6687,6817$ 8,6978 .

18-7907. Gómez de LA SERna, G.-"Jovellanos entre cuatro fuegos". $-R E P$, 1964, núm. 133, $85-110 . \| B I E A, 18$ (1964), 386-388 (Martínez Cachero).

18-7908. Prieto, R.- "Campomanes y Jovellanos ante el régimen agrario de Asturias". - AHDE, 30 (1961), 26g280.

18-79og. Dotor, ĀNGEL-Jovellanos. Estudio y antologia.-Cía. Bibliográfica Española, Madrid, 1964. 232 pp. (Un autor en un libro).

18-7910. Martínez Fernández, J. - "La lealtad de Jovellanos". - BIEA, 18 $(1964), 63-82$.

18-7911. Martínez Freríndez J. - “Los niños en la obra de Jovellanos".$B I E A, 17$ (1963), $106-119$.

18-7912. Jovfllanos, Gaspar Melchor de -Obras selectas. Sel., est. y notas por Francisco Cantera. $4^{\text {a }}$ ed.-Ebro, Zaragoza, 1964. 126 pp., ilustr. (Bibl. clásica Ebro, 31).

18-7913. Joiellanos, G. M. DE - Poesias (N. 17-6833). || Ins, 1964, núm. 209 (Cano); $A O, 14$ (1964), 3oo-301 (Garcia García).

18-7914. Zavala, I. M.--"Jovellanos y la poesia burguesa".-NRFH, 18 (1965. 66), $47-64$.

18-7915. Álvarez Buylla, J. B.--"La traducción de Jovellanos del libro primero del Paraiso perdido de Milton". -FM, 4 (1969), núm. 10, 1-47.

18-7916. Jovellanos, Gaspar Melchor de -El delincuente honrado. Ed., pról. y notas de I. Llácer.-Aguilar, Madrid, 1964. (Bibl. de iniciación hispánica).

18-7917. Castro González, J.-“El de lincuente honrado, drama sentimental".-AO, 14 (1964), 103-133.

18-7918. Jovellanos, Gaspar Melchor de -Obras sociales y politicas. Sel. e in- 
trod, de $P$. Peñalver Simó.-Publica. ciones Españolas, Madrid, 1963. $35^{6}$ pp. (El libro para todos).

18-7919. Morado, R.-"La reforma cons. titucional en Jovellanos y Martínez Marina". - BISD, 1963 , núms. 29/30, $79-93$.

18-7920. Jovellanos, Gaspar Melchor de -Reglamento para el Colegio de Calatrava. Ed. crítica, pról. y notas de José Caso González.-Gijón, 1964. 254 pp. II $A O, 14(1964), 302-303$ (García Ciarcía).

18-7921. Caso Gonzílez, J.-“Cartas inéditas de Jovellanos".-AO, 13 (1963), g92-310.

18-7922. Aguado, E.-"De Cadalso a Castelar".-ELL, 1964, núms. $282 / 3$.

18-7929. Caddiso, J. - Noches lugubres, ed. N. Glendinning (N. 17-3098). AO, 14 (1964), 276-281 (Caso González).

V. también núm. 5866 .

18-7924. VARELA, J. L.-“Larra ante el poder".-Ins, 1964, núm. 206.

18-7925. Sáenz de la Calzada, María Luisa-Mariano José de Larra y el romanticismo español. - Tesis de la Universidad Nacional Autónoma, México, 1963. $88 \mathrm{pl}$.

18-7926. Larra, Mariano José de-Obras completas. T. 1: Articulos. Ed., introd. y notas de C. Seco Serrano.-Planeta, Barcelona, 1964 . $1 x i+1096 \mathrm{pp}$.

18-7927. LARra, Mariano José DE - El Pobrecito Hablador. Ed., pról. y notas de A. del Hoyo. - Aguilar, Madrid, 1964. (Bibl. de iniciación hispanica).

18-7928. Larra, Mariano José de - Il Poweraccio Parlatore e altre prose scelte. Introd. di Flaviarosa Rossini Nicoletti. Trad. di Mario Puccini.Torino, 1964. 278 pp.-V. núm. 1230612.

18-7929. Larra, Mariano José de - $\boldsymbol{A}$. ticulos de costumbres. T. 1.-EspasaCalpe, Madrid, 1965. 28o pp. (Clás. cast., 45).-V. núm. 13-37846.

18-793o. Larra, Mariano José de - $A r$ ticulos de critica literaria. Ed. de $\mathrm{He}$ len Grant y Robert Johnson.-Anaya, Salamanca-Madrid, 1964. 120 pp. (Bibiloteca Anaya, $3^{\circ}$ ).

18-j991. Profeti, M. G. - "Sulla critica letteraria di Larra".-MSI, 1964, núm. 8, $61-84$.

18-7932. Fox, E. I.-"Historical and literary allusions in Larra's El hombre menguado" (N. 16-45561). $\| B I C C, 19$

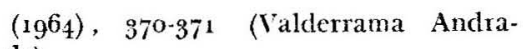
de).

18-7933. Domínguez, M. E.--"Larra y la generación del $98^{\prime \prime} .-P H, 8$ (1964), 443. 457 .

V. también núms. 5861,5866 .

18-7934. Entendimiento de don Miguel. $-E L, 1964$, núms. $300 / 1.88$ pp. [fiomenaje a Unamuno].

18-7935. M. L.-“A Estafeta Literária e o centenário de Unamuno".-OOcid, 67 $(1964), 23^{6-237}$.

18-7936. Homenaje a Miguel de Unamuno. $-A B C, 27$ de noviembre de 1964 .

18-7937. Homenaje a Miguel de Unamuno.-Imprenta Universitaria, Santiago de Chile, 1964. $173 \mathrm{pp}$.

18-7938. [Homenaje a Lnamuno].-O Estado de São Paulo, 3 de octubre de 1964. [Colaboran S. Alonso-Fueyo, D. Arrigucci Júnior, J. García Morejón, J. A. Mackay, J. C. Mota, A. Oliveros, F. de Onís, F. Prieto-Castro y Roumier, y A. Tovar].

18-7939. "Unamuno".-El Noticiero Universal, Barcelona, 3 nov. 1964. [Varias colaboraciones].

18-7940. "Unamuno". - La Vanguardia Española, Barcelona, 23 febr. 1964 . [Varias colaboraciones].

18-7941. BENítez, J. - "Mi homenaje a Unamuno".-Ins, 1964, núms. $216 / 7$.

18-7942. CANo, J. L.--"El centenario de Unamuno".-Asom, $19^{6} 4$, núm. 4. 39 . 42.

18-7943. Cossio del Pomar, F.-"Cientenario de Unamuno".-CCL, 1964, núm. $88,49-56$.

18-7944. "Unamuno: cien años".-IAL, 1964 , núms. $187 / 8$. [Colaboran F. Delgado, J. A. Somoa y Gutiérrez Arechabala].

18-7945. Fonrín, A.-“"Unamuno. En el centenario de su nacimiento". $-N T$, 29 (1964), 627-698.

18-7946. Kourim, Z.-"Sto let od narození Miguela de Unamuno".-Filoso. ficky Casopis, 12 (1964), 909-913.

18-7947. MaIA, J.-"No centenário de Miguel de Unamuno".-Bro, 79 (1964), $449-45^{2}$ ․

18-7948. MesvarD, P.-“Pour le centenaire de Unamuno".-Etudes Philosophiques, 19 (1964), 593-596.

18-7949. Muñoz Alonso, A.-“En el centenario de D. Miguel de Unamuno".$A P C, 29$ (1964), $3^{83-389 .}$

18-7950. NFú́sio, V.-“No centenário de Unainuno".-Co, 1964 , núm. 31 . 
18-7951. Samonì, C.-"Miguel de Unamuno nel centenario della nascita". $-T P$ r, 1964, núm. 4, 239-243.

18-7952. Valente, J. A.-"Notas para un centenario".-Ins, 1964 , núms. $216 / 7$.

18-7953. "Unamuno y Zurbarán. Dos centenarios".-PE, 1964, núm. 104.

18-7954. G.[ARcía] B[LANCo], M.- "El cen tenario de Unamuno fuera de España". -Ins, 1964, núms, 216/7.

18-7955. García Blanco, M. - "Crónica unamuniana (1961-62)". - $C M d U, 12$ (1962), 75-104.-V. núm, 17-3104.

18-7956. Fostre, D. W.-“Adiciones y suplemento a la bibliografia de Unamuno". - LT, 1964, núm. $4_{4}^{8}, 1655^{\circ}$ 172.

18-7957. Alcalá, M.-"Unamuno en la Biblioteca Nacional [de México]". $B B N M, 15 \quad(1964), 3-5$.

18-7958. Anabitarte Prrtegas, J--"Una muno. Preocupación y homenaje". Prensa Literaria, San Juan (P. R.), 1964 , núms. $6 / 8$.

18-7959. Machado, A.-"Image première de don Miguel de Unamuno". - $E$, 1964 , núms. $419 / 20,16-25$.

18-7960. Civdan, M.-"Soñando a Unamuno",-[En el vol. colectivo] Unamuno, Santiago de Chile, 1964 .

18-7961. Monteiro, D.- "Evocação de Miguel de Unamuno".-Co, 1964, núm. $31,43-45$.

18-7962. Pérez de Urbel, J.-"Mis encuentros con Unamuno". - EL, 1964, núm. 304.

18-7969. Laf́ Entralgo, P.-"Semblanza de Unamuno".-CuD, 1964 , núm. 13.

18-7964. Aub, M.- "Retrato de Unamuno, para uso de principiantes".-Ins, 1964 , núms. 216/7. [Y versión francesa, $E$, 1964, núms. $\left.4^{19 / 20,4} 4^{-15}\right]$-V. núm. 16 49910 .

18-7965. Andrade, R. - "Mascarilla de Unamuno".-CCL, 1964, núm. 82, 93-94.

18-7966. GimfFrrer, P.--“Unamuno y su esfinge".-PSA, $35 \quad(1964), 137-144$.

18-7967. Bergamín, J.-"Unamuno, solitaire et déchiré comme l'Espagne".Figaro Littéraire, 8-14 oct. 1964 .

18-7968. Morales, J. R.-“Unamuno, persona dramática".-[En el vol. colectivo] Unamuno, Santiago de Chile, 1964 .

18-7969. Ferrater Mora, J.-“Unamuno, $1964 "$ "-ROcc, 7 (1964), 29-40.

18-7970. García Bacca, D.-"Don Miguel de Unamuno. In memoriam"-Cults, 1964 , núm. 33 , 156-159.
18-7971. García Bacca, J. D.-"Don Miguel de Unamuno".-Rev. Brasileira de Filosofia, 14 (1964), 592-596.

18-7972. Iriarte, J.-"Miguel de Unamu-

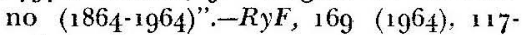
128.

18-7973. Rorg, R.-“Noviembre literario, 64. Unamuno".-HD, 40 (1964), 892893.

18-7974. PÉRfz, Dionisio-Don Miguel de Unamuno. Ensayo acerca de su iconografia y relación con las bellas artes.Autor, Santander, 1964. $5^{8}$ pp., 75 láms. I| $P S A, 35$ (1964), 231-233 (A. de V.); Ins, $196_{5}$, núms. $224 / 5$ (Esteban); EL, 1964, núms. $300 / 1$ (Ponce de Lećn).

18-7975. Abellán, José Luis-Miguel de Unamuno a la luz de la psicologia.Tecnos, Madrid, 1964. 242 pp. $-V$. núm. 17-3107. || REP, 1965, núms, 141/2, 264269 (Díaz); Ins, 1964, núms. $216 / 7$ (Marra-López); EL, 1964, núms. $300 / 1$ (Ponce de León); BHS, $4^{2} \quad\left(19^{6}\right)$, 202-203 (Shaw); Dialogos, Univ, de Puerto Rico, I (1964), núm. 1, $137^{\circ}$ $13^{8}$ (Soriano).

18-7976. Granjel, Luis S. - Miguel de Cnamuno. Ein Lebensbild. Ubers. von C. Meyer-Clason.-Ernst Klett Verlag, Stutgart, 1964. $268 \mathrm{pp} .-\mathrm{Y}$. núm. 17$686_{4}$.

18-7977. RudD, Margaret Thovias-The lone heretic. A biography of Miguel de Unamuno y Jugo. Pról. by F. de Onís-Univ. of Texas Press, Austin, 1963. xviii + 349 pp. $\| M L J, 49\left(19^{6}\right)$, 130-131 (Cannon); íns, 1964, núms. 216/7 (Gullón); FH, 2 (1964), 563-504 (Silvestroni).

18-7978. Marra-López, J. R.-“Unamumo visto por dos escritores jóvenes".-Ins, 1964, núms. 216/7. [Salcedo y Abe. Ilán].

18-7979. Castulo, A.-"Nada menos que todo un hombre".-Lyra, 1964, núins. $192 / 4$.

18-7980. Cassou, J. - "L'homme Lnamuno". - Esprit, 31 (1964), 796-80弓 ; 32 $(1964), 281-282$.

18-7981. Olivar-Bertrand, R. - "Los tiempos que le tocó vivir a Unamuno". -CuA, ig64, núm. 5, $177-200$.

18-7982. Garagorri, P. - "E1 vasco Unamuno". - ROcc, 7 (1964), $121-129$.

18-7983. Turin, Y.-Miguel de Unamuno universitaire (N. 17-6868). $\|$ AESC, 18 (1963), 1032-1036 (Léon); BHS, 41 (1964), $121-122$ (Ribbans). 
18-7984. TORre, G. DE-"Don Miguel de Unamuno y su trayectoria política".Ibér, sept. 1964 .

18-7985. Tudela, J. - "La tertulia del "Gato Negro*. Unamuno y [José María] Soltura".-Ins, ${ }^{1964}$, núms. $216 / 7$. 18-7986. Garcta Blanco, M.-“Unamuno, traductor y amigo de José Lázaro”.ROcc, 7 (1964), 97-120.

18-7987. Vargas Alvarado, L.-"Unamuno en Guadalupe".-El Monasterio de Guadalupe, Cáceres, 1964, núm. 554.

18.7988. Somoza, J. A. - "Unamuno en Palencia”. - IAL, 1964, núms. 187/ 188.

18-7939. Nuez, Stbastián de LA -Unamuno en Canarias. Las islas, el mar y el destierro.-Universidad, La Laguna, 1964. 291 pp. \| BHS, 42 (1965), 269-264 (Alberich); Ins, 1964, núm. 214 (CardenaI); RHM, 30 (1964), 316 (Iduarte); $R H C, \quad 29 \quad\left(19^{63}-64\right), \quad 15^{8}$ (Morales); BHi, 67 (1965), 206-208 (Ricard); $B A b r$, $4^{\circ}$ (1966), 193 (Sarmiento); $P S A, 34$ (1964), $3^{61-363}$ (Viñue1as).

18-799o. Fernández de la Mora, G., y L. GONZÁlEZ SEARA-"Sobre Unamuno".CuD, 1964, núm. 14 .

18-7991. Sevilla Bento, F.-"Dos artículos sobre Unamuno". - CMdU, 13 (1963), 41-52.

18-7992. Gorc, C.-"Unamuno como método".--[En el vol. colectivo] Unamuno, Santiago de Chile, 1964 .

18-7993. Chicharro de León, J.-"Varia unamuniana".-LNL, 1964, núms. 3/4, $12-30$.

18-7994. Ferro, A.-"D. Miguel de Unamuno, senhor feudal de Salamanca".Esp, 1964, núm. 3, 46-5o.

18-7995. Olaso, E. DE-"Los nombres de Unainuno".-PSA, 34 (1964), 9-38.

18-7996. Olaso, Ezequiel de-Los nombres de Unamuno. - Sudamericana, Buenos Aires, 1963. 116 pp. ॥ $E L$, 1963, núm. 278 (A. L.); $C M d U, 19$ (1963), 101-102 (Garcia Blanco); IAL, 1965, núm. 194 (M.); CCL, 1964, núm. 86, 73-74 (Murena); Rev. de Filosofia, La Plata, 1964, núm. 14, 94-96 (Nogueira); RHM, 30 (1964), 53 (Sobejano); Asom, 1964, núm. 2, 68-71 (Zavala).

18-7997. Stevens, H. S. - "El Unamuno múltiple".-PSA, 34 (1964), 253-284.

18-7998. ApAricio, J.-"Requiem antiacadémico. Don Miguel, el otro y el otro".-EL, 1964, núm. 3o4.
18-7999. Fernandes Fafe, J.- “As palavras e o tempo".- $S N, 43$ (1964), 195-200. [Unamuno].

18-800o. GonzÁlez Garci-Martín, F. M."Tres aspectos de Unamuno".-NEt, 1964, núm. 29, 173-176.

18-8001. SAlCEDo, E. - "Unamuno y el diálogo".-CuD, 1964, núm. 12.

18-8002. Zavala, I. M.-"Notas sobre el entrañamiento y extrañamiento unamunianos".-BISD, 1964, núm. 31, 237243 .

18-8003. Areilza, J. M. DE--"Una anécdota pictórica. Iñigo de Loyola y Miguel de Unamuno".-EL, 1964, núm. 18.

18-8004. LEóN, M. T.-“Le hibou de papier de $M$, de Unamuno". $-E$, I964, núms. 419/20, 26-31.

18-8005. SAlcedo, E.-“Cuando las pajaritas tienen alas".-ROcc, 7 (1964), 134-140.

I8-8006. Delgado, F.-“Paradoja". $-I A L$, 1964, núms. 187/188. [Sobre Unamuno].

18-8007. Castro y Calvo, J. M.-“El paradójico don Miguel". - Azor, 1964, núm. 17.

18-80o8. Gringoire, P.-"Miguel de Unamuno y su agonía".-Horizontes, Mé xico, 1964, núm. 39 .

18-80o9. GuY, A.-"L'itinéraire agonique d'Unamuno". - RUM, 13 (1964), 125144 .

18-8ono. Santa Cruz, L.-“O cristianismo agônico de Miguel de Unamuno".Cadernos Brasileiros, 1964 , núm. 6, 36$4^{6 .}$

18-8011. Marquínez Argote, G. - "Don Miguel de Unamuno y su agustinismo desesperado". - RJav, 62 (1964), 151166.

18-8012. GRAss, R.-“Unamuno's concept of struggle as seen in his shorter essays".-RNo, 6 (1964), 10-15.

18-8013. Montuld, T.-"La tragedia espiritual de Unamuno". - EstF, 13 (1964), 489-546.

18-8014. Calvetri, C. - La fenomenologia della credenza in Unamuno (N. 1021639). \|E EstF, 13 (1964), 180-181 (Soria).-V. núm. 16-49948.

18-8015. Tornos, A. M.-"La crisis religiosa de Unamuno". - CuD, 1964, núm. 12.

18-8016. Torrenti, R.-"Unamuno, pensador cristiano".--[En el vol. colectivo] Unamuno, Santiago de Chile, 1964 . 18-8017. Sánchez-Barbudo, A.-"Del dia- 
rio inédito de Unamuno".-Ins, 1964 , núms. $216 / 7$.

18-8018. Galmés, L.-“La incógnita religiosa de Unamuno". - TE, 9 (1965), $147-162$.

18-8o19. Cabezas, J. A. - "La psicología religiosa de don Miguel de Unamuno". -Salm, 11 (1964), 473-49o.

18-8020. Umbral, F.-"E1 hereje Unamuno", $-E L, 1964$, núms. 300/301.

18-8021. Gurpide Beope, Pablo - Carla pastoral en el centenario de Unamuno.Obispado, Bilbao, 1964. $28 \mathrm{pp}$.

18-8022. Enjuto, J.- “Unamuno ante la muerte. Dos actitudes”. - Ins, 1964, núms. 216/7.

18-8023. Marfas, J.- "La meditatio mortis, tema de nuestro tiempo".-ROcc, 7 (1964), 41-5o.

18-8024. Giménez, N.-"Miguel de Unamuno y su hambre de inmortalidad". $-U S F, 1964$, núm. 60, $105-115$.

18-8025. Sant'Anna Dionísio-"Unamuno e seu anseio de eternidade". - Esp, 1964 , núm. 3 .

18-8026. Guerra, M. L.-"Unamuno, Don Quixote da imortalidade". - Ocid, 67 $(1964), 141-157$.

18-8027. Serrano Poncela, S.-El pensamiento de Unamuno. $\mathrm{a}^{\mathrm{a}}$ ed.-Fondo de Cultura Económica, México, 1964. 268 pp. (Breviarios, 76). - V. núm. 10 15693 .

18-8028. Zavai.A, P. J.-"Unamuno, maestro del pensamiento".-IAL, 1964 , núm. 192.

18-8029. Fernández de la Mora, G. "Unamuno pensador".-IAL, 1964, núm. 190.

18-80zo. Gruz Hernández, M.-"La significación del pensamiento de Unamuno".-CMdU, 13 (1963), 5-11.

18-8og1. Peñalver, P.-"Significación filosófica de Unamuno".- $-N T, 22$ (1964), $653-667$.

18-8032. MEYer, F. - "Unamuno et les philosophes".-RUM, 13 (1964), 77-92; $A F L A$, 1964, núm. 38, 25-40.-V. núm. $17-6887$.

18-8033. IrIARTe, J.-."El puesto de Unamuno en la filosofía". - $R y F, 170$ (1964), 307-322.

18-8034. URIARTE, F.-"Lo prefilosófico en Unamuno".-[En el vol. colectivo] Unamuno, Santiago de Chile, 1964.

18-8035. Basave Fernández del Valle, A.- "Personalidad y filosofía de $\mathrm{Mi}$ guel de Unamuno". - Aug, 9. (1964), $343-3^{6} 4$.
18-8036. BASDEKIS, D. - "Rationalism in Unamuno and in Ortcga's Tema de nuestro tiempo". - RNo, 5 (1964), 118-123.

18-8037. Alonso, Salvio-Unamuno y Ortega y Gasset ante el hombre y la sociedad (visto a través de un obrero).-Gráf. Arabi, Madrid, 1964. 63 pp.

18-8og8. SÁnchez Ruz, J. M.-“La teoría del conocimiento en el irracionalismo unamuniano".- Salesianum, 24 (1963), $32-85$.

18-8039. Meyer, F.-La ontología de Miguel de Unamuno (N. 18-4016). il Map, 1964, núm. 3, 288-29o (Garcia).

18-8040. Paris, C.-"La inseguridad ontológica, clave del mundo unamuniano". $-R U M, 13$ (1964), 93-123.

18-8041. Tornos, A. - "El hombre y la vida en Unamuno".-Pens, 19 (1963), $93^{-10} 3$.

18-8042. HuERTAS-Jourda, José - The existentialism of Miguel de Unamuno. -The Univ. of Florida Press, Gaines. ville, 1963 . 70 pp. (Univ. of Florida Monographs) . || IAL, 1963, nún. $17^{8}$ (P. P.).

18-8043. Collado, J. A.--"Unamuno y el existencialismo de Soeren Kierkegaard". $-R U M, 13$ (1964), 145-161.

18-8044. Abrams, F. - "Sartre, Unamuno and the 'hole theory'", - RNo, 5 (1963), 6-11.

18-8045. Panilha, T. M.-“A existência segundo Miguel de Unamuno".-VeR, 21 (1964), $153^{-1} 74$.

18-8046. Villalobos, D.- "Unamuno y la importancia del sentimiento en la re. lación existencial". - Boletín Cultural de la Embajada Argentina en Espana, 1 (1969), núm. 3. 57-65.

18-8047. Santonastaso, G. - "La scienza del cuore di $M$. de Unamuno". $-N A$, 99 (1964), $35^{8-368 .}$

18-8048. RoF Carballo, J.-"El erotismo en Unamuno". - ROcc, 7 (1964), 7196.

18-8049. VAN der GRIJP, R. M. K.-“Ensueños: un motivo en el pensamiento de Unamuno".-CMdU, 13 (1963), 7593 .

18-805o. Bergamín, J. - "Au-dessous du rêve". - Esprit, 31 (1954), 806-811. [Unamuno].

18-8051. Senabre Sempere, R.-“Unamuno y la "visión taurina de la historia".$P S A, 35$ (1964), 249-260. 
18-8052. Earle, P. G. - "Unamuno and the theme of history".-IIR, 32 (1964), 319-339.

18-8053. González SEARA, L. - "La rclación sociedad-individuo, en Miguel de Unamuno". - RUM, 13 (1964), 163196.

18-8054. TuÑón dE LARA, M.-“L'Espagne d'Unamuno".-Esprit, 31 (1964), 781$789 ; 32 \quad(1964), 279-280$.

18-8055. Conde Gargollo, E.-"La espanolidad de Unamuno". - Ins, 1964, núms. $216 / 7$.

18-8056. ABeLlán, J. L.-“Notas sobre el «hombre español» al margen de Unamumo".-Asom, 20 (1964), 1, 33-44.

18-8057. Hirrrira, E.-“Unanumo y su sociología del lenguaje”. - Lect, ıg64, núm. 161, 59-61.

18-So58. Chaves, Jullo César-Unamino y el porvenir del español.-Inst. Paraguayo de Cultura Hispánica, Asun. ción, 1963. $31 \mathrm{pp}$.

18-8059. Chaves, J. C. - "Unamuno y el poivenir del español".-PFE, 1, 499-516.

18-806o. Urmeneta, F. DE - "Actualidad le Ia estética unamuniana",-RIEs, 21 (1963), 363-365.

18-8061. SopeñA, F.- "Las músicas de don Miguel de Unamuno".-ROcc, 7 (1964), $13^{0}-133$.

18-8062. Puente, J. DE LA -- "Unamuno: su cotejo Zuloaga-Sorolla".-Ins, 1965 , núm. 219 .

18-8063. BASDEKIs, D.-"Unamuno on literature and pueblo".-RNo, 6 (1965), g6- 98 .

18-8064. Diaz-Plaja, G.--"Unamuno, antimodernista".-Ins, 1964 , núms. $216 / 7$.

18-8o65. Coloma González, F.- "Miguel de Unamuno. Vida y obra”,-Rev. del Ministerio de Educación, Managua, 1964, núm. $31 ; 23 \mathrm{pp}$.

18-8066. Benítez Claros, R. - "Supuestos para su critica literaria”. - NT, 22 (1964), 639-652. [De Unamuno].

18-8067. Alarcos Llorach, E. - "Sobre Unamuno, o cómo no debe interpretarse la obra literaria".- $A O, 14$ (1964), $5^{-17}$.

18-8068. Laín, Milagros-La palabra en Unamuno.-Instituto de Filología "Andrés Bello", Universidad, Caracas, 1964 . $9^{2}$ pp. || CuH, 6o (1964), 549-552 (Acquaroni); RLit, 25 (1964), 263 (Romero).

18-8o69. Jiménez Precroso, Marta - El paisaje en Unamuno.-['Tesis, Univ. de Murcia, 1969]. 18-807o. UnAmuno, M. DE-Obras completas, t. 15: Poesia III (N. 18-407o). if $B H_{i}, 67$ (1965), 356-365 (de Kock).

18-8071. ONIEVA, ANTONIo J.-Unamuno. Estudio y antologia.-Cía. Bibliográfica Española, Madrid, 1964. 215 pp. (Col. Un autor en un libro).

18-8072. Unamuno, Miguel DE-[Anthologie]. Présentation, choix de textes, bibliographie par Alain Guy.-Seghers, Paris, 1964. 224 pp., ilustr. || Ins, 1964, núms. 216/7 (Gullón).

18-8073. Diego, G. - "Unamuno, poeta solo".-PEsp, 1964 , núm. 143 .

18-8074. Vivanco, L. F.- "Unamuno, poeta lírico".-Ins, 1964, núms. 216/7.

18-8075. YNDURÁis, F.-"Unamuno en su poética y como poeta".-HMU, $5^{8} 5$ 610 .

18-8076. Villar, A. DE - "La poesía en Unamuno".-Ins, 1964, núms. $216 / 7$.

18-8077. LefebVRe, A. - "El cantar de Unamuno".-[En el vol. colectivo] Unamuno, Santiago de Chile, 1964 .

18-8o78. Sainz de Robles, F. C. - "Las claves líricas de Unamuno".- $P E, 1964$, núm. 101 .

18-8079. Alvar, Manuel - Acercamientos a la poesia de Unamuno.-Universidad de La Laguna, Santa Cruz de Tenerife, 1964. $91 \mathrm{pp}$.

18-8o8o. Álvarez Angulo, Tomás - Unidad y evolución en la lirica de Unamuno.-Universidad, Granada, 1963. 59 $\mathrm{pp}$.

18-8081. Rocamora, P, - "Unamuno, ensayista agnóstico y poeta teologal".$A r b, 59$ (1964), 303-318.

18-8082. Zambrano, M. - "La religione poetica di Unamuno".-ApL, 11 (1963). núm. 21, 53-7o.-V. núm. 16-49981.

18-8083. Oliver Belmas, A. - "Unamuno, poeta imaginero". - PEsp, 1964, núm. 144.

18-8084. Совв, C. W.- "José Martí's influence on Unamuno's blank verse".KFLQ, 11 (1964), $7^{1-78 .}$

18-8085. UnAmuno, Miguex DE-Antologia poética. $5^{\text {a }}$ ed.-Espasa-Calpe, Madrid, 1964. 154 pp. (Austral, 601).-V. núm. $16-49982$.

18-8086. Kock, J. DE-“Aspecto formal de las fuentes escritas del Cancionero de Unamuno".-RHM, 3o (1964), 215-244. 18-8o87. Unamuno, Miguel De-El Cristo de Velázquez. $3^{\mathrm{a}}$ ed. - Espasa-Calpe, Madrid, ig63. 145 pp. (Austral, 781).V. núm. 12-34094.

18-8088. Unamuno, Miguel de-Il Cristo 
di Velazquez. Trad. di Antonio Gasparetti. $2^{\text {a }}$ ed. - Morcelliana, Brescia, 1963. $179 \mathrm{pp}$. (Confidenziali).

18-8089. Allué y Morer, F.-"Glosa a un soneto de Unamuno". - PEsp, 1964, núm, 143 .

18-8ogo. Garcfa Morejón, J.-“Génesis y elaboración del soneto Portugal de Unamuno".-Ib, 1963 , núm. 3 .

18-8091. Salvador, G.-"Análisis connotativo de un soneto de Unamuno".- $A O$, 14 (1964), 18-39.

18-8og2. Senabre Sempere, R.-."En tomo a un soneto de Unamuno".-CMdU, 13 (1963), 33-41.

18-8og3. Durán, M. - "Unamuno y su Elegía en la muerte de un perro".-Ins, 1964 , núms, $216 / 7$.

18-8og4. Garasa, D. L, - "Los empeños teatrales de Unamuno". - Ins, 1964, núms. $216 / 7$.

18-8095. Gullón, R.-"Teatro del alma". -RUM, 13 (1964), 197-210.

18-8og6. Guardia Celedón, G.-“¿Por qué fracasó el teatro de Unamuno?"-IHumboldt, 1964, núm. 20.

18-8097. Zavala, Iris M.-Unamuno y su teatro de conciencia. - Universidad, Salamanca, 1963. 222 pp. (Col. de memorias y trabajos cientificos). $\mid$ REP, 1964, núm. 133, 295-296 (Díax); Seg, 1 (1965), 463-464 (Esquer Torres); Asom, 1965, núm. 1, 75-84 (González); Aug, 9 (1964), 425-426 (Legarra); BHi, 68 (1966), 172-173 (Marrast); PSA, $3^{6}$ $(1965), 349-35^{2}$ (Viñuelas).

18-8098. Rimet, Danielle-Maternité et paternité dans les romans et le thétitre de Miguel de Unamuno.-[Tesis de la Sorbona, 1963 ].

18-8ogg. Unamuno, Miguel de-El otro. El hermano Juan. $2^{\text {a }}$ ed.-Espasa-Calpe, Madrid, 1964. 144 pp. (Austral, $647)$.

18-8100. Unamuno, Miguel de - Fedra. Soledad. El otro. - Losada, Buenos Aires, 1964. 134 pp.

10-8101. Valbuena Briones, A.- "Fedra". - EL, 1964, núm. 304. [De Unamuno!.

18-8102. Huerta, E.-"Unamuno novelis ta".-[En el vol. colectivo] Unamuno Santiago de Chile, I964.

18-8103. Benavides Lillo, R.-“Unamuno y su metanovela".-AUCh, 122 (1964), 639-652.

18-8104. Csép, A.-“Jellemábrázolás és lélekrajz Unamuno regényeiben".-Filologiai Közlöny, 1962, 60-71.
18-8105. Rocamora, P.-"Problemática da realidade-ficção na novelística unamuriana".-Esp, 1964, núm. 3, 9-14.

18-8106. Moncy, A. - "La creación del personaje en las novelas de Unamuno". $-L T, 1963$, núm. 42, $145^{-188}$.

18-8107. Moncy, Agnes-La creación del personaje en las novelas de Unamuno. -La Isia de los Ratones, Santander, 1963. 81 pp. || CuH, 57 (1964), 323-326 (Gil); EL, 1965, núm. 310 (Iglesias Laguna); RLit, 24 (1963), $28_{3}$ (Jiménez Martos); Ins, 1964, núm, 207 (Martínez Palacio).

18-8108. Almeida Prado, A. L. df - "O processo de ficção da nivola unamuniana e das favole intellettuali de Ccsare Pavese".-CMdU, 13 (1963), 63. 74 .

18-8109. Kinney, A.-"The multiple heroes of Abel Sánchez". - Studies in Short Fiction, Newberry, 1 (1964), 251257.

18-8110. Unamuno, Mrguel de - Amor $y$ pedagogia. $8^{\text {a }}$ ed.-Espasa-Calpe, Madrid, 1964.170 pp. (Austral, 141). -V. núm. 17-3146.

18-8111. VALdÉs, M. J.- "Amor y pedagogia y lo grotesco"-CMdU, 13 (1963), 54-62.

18-8112. Unamuno, Miguel DE - Nieblu. Introd, de H. S. Stevens y R. Gullón.Taurus, Madrid, 1964. 190 pp. (Temas de España, 28).

18-8113. Unamuno, Miguel de - Niebla. $10^{*}$ ed. - Espasa-Calpe, Madrid, 1963 . 166 pp. (Col. Austral, 99).--V. núm. $17-3151$.

18-8114. Blanco Aguinaga, C.-"Unamuno's Niebla: existence and the game of fiction". - MLN, 79 (1964), 188 205 .

18-8115. Moncy, A.- "Un puñado de niebla".-Ins, 1964, núms. $216 / 7$.

18-81,6. WFBBER, R. H.-"Kierkegaard and the elaboration of Unamuno's Niebla". $-H R, 32$ (1964), 118-134. $\| B I C C, 22$ (1967), 311-312 (Valderrama Andrade).

18-8117. Agurlers, C.-"Fe religiosa y su problemática en San Manuel Bueno, mártir". - BBMP, $4^{\circ}$ (1964), $205^{-}$ 307.

18-\$118. FALCONiERi, J. V.-"San Manuel Bueno, mártir-spiritual autobiography. A study in imagery". $-S, 18$ (1964), 128 . 141.

18-8119. Gullón, R.-"El testamento de Unamuno".-UMx, 18 (1963-64), núm. 9. [San Manuel Bueno]. 
18-8120. Morón Arroyo, C. - "San Manuel Bueno, mártir y el ssisteman de Unamuno".-HR, 32 (1954), 227-246.

18.8121. Unamuno, Miguel de - La tia Tuia. $8^{\text {a }}$ ed. - Espasa-Calpe, Madrid, 1964. 149 pp. (Austral, 122).-V. núm. $11-26985$.

18-8122. Aranda, J. F.-"La tia Tula".Ins, 1964, núm. 214. [Película de Miguel Picazo].

18-8123. Egrido, L. G. - "La agonía de Unamuno. Adaptación cinematográfica de La tía Tula". - Ins, 1964, núms. $216 / 7$.

18-8124. Núñez, A.- "Unamuno al cine. (Miguel Picazo y La tía Tula)".-Ins, 1964 , núms. $216 / 7$.

18-8125. Unamuno, Mrguel de-Tres novelas ejemplares. $11^{\text {s }}$ ed.-Espasa-Calpe, Madrid, I964. 164 pp. (A ustral, 7o).V. núm. $17-3157$.

18-8126. Unamuno, Miguel De-[Tres novelas ejemplares y un prólogo. Abel Sánchez. La tia Tula. Nueve relatos breves, Trad, rusa. Pról. de Valeri Stolbov.-Ed. Literaria, Moscú, I964]. || LS, 1964, núm. 5, 185 (Kamiónskaia).

18-8127. Blanco Agunaga, C.-"Aspectos dialécticos de las Tres novelas ejem. plares".-ROcc, 7 (1964), $5^{1-70 .}$

18-8128. Benavides Lillo, R. - "Para Ia genealogía de Augusto Pérez".-[En el vol. colectivo] Unamuno, Santiago de Chile, 1964 .

18-8129. Gullón, R.--"Don Sandalio o el juego de los espejos".-PSA, so (1963), 299-325.

18-813o. Granados, JuAna-Los ensayistas del noventiocho: Miguel de Unamuno -Goliardica, Milano, 1964. - V. nún. $17-6384$.

18-8131. Gallegos Vaidés, L.-"Don Miguel de Unamuno y el ensayo".-Cults, 1964, núm. 39, 57-70.

18-8132. URrutia, L. - "Una variación y un ensayo de Miguel de Unamuno".LNL, 1964 , núms. 3/4, 31-43.

18-8133. Unamuno, Miguel de-La agonia del cristianismo. $2^{\text {a }} \mathrm{ed}$. - Losada, Buenos Aires, 1964. (Contemporánea, 1).

18-8134. Unamuno, Miguel De-Andanzas $y$ visiones españolas. $8^{a}$ ed. - EspasaCalpe, Madrid, 1964. 272 pp. (Austral, 160).-V. núm. 17-3167.

18-8135. Unamuno, Miguel De-Del sentimiento trágico de la vida.-Compañía Argentina de Editores, Buenos Aires, 1962. 272 pp.
18-8136. Unamuno, Miguel De-Del sentimiento trágico de la vida. - Losada, Buenos Aires, 1964. 287 pp. (Contemporánea, 166).

18-8137. Vivanco, L. F. - "Releyendo $E l$ sentimiento trágico de la vida". $-\mathrm{CuD}$, 1964 , núm. 12 .

18-8138. Unamuno, Miguel de-Mi reli. gión $y$ oiros ensayos. $4^{\text {a }}$ ed.-Espasa. Calpe, Madrid, 1964. $15^{2}$ pp. (Austral, 299).

18-8139. Unamuno, Miguel de-Por tierras de Portugal y España. 6 ${ }^{\mathrm{a}}$ ed.-Espasa-Calpe, Madrid, 1964. 188 pp. (Austral, 221).-V. núm. 17-3178.

18-8140. Unamuno, Miguel pe-Vida de Don Quijote y Sancho.--Eds. R, La Habana, 1964. (Bibl. básica de lit. española).

18-8141. PrFdmore, M. P.-"Madariaga's debt to Unamuno's Vida de Don Qui. jote y Sancho".-H, 47 (1964), 288-294.

18-8142. Armas Ayala, A. - "Del aislamiento $y$ otras cosas. Textos inéditos de Miguel de Unamuno".-AEAtl, 9 (1963), 335-438. || IAL, 1964, núm. 192 (Martín); RHC, 29 (1963-64), 158-159 (Morales).

18-8143. Unamuno-"Un inédito: Discurso sobre la espiritualidad francesa".Ins, 1964 , núms. $216 / 7$.

18-8144. "Dois autógrafos de Miguel de Unamuno". - Ocid, 67 (1964), 158160 .

18-8145. Torre, G. DE-“Unamuno, escritor de cartas”. - Ins, 1964, núms. 216/7; Los Sesenta, México, 1965, núm. 2.

18-8146. Fernández Larrafin, S.--"Algo de Unamuno a través de un epistolario". - Map, 1964, núm. 1, $205-254$.

18-8147. Aparicio, T. - "Don Miguel de Unamuno: su genio, su fe y su afán a través de un epistolario".- $R y C, 9$ (1964), 417-438.

18-8148. Garcia Blanco, M.--"Una carta inédita de Menéndez Pelayo a Unamuno".-BBMP, 40 (1964), 199-203.

18-8149. Unamuno, M. DE-"Carta inédita".-CCL, 1964, núm. 91, 32 .

18-8150. Unamuno, M. DE--"Duas cartas a Teixeira de Pascoaes”. - Esp, 1964 , núm. 3, 42-45.

18-8151. Demerson, G. - "Unamuno y Francia. Dos cartas inéditas". - Ins, 1964, núms. $216 / 7$.

18-8152. "Correspondencia entre Miguel de Unamuno y Silvio Julio".- $L L, 1964$, núms. $72 / 3$, 209-211. 
18-8153. Unamuno, M. DE-“Cartas a Alcides Arguedas".-CCL, 1964, núm. 88, $57-62$.

18-8154. Bl.anco Aguinaga, C.-“Unamuno fuera de España”.-Íns, 1964, núms. $216 / 7$.

18-8155. Gullón, R. - "Unamuno en el extranjero".-Ins, 1964, núms. $216 / 7$.

18-8156. EARLE, P. G.-Unamuno and English literature (N. 17-6938). $\| M L N$, 78 (1969), $105^{-110}$ (Blanco Aguinaga); LR, 17 (1963), 191-193 (Borgers); $C L, 15$ (1963), 88-89 (Gicovate); $R F, 77$ (1965), 209-210 (Sobejano).

18-8157. Dumas, C.-“Algunos aspectos de Unamuno galófobo".-CuA, 1964, núu. $6,237-248$.

18-8158. BAtchelor, E.-“Unamuno devant la littérature française". - Nottingham French Studies, 3 (1964), 35$47,82-93$.

18-8159. García Blanco, M.-“Unamuno y el profesor francés Jacques Chevalier".-RUM, 13 (1964), 7-76.

18-816o. PARfs, C.--Unamuno y Teilhard de Chardin".-CuD, 1964, núm. 15.

18-8161. Garcla Blanco, M.-“"Unamuno y Papini”.-AION-R, 6 (1964), 133. 162.

18-8162. Amiama, G.-"Algo sobre Unamuno y Rusia".-RUM, 13 (1964), 277295.

I8-8163. ILIE, P.-“Unamuno, Gorky and the Cain myth" (N. 17-3125). 19 (1964), 381-382 (Valderrama Andrade).

18-8164. NiEDERMAXER, F. - "Unamuno und Deutschland: zum 100. Geburtstag Miguel de Unamunos am 29. September 1964".-Literaturwissenschaftliches Jahrb. der Görres-Gesellschaft, 5 (1964), $177-200$.

18-8165. H. J. S.-“La Sociedad Alemana de Unamuno".-Arb, $59 \quad(1964), 23^{6-}$ 237.

18-8166. Baquero, G.-"La América de Unamuno".-PE, 1964, núms. 99/100, 91-113.

18-8167. CAmpos, J.-“América y Unamuno".-Ins, 1964, núms. 216-7.

18-8168. BAQuero, G.-"Spain, Unamuno and Hispanic America". - $A W, 16$ (1964), 8-14.

18-816g. Cúneo, Dardo - Sarmiento $y$ Unamuno. - Pleamar, Buenos Aires, 1969. $23^{8}$ pp. (Arquetipos).-V. núm. 16-45644. \| HAHR, 45 (1965), 152-153 (Trifilo).

18-817o. MEJíA SANCHEZ, E.-“Unamuno y México".-Cults, 1964, núm. 34, 1115 .

18-8171. Mejía SÁNChez, E.-"Más sobre Unamuno y [Alfonso] Reyes".-BBNM, 1964, núms. $3 / 4$.

18-8172. García Blanco, M.-"Unamuno $y$ el novelista norteamericano Melville".-Ins, 1964, núms. $216 / 7$.

18-8173. Paxton, C. - "Unamuno's indebtedness to Whitman".-Walt Whitman Rev., 9 (ig63), 16-19.

18-8174. YNDURÁIn, F.-“Afinidades electivas: Unamuno y Holmes".-RJ, 15 (1964), 335-354.

18-8175. Castellanos, J.-“Lo trágíco en Beckett y Unamuno".-PE, 1969, núm. go.

18-8176. CUnha LeÃo - "Unamuno e o enigma português. $-E s p, 19^{6} 4$, núm. 3, $15^{-23}$.

18-8177. Quadros, A.-"Meditação portuguesa a partir de Unamuno”. - Esp, 1964, núm. 3, 26-41.

18-8178. García Morejón, J.-"Miguel de Unamuno y Manuel Laranjeira”. AION-R, 6 (1964), 21-42.

18-8179. García Morejón, J.-“Unamuno y Oliveira Martins".-MSI, 2 (196ิ3), $73-98$.

18-818o. Domєnech, R. - "La Reflexión dramática sobre textos de Unamuno, presentada por Dido, Pequeño Teatro de Madrid".-PA, 1964, núm. 59 .

18-8181. MONLEón, J.- "La Reflexión dramática sobre textos de Unamuno".$P A, 1964$, núm. 59.

V. también núms. $5^{167}, 534^{0-2}, 5593,5^{806}$, $5846,6269-70,7014,7104,7190,7266$, 7664 .

18-8182. “Azorín"-Libros y Discos, Madrid, 1964 , núm. 9 .

18-8183. Fernández-Luna, C. - "Azorín". $-B D G A, 1964$, núm. 79, 41-43.

18-8184. Pérez de Ayala, Ramón-Ante Azorin. Ed. recogida, ordenada y prologada por J. García Mercadal.-Biblio. teca Nueva, Madrid, 1964. $24^{8} \mathrm{pp}$.

18-8185. CAMPOS, JORGE - Conversaciones con Azorin.-Taurus, Madrid, 1964. $28_{5}$ pp. (Col. Diálogos). II Ins, 1964, núm. 210 (Cano); Agora, $1963-64$, núms. 85/93 (Fraile); $B A b r, 39$ (1965), 326 (Sarmiento); $I A L, 1964$, núm. 186 (T.). 18-8186. Azorín. La vida, el estilo y el tema de España en la obra del gran maestro de las letras españolas.-Prensa Española, Madrid, 1964. 310 pp. [Colaboran H. Carpintero, S. Riopérez y J. A. Pérez Rioja]. 
18-8187. Gómez Galán, Antonio-Segovia en la obra de Azorin.-Jefatura Provincial del Movimiento, Segovia, 1964. $30 \mathrm{pp}$.

18-8188. Coscayón, F.-“E1 Escorial en Azorin".-NEt, 1963, nứms. 26/27, 153161.

18-8189. Ruiz MiláN, Estr.la-El impre sionismo en Azorin.-Universidad Nacional Autónoma, México, 1963. 137 pp. [Tesis].

18-8ıgo. Lort, R. E. - "Azorin's experimental period and surrealism". PMLA, 79 (1964), 305-320.

18-8191. Zuleta, E. DE - "Azorín como crítico literario".-RLMo, 3 (1964), $31-43$.

18-8192. Fox, EDWARD INMAN-Azorin as a literary critic.-Hispanic Institute in the United States, New York, 1962. 176 pp. - V. núm. 17-3226. || BHS, $4^{1}$ (1964), $5^{8-59}$ (Bacarisse); $R P h, \quad 17$ (1963-64), 822 (Bäuml); fns, 1964, núm. 215 (Gullón); HR, 32 (ig64), 276-279 (Livingstone); $H, 4^{6}$ (1963), 666 (Rand). 18-8193. Fox, E. I.-"A rejoinder to professor Livingstone". - HR, 32 (1964), $280-281$.

18-8194. SÁenz, G. P.-“El interés azoriniano en la literatura francesa".-DHR, $3(1964), 35-47$.

18-8195. Azorín-Obras completas. T. 9. $2^{7}$ ed.-Aguilar, Madrid, 1964. 1462 pp. $-V$. núm. 10-24251.

18-8196. LAJoHN, L.- "Surrealism in Azorín's theater". $-K F L Q, 10$ (1963), 20-25.

18-8197. LoTt, RoBerT E.-The structure and style of Azorin's " $\mathrm{El}$ caballero inactual"-. Univ. of Georgia Press, Athens, 1963. 108 pp. (Univ. of Georgia Monographs, 10). || BHS, 41 (1964), 260-261 (Bacarisse); Ins, 1964, núm. 215 (Gullón); H, 47 (1964), 428-429 (LaJohn); $H R, 33$ (1965), 415-417 (Rand); RHM, 3o (1964), 149 (de del Río).

18-8198. Durán, M.-“Azorín's broken record device in Doña Inés".-RNo, 4 (1969), núm. 2, 112-116.

18-8199. Guillén Villena, Benilde $-E l$ cuento en Azorin. - [Tesis, Univ. de Murcia, 1963].

18-820o. Azorín-Blanco en azul. $4^{\mathrm{a}}$ ed.Espasa-Calpe, Madrid, 1964. 152 pp. (Austral, 461).-V. núm. 12-32257.

18-8201. Azorín-Lecturas españolas. $9^{\text {a }}$ ed.-Espasa-Calpe, Madrid, 1964. 146 pp. (Austral, 36).-V. núm. 12-32261.

18-8202. Azoris-Madrid. - Ayuntamiento, Madrid, 1964. 318 pp.
18-8203. Azorín - El paisaje de España visto por los españoles. 6a ed.-EspasaCalpe, Madrid, 1964. $15^{\circ}$ pp. (Austral, 164).-V. núm, 16-45661.

13-8204. Azorín-La ruta de Don Quijote. Castilla. - E.D.A.F., Madrid, 1964 . 288 pp. (Biblioteca E.D.A.F.).

18-8205. Azorín-La ruta de Don Quijote. $6^{\text {a }}$ ed.-Losada, Buenos Aires, 1964 . 140 pp. (Contemporánea, 13).-V. núm. 12-34121.

V. también núms. $5806,5^{866,6823}, 6873$, $7837-8$.

18-8206. Rivas Andrés, V. - "Notas para memorias de Ramón Gómez de la Serna".-HD, $1963,202-208$.

18-8207. Salazar, A. - "Ramón".-Cults, 1964, núm. 33, $7^{6-81}$.

18-8zo8. Diego, Gerardo-Lope y Ramón. - Edit. Nacional, Madrid, 1964. $3^{8} \mathrm{pp}$. \|l $H, 4^{8}$ (1965), 386-397 (Nagy).

18-8ュog. Gómez de LA Serna, G.-"Ramón, río mayor".-RIEs, 21 (1963), $17^{-}$ 25 .

18-8210. Borrás, T.-“El descubridor de continentes inéditos en el mar del castellano".-RIEs, 21 (1963), 27-35.

18-8211. Montero Padilla, J. - "Ramón Gómez de la Serna y Segovia".-ESeg, $15(1964), 489-504$.

18-8212. APONTE, B. B.-"El diálogo entre Ramón y Alfonso Reyes".-Ins, 1964 , núm. 210.

18-8213. Gómez de la Serna, R.-“Diario póstumo".-CCL, 1964, núm. 83, 35-42. 18-8214. Gómez de LA Serna, GasparRamón. Obra y vida.-Taurus, Madrid, 1963. 305 pp., 14 láms. (Persiles). I| $I A L, 1964$, núms. $187 / 8$ (Azancot); $E L$, (1964), núm. 297 (Iglesias Laguna); $B A b r, 39$ (1965), 72 (Jackson); Ins, 1965, núm. 222 (Marra-López).

18-8215. Granjex, Luis S. - Retrato de Ramón. Vida y obra de Ramón Gómez de la Serna.-Guadarrama, Madrid, 1963. 260 pp., 86 ilustr. \| $E L, 1963$, núm. 271 (Âragonés); Ins, 1963, núm. 203 (Marra-López); ROcc, 6 (1964), 246-249 (Salcedo); PSA, 32 (1964), 111 112 (Sobejano).

18-8216. HORNEDO, R. M. DE-"E1 catolicismo de Ramón Gómez de la Serna”. $-R y F, 167 \quad$ (1963), 341-356.

18-8217. Gómez de la Serna, G. - "Ramón: medida de su humorismo".- $\mathrm{CuH}$, 60 (1963), $9^{1-96 .}$

18-82 18. Moreno Galván, J. M.-"La ramonidad". - Aulas 63, Madrid, 1963, núm. 1. 
18-8219. Díaz de León, Luz Elena-Ramonismo de Ramón Gómez de la Serna.-[Tesis, Universidad Nacional Autónoma, México 1963]. $129 \mathrm{pp}$.

18-8220. Gómez de LA Serna, R.- "Textos [sobre estética]". Sel. y nota prel. por Enrique Pardo Canalís. - RIEs, 21 (1963), $65-96$.

18-8221. Camón Aznar, J.-"Ramón en las cosas y en el arte".-RIEs, 21 (1963), $9^{-15}$.

18-8222. SÁNCHEZ-CAMARGo, M.-“Un crítico de arte: Ramón Gómez de la Serna".-CuH, 55 (1963), 258-260.

18-8223. Torrente Ballester, G.-“'Teatro de Ramón".-Ins, 1963, núm. $19^{6}$. 18-8224. Marquerie, A.- "El fabuloso teatro de Ramón”. - Aulas 63, Madrid, $196_{3}$, núm. 1.

18-8225. Doménech, R.-“La corona de hierro, de Ramón Gómez de la Serna". $-P A, 1963$, núm. 43,5 o.

18-8226. Gómez de la Serna, Ramón-El dueño del átomo. - Dédalo, Madrid, 1963. 68 pp. (Novelas y cuentos).

18-8227. Torrente Ballester, G.- "Crítica de Escaleras, representada en la Plaza Mayor, de Ramón Gómez de la Serna". $-P A, 1053$, núm. 44 .

18-8228. Gómez de la Serna, Ramón-El secreto del acueducto.-Edhasa, Barcelona, $1963.192 \mathrm{pp}$. (El puente). II ROcc, 7 (1964), 249-250 (Scuderi).

18-8229. Gómez de la Serna, Ramón-Ensayo sobre lo cursi.-Cruz del Sur, Santiago de Chile, 1963. 109 pp. (Renuevos de Cruz y Raya). || Ins, 1965 , núms. 224/5 (Mainer).

18-823o. TORRE, E.- "Ramón y lo cursi". -Ins, 18 (1969), núm. 196.

18-823i. Gómez de la Serna, Ramón Greguerias. Introd. y sel. de Gaspar Gómez de la Serna.-Anaya, Salamanca, 1963. (Bibl. Anaya, 51).

18-8232. Jackson, Richard LAwson-The "guegueria" of Ramón Gómez de la Serna: A study of the genesis, composition, and significance of a new literary genre. - [Tesis, Ohio State Univ.; resumen en $D A, 24 \quad(1963-64), 4700] .161 \mathrm{pp}$.

18-8233. Gómez de la Serna, G.-"Hacia el concepto de greguería". - PSA, 30 (1963), 197-204.

18-8234. Murciano, C. - "La vida, esa greguería".-PE, 1963, núm. 81. - V. núm. 18-4ı16.

18-8235. Muelas, F.-"Ramón y la verdadera poesia".-Aulas 63, Madrid, $196_{3}$, núm. 1 .
18-8236. Gómez de la Serna, Ramón-Caprichos.-Vergara, Barcelona, 1963. $25^{6}$ pp.

18-8237. Otaola - "Nota sobre Senos".PSA, 32 (1964), 293-236. [Se publica a continuación, pp. 237-254, este texto de Gómez de la Serna].

18-8238. García Fernández, A.- "Gómez de la Serna en su Automoribundia".Crítica $6_{3}$, Rosario, 1963 , núms. $4 / 5$, $25-30$.

18-8299. GómFz de LA SERna, Ramón Goya.-Eds. R, La Habana, 1964. (Bibl. básica de lit. española).

18-8240. Gómez de La SERna, RAmón Madrid y su gente.-Madrid, 1963 .

18-8241. Gómfz de La Serna, Ramón Pombo. - Editorial Juventud, Barcelona, 1963. 221 pp. (Col. Z, 57).-V. núm. $16-45671$

18-8242. OSório de OLIVeIrA, J.-“O monólogo de Ramón Gómez de la Serna sobre Pcrtugal".-Co, 1963 , núm. 23, $45-47$.

V. también núm. 7385 .

18-8243. Zuleta, E. DE - "La novela de Benjamín Jarnés".-İns, 1963, núm. 203. 18-8244. LlenzA, A.-"Comentarios sobre la obra Locura y muerte de nadie, de Benjamín Jarnés". - Educación, San Juan de Puerto Rico, 1964, núm. 12, 131-139.

18-8245. Cammarano, L.-“José Bergamín o l'arte che interpreta se stessa".-TP, 8 (1963), núm. $7,63-68$.

18-8246. Bergamín, José-El arte de birlibirloque. La estatua de don Tancredo. El mundo por montera.-Cruz del Sur, Santiago de Chile, 1961. 130 pp. (Renuevos de Cruz y Raya).

18-8247. Bergamín, José-Al volver. Ensayos.-Seix Barral, Barcelona, 1962. 239 pp. (Biblioteca breve. Ensayos, 164). $R y F, 167 \quad$ (1963), $65^{8} \quad$ (Blanch); $I A L$, 1962, núm. 166 (Càstro); MLR, 60 (1965), 291-292 (Johnson); H, 46 (1963). 177 (Lacosta); Ins, 1963, núm. 195 (Marra-Lópcz); USF, 1962, núm. 53, 308 (Rivacoba); PSA, 28 (1963), 317-319 (Sobejano).

18-8248. Bergamín, JosÉ - Duendecitos y coplas.-Cruz del Sur, Santiago de Chile, 1963. 228 pp. (Renuevos de Cruz y Raya).

18-8249. BERGAMÍN, JosÉ-Rimas y sonetos rezagados.-Cruz del Sur, Santiago de Chile, 1962. $210 \mathrm{pp}$. (Renuevos de Cruz y Raya). || Map, $19_{5}^{5}$, núm. 1, 199202 (Soria y Puig). 